Universidade de São Paulo

Instituto de Física

\title{
Modelo de Preisach e análise FORC aplicados a filmes com Exchange Bias
}

\author{
Leonardo Alonso
}

Orientador: Prof. Dr. Daniel Reinaldo Cornejo

Banca Examinadora

Prof. Dr. Daniel Reinaldo Cornejo (IF-USP)

Prof. Dr. Frank Patrick Missell (IF-USP/UCS)

Prof. Dr. Guilherme Matos Sipahi (IF-USP/São Carlos)

Dissertação de mestrado apresentada ao Instituto de Física para a obtenção do título de Mestre em Ciências 
"Não há fatos eternos, como não há verdades absolutas."

Friedrich Nietzsche 


\section{Agradecimentos}

Agradeço primeiramente minha família, que me ajudou e me apoiou em todos os momentos da minha vida.

Agradeço à Rachel que esteve do meu lado e compartilhou comigo todas as alegrias e dificuldades.

Agradeço meu Orientador, que transmitiu a mim seus conhecimentos e metodologias científicas, dando a mim uma nova visão sobre a Física.

Agradeço todo o Laboratório de Materiais Magnéticos, onde todos estiveram envolvidos com o projeto de alguma forma.

Agradeço ao pessoal do LAMFI pelas caracterizações em RBS, à Prof ${ }^{\mathrm{a}}$ Dra. Márcia Fantini por disponibilizar o equipamento de Raio X para medidas, assim como o Prof. Dr. Marcelo Knobel por disponibilizar o VSM para medidas.

Agradeço ao pessoal da CPG pela dedicação que tiveram comigo.

Agradeço a todos os colegas que me apoiaram e me incentivaram. 


\section{Índice}

Resumo 6

$\begin{array}{ll}\text { Abstract } & 7\end{array}$

Motivação $\quad 8$

1 - Introdução 9

1.1 - Energia livre em filmes finos magnéticos 9

Termos relevantes na Energia Magnética Livre de um filme fino 9

Energia Zeeman 10

Energia de Desmagnetização 10

Energia magnetocristalina $\quad 11$

$\begin{array}{ll}\text { Anisotropia Uniaxial } & 13\end{array}$

Anisotropia Unidirecional 14

1.2 - Anisotropia unidirecional e o fenômeno de Exchange Bias 15

Descrição qualitativa $\quad 15$

Modelos teóricos de Exchange Bias $\quad 17$

$\begin{array}{ll}\text { Modelo de Meiklejohn e Bean } & 17\end{array}$

Modelo de Malozemoff 18

Modelo de Mauri 19

Modelo microscópico para anisotropia de troca 20

Modelo de Preisach com Exchange Bias $\quad 21$

Métodos de medição $\quad 24$

1.3 - Válvulas de Spin 26

1.4 - Bicamadas de NiFe/FeMn com Exchange Bias 28

Propriedades magnéticas do Py 28

Propriedades magnéticas do FeMn $\quad 29$

Comportamento magnético do NiFe/FeMn 29

A influência da camada semente (buffer) 29

A influência da camada de FeMn 30

A influência da camada de Py 30

1.5 - Modelos de Preisach $\quad 32$

Modelo clássico de Preisach $\quad 32$

Modelo Móvel de Preisach 36

Representação da função de distribuição 38

2 - Preparação e caracterização das amostras $\quad 41$

2.1 - Equipamentos Utilizados 41

2.2 - Crescimento dos filmes $\quad 41$

2.3 - Tratamento Térmico com campo aplicado 44

2.4 - Difrações de Raios X 44

2.5- Determinação das espessuras por RBS 46

3 - Aplicação do modelo de Preisach em filmes com Exchange Bias 49

3.1 - Descrição das simulações computacionais $\quad 49$

3.2- Estudo de assimetrias no Modelo de Preisach com Exchange Bias 51 
4- Medidas magnéticas e a aplicação do modelo de Preisach com Exchange Bias nos filmes de $\mathrm{Cu} / \mathrm{Py} / \mathrm{FeMn} / \mathrm{Ta}$

4.1 - Dependência Angular e Valores Máximos de $\mathrm{H}_{\mathrm{EB}}$ e $\mathrm{H}_{\mathrm{C}}$ à temperatura ambiente

4.2 - Curvas de inversão de primeira ordem (FORCs) e simulações à temperatura ambiente

4.3 - Medidas à baixas temperaturas e efeitos do tratamento térmico

5 - Medidas magnéticas em válvulas de spin

88

5.1 - Obtenção dos diagramas de FORCs

88

5.2 - Estudo em baixas temperaturas

6 - Conclusões 


\section{Resumo}

Neste trabalho foram produzidos filmes finos de Si[100]/buffer $/ \mathrm{NiFe} / \mathrm{FeMn} / \mathrm{Ta}$ (buffer = $\mathrm{Cu}$; Ta) e válvulas de spin de $\mathrm{Si}[100] / \mathrm{Cu} / \mathrm{NiFe} / \mathrm{Cu} / \mathrm{NiFe} / \mathrm{FeMn} / \mathrm{Ta}$ via Sputtering, e seus comportamentos magnéticos foram estudados analisando curvas de inversão de primeira ordem (First Order Reversal Curves, FORCs).

Um Modelo de Preisach com Exchange-Bias foi desenvolvido e sua implementação computacional permitiu simular a histerese e as curvas forc's das bicamadas de $\mathrm{NiFe} / \mathrm{FeMn}$. O modelo também permitiu reproduzir os comportamentos assimétricos dos dois ramos da curva de histerese destes filmes. A análise dos resultados evidenciou os efeitos de campo médio sobre a camada de Py em função da espessura da camada de FeMn.

A aplicação da análise FORC nas válvulas de spin se revelou interessante para estudar o grau de acoplamento entre as camadas livre e pressa, assim como os efeitos de campo médio em cada camada. 


\section{Abstract}

In this work, thin films of $\mathrm{Si}[100] /$ buffer $/ \mathrm{NiFe} / \mathrm{FeMn} / \mathrm{Ta}($ buffer $=\mathrm{Cu}$; Ta) and spin valves of $\mathrm{Si}[100] / \mathrm{Cu} / \mathrm{NiFe} / \mathrm{Cu} / \mathrm{NiFe} / \mathrm{FeMn} / \mathrm{Ta}$ were produced via sputtering and their magnetic behavior were studied by First Order Reversal Curves (FORC's) analysis.

A Preisach Model with Exchange-Bias was developed and applied in order to simulate the hysteresis and the first order reversal curves of the NiFe/FeMn bilayers. In addition, the model allowed to reproduce the asymmetric behaviors present in both branches of the hysteresis curve in these films. The study put in evidence the mean field effects on de Py layer as a function of the thickness of the FeMn layer.

The application of the FORC analysis in the spin valves was interesting to study the degree of coupling between the free and the pressed layers, as well as the effect of mean field in each layer. 


\section{Motivação}

Com o avanço tecnológico, novas fronteiras científico-tecnológicas como a nanotecnologia foram impulsionadas e um dos logros disto é que novos componentes eletrônicos mais eficientes vêm surgindo e substituindo os antigos. Dois desses componentes eletrônicos são de vital importância para o funcionamento de computadores, como memórias de acesso aleatório (MRAMs) e cabeçotes de leitura de dados[1]. As nanoestruturas que possuem anisotropia de troca (Exchange Bias) são, atualmente, fontes de pesquisas devido a estas aplicabilidades tecnológicas e o entendimento de suas propriedades magnéticas dinâmicas são de suma importância para o desenvolvimento dos mesmos. Em particular, as estruturas de $\mathrm{NiFe} / \mathrm{FeMn}$ poderão ser utilizadas como os dispositivos já mencionados devido às suas propriedades que serão mostradas e exploradas neste trabalho. 


\section{Capítulo 1}

\section{Introdução}

Desde a antiguidade, materiais magnéticos despertaram um grande interesse no Homem devido às forças atuantes. Não era possível explicar porque certas pedras eram atraídas ou repelidas sem que nenhum objeto pudesse estar atuando diretamente nelas. Uma compreensão matemática do fenômeno se deu no século XIX, onde vários pesquisadores como Gauss, Faraday e Maxwell desmembraram os conceitos envolvidos e, após trabalhos brilhantes, estabeleceram as equações da teoria eletromagnética. A partir disso o desenvolvimento tecnológico, assim como a compreensão do mundo, mudou radicalmente. Ainda hoje, a pesquisa nesse campo é inovadora e, com o advento da nanociência e o interesse pela spintrônica, efeitos que surgem em escala nanométrica tornaram-se relevantes e com aplicabilidades tecnológicas. Desta forma, a compreensão de fenômenos magnéticos nesta escala continua em um processo intenso, abrindo um campo exploratório de imensa riqueza.

Para ser possível compreender os mecanismos que causam fenômenos como o Exchange Bias, torna-se necessário o estudo de seus termos de energia magnética livre, aprofundando a descrição em termos cristalinos e anisotrópicos. Uma breve descrição energética encontra-se a seguir, pois a compreensão básica dos mesmos são essenciais para o estudo de bicamadas antiferromagnéticas/ferromagnéticas (AF/FM), assim como em válvulas de spin.

\section{1 - Energia livre em filmes finos magnéticos}

\section{Termos relevantes na Energia Magnética Livre de um filme fino}

A descrição das interações magnéticas que resultam na energia magnética livre se baseia nos termos de Zeeman, de desmagnetização, das anisotropias de superfície e magnetocristalina, da interação de troca indireta entre duas camadas magnéticas separadas por uma não magnética (este conceito será abordado posteriormente) e de anisotropia unidirecional, resultante da interação entre uma camada ferromagnética e outra antiferromagnética (fig. 1.1).

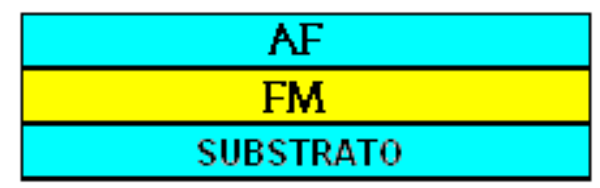

Figura 1.1 - Estruturas de bicamadas de filmes finos.

A energia livre do filme é formada pelo acoplamento direto de troca na interface AF/FM e pela contribuição ferromagnética, onde esta é dependente da energia Zeeman, a energia de desmagnetização e a magnetocristalina. Deste modo, podemos expressar, na forma mais generalizada o possível, a energia livre como sendo

$$
E=E_{F M}+E_{E A}
$$

Onde $\mathrm{E}_{\mathrm{FM}}$ é a contribuição ferromagnética e $\mathrm{E}_{\mathrm{EA}}$ a do acoplamento direto. 


\section{Energia Zeeman}

Tratando cada termo de forma separada, pode-se aprofundar o conhecimento de forma coerente e organizada. A energia Zeeman pode ser escrita como

$$
E_{\text {Zeeman }}=-\mu_{0}(\vec{H} \cdot \vec{M}) t_{F M}
$$

e representa a interação da magnetização do filme FM com o campo externo H. Este resultado provém do efeito da quebra de degenerescência energética devido à presença de um campo magnético.

\section{Energia de Desmagnetização}

Em amostras finitas, a formação de dipolos não compensados, induzidos na superfície do material magnetizado, provoca o aparecimento de um campo interno resultante $\mathrm{H}_{\mathrm{i}}$ no material, dado por $\mathrm{H}_{\mathrm{i}}=\mathrm{H}-\mathrm{H}_{\mathrm{D}}$ (fig. 1.2), onde $\mathrm{H}_{\mathrm{D}}$ é o campo de desmagnetização.

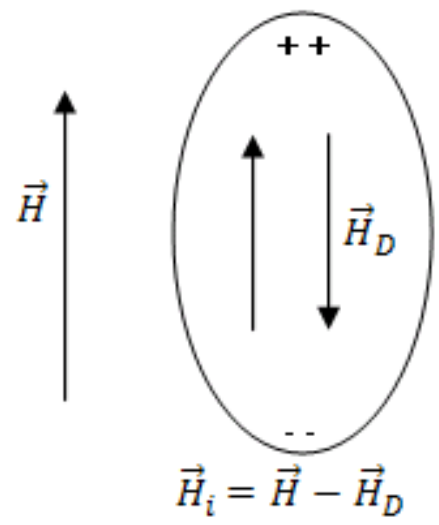

Figura 1.2 - Campo interno produzido pelos dipolos não compensados induzidos na superfície da amostra.

O campo de desmagnetização pode ser inicialmente aproximado por

$$
\vec{H}_{D}=-\overleftrightarrow{N} \cdot \vec{M}
$$

onde $\overleftrightarrow{N}$ é um tensor dependente da geometria da amostra. Desconsiderando efeitos de borda, a energia dipolar (ou de desmagnetização) toma a forma[4, 5]

$$
E_{D}=-\frac{\mu_{0}}{2} \int \vec{M} \cdot \vec{H}_{D} d V
$$

Para o caso de um filme fino, a única componente não nula do tensor é $\mathrm{N}_{\mathrm{Xx}}=1$ (S.I.). Integrando a equação 1.4 se obtém

$$
E_{D}=\left(\frac{\mu_{0}}{2} M^{2} \cos ^{2} \theta\right) t=\frac{\mu_{0}}{2}(\vec{M} \cdot \hat{n})^{2} t
$$

onde $\mathrm{n}$ é o versor perpendicular ao plano do filme. Pela equação 1.5 , pode-se obter que a direção $\theta=\pi / 2$ entre o versor e o campo $H$ fornece a mínima energia de desmagnetização, evidenciando assim que a direção de fácil magnetização está no plano do filme. 


\section{Energia magnetocristalina}

A forma de energia magnetocristalina provém da interação spin-órbita, que depende da orientação da magnetização em relação aos eixos cristalinos. Esses eixos cristalinos influenciam diretamente o comportamento referente aos eixos "moles" e os eixos "duros", ou seja, as direções de magnetização preferenciais. A energia de anisotropia é a diferença de energia entre o sistema saturado ao longo do eixo duro e ao longo do eixo mole. No entanto, pode-se demonstrar que, em primeira aproximação, a contribuição dipolar para esta anisotropia em cristais cúbicos é nula $[2,3]$.

Tomando um cristal simples magneticamente saturado e não levando em conta a simetria do mesmo, pode-se expressar a energia magnetocristalina em função dos cossenos provenientes da direção da magnetização com um sistema cartesiano (fig. 1.3). Tomando $\alpha_{1} \alpha_{2}$ $\alpha_{3}$ como sendo[6]

$$
\begin{gathered}
\alpha_{1}=\cos \beta=\operatorname{sen} \theta \cos \phi \\
\alpha_{2}=\cos \gamma=\operatorname{sen} \theta \operatorname{sen} \phi \\
\alpha_{3}=\cos \delta=\cos \theta \\
\theta=\text { ângulo polar } \\
\phi=\text { ângulo azimutal }
\end{gathered}
$$

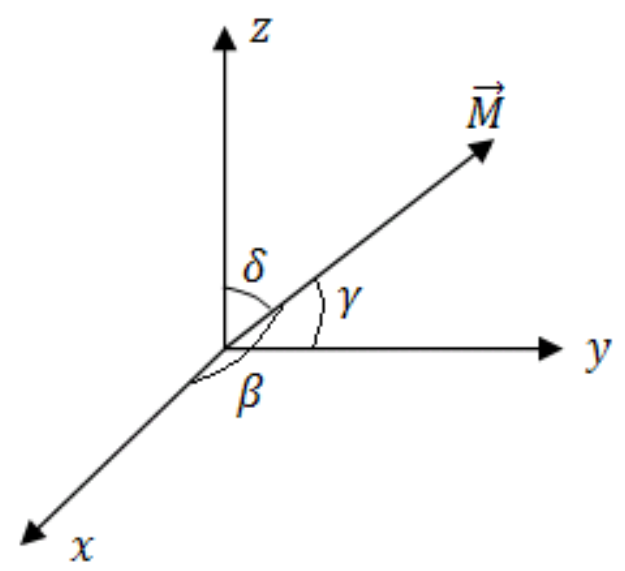

Figura 1.3 - Magnetização expressa referente a um sistema cartesiano de coordenada.

podemos expressar a energia como sendo

$$
E_{A}\left(\alpha_{1}, \alpha_{2}, \alpha_{3}\right)=\left(\sum_{i} b_{i} \alpha_{i}+\sum_{i, j} b_{i j} \alpha_{i} \alpha_{j}+\sum_{i, j, k} b_{i j k} \alpha_{i} \alpha_{j} \alpha_{k}+\sum_{i j k l} b_{i j k l} \alpha_{i} \alpha_{j} \alpha_{k} \alpha_{l}+\cdots\right) t
$$

As formas mais comuns são a anisotropia uniaxial e a cúbica.

$\mathrm{Na}$ anisotropia cúbica, alguns termos da equação 1.7 são nulos devido à condição de contorno que explicita que a energia livre precisa ser invariante em relação à inversão do 
sentido da magnetização e troca de eixos. Assim, todos os termos ímpares de $\alpha$ são nulos e todos os termos cruzados $\alpha_{\mathrm{i}} \alpha_{\mathrm{j}}$ também são. Assim, a expressão $b_{1} \alpha_{1}^{2}+b_{2} \alpha_{2}^{2}+b_{3} \alpha_{3}^{2}$ possui $\mathrm{b}_{1}=\mathrm{b}_{2}=\mathrm{b}_{3}$ e tomando $\alpha_{1}^{2}+\alpha_{2}^{2}+\alpha_{3}^{2}=1$, teremos como resultado nenhuma anisotropia deste termo.

Além disso, como $\alpha_{1}^{2} \alpha_{2}^{2}+\alpha_{1}^{2} \alpha_{3}^{2}+\alpha_{2}^{2} \alpha_{3}^{2}=\frac{1}{2}-\frac{1}{2}\left(\alpha_{1}^{4}+\alpha_{2}^{4}+\alpha_{3}^{4}\right)$, tornam-se desnecessários os termos de quarto grau. Com isto, a equação 1.7 toma a forma

$$
E_{C}\left(\alpha_{1}, \alpha_{2}, \alpha_{3}\right)=\left[K_{C 1}\left(\alpha_{1}^{2} \alpha_{2}^{2}+\alpha_{1}^{2} \alpha_{3}^{2}+\alpha_{2}^{2} \alpha_{3}^{2}\right)+K_{C 2} \alpha_{1}^{2} \alpha_{2}^{2} \alpha_{3}^{2}\right] t
$$

onde $\mathrm{K}_{\mathrm{C} 1}\left(\mathrm{erg} / \mathrm{cm}^{2}\right)$ e $\mathrm{K}_{\mathrm{C} 2}$ são as constantes da anisotropia cúbica de primeira e segunda ordem, respectivamente. A desconsideração do segundo termo simplifica os cálculos mas, mesmo quando os valores ainda são equiparáveis, desconsidera-se este elemento, pois seus termos multiplicativos sempre são de menor ordem $\left(\alpha_{1}^{2} \alpha_{2}^{2} \alpha_{3}^{2}<\alpha_{1}^{2} \alpha_{2}^{2}+\alpha_{1}^{2} \alpha_{3}^{2}+\alpha_{2}^{2} \alpha_{3}^{2}\right)$.

No caso da anisotropia uniaxial, há apenas um eixo onde pode ocorrer a minimização energética. Um exemplo disso é dado no caso do eixo $c$ de simetria de uma estrutura hexagonal. Qualquer direção perpendicular à $c$ é um eixo duro. A energia anisotrópica pode ser dada por

$$
\begin{aligned}
& E_{U}\left(\alpha_{1}, \alpha_{2}\right)=\left[K_{U}^{(1)}\left(\alpha_{1}^{2}+\alpha_{2}^{2}\right)+K_{U}^{(2)}\left(\alpha_{1}^{2}+\alpha_{2}^{2}\right)^{2}\right] t \\
& E_{U}(\theta)=\left(K_{U}^{(1)} \operatorname{sen}^{2} \theta+K_{U}^{(2)} \operatorname{sen}^{4} \theta\right) t
\end{aligned}
$$

Esta última expressão revela um mínimo em $\theta=0$ e em $\theta=\pi$. Algumas amostras possuem anisotropias direcionadas em $\theta=\pi / 2$. Assim, a equação 1.10 deve ser reescrita com potências pares de $\operatorname{sen}\left(\phi-\phi_{\mathrm{U}}\right)$.

$$
E_{U}(\theta, \phi)=\left[K_{U}^{(1)} \operatorname{sen}^{2} \theta \operatorname{sen}^{2}\left(\phi-\phi_{U}\right)+K_{U}^{(2)} \operatorname{sen}^{4} \theta \operatorname{sen}^{4}\left(\phi-\phi_{U}\right)\right] t
$$

onde $\phi_{U}$ define a direção do eixo uniaxial em relação aos eixos cristalinos e $K_{U}^{(1)}$ e $K_{U}^{(2)}$ são as constantes de anisotropia uniaxial de primeira e segunda ordens.

Para o caso de filmes finos, existe uma quebra de simetria devido à efeitos de superfície, sendo assim necessária a inclusão de um termo do tipo $-K^{\prime} \cos ^{2} \theta$, com $K$ ' sendo uma nova constante de anisotropia de superfície e $\theta$ o ângulo entre a direção da magnetização e a normal ao plano do filme[7]. Assim, a energia magnetocristalina pode ser agora aproximada em primeira ordem como sendo

$$
\begin{gathered}
E_{D}+E_{A N}=\left[\frac{\mu_{0}}{2} M^{2} \cos ^{2} \theta+K_{C 1}\left(\alpha_{1}^{2} \alpha_{2}^{2}+\alpha_{1}^{2} \alpha_{3}^{2}+\alpha_{2}^{2} \alpha_{3}^{2}\right)+K_{U}^{(1)} \operatorname{sen}^{2} \theta \operatorname{sen}^{2}\left(\phi-\phi_{U}\right)\right. \\
\left.-K^{\prime} \cos ^{2} \theta\right] t
\end{gathered}
$$

A dedução da energia de desmagnetização foi feita supondo um filme contínuo. Um filme real, de algumas monocamadas, deve ser tratado como um sistema discreto de dipolos magnéticos. Assim, o tensor $\mathrm{N}$ deve ser corrigido. De fato, a energia dipolar dos planos superficiais é menor em relação aos planos mais internos, gerando assim uma energia de desmagnetização média que pode ser expressa como a soma de um termo de volume com um termo proporcional à $1 / t$. Supondo $K^{\prime}$ proporcional à $1 / t$, a energia magnetocristalina livre por unidade de superfície pode ser reescrita a partir da equação anterior como sendo 


$$
\begin{gathered}
E_{D}+E_{A N}=\left[\left(\frac{\mu_{0}}{2} M^{2}-\frac{K_{S}}{t}\right) \cos ^{2} \theta+K_{c 1}\left(\alpha_{1}^{2} \alpha_{2}^{2}+\alpha_{1}^{2} \alpha_{3}^{2}+\alpha_{2}^{2} \alpha_{3}^{2}\right)+K_{U}^{(1)} \operatorname{sen}^{2} \theta \operatorname{sen}^{2}\left(\phi-\phi_{U}\right)\right. \\
\left.-K^{\prime} \cos ^{2} \theta\right] t
\end{gathered}
$$

Assim, a energia livre por unidade de área pode ser escrita da forma

$$
E=-\mu_{0} \vec{H} \vec{M} t+\left[\left(\frac{\mu_{0}}{2} M^{2}-\frac{K_{S}}{t}\right)\left(\frac{\vec{M} \cdot \hat{n}}{M}\right)^{2}-K_{U}\left(\frac{\vec{M} \cdot \hat{u}}{M}\right)^{2}\right] t+E_{E A}
$$

Para o caso de uma válvula de spin, o tratamento matemático da interação entre as camadas ferromagnéticas pode ser feito a partir de conceitos de exchange indireto[8], sendo dependente da espessura e da composição da não magnética, tendo suas interações classificadas como bilineares ou biquadráticas[9-11], não sendo abordadas neste tópico.

\section{Anisotropia Uniaxial}

Uma explicação fenomenológica pode ser feita em termos da energia livre sem a consideração de mecanismos físicos. Na maioria dos casos, pode-se tomar uma expansão de uma função de base apropriada. Se tomarmos $u_{a}$ como sendo a densidade da energia livre magnética atribuída à anisotropia uniaxial (U/V), podemos expressá-la da forma[12]

$$
u_{a}=\frac{U_{0}}{V_{0}}=\sum_{n} K_{u n} \sin ^{2 n} \theta
$$

Uma aproximação cuidadosa indica que apenas os três primeiros termos são consideráveis[12].

$$
u_{0}=K_{u 0}+K_{u 1} \sin ^{2} \theta+K_{u 2} \sin ^{4} \theta+\cdots
$$

onde $\mathrm{K}_{\mathrm{u} 0}$ não possui significado para o estudo das propriedades anisotrópicas porque não depende da orientação da magnetização e $\theta$ é o ângulo entre a magnetização e o eixo fácil. Por convenção, $\mathrm{K}_{\mathrm{ul}}>0$ implica em um eixo fácil. Os valores das constantes para o cobalto fornecem uma ordem de grandeza, sendo de $4,1 \times 10^{5} \mathrm{~J} / \mathrm{m}^{3}$ para $\mathrm{K}_{\mathrm{u} 1}$ e de $1,5 \times 10^{5} \mathrm{~J} / \mathrm{m}^{3}$ para $\mathrm{K}_{\mathrm{u} 2}$.

Esta expansão não é única, apesar de ser a forma mais usada para a modelagem de dados experimentais. Callen e Callen(1960) expandiu essa forma energética em termos de funções ortogonais e normalizadas baseadas nos polinômios de Legendre, sendo esta a mais apropriada.

$$
u_{a}^{\text {hex }}=\sum_{l=0} k_{l} g_{l}(\alpha)=k_{0}+k_{2}\left(\alpha^{2}-\frac{1}{3}\right)+k_{4}\left(\alpha^{4}-\frac{6}{7} \alpha^{2}+\frac{3}{35}\right)+\cdots
$$

onde o argumento $\alpha$ representa o cosseno entre a magnetização e o eixo fácil.

$$
g_{l}(\alpha)=\sum_{m=-l}^{l} A_{l}^{m} Y_{l}^{m}(\alpha)
$$


Os coeficientes de $\mathrm{g}_{\mathrm{l}}(\alpha)$ são harmônicos esféricos. Devido à simplicidade de representação da expansão em termo dos senos, um exemplo de uso pode ser feito na investigação da magnetização no eixo duro. Tomando a energia Zeeman na forma $-\mu_{0} M_{S} H \operatorname{sen} \theta$, podemos adicioná-la à expansão de senos. A condição de ausência de torque $(\partial \mathrm{u} / \partial \theta=0)$ nos dá

$$
2 K_{u 1} \operatorname{sen} \theta \cos \theta+4 K_{u 2} \operatorname{sen}^{3} \theta \cos \theta=\mu_{0} M_{S} H \cos \theta
$$

Abaixo da saturação $(\cos \theta>0)$, e considerando $m=M / M_{s}$, teremos

$$
\mu_{0} H M_{S}=2 K_{u 1} m+4 K_{u 2} m^{3}
$$

Esta equação descreve o processo de magnetização até o termo de segunda ordem. Em uma primeira aproximação grosseira, podemos aferir o valor do campo de anisotropia uniaxial tomando $\mathrm{K}_{\mathrm{u} 2}=0$ e $\mathrm{M}(\mathrm{H})$ muito próximo à saturação, tendo assim $\mathrm{m} \approx 1$. Desta forma, teremos

$$
H_{a}=\frac{2 K_{u 1}}{\mu_{0} M_{S}}
$$

\section{Anisotropia unidirecional}

Como este tema será abordado em detalhes no ponto seguinte, seus termos energéticos serão apenas expostos aqui

De acordo com Meiklejohn e Bean, a energia associada ao fenômeno de Exchange Bias pode ser fenomenologicamente escrita da forma [13]

$$
E_{E A}=-J_{E X} \cos \left(\phi-\phi_{E X}\right)
$$

onde $\mathrm{J}_{\mathrm{EX}}$ é uma constante de Anisotropia de Exchange e $\phi_{\mathrm{EX}}$ é o ângulo entre a direção do campo de anisotropia e a magnetização.

O termo energético associado às paredes de domínios pode ser introduzido pelo modelo de Mauri[14]. Esta última possui a forma[14, 15]

$$
E_{W}=\sigma_{W}(1-\cos \beta)
$$

onde $\sigma_{W}=2 \sqrt{A K_{A F}}$ é a energia por unidade de área da parede de domínio do AF, $\beta$ é o ângulo entre a magnetização da primeira camada do $\mathrm{AF}$ em contato com a interface AF/FM e a direção do eixo uniaxial de anisotropia do mesmo (eixo $\mathrm{x}$ ), $\mathrm{K}_{\mathrm{AF}}$ é a constante de anisotropia magnetocristalina e A é a constante de exchange do AF. Efeitos de Anisotropia Rotatória[16,17] também podem ser abordados, mas não serão considerados neste trabalho por não serem relevantes na descrição energética dos filmes aqui estudados.

Considerando $\phi_{\mathrm{Ex}}=\beta$ (de acordo com M-B) a energia magnética livre por unidade de área pode agora ser reescrita da forma 


$$
\begin{aligned}
E=-\mu_{0} \vec{H} \cdot \vec{M} t & +\left[\left(\frac{\mu_{0}}{2} M^{2}-\frac{K_{S}}{t}\right)\left(\frac{\vec{M} \cdot \hat{n}}{M}\right)^{2}-K_{U}\left(\frac{\vec{M} \cdot \hat{u}}{M}\right)^{2}\right] t \\
& -J_{E X} \cos (\phi-\beta)+\sigma_{W}(1-\cos \beta)
\end{aligned}
$$

\section{2 - Anisotropia unidirecional e o fenômeno de Exchange Bias}

\section{Descrição qualitativa}

Desde seu descobrimento em 1956[18], o fenômeno de anisotropia de troca teve seu conceito bem desenvolvido, resultando em aplicações tecnológicas como o seu uso em MRAM's e em válvulas de spin, entre outras. Estudos teóricos e fenomenológicos deram um detalhamento maior sobre tal fenômeno, permitindo assim um grande aprofundamento no assunto.

Observado em sistemas de junções Ferromagnéticas (FM) com Antiferromagnéticas (AF), como, por exemplo, partículas FM de Co cobertas com uma camada AF de CoO[18], assim como em materiais não homogêneos e também em filmes finos, é responsável pelo deslocamento de curvas de histerese representadas nos eixos $\mathrm{M}$ x $\mathrm{H}$ devido ao campo adicional $\mathrm{H}_{\mathrm{EB}}$ chamado de campo de "Exchange Bias" (fig. 1.4), onde este fenômeno está associado à anisotropia unidirecional.

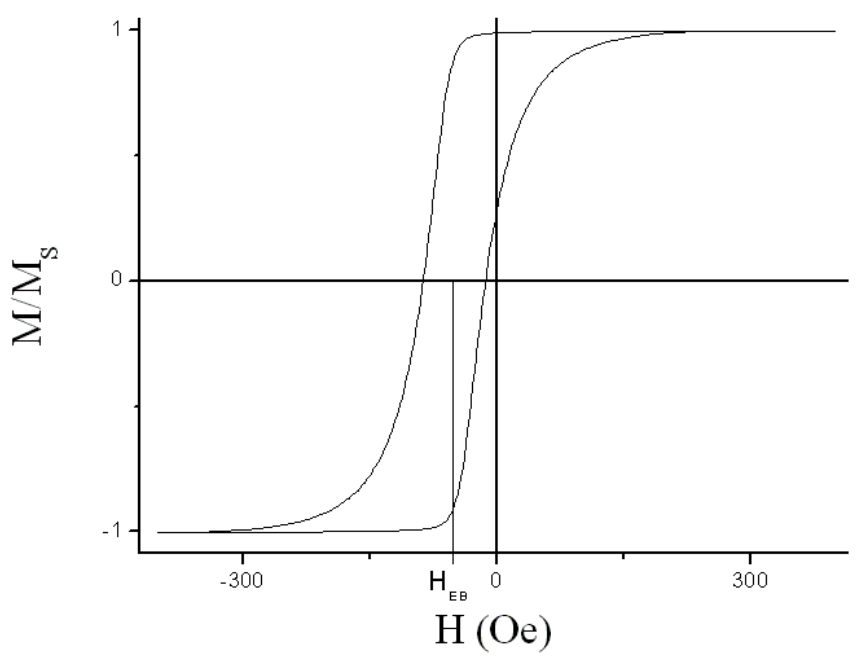

Figura 1.4 - Curva de histerese de um sistema com uma junção FM/AF. O campo $\mathrm{H}_{\mathrm{eb}}$ está indicado.

Filmes finos que possuem anisotropia de troca são basicamente formados por uma camada FM acoplada a uma AF. Para estas estruturas, a intensidade do fenômeno está vinculada à rugosidade da interface, às espessuras das camadas AF e FM, ao modo de deposição (com ou sem campo aplicado), ao tratamento térmico que pode ser feito na mesma, à energia de anisotropia unidirecional da amostra e à sua temperatura, sem contar inúmeros fatores como o parâmetro de rede de cada estrutura, por exemplo. 
Modelos teóricos têm sido propostos desde o descobrimento do fenômeno, mas antes de abordá-los, é imprescindível um maior entendimento qualitativo da dinâmica do efeito. Uma descrição baseada em filmes finos, que é, inclusive, o foco do trabalho, dará uma noção do efeito.

Uma amostra FM/AF obtida, por exemplo, via Sputtering sem a presença de um campo magnético orientacional, ao ser submetida à um campo $\mathrm{H}$ após a deposição a uma temperatura $\mathrm{T}_{\mathrm{N}}<\mathrm{T}<\mathrm{T}_{\mathrm{C}}$ com $\mathrm{T}_{\mathrm{N}}$ sendo a temperatura de Néel e $\mathrm{T}_{\mathrm{C}}$ a de curie, terá os spins do $\mathrm{FM}$ alinhados com o campo, enquanto os spins do AF permanecerão de forma aleatória (fig. 1.5a). Ao se resfriar a amostra com o campo aplicado até $\mathrm{T}<\mathrm{T}_{\mathrm{N}}$, os spins mais próximos da camada FM irão se alinhar à mesma devido à energia de troca. Os spins subseqüentemente abaixo irão estar alinhados de acordo com a ordem $\mathrm{AF}$ em relação à primeira camada para produzirem uma magnetização resultante zero(fig. 1.5b). Quando o campo aplicado for revertido, os spins começarão a rotacionar. Entretanto, se tivermos uma anisotropia alta no material AF, esses spins preservarão suas estruturas, fazendo com que somente os do material FM invertam suas magnetizações (fig. 1.5c).

Devido ao alinhamento da última camada $\mathrm{AF}$, os spins do FM tenderão a estarem alinhados com esta para uma configuração de energia mínima. Este fenômeno tem como resultado a criação de um torque nos spins FM e nos diz que a anisotropia é unidirecional. Assim, um campo maior se torna necessário para reverter a magnetização da camada FM em contato com a AF, para superar o torque (fig. 1.5d). Para reverter os spins de volta ao alinhamento, um campo menor será exigido, pois a interação será favorável à inversão (fig. 1.5e). Este comportamento supõe um campo adicional criado na amostra, fazendo com que curvas de histerese apareçam deslocadas.
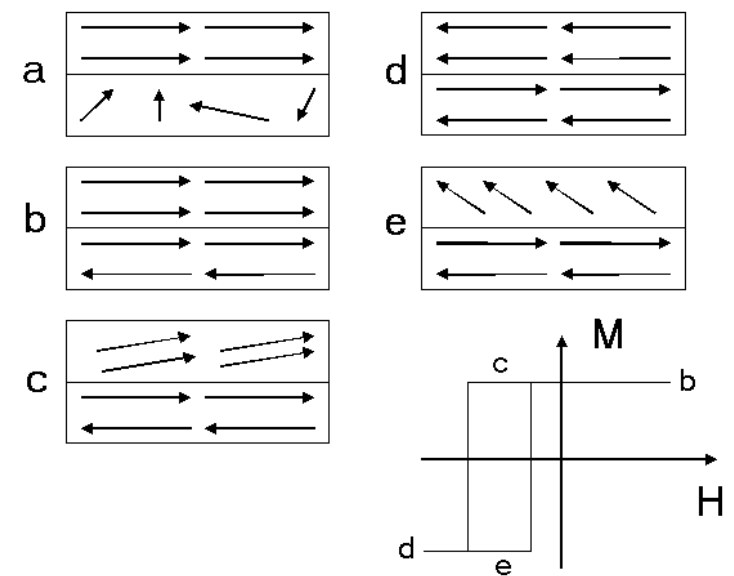

Figura 1.5 - Descrição qualitativa das possíveis configurações de spins de um sistema FM/AF com um campo aplicado $\mathrm{H}$ variável.

Este fenômeno pode também influenciar na formação de domínios[19] e na viscosidade magnética[20], por exemplo.

Um outro conceito relevante é o conceito de interfaces compensadas e nãocompensadas. Volumetricamente, a camada AF é dita compensada, ou seja, possui uma estrutura de spins que gera uma magnetização total nula, com efeitos de superfície desprezados. 
No entanto, para uma estrutura interfacial colinear, com os spins numa mesma interface alinhados paralelamente, dizemos que a interface AF é não-compensada (fig. 1.6). Para os spins com alinhamentos antiparalelos numa mesma interface, denominamos que a interface AF é compensada.

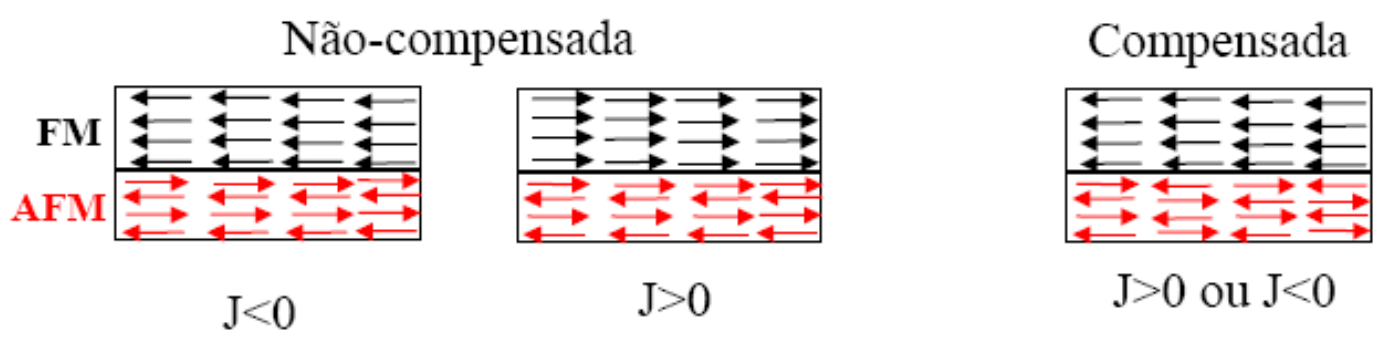

Figura 1.6 - Interfaces não-compensadas e compensadas numa estrutura AF-FM.

\section{Modelos teóricos de Exchange Bias}

\section{Modelo de Meiklejohn e Bean}

A primeira descrição do fenômeno foi dada por Meiklejohn e Bean. Este modelo aborda o fenômeno como tendo uma rotação coerente na magnetização da camada FM.

Neste modelo fenomenológico [13] e relativamente simples, podemos considerar a energia livre por unidade de área dada por

$$
E=-\mu_{0} H M_{F M} t_{F M} \cos (\theta-\beta)+K_{F M} t_{F M} \sin ^{2}(\beta)+K_{A F} t_{A F} \sin ^{2}(\alpha)-J_{I N T} \cos (\beta-\alpha)
$$

onde $\mathrm{H}$ é o campo aplicado, $\mathrm{M}_{\mathrm{FM}}$ é a magnetização de saturação, $\mathrm{t}_{\mathrm{FM}}$ é a espessura da camada $\mathrm{FM}, \mathrm{t}_{\mathrm{AF}}$ é a espessura da camada $\mathrm{AF}, \mathrm{K}_{\mathrm{FM}}$ é a anisotropia magnetocristalina da camada $\mathrm{FM}, \mathrm{K}_{\mathrm{AF}}$ é a anisotropia magnetocristalina da camada AF e $\mathrm{J}_{\mathrm{INT}}$ é a constante de acoplamento das camadas. Os ângulos $\theta, \beta$ e $\alpha$ da equação 1.25 podem ser vistos na figura 1.7 e referem-se ao campo $\mathrm{H}$ aplicado, $\mathrm{M}_{\mathrm{FM}}$ e $\mathrm{M}_{\mathrm{AF}}$ em relação aos eixos de anisotropias, respectivamente. Aqui as anisotropias foram consideradas orientadas sob um mesmo eixo. 


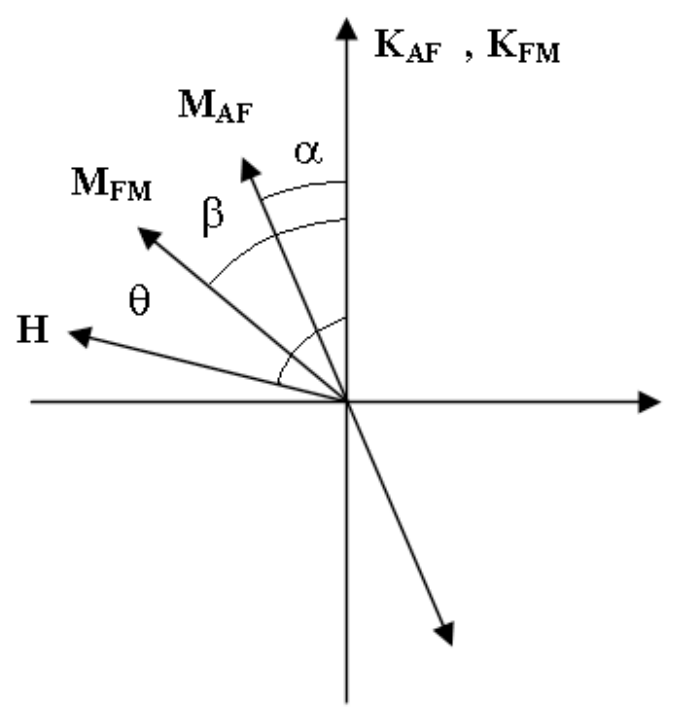

Figura 1.7 - eixos de $\alpha, \beta$ e $\theta$. Como a magnetização $\mathrm{AF}$ total é nula, $\mathrm{M}_{\mathrm{AF}}$ é compensada pela magnetização contrária $-\mathrm{M}_{\mathrm{AF}}$.

Assumindo que $\mathrm{K}_{\mathrm{AF}} \mathrm{t}_{\mathrm{AF}}>>\mathrm{K}_{\mathrm{FM}} \mathrm{t}_{\mathrm{FM}}$ e minimizando a energia, obtemos

$$
\mathrm{H}_{\mathrm{EB}}=\frac{\mathrm{J}_{\mathrm{INT}}}{\mu_{0} \mathrm{M}_{\mathrm{FM}} \mathrm{t}_{\mathrm{FM}}}
$$

onde $\mathrm{H}_{\mathrm{EB}}$ é conhecido como o campo de Exchange Bias. É conhecido que esse campo é crescente para $\mathrm{t}_{\mathrm{AF}}$ até uma valor específico, sendo capaz de manter o campo constante para $\mathrm{t}_{\mathrm{AF}}$ mais espessas. Com relação à camada FM, observa-se que o campo é proporcional ao inverso de sua espessura a partir de um certo valor de $\mathrm{t}_{\mathrm{FM}}$. A rugosidade da superfície também deverá influenciar na grandeza, pois sabe-se que amostras feitas em Molecular Beam Epitaxy (MBE) apresentam valores muito diferentes de $\mathrm{H}_{\mathrm{EB}}$ em comparação às feitas via Sputtering. Deste modo, esta descrição torna-se um tanto simplificada, mas ainda assim é comportamentalmente válida para muitos sistemas.

Para o modelo de Meiklejohn e Bean, os valores de Exchange Bias previstos são maiores que o medido. O valor experimental da constante de troca $\mathrm{J}$ do $\mathrm{NiFe}$ é da ordem de $5 \times 10^{-14} \mathrm{erg}$, e com isto teríamos um valor calculado de $\mathrm{H}_{\mathrm{EB}}\left(\approx 10^{5} \mathrm{Oe}\right)$ mil vezes maior que o observado. Outros modelos surgiram posteriormente, como o modelo de Néel [21], considerando uma interface AF não compensada, mas divergente para espessuras de filmes da ordem de nanômetros.

\section{Modelo de Malozemoff}

Desenvolvido em 1987 [22, 23], o modelo se baseia na criação da anisotropia de troca nas junções AF/FM que possuam uma rugosidade da ordem das amostras feitas via Sputering. O 
modelo supõe que a interface rugosa têm a possibilidade de gerar um campo magnético randômico atuando nos spins interfaciais, produzindo assim a anisotropia de troca.

Podemos considerar que a camada AF possui uma estrutura de multidomínios com as paredes perpendiculares ao plano do filme. Calculando o tamanho desses domínios pode-se determinar o valor para o campo de Exchange Bias. Tomando $a$ como sendo o parâmetro de rede da camada AF e $z$ como sendo um parâmetro a ser determinado e que é proporcional ao número de spins não compensados da camada $\mathrm{AF}$ que participam do efeito de Exchange Bias, obtemos

$$
H_{E B}=\frac{2 z}{\pi^{2} M_{S} t_{F M}} \sqrt{\frac{J_{A F} K_{A F}}{a}}
$$

Este modelo está de acordo com muitos sistemas, mas possui divergências para materiais com baixa rugosidade, típicos de filmes feitos em MBE. Assim, a aplicação do modelo de Malozemoff só pode ser feita em materiais que possuam uma rugosidade não desprezível em materiais nanoestruturados, e que parece estar em acordo com as amostras obtidas experimentalmente. De acordo com o modelo, se tomarmos $\mathrm{z} \approx 1$, teremos um sistema desordenado, no qual teremos poucos spins não compensados e "travados" participando efetivamente do efeito de Exchange Bias. Se tomarmos z da ordem de 10, teremos uma grande população de spins corretamente configurados, tendo assim um acréscimo no valor de $\mathrm{H}_{\mathrm{EB}}$. $\mathrm{O}$ que torna inviável neste modelo é o parâmetro livre $\mathrm{z}$, que pode, inicialmente, tomar qualquer valor, fazendo com que sempre seja possível obter o valor experimental de $\mathrm{H}_{\mathrm{EB}}$. Com este modelo, torna-se necessário o estudo da configuração da interface de contato da camada AF.

\section{Modelo de Mauri}

De forma temporalmente paralela ao trabalho de Malozemoff, Mauri[14] e colaboradores propuseram um modelo que descrevesse o fenômeno de anisotropia de troca para materiais com baixa rugosidade, característicos de filmes crescidos em MBE. Considerando um filme ferromagnético com uma espessura pequena, de não mais de poucas dezenas de angstroms, juntamente com um filme antiferromagnético, espesso o suficiente para ser aproximado como um filme de espessura infinita e anisotropia uniaxial no plano do filme (direção z), teremos uma interface de espessura $\varepsilon$ perfeitamente lisa onde os spins AF e FM se acoplam de maneira FM. Tomando também a espessura $t$ da camada FM muito menor que a largura das paredes de domínios ferromagnéticos, podemos assumir que os spins desta estão todos na mesma direção, formando um ângulo $\beta$ com o eixo z. Se $\alpha \neq 0$ (fig. 1.8), uma parede de domínios se forma na camada $\mathrm{AF}$, resultando numa energia total magnética da forma

$$
\delta=2 \sqrt{A K}(1-\cos \alpha)+A_{12} \frac{[1-\cos (\alpha-\beta)]}{\varepsilon}+K_{F M} t \cos ^{2} \beta+\mu_{0} H M t(1-\cos \beta)
$$

com o primeiro termo sendo a energia de formação das paredes de domínios da camada $\mathrm{AF}$, com $\mathrm{A}=\mathrm{J}_{\mathrm{AF}} / \mathrm{a}$, onde $a$ é o parâmetro de rede da camada e $\mathrm{J}_{\mathrm{AF}}$ a constante de troca de Heisenberg. $\mathrm{O}$ segundo termo é a constante de troca, com $\mathrm{A}_{12}$ sendo a constante de rigidez da interface. $\mathrm{O}$ terceiro termo é a energia anisotrópica da camada FM e o quarto termo é a energia magnetostática. Minimizando a equação 1.28 em relação aos ângulos, teremos uma relação para $\mathrm{H}_{\mathrm{EB}}$, dada por 


$$
\begin{aligned}
t H_{E B} & =-\frac{A_{12}}{\mu_{0} \varepsilon M} \text { para } \frac{A_{12}}{2 \varepsilon \sqrt{A K}} \ll 1 \\
t H_{E B} & =-2 \frac{\sqrt{A K}}{\mu_{0} M} \text { para } \frac{A_{12}}{2 \varepsilon \sqrt{A K}} \gg 1
\end{aligned}
$$

Este resultado está de acordo com os valores encontrados para $\mathrm{H}_{\mathrm{EB}}$, pois um limite superior para a energia de troca é imposto pela formação de paredes de domínio na camada AF. Uma limitação do modelo se dá quando a energia anisotrópica da camada AF não é muito pequena, pois isto pode favoreces a formação de paredes de domínio na camada FM.

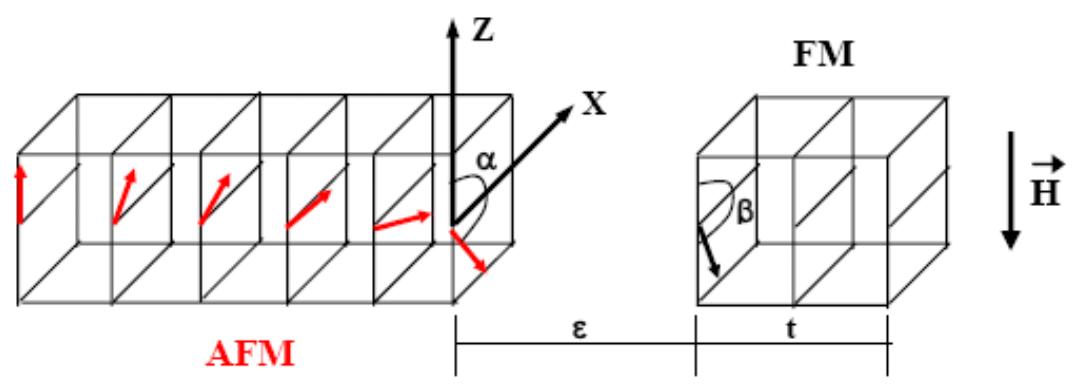

Figura 1.8 - Modelo de Mauri.

Para o modelo de Mauri, uma limitação já é imposta para as amostras, que é a baixa rugosidade. Ou seja, o modelo é capaz de reproduzir resultados satisfatórios de $\mathrm{H}_{\mathrm{Eв}}$ para filmes feitos em MBE, mas possui divergências para os produzidos em Sputtering. Mauri utilizou a condição $\lambda>1$ e impôs os parâmetros $\mathrm{A}_{\mathrm{AF}}=2 \times 10^{-6} \mathrm{erg} / \mathrm{cm}$ e $\mathrm{K}_{\mathrm{AF}}=1,6 \times 10^{4} \mathrm{erg} / \mathrm{cm}^{3}$. Estes parâmetros são compatíveis com filmes em que a espessura das paredes de domínios $(\approx 350 \mathrm{~nm})$ são menores que a espessura do FeMn. Para filmes da ordem de poucos nanômetros $(\approx 10 \mathrm{~nm})$, o valor de $\mathrm{H}_{\mathrm{EB}}$ previsto é de 1034 Oe, não reproduzindo o observado, que é da ordem de 70 Oe.

\section{Modelo microscópico para anisotropia de troca}

Um modelo microscópico simples[25] foi desenvolvido com base no modelo de Ising para bicamadas AF/FM. O modelo assume duas monocamadas, sendo a camada AF compensada e a FM com spins acoplados. O fenômeno de rugosidade foi introduzido fazendo substituições aleatórias de Spins AF na camada FM e, considerando uma aproximação de campo médio a partir das interações de Ising, a magnetização foi numericamente determinada. Assim, considerando uma rede quadrada, a hamiltoniana do sistema por ser tomada da forma

$$
H=H_{A F}+H_{F M}+H_{C}
$$

onde $\mathrm{H}_{\mathrm{AF}}, \mathrm{H}_{\mathrm{FM}}$ e $\mathrm{H}_{\mathrm{C}}$ são, respectivamente, as energias de interações antiferromagnéticas, ferromagnéticas e de acoplamento AF/FM. Assim, pelo modelo de Ising, teremos

$$
H_{A F}=-\sum_{i j} J_{i j}^{(1)} \sigma_{i}^{(1)} \sigma_{j}^{(1)}-D_{1} \sum_{i} \sigma_{i}^{(1)^{2}}-h \sum_{i} \sigma_{i}^{(1)}
$$

onde $\sigma_{i}^{(1)}$ representa um spin na camada AF no sítio i interagindo com a vizinhança próxima através de uma interação de exchange direto $\mathrm{J}_{\mathrm{ij}}{ }^{(1)}=\mathrm{J}_{1}<0$ e (ij) representa a soma sobre toda a vizinhança. $\mathrm{D}_{1}$ é a anisotropia uniaxial local do material AF e $h$ é o campo externo. 
Tomando uma distribuição randômica local na interface FM com a variável $\eta=1,0$ especificando a presença $(=1)$ ou a ausência $(=0)$ de um átomo $F M$ no sítio i com $S p i n S_{i}$ da camada ferromagnética com interação $\mathrm{I}_{\mathrm{ij}}, \mathrm{D}_{2}$ uma anisotropia uniaxial local da camada FM e $\sigma_{\mathrm{i}}^{(2)}$ o momento de um átomo AF na camada FM, teremos a hamiltoniana ferromagnética dada por

$$
H_{F M}=-\sum_{i j} I_{i j}-\sum_{i}\left[D_{2} \eta_{i} S_{i}^{2}+D_{1}\left(1-\eta_{i}\right)\left(\sigma_{i}^{(2)}\right)^{2}\right]-h \sum_{i}\left[\eta_{i} S_{i}+\left(1-\eta_{i}\right) \sigma_{i}^{(2)}\right]
$$

Devido à substituição randômica na camada FM por átomos $\mathrm{AF}, \mathrm{I}_{\mathrm{ij}}$ toma a forma

$$
\begin{aligned}
I_{i j}=J_{2} \eta_{i} \eta_{j} S_{i} S_{j} & +J_{1}\left(1-\eta_{i}\right)\left(1-\eta_{j}\right) \sigma_{i}^{(2)} \sigma_{j}^{(2)} \\
& +J_{C}\left[\left(1-\eta_{i}\right) \eta_{j} \sigma_{i}^{(2)} S_{j}+\eta_{i}\left(1-\eta_{j}\right) S_{i} \sigma_{j}^{(2)}\right]
\end{aligned}
$$

onde $\mathrm{J}_{2}$ é a constante de interação entre vizinhos $\mathrm{FM}$ e $\mathrm{J}_{\mathrm{C}}$ representa o acoplamento entre átomos FM e AF. A hamiltoniana de interação entre as camadas pode ser dada por

$$
H_{C}=-\sum_{i}\left[J_{C} \eta_{i} S_{i} \sigma_{i}^{(1)}+J_{1}\left(1-\eta_{i}\right) \sigma_{i}^{(1)} \sigma_{i}^{(2)}\right]
$$

onde a soma é dada sobre todos os sítios da interface.

O último termo das equações 1.33 e 1.35 atua como um campo efetivo aleatório na interface que quebra a simetria ferromagnética, gerando assim um deslocamento atribuído à anisotropia unidirecional[22].

Com devidas aproximações[26] de campo médio, pode-se introduzir a temperatura na formulação da magnetização. Tomando $\beta=1 / \mathrm{k}_{\mathrm{B}} \mathrm{T}$, spin 1 para simplificação, uma média termodinâmica sobre todas as componentes de $\operatorname{spin} \sigma_{\mathrm{i}}{ }^{(\mu)}$ e $\mathrm{S}_{\mathrm{i}}=0, \pm 1$, a magnetização $\mathrm{M}_{\mathrm{i}}{ }^{(\mu)}$ tomará a forma

$$
M_{i}^{(\mu)}=\frac{\operatorname{senh}\left(\beta \phi_{i}^{(\mu)}\right)}{\left[\cosh \left(\beta \phi_{i}^{(\mu)}\right)+0.5 e^{-\beta D_{\mu}}\right]}
$$

com

$$
\phi_{i}^{(\mu)}=\sum_{\mu} \sum_{i j}\left(J_{i j} M_{j}^{(\mu)}+h\right)
$$

sendo o campo local na aproximação de campo médio. $\mu=1,2$ especifica, respectivamente, átomos da camada FM e da AF.

O modelo microscópico para a anisotropia de troca é um modelo teórico, mas não é capaz de reproduzir valores de $\mathrm{H}_{\mathrm{EB}}$ da mesma ordem de grandeza das curvas obtidas experimentalmente, tendo $\mathrm{H}_{\mathrm{EB}}<<\mathrm{H}_{\mathrm{C}}$, sendo assim não aplicável aos filmes estudados.

\section{Modelo de Preisach com Exchange Bias}

Este modelo, desenvolvido por D. R. Cornejo e colaboradores [24], foi inicialmente utilizado para descrever o fenômeno de Exchange Bias em sistemas de pós de nanopartículas 
heterogêneas de $\mathrm{FeCo}+\mathrm{MnO}$ e $(\mathrm{Fe})_{1-\mathrm{x}}+(\mathrm{NiO})_{\mathrm{X}}$. Recentemente também foi utilizado em $\mathrm{FeNi}$ $+\mathrm{OX}(\mathrm{X}=\mathrm{Cu}, \mathrm{Ni}, \mathrm{Co})$ [58]. Neste trabalho, o modelo é extendido de forma que seja possível descrever Exchange Bias em filmes finos.

Consideremos uma bicamada $\mathrm{AF} / \mathrm{FM}$, com nenhuma consideração sendo feita em relação à camada $\mathrm{AF}$. A camada FM, no entanto, é considerada como sendo formada por uma coleção de partículas com forma de paralelepípedos de base quadrada de lado $r_{i}$ e altura $t$ (a espessura do filme). $\mathrm{r}=\left\langle\mathrm{r}_{\mathrm{i}}\right\rangle$ representa o valor médio do tamanho das partículas FM no plano do filme (fig. 1.9). Cada partícula possui um campo coercivo $h c_{i}$ e está sob a ação de um campo de interação local $h_{\mathrm{i}}$. Assim, temos uma distribuição $\rho\left(h_{c}, h_{b}\right)$ que representa a camada FM da bicamada.

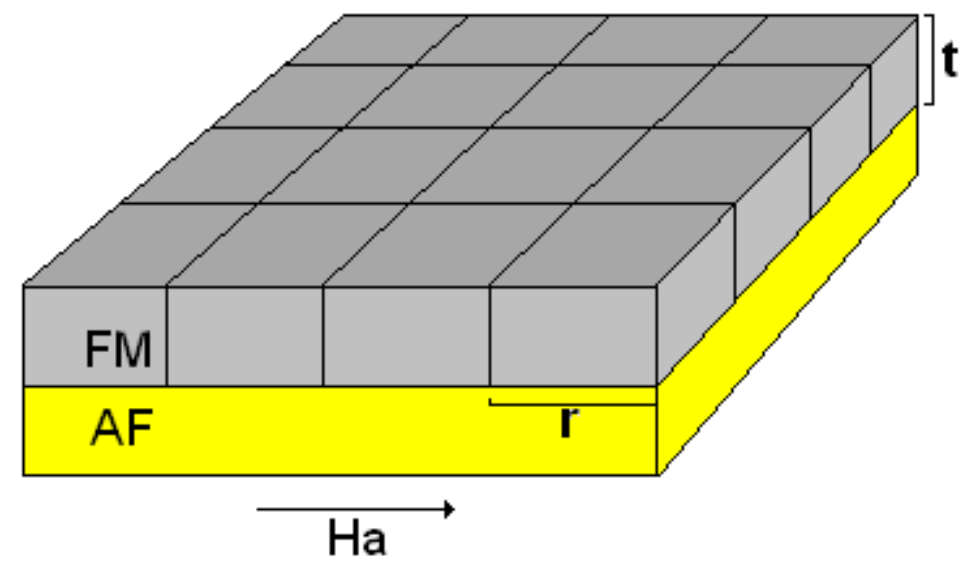

Figura 1.9 - representação da distribuição de partículas ferromagnéticas no filme fino.

A energia livre e a magnetização do material podem ser expressas por [59]

$$
\begin{aligned}
& F(M, T)=2 \mu_{0} M_{S} \int_{0}^{\infty} d h_{c} \int_{0}^{H+\lambda\left(h_{c}\right)} h_{u} \rho\left(h_{c}, h_{b}\right) d h_{b}+F_{M F} \\
& M(H, \lambda)=M_{S} \int_{0}^{\infty} d h_{c} \int_{0}^{H+\lambda\left(h_{c}\right)} \rho\left(h_{c}, h_{b}\right) d h_{b}
\end{aligned}
$$

onde $\mathrm{M}_{\mathrm{s}}$ é a magnetização de saturação, $\mathrm{H}$ é o campo efetivo do modelo e $\lambda\left(\mathrm{h}_{\mathrm{c}}\right)$ é o contorno limitante que separa partículas orientadas paralela e antiparalelamente ao campo aplicado $\mathrm{H}_{\mathrm{a}}$. $\mathrm{O}$ primeiro termo da equação 1.38 representa a estrutura fina da superfície de energia livre, responsável pelos efeitos de histerese, viscosidade, etc. $\mathrm{O}$ segundo termo representa $\mathrm{o}$ comportamento em grande escala da energia livre: $\mathrm{F}_{\mathrm{MF}}$ é crucial para a determinação do campo efetivo responsável pela inversão do momento magnético das partículas da amostra. De fato, $\mathrm{H}$ pode ser explicitado por

$$
H=H_{a}+H_{M F}=H_{a}-\frac{1}{\mu_{0}}\left[\frac{\partial F_{M F}}{\partial M}\right]_{T}
$$

onde $\mathrm{H}_{\mathrm{a}}$ é o campo aplicado e $\mathrm{H}_{\mathrm{MF}}$ é o campo médio do modelo.

Consideramos que as partículas FM sejam fortemente influenciadas por interações tais como o acoplamento de exchange e anisotropia magnetocristalina. Por outro lado, $\mathrm{F}_{\mathrm{MF}}$ tem que 
ser, principalmente, determinado por interações dipolares e configurações de domínios do sistema. Tomando $\mathrm{S}_{\mathrm{AF}-\mathrm{AF}}, \mathrm{S}_{\mathrm{FM}-\mathrm{FM}}$ e $\mathrm{S}_{\mathrm{AF}-\mathrm{FM}}$ como sendo as superfícies de contato por unidade de volume entre partículas $\mathrm{AF}-\mathrm{AF}, \mathrm{FM}-\mathrm{FM}$ e AF-FM respectivamente, poderemos explicitar $\mathrm{F}_{\mathrm{MF}}$ da forma

$$
F_{M F}=\frac{\mu_{0}}{2} N_{e f f} M^{2}+\gamma_{F M} S_{F M-F M} v(M)+\gamma_{A F} S_{A F-A F} \xi(M)+\gamma_{A F-F M} S_{A F-F M} \zeta(M)
$$

Nesta equação, o primeiro termo representa a densidade de energia magnetostática, com $\mathrm{N}_{\text {eff }}$ sendo um parâmetro fenomenológico relacionado à componente desmagnetizante. Os outros termos são diferentes densidades de energia resultante das paredes de domínio. Os $\gamma_{\mathrm{s}}$ são as energias por unidade de superfície para as áreas de contato especificadas. As funções $v(\mathrm{M})$, $\xi(\mathrm{M})$ e $\zeta(\mathrm{M})$ expressam a dependência de $\mathrm{F}_{\mathrm{MF}}$ com as estruturas de domínios durante a evolução da magnetização $\mathrm{M}$ com o campo $\mathrm{H}$. No contato entre domínios ferromagnéticos, teremos

$$
v(M)=1-\frac{M^{2}}{M_{S}^{2}}
$$

Também é esperada uma dependência muito pequena de $\mathrm{M}$ com $\mathrm{F}_{\mathrm{MF}}$ nos contatos $\mathrm{AF}_{\mathrm{s}}$ devido à alta anisotropia das mesmas. Em uma primeira aproximação, podemos admitir $\xi(\mathrm{M})=1$. Nas interfaces AF-FM, devemos considerar que deve haver um mínimo para a saturação negativa e um máximo para a positiva. Podemos esperar também uma dependência em $\mathrm{M}$ devido a anisotropia unidirecional. Com base nisto, podemos tomar

$$
\zeta(M)=\frac{M}{M_{S}}
$$

De acordo com as considerações da forma das partículas e desconsiderando efeitos de borda, as superfícies por unidade de volume serão explicitadas por

$$
S_{F M-F M}=\frac{4 r t}{r^{2} t}=\frac{4}{r}, S_{A F-F M}=\frac{r^{2}}{r^{2} t}=\frac{1}{t}
$$

Assim, de (1.40) à (1.44), e assumindo que $\mathrm{S}_{\mathrm{AF}-\mathrm{AF}}$ seja constante, teremos $\mathrm{H}_{\mathrm{MF}}$ como sendo

$$
H_{M F}=\left(-N_{e f f}+\frac{8}{r} \frac{\gamma_{F M}}{\mu_{0} M_{S}^{2}}\right) M-H_{E B}
$$

com

$$
H_{E B}=\frac{\gamma_{A F-F M}}{t \mu_{0} M_{S}}
$$

O primeiro termo em (1.45) reflete o campo magnetostático local, enquanto que o segundo termo, explicitado em (1.46), reflete o campo de Exchange Bias.

O modelo de Preisach com Exchange Bias é um modelo fenomenológico, tornando-se assim concordante com dados experimentais [24]. Este modelo foi bem sucedido com a descrição dos fenômenos magnéticos ao qual foi submetido, e ainda permite o estudo de assimetrias de magnetização e, conseqüentemente, de diagramas de FORCs sem muitas 
complicações (este assunto será explorado adiante), sendo assim adequado ao estudo das amostras obtidas.

\section{Métodos de medição}

A anisotropia de troca pode ser estudada através de muitas técnicas [13], onde as mesmas fornecem diferentes informações sobre a configuração do material estudado, permitindo a caracterização do mesmo. Estão descritos, a seguir, os principais métodos de medição que permitem o estudo dos efeitos da anisotropia de troca.

\section{Magnetização}

Loops de histerese provenientes da medição da magnetização em função do campo aplicado podem dar um valor direto do campo de Exchange Bias $\mathrm{H}_{\mathrm{EB}}$. Estas medições podem ser feitas com o uso de diversos equipamentos, como o SQUID, VSM (Vibrating Sample Magnetometer), MOKE (magnetic optical Kerr Effect), etc. Através desta técnica, a coercividade também pode ser aferida.

\section{Torque}

O magnetômetro de torque, no qual a magnetização é medida enquanto a amostra é rotacionada, fornece a direção da anisotropia unidirecional do material.

\section{Ressonância Ferromagnética}

Na ressonância ferromagnética, a amostra é inserida numa cavidade de microondas e submetida à altas frequiências $(\mathrm{GHz})$ de campo magnético enquanto um campo DC é acrescido durante a ressonância. Através dos picos de linhas de ressonância, pode-se determinar o valor de $\mathrm{H}_{\mathrm{EB}}$ e a anisotropia unidirecional.

\section{Difração de Nêutrons}

Devido à natureza magnética dos nêutrons, sua difração é de grande importância para o estudo de estruturas magnéticas. A homogeneidade das camadas podem ser medidas, assim como a formação de domínios. A difração para grandes ângulos podem fornecer informações sobre a configuração dos spins. 


\section{Magnetoresistência}

O estudo da resistência elétrica de sistemas com Exchange Bias têm sido usados em válvulas de spin (AF/FM/(não magnético)/FM). Neste sistema, a camada FM em contato com a AF permanece "presa" enquanto que a outra FM fica "livre". Nesta configuração, a resistência à passagem de corrente elétrica sob o material muda bruscamente ao se aplicar pequenos campos positivos ou negativos. Este sistema possui aplicações tecnológicas e serve também para a determinação de $\mathrm{H}_{\mathrm{EB}}$ e $\mathrm{H}_{\mathrm{C}}$.

\section{Susceptibilidade AC}

Na susceptibilidade $\mathrm{AC}$, a mudança no fluxo magnético criada pela amostra devido à presença de um campo alternado é medida como função dos campos AC e DC aplicados, temperatura ou freqüência. $\mathrm{H}_{\mathrm{C}}$ e $\mathrm{H}_{\mathrm{EB}}$ são obtidos da dependência do campo DC com a susceptibilidade AC.

\section{Observação de domínios}

Os domínios nas camadas FM e AF têm importância vital para o efeito de $\mathrm{H}_{\mathrm{EB}}$. Essas formações podem ser vistas através de técnicas como o efeito Kerr, microscopia de Lorentz, efeito Faraday, microscopia de força magnética, entre outras. Essas técnicas permitem apenas o estudo de formações de domínios nos quais estão orientados de forma perpendicular à interface. Domínios orientados de forma paralela à interface apenas podem ser vistos de forma indireta, como a mudança na anisotropia local, por exemplo. Os domínios do material FM dependem de sua espessura e da junção das interfaces.

\section{Espalhamento Brillouin}

Quando uma amostra recebe um feixe de laser em sua superfície, terá a luz espalhada. As mudanças do espectro de espalhamento dão informações sobre a frequiência de ondas de spin. O deslocamento da freqüência das ondas de spin fornece a informação sobre o efeito de $\mathrm{H}_{\mathrm{EB}}$.

\section{Dicroísmo Magnético}

Os elétrons da amostra são bombardeados por raios-X, fazendo com que os fótons emitidos da recombinação do elétron com os estados menos energéticos sejam medidos como função do campo magnético e da temperatura. Este método permite um estudo de propriedades magnéticas para diferentes profundidades numa camada. 


\section{Efeito Mössbauer}

Nas camadas FM e/ou AF, um isótopo radioativo de um dos elementos estudados pode ser introduzido na rede, que emitirá raios- $\gamma$, sendo estes detectados. Esta técnica permite a introdução de isótopos radioativos em diferentes partes de uma amostra, no qual dão informações sobre a configuração local.

\section{3 - Válvulas de Spin}

Em um sistema de bicamadas, temos o material AF interagindo com o FM, onde propriedades magnéticas são manifestadas, sendo uma destas o campo de Exchange Bias. Um outro sistema, baseado nesta estrutura, consiste no crescimento de uma amostra FM/NM/FM/AF (fig. 1.10), onde NM é um material não magnético e condutor, também conhecido como espaçador. Desta forma, pode-se obter um material ferromagnético acoplado ao antiferromagnético, sendo esta camada FM denominada de camada presa, manifestando o campo $\mathrm{H}_{\mathrm{EB}}$ e o aumento da coercividade do material magnético, e outra camada ferromagnética, chamada de camada livre, interagindo em menor ordem, com a intensidade de interação sendo diretamente influenciada pela espessura do material NM. Esta estrutura é conhecida como válvula de spin em sua forma mais simples[27].

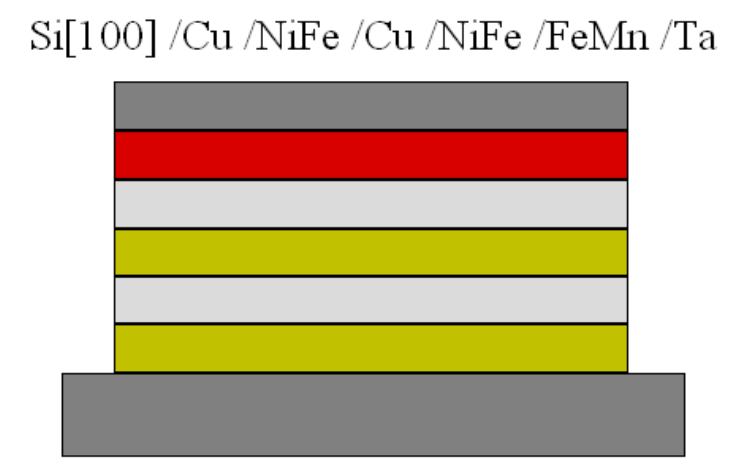

Figura 1.10 - Estrutura de uma válvula de Spin em seu modo mais simples.

Neste sistema, curvas de histerese podem ser utilizadas como um parâmetro para estabelecer critérios de interação (fig. 1.11 a) entre as camadas ferromagnéticas e diagramas de FORCs podem ser utilizados para um melhor entendimento sobre os processos de magnetização de uma amostra e a forma com que as camadas interagem.

Basicamente, quando temos um campo de Exchange Bias suficientemente grande para manter a camada presa saturada a campo nulo e quando temos uma camada não magnética em uma espessura adequada para que a camada livre seja saturada positivamente e negativamente a baixos campos (quando comparada à $\mathrm{H}_{\mathrm{EB}}$ e $\mathrm{H}_{\mathrm{C}}$ da camada presa), teremos assim duas configurações de alinhamento magnético: camadas alinhadas paralelamente ou antiparalelamente, e este efeito têm uma influência direta nas propriedades de transmissão de elétrons, tendo como um dos principais efeitos o diferente espalhamento de elétrons spin up e spin down e a manifestação da magnetoresistência anisotrópica (MRA) [28] (fig. 1.10 b). 


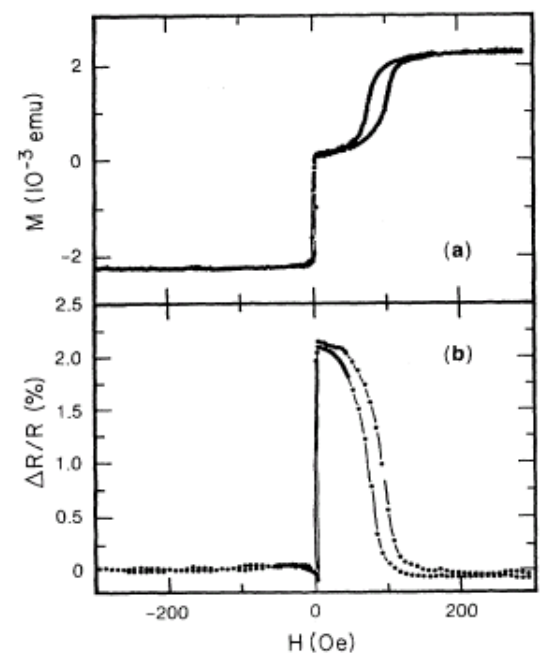

Figura 1.11 - a) Curva de magnetização à temperatura ambiente com $\mathrm{H}$ no plano da amostra de uma válvula de spin juntamente com b) sua curva resistiva $\Delta \mathrm{R} / \mathrm{R}$ em função de $\mathrm{H}$ para o sistema $\mathrm{Si} / \mathrm{NiFe}(15 \mathrm{~nm}) / \mathrm{Cu}(2,6) / \mathrm{NiFe}(15) / \mathrm{FeMn}(10) / \mathrm{Ag}(2)$ [28].

Para campos ligeiramente negativos, as duas magnetizações estarão no mesmo sentido, negativamente saturadas. Pode-se observar na figura 1.11a que, para campos ligeiramente positivos, as magnetizações estarão contrárias, trazendo como conseqüência o aumento da resistência. O mecanismo envolvido neste processo está relacionado com o espalhamento de elétrons no meio de propagação.

Em ligas de $\mathrm{NiFe}$, sabe-se que o espalhamento de elétrons com spin-down nos elementos de $\mathrm{Fe}$ (toma-se aqui o $\mathrm{Ni}$ em uma proporção muito maior) possui uma seção de choque muito maior que para o espalhamento de spins-up [29] $\left(\rho_{\downarrow} / \rho_{\uparrow}=20\right)$. Desta forma, para o alinhamento paralelo das magnetizações, a corrente de elétrons com spins-up será maior devido ao maior caminho livre em toda a estrutura, sendo esta a configuração de menor resistência. Para o alinhamento antiparalelo das magnetizações, teremos um elevado espalhamento para ambas as populações spin-up e spin-down. Desta forma, a resistência torna-se maior relativamente à configuração de alinhamento magnético paralelo.

Outros mecanismo também são responsáveis pelo efeito de MRA, como manifestações de spin-flip para o alinhamento antiparalelo e a interdifusão atômica [30] por exemplo, mas todos são efeitos de menor ordem.

Espaçadores de Ta e Al não apresentam o efeito de válvula de spin esperado, pois há um decréscimo considerável na transmissão de elétrons polarizados [28]. A amplitude de polarização do fluxo, e até mesmo o próprio fluxo, são afetados, pois, além desses elementos não serem bons condutores, os elétrons ainda podem ser despolarizados por materiais paramagnéticos formados nas junções com o Ni.

Uma outra interpretação para o efeito de magnetoresistência observado em válvulas de spin pode ser feita de forma qualitativa (fig. 1.12). 

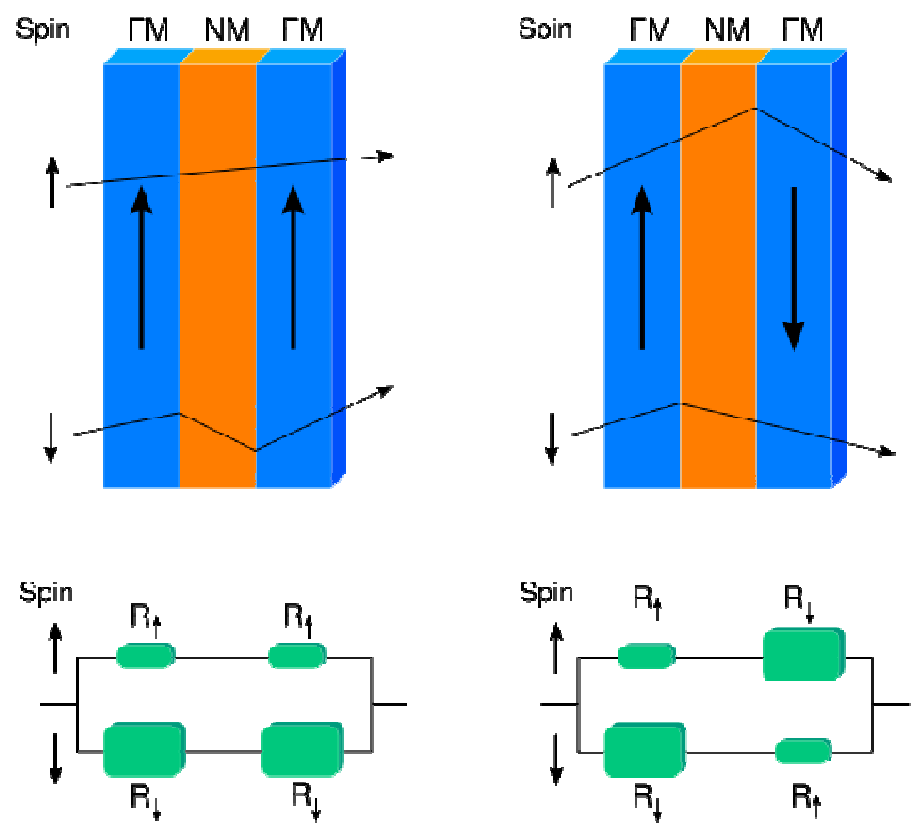

Figura 1.12 - Descrição qualitativa do fenômeno de espalhamento de elétrons, tendo como consequiência diferentes valores de resistências para as duas configurações de spin.

Nela, o espalhamento eletrônico está representado de forma clássica e intuitiva. À esquerda, vê-se dois materiais FM magneticamente alinhados e separados por uma camada NM. Um elétron spin-up é inserido em uma das camadas e atravessa o material sem ser espalhado, enquanto que o elétron spin-down sofre um espalhamento na camada onde a magnetização é contrária ao seu alinhamento. À direita, observa-se o espalhamento para ambos os elétrons injetados. Abaixo da ilustração, está esquematizada uma configuração equivalente com o uso de resistores atuando em correntes de spins polarizados.

Esta esquematização permite um entendimento qualitativo do que ocorre de fato nas válvulas de spin.

Decorrente do fato de o material possuir suas camadas magnéticas separadas, espera-se observar comportamentos distintos para ambas nos diagramas de FORCs, como a distribuição nos campos de interação e de inversão. Estes, por sua vez, podem estar relacionados devido às possíveis interações entre as duas camadas[30-32]. As análises dos resultados obtidos para as válvulas de spin serão feitas com base nos modelos matemáticos já descritos e em uma análise comportamental.

\section{4 - Bicamadas de NiFe/FeMn com Exchange Bias}

\section{Propriedades magnéticas do Py}

O Permalloy $\left(\mathrm{Ni}_{80} \mathrm{Fe}_{20}\right)$ possui uma baixa anisotropia magnetocristalina, de aproximadamente $5 \times 10^{2} \mathrm{~J} / \mathrm{m}^{3}$ e magnetostricção praticamente nula $\left(\approx 10^{-6}\right)[33]$. Também possui uma coercividade muito baixa $(\approx 1 \mathrm{Oe})$, sendo assim considerado um material magneticamente 
mole. O Py tem estrutura cúbica FCC mas o Fe ocupa posições aleatórias na rede, resultando em uma energia de anisotropia cristalina quase nula.

A energia magnetocristalina pode ser expressa por

$$
E=K_{0}+K_{1}\left(\propto_{1}^{2}+\propto_{2}^{2}+\propto_{3}^{2}\right)+K_{2} \propto_{1}^{2} \propto_{2}^{2} \propto_{3}^{2}
$$

Com $\mathrm{K}_{2}<<\mathrm{K}_{1}$. Se assumirmos um processo de rotação coerente para a inversão de magnetização, o campo de anisotropia $\mathrm{H}_{\mathrm{A}}$ será

$$
H_{A}=\frac{2 K_{1}}{\mu_{0} M_{S}}
$$

o que nos leva à uma permeabilidade rotacional relativa dada por

$$
\mu_{r}=\frac{\mu_{r o t}}{\mu_{0}}=1+\frac{M_{S}}{H_{A}}=1+\frac{\mu_{0} M_{S}^{2}}{2 K_{1}}
$$

Para uma liga $\mathrm{Ni}_{0.78} \mathrm{Fe}_{0.22}, \mathrm{~K}_{1} \approx-5 \times 10^{2} \mathrm{~J} / \mathrm{m}^{3}$ e $\mathrm{M}_{\mathrm{S}}=835 \times 10^{3} \mathrm{~A} / \mathrm{m}$, teremos $\mu_{\mathrm{r}} \approx 800$. Sabe-se que esses materiais possuem $\mu_{\mathrm{r}} \approx 8000$. Assim, Chikazumi(1952) sugeriu que rotações incoerentes aliadas à um (em menor intensidade) deslocamento de paredes de domínios são os mecanismos de inversão de magnetização característicos desta liga.

\section{Propriedades magnéticas do FeMn}

A liga $\gamma-\mathrm{Fe}_{50} \mathrm{Mn}_{50}$ (cfc) estudada se encontra no estado antiferromagnético. Sua deposição não depende de processos reativos e a temperatura de Néel é de $\approx 519 \mathrm{~K}\left(246^{\circ} \mathrm{C}\right)$, sendo assim estável à temperatura ambiente. $\mathrm{O}$ bulk na fase $\gamma$ possui um comportamento de uma liga INVAR, ou seja, não possui dilatação térmica. A transição estrutural da fase $\gamma$ para a fase $\varepsilon$ (hcp, hexagonal close packed) se dá em $\approx 80 \mathrm{~K}\left(-193^{\circ} \mathrm{C}\right)$.

Segundo a literatura[34], a estrutura de spins da fase $\gamma$ possui uma localização aleatória, tendo em vista que os átomos de Fe e Mn não ocupam um sítio preferencial. Devido ao crescimento das amostras em Sputtering (ou seja, com rugosidade), espera-se uma interface nãocompensada, reforçada ainda pela hipótese de este método de deposição favorecer a interdifusão atômica.

\section{Comportamento magnético do $\mathrm{NiFe} / \mathrm{FeMn}$}

$\mathrm{O}$ crescimento de filmes de $\mathrm{NiFe}$ em contato com o FeMn provoca mudanças magnéticas que o torna interessante à pesquisa, devido principalmente ao efeito de anisotropia de troca. Uma breve descrição desses efeitos encontra-se a seguir, com algumas características mais importantes conhecidas sobre essas bicamadas.

\section{A influência da subcamada (buffer)}

$\mathrm{O}$ efeito de anisotropia de troca nas junções $\mathrm{NiFe} / \mathrm{FeMn}$ está diretamente ligado com a formação da fase $\gamma-\mathrm{Fe}_{50} \mathrm{Mn}_{50}$ [35] e que a formação desta estrutura depende fortemente da sequência de deposições, assim como da subcamada (buffer) utilizada. 
A utilização do Ta como buffer para o crescimento de bicamadas $\mathrm{NiFe} / \mathrm{FeMn}$ favorece a formação de grãos de dimensão pequena e baixa rugosidade, favorecendo o aumento do efeito de Exchange Bias[36]. O Ta possui peculiaridades que o tornam interessante para o estudo de bicamadas, pois favorece uma maior estabilidade da fase $\gamma$ do FeMn e é capaz de produzir o efeito de $\mathrm{H}_{\mathrm{EB}}$ com espessuras pequenas, da ordem de $10 \mathrm{~nm}$, além de favorecer uma baixa coercividade no NiFe.

Para o cobre, é evidenciado que o efeito de $\mathrm{H}_{\mathrm{EB}}$ aumenta de forma linear com o aumento da espessura do mesmo até uma espessura de aproximadamente 30nm[36], permitindo inclusive valores maiores de Exchange Bias que com amostras feitas com Ta.

\section{A influência da camada de FeMn}

Sabe-se que [14] para espessuras de FeMn menores que $\approx 5 \mathrm{~nm}$ feitas em Sputtering, não é possível a observação do efeito de $\mathrm{H}_{\mathrm{EB}}$, pois a anisotropia magnetocristalina do FeMn não se torna capaz de se manter fixa, mudando sua orientação com a mudança da magnetização do $\mathrm{NiFe}$, criando apenas um aumento na coercividade do material ferromagnético.

Para a camada de FeMn crescida sobre a camada de NiFe, pode-se observar um comportamento do tipo[37] $\mathrm{H}_{\mathrm{EB}} \alpha \mathrm{t}_{\mathrm{FM}}{ }^{-1}$ para espessuras entre $10 \mathrm{~nm}$ e $1000 \mathrm{~nm}$ do FeMn. Para espessuras menores que $10 \mathrm{~nm}$ do FeMn, espera-se flutuações nos valores de $\mathrm{H}_{\mathrm{EB}}$ devido à instabilidade estrutural da fase $\gamma$.

$\mathrm{O}$ comportamento típico observado da dependência de $\mathrm{H}_{\mathrm{EB}}$ e $\mathrm{H}_{\mathrm{C}}$ com a espessura de FeMn encontra-se na figura a seguir. Sabe-se também que o comportamento característico de dependência destes parâmetros também sofrem variações com a mudança da espessura do Permalloy.
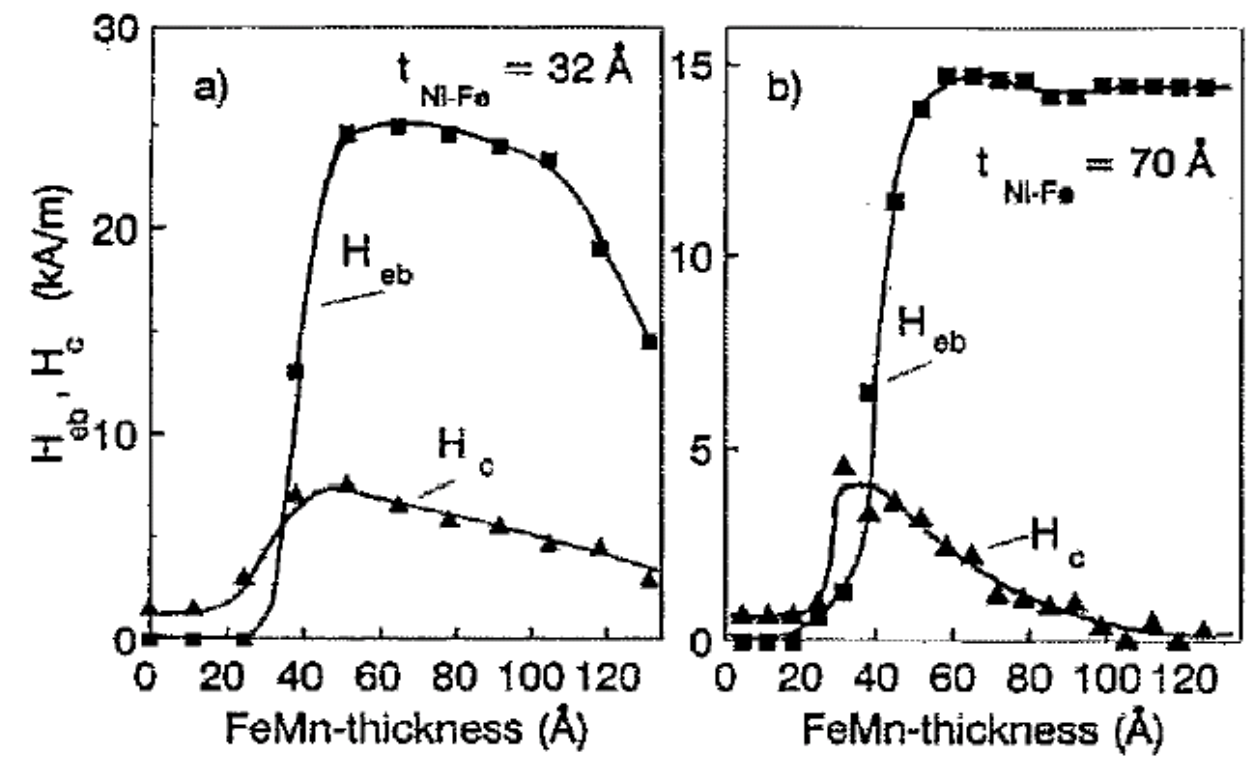

Figura 1.13 - Dependência de $\mathrm{H}_{\mathrm{EB}}$ e $\mathrm{H}_{\mathrm{C}}[38]$ para a amostra $\mathrm{Cu}[111] / \mathrm{Py}(32$ e $70 \AA$ ̊)/FeMn/Au(20 ̊).

\section{A influência da camada de Py}

Sabe-se que [38] amostras com uma camada de Py com espessuras maiores que 50nm proporcionam valores de $\mathrm{H}_{\mathrm{EB}}$ desprezíveis se comparados aos valores com espessuras da ordem de $10 \mathrm{~nm}$. Isto se deve ao comportamento de dependência de $\mathrm{H}_{\mathrm{EB}}$ com $\mathrm{t}_{\mathrm{FM}}{ }^{-1}$. Espera-se também 
valores da mesma ordem de grandeza para a coercividade, com esta podendo ter uma dependência mais intensa com $\mathrm{t}_{\mathrm{FM}}{ }^{-\mathrm{d}}$, onde $\mathrm{d}$ é, em geral, maior que 1 .
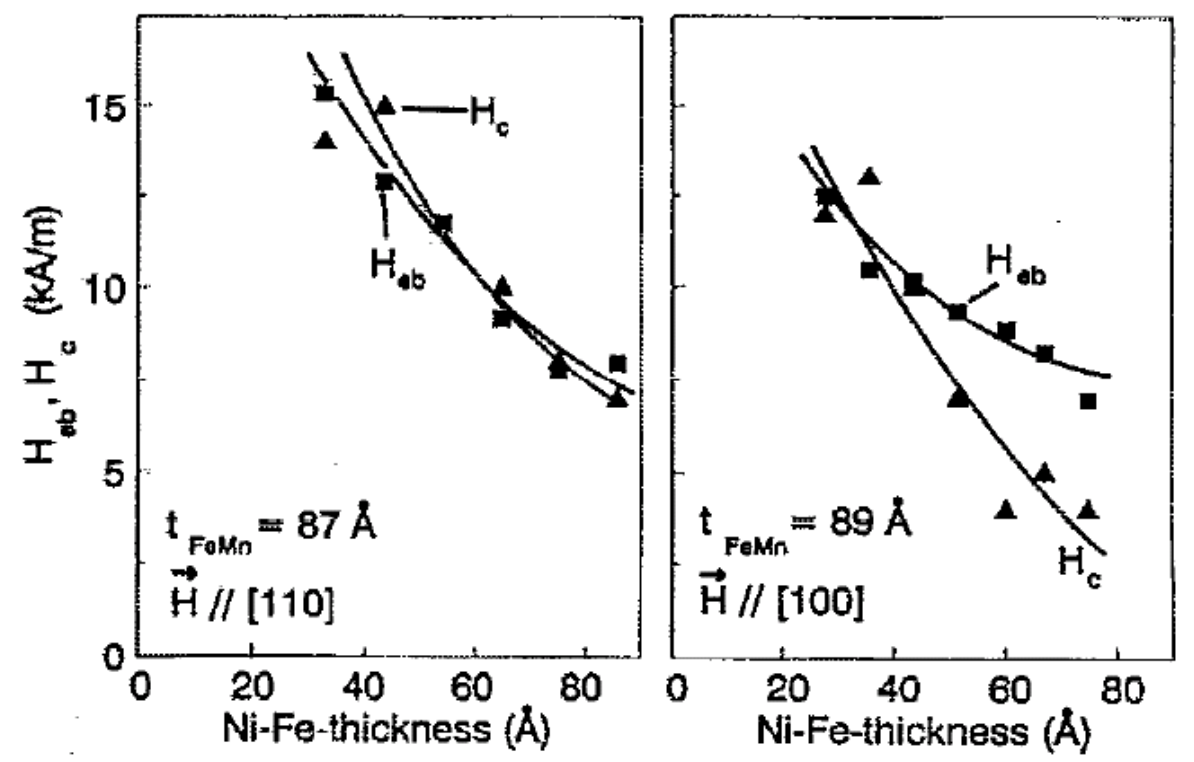

Figura 1.14 - Dependência de $\mathrm{H}_{\mathrm{EB}}$ e $\mathrm{H}_{\mathrm{C}}[38]$ para a amostra $\mathrm{Cu}[001] / \mathrm{Py} / \mathrm{FeMn}(87$ e $89 \AA$ A)/Au(20 ̊̊) para diferentes orientações de campo em relação ao plano da amostra.

Amostras feitas em MBE (Molecular Beam Epitaxy) evidenciam [38] claramente os máximos e mínimos tanto para $\mathrm{H}_{\mathrm{EB}}$ quanto para $\mathrm{H}_{\mathrm{c}}$ (fig. 1.15) para diferentes espessuras de cada camada.

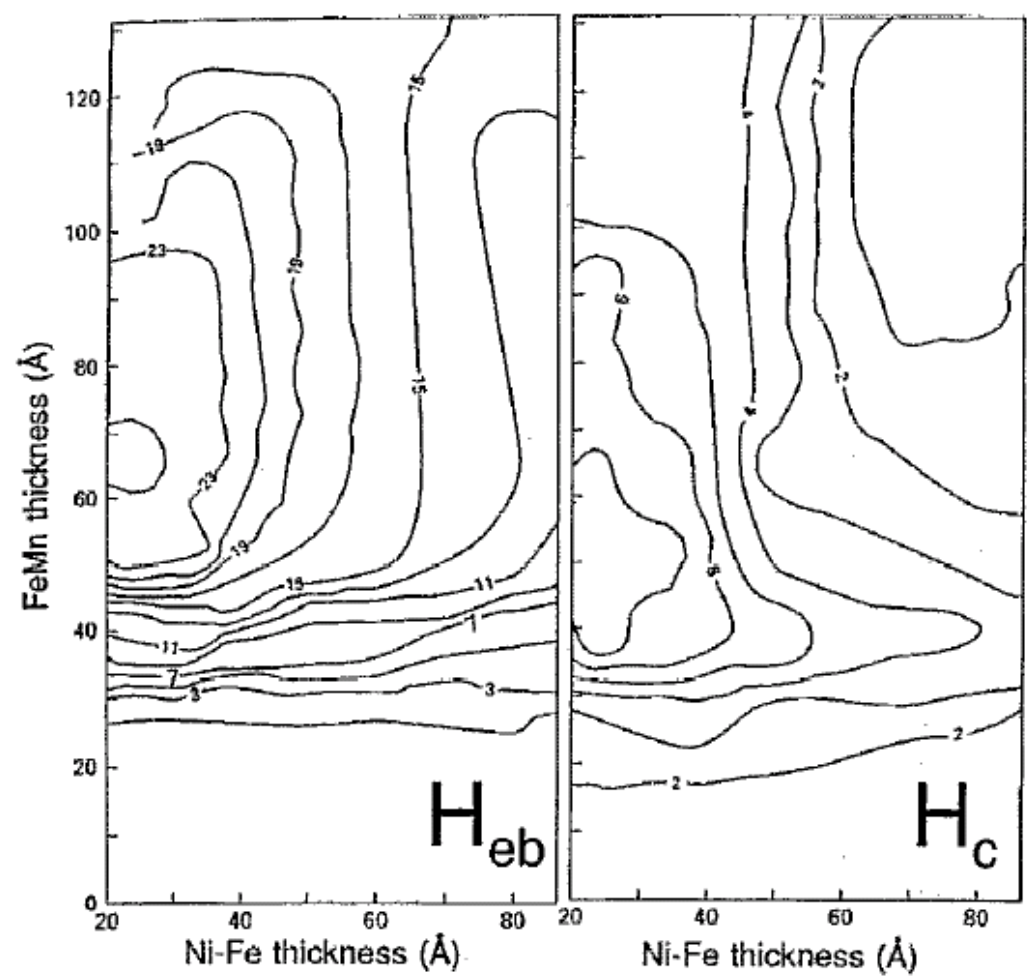

Figura 1.15 - Dependência de $\mathrm{H}_{\mathrm{EB}}$ e $\mathrm{H}_{\mathrm{C}}$ com as espessuras de $\mathrm{Ni}_{0,80} \mathrm{Fe}_{0,20} / \mathrm{Fe} 0_{, 50} \mathrm{Mn}_{0,50}$ [38]. 
Para amostras produzidas via Sputtering, espera-se um comportamento similar, mas com grandezas diferentes devido aos efeitos de rugosidade na interface.

\section{5 - O Modelo de Preisach}

O modelo de Preisach será exposto com a finalidade de ser usado para entender os processos de magnetização das amostras obtidas através de curvas de inversão de primeira ordem, onde a matemática dos Diagramas de FORCs será explorada para que possa ser usada em simulações.

\section{Modelo clássico de Preisach}

Uma descrição para o fenômeno de histerese foi proposto por Preisach no ano de 1935[39]. Preisach basicamente considerou partículas que possuíssem duas possibilidades de orientação magnética: $\pm \mathrm{m}_{\mathrm{s}}$. Também considerou que, quando sob a orientação de um campo magnético alto, elas possuíssem a orientação do mesmo, e, com o decréscimo do campo, haveria um valor crítico em que ocorresse a inversão de magnetização. Este valor foi denominado de campo de inversão (switching field) $\mathrm{H}_{\mathrm{sw}}$. Tendo esta propriedade, pode-se constatar que uma partícula, ao ser submetida a um campo decrescente passando pelo valor de inversão, esta terá sua magnetização invertida, sem que haja um intervalo de transição. As considerações são válidas para a situação inversa, para um campo alto com valor negativo. A evolução da magnetização está evidenciada na figura 1.16, mostrando o comportamento descrito aqui.

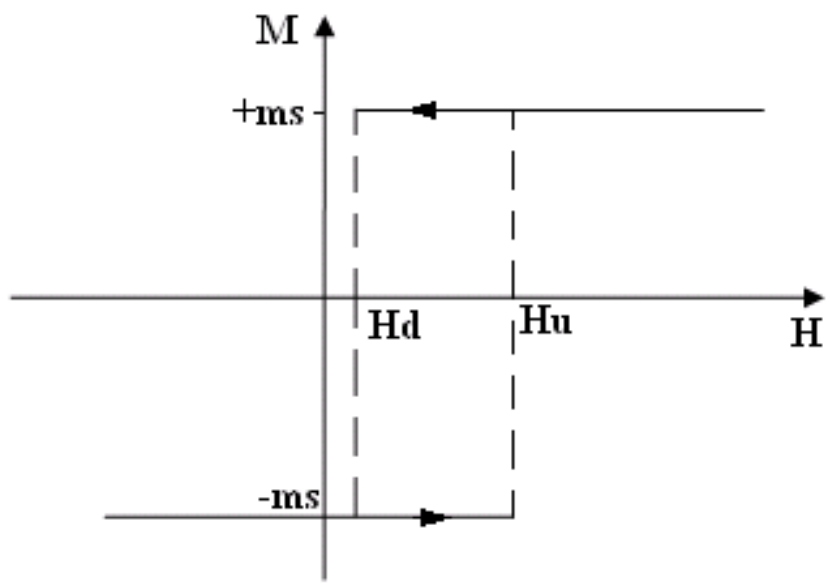

Figura 1.16 - Uma única partícula com magnetização $\pm m_{s}$ sob ação de uma campo $H$, com campos de inversão $H_{u}$ e $\mathrm{H}_{\mathrm{d}}$

Preisach considerou que, para um sistema com muitas partículas, os campos de inversão poderão não ser os mesmos para cada uma. Assim, estatisticamente, teremos uma distribuição no campo de inversão.

Num aprofundamento matemático do modelo, consideramos um operador $\gamma$, responsável por mudar o sinal da magnetização de uma partícula (ou domínio) atuando sobre $\mathrm{m}\left(\mathrm{H}_{\mathrm{u}}, \mathrm{H}_{\mathrm{d}}\right)$, que é a notação para uma partícula com um loop de histerese dado pela figura 1.16. 
Para uma função de distribuição $\varphi\left(\mathrm{H}_{\mathrm{u}}, \mathrm{H}_{\mathrm{d}}\right)$ para a inversão dum conjunto de partículas, teremos a magnetização total dada por

$$
M=\iint_{H u \geq H d} \varnothing\left(H_{u}, H_{d}\right) m\left(H_{u}, H_{d}\right) H(t)\left(d H_{u}\right)\left(d H_{d}\right)
$$

Onde $M$ é a magnetização total, $m\left(H_{u}, H_{d}\right) H(t)=+m_{s}$ se as partículas mudarem a magnetização positivamente e $m\left(H_{u}, H_{d}\right)=-m_{s}$ se as partículas mudarem a magnetização negativamente. Uma investigação matemática do modelo de Preisach é facilitada pela interpretação geométrica. Esta interpretação é baseada no fato de que há uma correspondência unívoca entre os operadores $\gamma(\alpha, \beta)$ (onde $\alpha=\mathrm{H}_{\mathrm{u}}$ e $\beta=\mathrm{H}_{\mathrm{d}}$ ) e os pontos $(\alpha, \beta)$ no semi-plano $\alpha \geq \beta$. Em outras palavras, cada ponto do semi-plano $\alpha \geq \beta$ pode ser identificado com apenas um operador particular $\gamma$ de campos de inversão.

A representação da distribuição dos operadores $\gamma_{s}$ num sistema de coordenadas $\alpha$ e $\beta$ permite entender de forma clara o processo de magnetização. Esta distribuição, uma vez conhecida, pode ser integrada de forma a se obter as contribuições para a magnetização de partículas orientadas negativamente e positivamente. Caso a distribuição for desconhecida, ela poderá ser obtida através da obtenção de derivadas de curvas de magnetização experimentais. A seguir, segue uma descrição matemática detalhada sobre os mecanismos do modelo de Preisach.

Considere um triângulo T (fig. 1.17). Seguindo a definição $\alpha \geq \beta$, definimos a geometria com $\alpha_{0}=-\beta_{0}$. Este triângulo será chamado de limitante para uma dada função $\mu(\alpha, \beta)$ finita e restrita ao triângulo, ou seja, será zero fora dele.

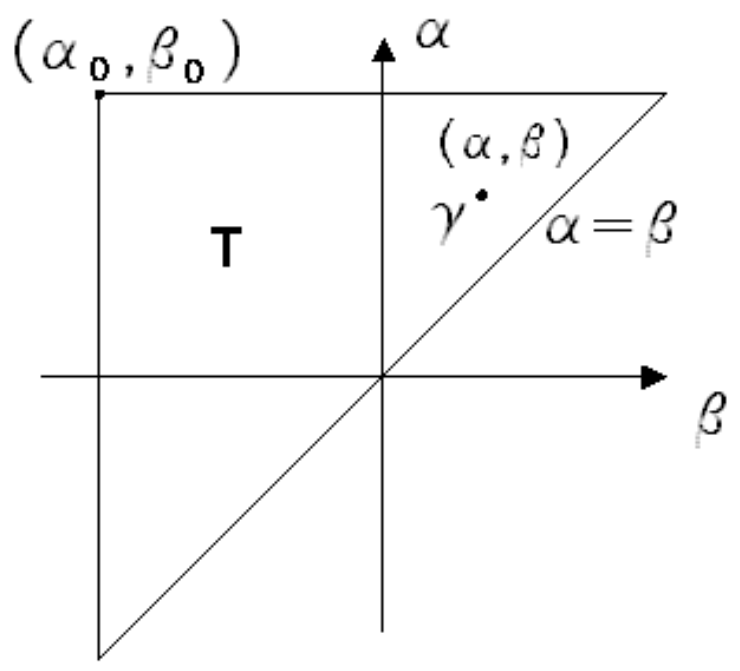

Figura 1.17 - Triângulo limitante do modelo de Preisach.

Considerando agora um valor de entrada $\mathrm{u}(\mathrm{t})$ em $\mathrm{t}_{0}$ (figura 1.17), o triângulo estará dividido em duas áreas. A área de cima, $S^{-}(t)$, integrada sobre a função $\mu(\alpha, \beta)$ e multiplicada pelo sinal negativo, nos dará o valor total da magnetização das partículas que estiverem orientadas negativamente. Do mesmo modo, a outra área integrada sobre $\mu(\alpha, \beta)$ nos dará o 
valor total da magnetização das partículas orientadas positivamente. A soma das duas integrais dará a magnetização total do sistema.

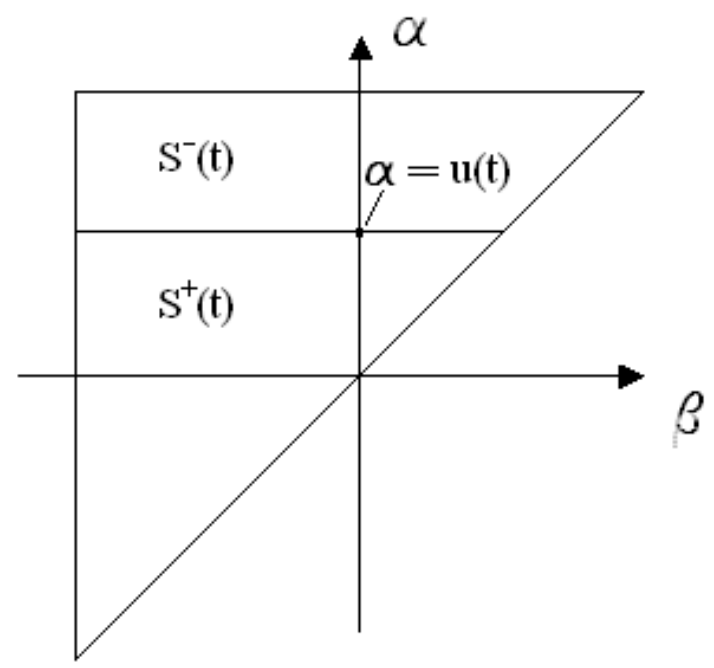

Figura 1.18 - Diagrama representando uma entrada $u(t)$.

Caso agora $\mathrm{u}(\mathrm{t})$ levar $\beta$ de $\beta=\alpha$ para $\beta=\beta_{1}$ (fig. 1.19), então teremos um novo balanço das integrais, podendo gerar uma magnetização total diferente da anterior. Caso uma nova entrada de $u(t)$ gerar um acréscimo em $\alpha$ (fig. 1.20), teremos novamente outras regiões a serem integradas sobre $\mu(\alpha, \beta)$.

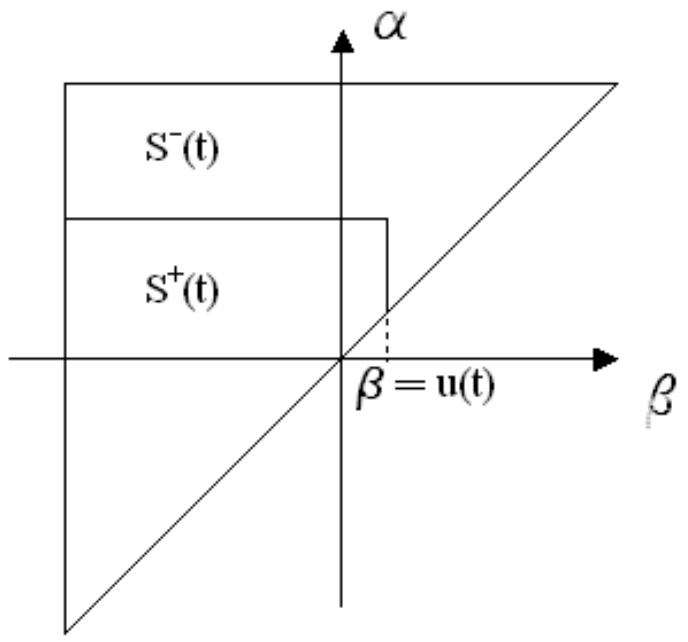

Figura 1.19 - Triângulo T subdividido em $\mathrm{S}^{+}(\mathrm{t})$ e $\mathrm{S}^{-}$

(t).

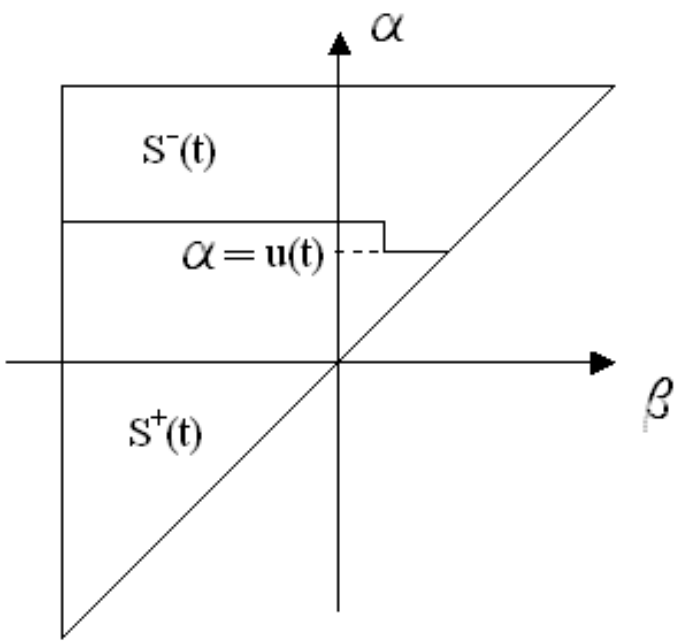

Figura 1.20 - Triângulo T subdividido em $\mathrm{S}^{+}(\mathrm{t})$ e $\mathrm{S}^{-}$ (t).

A formalização deste processo pode ser dada se considerarmos os operadores de inversão. De uma maneira generalizada, teremos a contribuição total da distribuição dada por

$$
f(t)=\iint_{\mathrm{S}+(\mathrm{t})} \mu(\alpha, \beta) \gamma u(t) d \alpha d \beta+\iint_{\mathrm{S}-(\mathrm{t})} \mu(\alpha, \beta) \gamma u(t) d \alpha d \beta
$$

$\operatorname{com} \gamma=+1$ caso $(\alpha, \beta) \in \mathrm{S}^{+}(\mathrm{t})$ e $\operatorname{com} \gamma=-1$ caso $(\alpha, \beta) \in \mathrm{S}^{-}(\mathrm{t})$. 
Uma consequiência desse modelo é a criação de curvas de histerese se considerarmos um campo inicial alto e integrarmos até um campo negativamente alto, com $\mu(\alpha, \beta)$ conhecido. O contrário irá completar a curva(fig. 1.4).

Para a determinação de $\mu(\alpha, \beta)$, vemos pela equação 1.51 que, de forma equivalente, obtemos

$$
\mu(\alpha, \beta)=\frac{1}{2} \frac{\partial^{2}}{\partial \alpha \partial \beta} f_{\alpha \beta}
$$

Uma das possíveis formas de se determinar a função $\mu(\alpha, \beta)$ experimentalmente é a de se fazer variações determinadas em $\alpha$ e $\beta$ para que seja possível obter as derivadas desejadas, descritas a seguir. Partindo da saturação $S^{+}$, leva-se $\beta$ até um valor pouco abaixo de seu valor inicial, com a volta para a saturação através do acréscimo em $\alpha$. No próximo ciclo, toma-se $\beta$ um pouco menor que o valor anterior, e torna-se a saturar o sistema. Fazendo as variações de $\beta=\alpha_{0}$ até $\beta=-\alpha_{0}$, teremos uma sequiência de linhas sucessivas que podem nos dar a forma de $\mu(\alpha, \beta)$, que são chamadas de curvas de inversão primeira ordem, ou First Order Reversal Curves, usando os parâmetros de campo $\mathrm{H}_{\mathrm{a}}$ e $\mathrm{H}_{\mathrm{r}}$, descritos a seguir.

Partindo de uma magnetização de saturação positiva, por exemplo, leva-se o campo $\mathrm{H}$ até um certo valor em que a magnetização $\mathrm{M}(\mathrm{H})$ da amostra esteja entre o mínimo e o máximo. Num determinado valor de campo $\mathrm{H}_{\mathrm{r}}$, leva-se o campo novamente à saturação pelo campo $\mathrm{H}_{\mathrm{a}}$. A magnetização $\mathrm{M}\left(\mathrm{H}_{\mathrm{a}}, \mathrm{H}_{\mathrm{r}}\right)$ no segundo trecho estará no interior da curva de histerese (fig. 1.21). Assim, para sucessivas curvas, obteremos a forma de $\rho\left(\mathrm{H}_{\mathrm{r}}, \mathrm{H}_{\mathrm{a}}\right)$, que é o recíproco de $\mu(\alpha, \beta)$, e pode ser chamada de distribuição de FORCs, que compõe o diagrama.

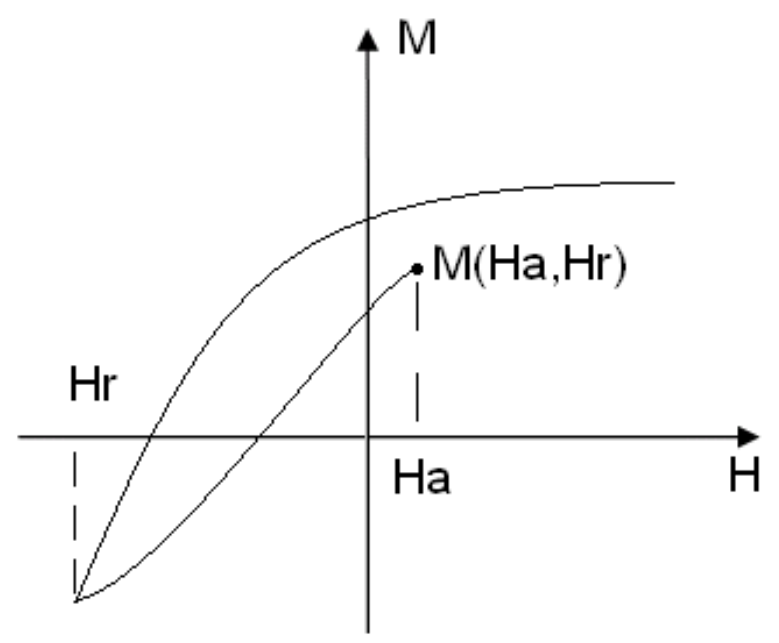

Figura 1.21 - Curva de inversão de primeira ordem.

Este modelo possui algumas limitações intrínsecas, surgindo assim a necessidade de modificações no mesmo.

Devido ao fato do modelo clássico ser incapaz de descrever desvios de congruência de ciclos menores (ciclos internos à curva de histerese) e não levar em conta processos dinâmicos, por exemplo, o Moving Preisach Model of Hysteresis (Modelo móvel de Preisach de histerese) foi criado, visto às necessidades de modificações do modelo clássico. 


\section{Modelo Móvel de Preisach}

O Modelo Móvel[39] tem origem no modelo clássico, mas com algumas modificações. Para ser possível eliminar as limitações intrínsecas do modelo clássico, algumas generalizações se tornam necessárias, e essas mudanças refletem na introdução de uma nova região de integração do diagrama, denominada de componente R.

Se tomarmos o triângulo $\mathrm{T}$ (fig. 1.17) e o subdividirmos em três componentes, definindo-as como $\mathrm{S}_{\mathrm{u}(\mathrm{t})}^{+}, \mathrm{S}_{\mathrm{u}(\mathrm{t})}^{-}$e $\mathrm{R}_{\mathrm{u}(\mathrm{t})}$, teremos a figura 1.22.

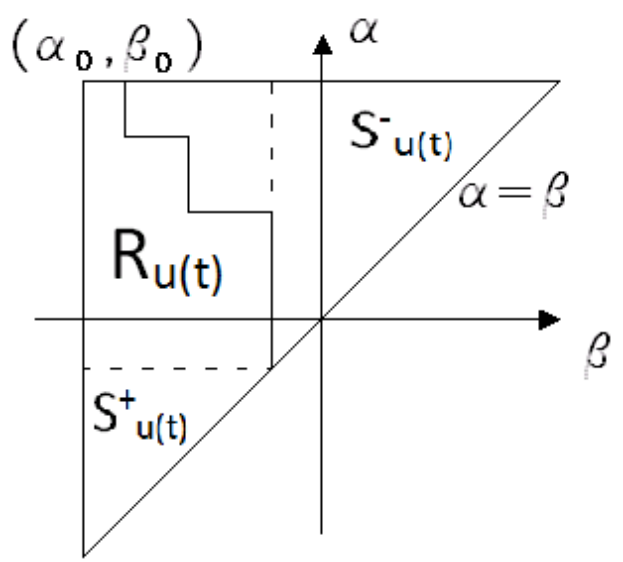

Figura 1.22 - Diagrama representado pelo modelo móvel de Preisach.

Assim, a equação 1.51 pode ser reescrita da forma

$$
f(t)=\iint_{\mathbf{S}_{\mathbf{u}(t)}^{+}} \mu(\alpha, \beta) \gamma u(t) d \alpha d \beta+\iint_{S_{u(t)}} \mu(\alpha, \beta) \gamma u(t) d \alpha d \beta+\iint_{R_{u(t)}} \mu(\alpha, \beta) \gamma u(t) d \alpha d \beta
$$

Com $u(t) \geq \alpha$ para qualquer $(\alpha, \beta)$ pertencente à $S^{+}{ }_{u(t)}$ teremos $\gamma_{\alpha \beta} u(t)=+1$. Similarmente, para $\mathrm{u}(\mathrm{t}) \leq \beta$ para qualquer $(\alpha, \beta)$ pertencente à $\mathrm{S}_{\mathrm{u}(\mathrm{t})}^{-}$teremos $\gamma_{\alpha \beta} \mathrm{u}(\mathrm{t})=-1$.

Reescrevendo a equação 1.53 , teremos

$$
f(t)=\iint_{R_{u(t)}} \mu(\alpha, \beta) \gamma u(t) d \alpha d \beta+\iint_{\mathrm{S}_{\mathrm{u}(\mathrm{t})}^{+}} \mu(\alpha, \beta) d \alpha d \beta-\iint_{S_{u(t)}^{-}} \mu(\alpha, \beta) d \alpha d \beta
$$

Para simplificarmos os dois últimos termos, devemos expressar suas integrais na forma $\mathrm{de}^{+}$e f. Assim, saindo de um estado saturado negativamente, podemos encontrar que $\mathrm{f}^{+}$é da forma

$$
f_{u(t)}^{+}=-\iint_{R_{u(t)}} \mu(\alpha, \beta) \gamma u(t) d \alpha d \beta+\iint_{S_{u(t)}^{+}} \mu(\alpha, \beta) d \alpha d \beta-\iint_{S_{u(t)}^{-}} \mu(\alpha, \beta) d \alpha d \beta
$$

De forma similar, saindo do estado de saturação positiva, teremos 


$$
f_{u(t)}^{-}=\iint_{R_{u(t)}} \mu(\alpha, \beta) \gamma u(t) d \alpha d \beta+\iint_{\mathrm{S}_{\mathbf{u}(t)}^{+}} \mu(\alpha, \beta) d \alpha d \beta-\iint_{S_{u(t)}^{-}} \mu(\alpha, \beta) d \alpha d \beta
$$

A soma de $\mathrm{f}^{+}$com $\mathrm{f}^{-}$nos dá

$$
\iint_{\mathrm{S}_{\mathrm{u}(\mathrm{t})}^{+}} \mu(\alpha, \beta) d \alpha d \beta-\iint_{S_{u(t)}^{-}} \mu(\alpha, \beta) d \alpha d \beta=\frac{1}{2}\left(f_{u(t)}^{+}+f_{u(t)}^{-}\right)
$$

Substituindo 1.57 em 1.54, teremos então

$$
f(t)=\iint_{R_{u(t)}} \mu(\alpha, \beta) \gamma u(t) d \alpha d \beta+\frac{1}{2}\left(f_{u(t)}^{+}+f_{u(t)}^{-}\right)
$$

Esta expressão é formalmente equivalente ao modelo clássico. Entretanto, nesta expressão, a integração não é feita sobre um triângulo limitante $T$, mas sim sobre um retângulo $R_{u(t)}$, que muda conforme as variações são efetuadas. Por este motivo, a equação 1.58 foi designada como sendo a equação do Modelo Móvel de Preisach. Nela, o termo $\frac{1}{2}\left(f_{u(t)}^{+}+f_{u(t)}^{-}\right)$representa completamente a componente R. Esta componente é atribuída à contribuição da magnetização reversível. O primeiro termo do lado direito é atribuído à contribuição da magnetização irreversível. Esta nova solução pode causar mudanças em simulações de FORCs se compararmos o modelo clássico com o modelo móvel[40]. Para acharmos o equivalente ao $\mu(\alpha, \beta)$, ou seja $\rho\left(\mathrm{H}_{\mathrm{a}}, \mathrm{H}_{\mathrm{r}}\right)$, devemos fazer algumas manipulações matemáticas em duas situações diferentes.

Supondo ter uma amostra negativamente saturada, leva-se $\mathrm{u}(\mathrm{t})$ até um valor $\alpha$. Leva-se, novamente, $\mathrm{u}(\mathrm{t})$ até um novo valor, menor, $\beta$ (figura 1.23 ). Pela equação $1.58, \mathrm{f}_{\alpha \beta}$ toma a forma

$$
f_{\alpha \beta}=\iint_{R\left(\alpha, \beta_{0} ; \beta, \beta\right)} \mu\left(\alpha^{\prime}, \beta^{\prime}\right) d \alpha^{\prime} d \beta^{\prime}-\iint_{R\left(\alpha_{0}, \beta_{0} ; \alpha, \beta\right)} \mu\left(\alpha^{\prime}, \beta^{\prime}\right) d \alpha^{\prime} d \beta^{\prime}+\frac{f_{\beta}^{+}+f_{\beta}^{-}}{2}
$$

onde R é o retângulo de vértices opostos a ser integrado.

Supondo agora a situação contrária, onde parte-se da saturação positiva (fig. 1.24), teremos

$$
f_{\beta}^{-}=\iint_{R\left(\alpha_{0}, \beta_{0} ; \beta, \beta\right)} \mu\left(\alpha^{\prime}, \beta^{\prime}\right) d \alpha^{\prime} d \beta^{\prime}+\frac{f_{\beta}^{+}+f_{\beta}^{-}}{2}
$$

e, introduzindo a função

$$
T(\alpha, \beta)=f_{\beta}^{-}-f_{\alpha \beta}
$$

que é igual ao incremento entre a linha descentente (primeira hipótese) e uma FORC (segunda hipótese). Das equações 1.59, 1.60 e 1.61, encontramos 


$$
T(\alpha, \beta)=2 \int_{\alpha}^{\alpha_{0}} \int_{\beta_{0}}^{\beta} \mu\left(\alpha^{\prime}, \beta^{\prime}\right) d \beta^{\prime} d \alpha^{\prime}
$$

que na forma diferencial fica

$$
\mu(\alpha, \beta)=-\frac{1}{2} \frac{\partial^{2}}{\partial \alpha \partial \beta} T(\alpha, \beta)=\frac{1}{2} \frac{\partial^{2}}{\partial \alpha \partial \beta} f_{\alpha \beta}
$$

que coincide com a equação 1.52 do Modelo Clássico de Preisach.
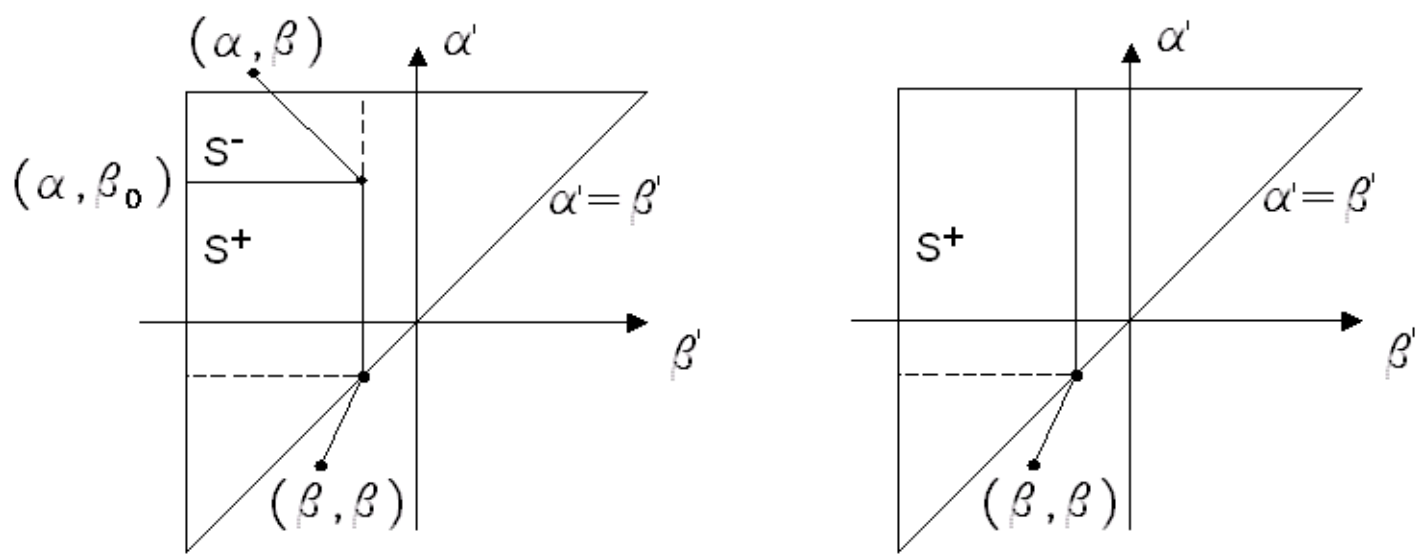

Figura 1.23 - Entrada de valores no modelo móvel. Figura 1.24 - Evolução de valores de entrada no modelo móvel.

\section{Representação da função de distribuição}

A representação dos diagramas $\rho\left(\mathrm{H}_{\mathrm{A}}, \mathrm{H}_{\mathrm{R}}\right)$ de FORCs pode ser dada nas coordenadas $\mathrm{H}_{\mathrm{A}}$ e $\mathrm{H}_{\mathrm{R}}$, com $\mathrm{H}_{\mathrm{A}}$ sendo um determinado valor do campo magnético aplicado entre o campo de retorno da FORC e a saturação e $H_{R}$ sendo o valor do campo de retorno. Entretanto, podemos introduzir novas variáveis[41]. Tomando

$$
h_{c}=\frac{H_{A}-H_{R}}{2} \text { e } h_{b}=\frac{H_{A}+H_{R}}{2}
$$

teremos $h_{c}$ representando os campos coercivos e $h_{b}$ os de interação (fig. 1.25). Vê-se que, desta forma, teremos sempre $h_{c} \geq 0$. 


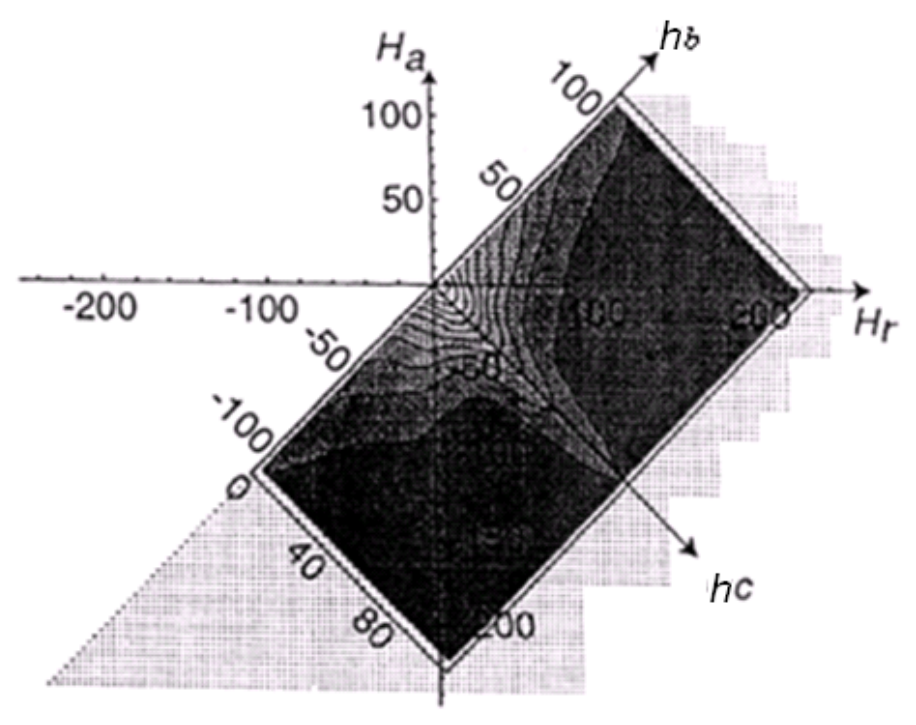

Figura 1.25 - Representação do diagrama de FORCs em termos das coordenadas $\left(\mathrm{h}_{\mathrm{b}}, \mathrm{h}_{\mathrm{c}}\right)$.

Desta forma, podemos analisar melhor os diagramas obtidos experimentalmente, além de dar suporte para o desenvolvimento teórico do modelo para simulações, com a distribuição sendo agora representada por $\rho\left(\mathrm{h}_{\mathrm{c}}, \mathrm{h}_{\mathrm{b}}\right)$. O eixo $\mathrm{h}_{\mathrm{b}}$ refere-se à todas as contribuições de interação, sejam elas entre paredes de domínios, exchange direto ou dipolares, entre outras. Assim, sempre que for feita a referência sobre o "campo de interação", deve-se entender que se trata de uma expressão generalizada, resultante de todas as contribuições possíveis do sistema.

Assim, ao se observar um diagrama de FORCs, espera-se ver uma forma com um pico com uma distribuição tipo lognormal(no caso específico deste trabalho), e este pico poderá servir como uma estimativa para a coercividade. A distribuição no eixo $h_{b}$ pode ser tomada, como uma primeira aproximação, com uma forma gaussiana. A posição do pico neste eixo pode ser relacionada com o campo de Exchange Bias. Estas observações reforçam ainda mais a necessidade de mudança de eixos para que uma melhor análise seja feita.

Deve-se mencionar novamente que, experimentalmente, o diagrama obtido provém da derivada segunda da curva de magnetização (fig. 1.21), sob a forma

$$
\rho\left(H_{R}, H_{A}\right)=-\frac{1}{2} \frac{\partial^{2} M}{\partial H_{R} \partial H_{A}}
$$

e, após esta etapa, deve-se efetuar a mudança de eixos.

Ao se efetuar esses cálculos, um último procedimento é efetuado. Com a intenção de se eliminar ruídos que podem inclusive impossibilitar a visualização de quaisquer regiões definidas no diagrama de FORCs, utiliza-se uma ferramenta chamada Smooth Factor (SF), que é um método de amortização dos resultados. Sem um aprofundamento matemático sobre o assunto, basta saber que sua finalidade é a de se ajustar um ponto com base em um quadrado com seus primeiros vizinhos. Assim, para $\mathrm{SF}=3$, por exemplo, tem-se um ponto sendo amortizado pelos pontos dentro de um quadrado que atinge os três primeiros vizinhos de cada lado. Essa ferramenta traz como conseqüência a amortização da curva juntamente com uma maior dispersão da distribuição, podendo assim alterar a distribuição no diagrama de FORCs, alargando-a. 
A obtenção dos diagramas de FORCs foi feita com o uso de um algoritmo desenvolvido para o programa MATLAB, que utiliza o método de convolução de Savitzky-Golay, explorado por David Heslop [60]. 


\section{Capítulo 2}

\section{Preparação e caracterização das amostras}

As amostras foram produzidas via Sputtering e submetidas à medidas de Raios X para a determinação das estruturas cristalinas e RBS (Rutherford Backscattering Spectrometry) para a determinação das espessuras.

\section{1 - Equipamentos Utilizados}

A produção das amostras foi feita em um Sputtering, pertencente ao Laboratório de Materiais Magnéticos (LMM) do IFUSP, modelo ATC 2000 AJA International.

As medidas magnéticas à temperatura ambiente foram feitas em um VSM modelo 4500 da EG\&G Parc, com a fonte modelo BOP 36-12M da Kepco. Para este equipamento, foi utilizada uma bobina cilíndrica de indução magnética produzida no LMM do IFUSP para a detecção da magnetização da amostra. Algumas medidas iniciais foram feitas com o uso de um equipamento VSM, pertencente à Unicamp, modelo 7400 da LakeShore.

As medidas em baixas temperaturas foram feitas com o uso de uma bobina supercondutora resfriada à He num equipamento criogênico modelo $150 \mathrm{~A}$ da Janis, acoplado à um VSM modelo 4500 da EG\&G Parc, com a fonte modelo 625 da LakeShore. O controlador de temperatura utilizado foi o modelo DRC91C da LakeShore.

\section{2 - Crescimento dos filmes}

Foram feitas, primeiramente, 36 amostras de filmes finos via Magnetron Sputtering com dois buffers diferentes e espessuras variáveis. Basicamente, a sequiência de deposição resultou numa amostra com a estrutura $\mathrm{Si}[100] / \mathrm{Buffer} / \mathrm{NiFe} / \mathrm{FeMn} / \mathrm{Ta}$ (fig. 2.1). Posteriormente ao estudo e às caracterizações, duas amostras deste mesmo sistema foram reproduzidas via Sputtering sob as mesmas condições de deposição com dimensões espaciais reduzidas para que fosse possível introduzi-las em um magnetômetro utilizando uma bobina supercondutora para medidas em baixas temperaturas. Cinco válvulas de Spin também foram feitas, caracterizadas pela estrutura $\mathrm{Si}[100] / \mathrm{Cu} / \mathrm{NiFe} / \mathrm{Cu} / \mathrm{NiFe} / \mathrm{FeMn} / \mathrm{Ta}$ (fig. 1.10).

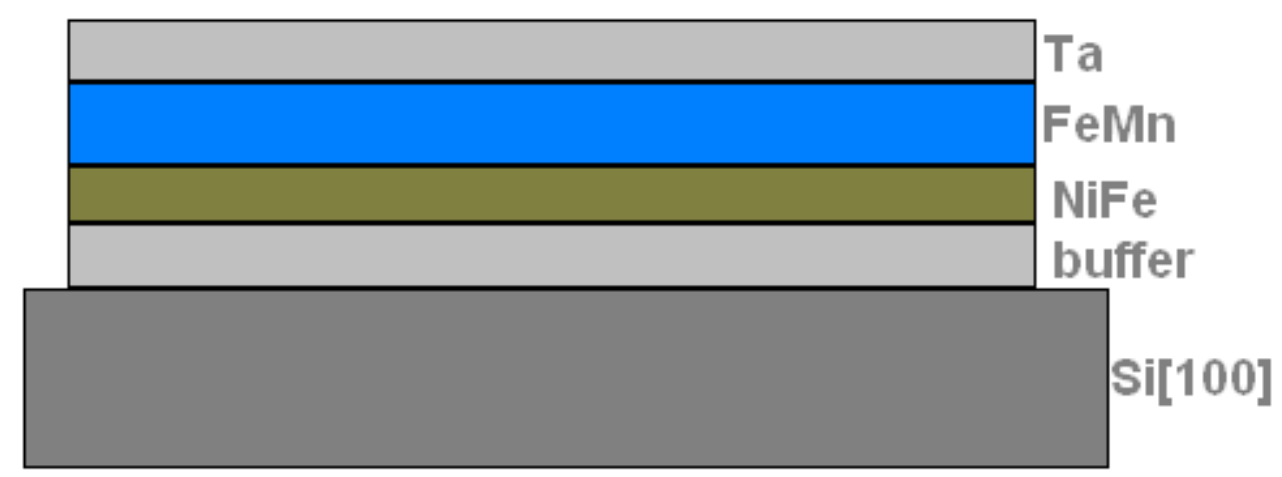

Figura 2.1 - Estrutura utilizada para o crescimento dos filmes. 
O silício utilizado foi o $\mathrm{Si}[100]$, ou seja, com a orientação dos planos cristalinos perpendiculares à direção [100]. Sua superfície precisou ser limpa de quaisquer tipos de óxidos ou outras substâncias presentes para que a deposição se desse diretamente em cima da estrutura do silício, evitando assim imperfeições no crescimento, além de evitar possíveis mudanças nas interações atômicas dos filmes. Para isto, foi necessária a utilização do ácido fluorídrico (HF $10 \% \mathrm{H}_{2} \mathrm{O} 90 \%$ durante 2 minutos, com limpeza posterior com água deionizada, álcool etílico e seco em $\mathrm{N}_{2}$ ) antes de inserir as estruturas no porta-amostras do Sputtering (fig. 2.2), que permite que as deposições dos filmes sejam feitas numa região circular de diâmetro de aproximadamente $8 \mathrm{~mm}$. As dimensões das estruturas de Si utilizadas foram de $1 \mathrm{~cm} \times 1 \mathrm{~cm}$, sendo que as outras duas amostras e as válvulas de Spin feitas posteriormente possuíam $1 \mathrm{~cm} \times 0.5 \mathrm{~cm}$ em um porta-amostras com seis compartimentos para a fixação dos substratos, tendo apenas três deles utilizados e com uma janela para cada abertura com o propósito de preservar uma amostra durante o crescimento de outra contida no mesmo porta-amostras. $\mathrm{O}$ equipamento de Sputtering possuía um mecanismo manual de alavancas capaz de abrir ou fechar qualquer janela, permitindo assim o total controle sobre o processo.

Assim, inseridos os substratos no Sputtering, com uma pressão inicial variando normalmente de 1E-7 à 2E-7 Torr, a deposição do Buffer foi feita com todas as janelas abertas, permitindo assim uma equalização de espessuras para todas as amostras em crescimento. Os buffers utilizados foram o $\mathrm{Cu}$ e, posteriormente, em outras amostras, o Ta. Para o cobre, a espessura estimada através de calibrações anteriores [42] foi de 20nm, sendo depois determinada através de espectros de RBS. Para isto ser possível, as deposições foram feitas com o equipamento funcionando em modo DC à temperatura ambiente, com o uso de 5mTorr de

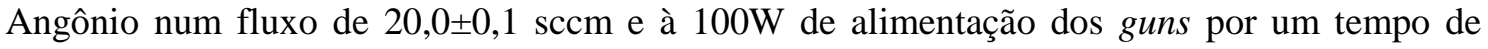
4'18'. Para o buffer de Ta, pôde-se esperar uma camada da ordem de 30nm. Para isto, o tempo de deposição foi alterado para 16' e a potência para $50 \mathrm{~W}$.

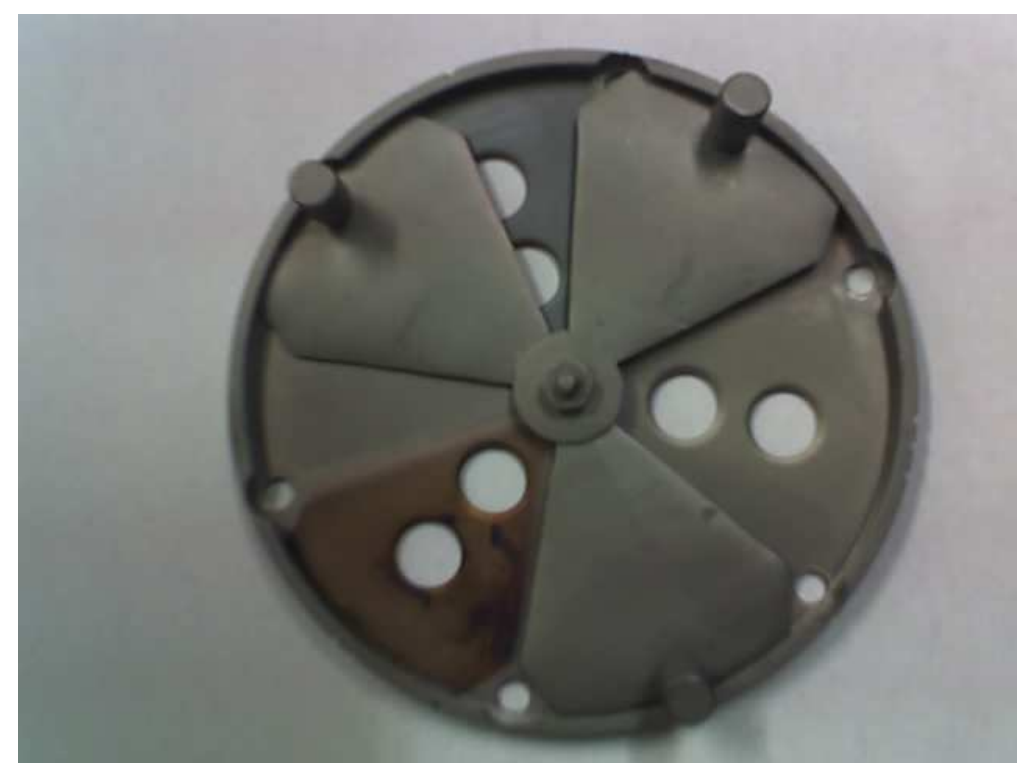

Figura 2.2 - Porta-amostras utilizado no Sputtering 
Após a deposição dos buffers, a camada de $\mathrm{Ni}_{0,81} \mathrm{Fe}_{0,19}$ (Permalloy(Py)) foi depositada com o próprio alvo de Py, com a camada de $\mathrm{Fe}_{50} \mathrm{Mn}_{50}$ em seguida com o alvo de FeMn e, para proteger a amostra de possíveis oxidações e contaminações, uma camada de aproximadamente $10 \mathrm{~nm}$ de Ta foi utilizada (capping layer), evidenciada posteriormente por RBS.

As amostras foram feitas primeiramente com a camada de NiFe constante à 10nm e com a camada de FeMn variando de $2 \mathrm{~nm}$ a $30 \mathrm{~nm}$. Para a deposição do $\mathrm{NiFe}$, a única alteração feita no equipamento foi o tempo de deposição, que, para a produção de $10 \mathrm{~nm}$ de camada, estimou-se um tempo de 5 40", tendo todos os outros parâmetros, como fluxo e potência constantes com os utilizados para a deposição do $\mathrm{Cu}$. Em seguida, a camada de FeMn foi mantida constante em $10 \mathrm{~nm}$ e variou-se a espessura do $\mathrm{NiFe}$ de $2 \mathrm{~nm}$ a $30 \mathrm{~nm}$. Para isto, os parâmetros utilizados no Sputtering foram os mesmos que os utilizados anteriormente, com o tempo de deposição estimado em 5 24". Após a obtenção destas amostras para o buffer de $\mathrm{Cu}$, o mesmo foi feito para o Ta. Assim, obtemos quatro famílias de amostras, descritas pela tabela 2.1.

\begin{tabular}{|c|c|c|c|}
\hline $\mathrm{Ta}(\mathrm{nm})$ & $\mathrm{Cu}(\mathrm{nm})$ & $\mathrm{NiFe}(\mathrm{nm})$ & $\mathrm{FeMn}(\mathrm{nm})$ \\
\hline 30 & 20 & 10 & $2 / 5 / 7 / 10 / 12 / 15 / 20 / 25 / 30$ \\
\hline 30 & 20 & $2 / 5 / 7 / 10 / 12 / 15 / 20 / 25 / 30$ & 10 \\
\hline
\end{tabular}

Tabela 2.1 - Espessuras estimadas para as amostras. Para uma camada em uma espessura fixa, amostras foram produzidas variando-se a espessura do outro material, tanto para buffers de $\mathrm{Cu}$ quanto para buffers de Ta.

Devido aos imãs localizados dentro do Sputtering, as camadas foram criadas com campo magnético presente, criando assim uma direção de magnetização para a deposição do $\mathrm{NiFe}$, permitindo assim uma deposição do FeMn com a orientação de spins definida, evidenciando a anisotropia do material.

De acordo com a calibração [42], as espessuras dos materiais deveriam seguir a regra t=kT, onde t é a espessura, k é uma constante e T é o tempo(tab. 2.2).

\begin{tabular}{|c|c|}
\hline Material & $\mathrm{k}(\mathrm{nm} / \mathrm{s})$ \\
\hline $\mathrm{Cu}$ & 0.078 \\
\hline $\mathrm{Ta}$ & 0.031 \\
\hline $\mathrm{FeMn}$ & 0.031 \\
\hline $\mathrm{NiFe}$ & 0.029 \\
\hline
\end{tabular}

Tabela 2.2 - valores previstos para $\mathrm{k}$ em $\mathrm{nm} / \mathrm{s}$. 
A obtenção das amostras posteriores foi feita através do mesmo processo, tendo todos os seus parâmetros de crescimento equivalentes, sendo assim redundante a explicação da produção das mesmas.

Deve-se explicitar que as válvulas de Spin obtidas tiveram apenas a camada não magnética variada, tendo todas as suas outras mantidas de forma inalterada. As amostras obtidas estão descritas na tabela 2.3

\begin{tabular}{|c|}
\hline Espessuras estimadas (nm) \\
\hline $\mathrm{sv} 1-\mathrm{Cu}(20) / \mathrm{NiFe}(10) / \mathrm{Cu}(1) / \mathrm{NiFe}(10) / \mathrm{FeMn}(30) / \mathrm{Ta}(10)$ \\
\hline $\mathrm{sv} 2-\mathrm{Cu}(20) / \mathrm{NiFe}(10) / \mathrm{Cu}(2) / \mathrm{NiFe}(10) / \mathrm{FeMn}(30) / \mathrm{Ta}(10)$ \\
\hline $\mathrm{sv} 3-\mathrm{Cu}(20) / \mathrm{NiFe}(10) / \mathrm{Cu}(3) / \mathrm{NiFe}(10) / \mathrm{FeMn}(30) / \mathrm{Ta}(10)$ \\
\hline $\mathrm{sv} 4-\mathrm{Cu}(20) / \mathrm{NiFe}(10) / \mathrm{Cu}(4) / \mathrm{NiFe}(10) / \mathrm{FeMn}(30) / \mathrm{Ta}(10)$ \\
\hline $\mathrm{sv} 6-\mathrm{Cu}(20) / \mathrm{NiFe}(10) / \mathrm{Cu}(6) / \mathrm{NiFe}(10) / \mathrm{FeMn}(30) / \mathrm{Ta}(10)$ \\
\hline
\end{tabular}

Tabela 2.3 - Espessuras estimadas para as amostras de válvulas de Spin.

\section{3 - Tratamento Térmico com campo aplicado}

O tratamento térmico foi feito em alguns filmes com a finalidade de se comparar comportamentos antes e depois do processo. Basicamente, introduz-se a amostra dentro de uma região com um campo magnético, onde a mesma, à vácuo, tem sua temperatura elevada de forma a ser maior que a temperatura de Néel do material antiferromagnético para que haja o desordenamento magnético desta camada. A seguir, resfria-se a amostra com o campo aplicado até a temperatura ambiente. Este processo de resfriamento provoca o ordenamento antiferromagnético do material, tendo como consequiências [43] o aumento da constante de anisotropia antiferromagnética e, para as bicamadas, o aumento do campo de Exchange Bias.

As amostras foram submetidas a um campo de $5 \mathrm{kOe}$ de um imã direcionado no plano do filme, onde, sob uma pressão de aproximadamente $10^{-5}$ Torr, foram submetidas à temperaturas de $290^{\circ} \mathrm{C}$ durante 40 minutos, sendo naturalmente resfriadas por irradiação térmica após o tratamento térmico, durante aproximadamente duas horas.

\section{4 - Difrações de Raios X}

Amostras-testes sobre substratos de $\mathrm{Si}[100]$ foram feitas via Sputtering para medições em Raios-X (RX) e calibrações em RBS. Amostras de $\mathrm{Cu} / \mathrm{Ta}, \mathrm{FeMn} / \mathrm{Ta}$ e $\mathrm{NiFe} / \mathrm{Ta}$ foram analisadas por difratometria de RX e, posteriormente, amostras de $\mathrm{Cu} / \mathrm{NiFe} / \mathrm{FeMn} / \mathrm{Ta}$ sem e com tratamento térmico também foram analisadas.

O cobre da amostra de $\mathrm{Cu} / \mathrm{Ta}$ apresentou uma alta orientação cristalina na direção (111), tendo também um pico menor na (200) (fig. 2.3). As amostras de NiFe/Ta e FeMn/Ta também apresentaram um pico bem definido na direção (111), o que corresponde às fases cúbicas do $\mathrm{NiFe}$ e do FeMn. O Ta, por outro lado, apresenta um pico na região dos $36^{0}$, mas sua largura é muito grande, o que sugere que ele esteja em um estado quase amorfo. Assim, pode-se concluir que o $\mathrm{Si}[100]$ tende a orientar as estruturas a terem uma orientação preferencial (111). 


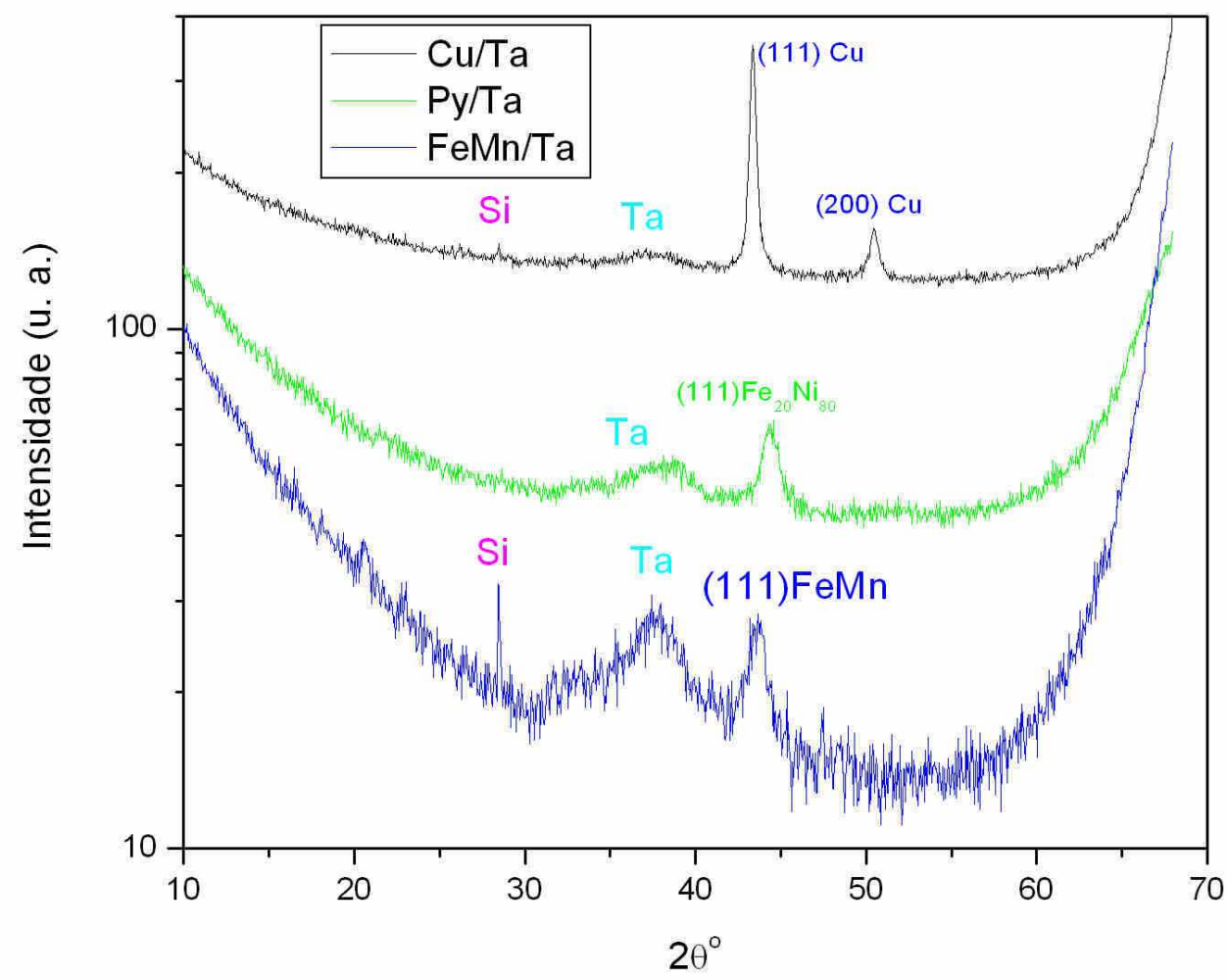

Figura 2.3 - Varredura 2 $\theta$ X Intensidade para amostras com substratos de Si[100] com materiais de Cu/Ta, Py/Ta e FeMn/Ta. Os gráficos foram propositalmente deslocados para uma melhor visualização.

A difratometria de $\mathrm{RX}$ da estrutura de $\mathrm{Cu}(20 \mathrm{~nm}) / \mathrm{Py}(10) / \mathrm{FeMn}(30) / \mathrm{Ta}(10)$ antes e após o tratamento térmico com campo aplicado possibilitou comparar a preferência das orientações cristalinas para cada caso. Como era esperado [44] sem o tratamento térmico, os picos na direção (111) dos materiais FeMn, Py e $\mathrm{Cu}$ se sobrepõem, tendo a direção (200) sendo principalmente atribuída ao $\mathrm{Cu}$ (fig. 2.4). No pós-tratamento térmico, pôde-se observar uma inversão de intensidades de picos, tendo o pico (200) mais intenso que o (111), evidenciando que o tratamento térmico não modificou apenas a estrutura de spins antiferromagnéticos, mas também provocou mudanças estruturais na formação cristalina das camadas. Pode-se observar que tanto o Py quanto o FeMn se orientaram mais intensamente na direção (200) se comparada à medição antes do tratamento térmico, tendo o $\mathrm{Cu}$ seguindo a mesma tendência.

Devido à sobreposição dos picos, uma definição exata das proporções não pôde ser determinada, sendo assim possível apenas aferir as tendências de forma qualitativa. 


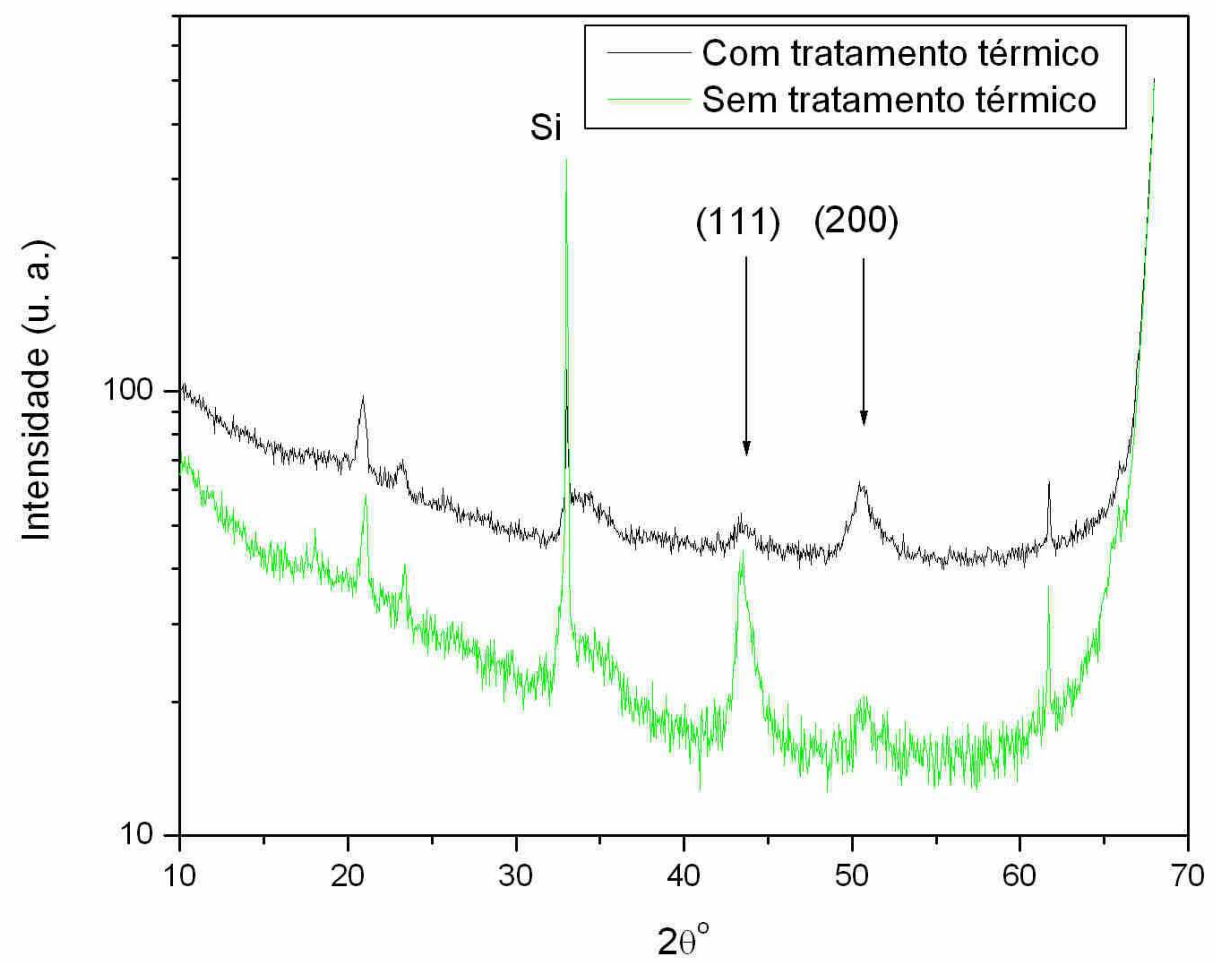

Figura 2.4 - Varredura 2 $\theta$ X Intensidade para amostras com substratos de Si[100] com as camadas de $\mathrm{Cu}(20 \mathrm{~nm}) / \mathrm{Py}(10) / \mathrm{FeMn}(30) / \mathrm{Ta}(10)$ sem e com tratamento térmico com campo aplicado.

Com base nestas mudanças cristalinas observadas, elas serão atribuídas à mudanças relevantes em diagramas sem e com o tratamento térmico, vistas mais adiante nos diagramas de FORCs.

\section{5- Determinação das espessuras por RBS}

As espessuras foram determinadas pela técnica de retroespalhamento Rutherford(Rutherford BackScattering, RBS), sendo assim possível confirmar se os valores esperados estavam de acordo com os obtidos. A determinação é feita com o ajuste de uma curva modelada sobre o espectro experimental (fig. 2.5). 


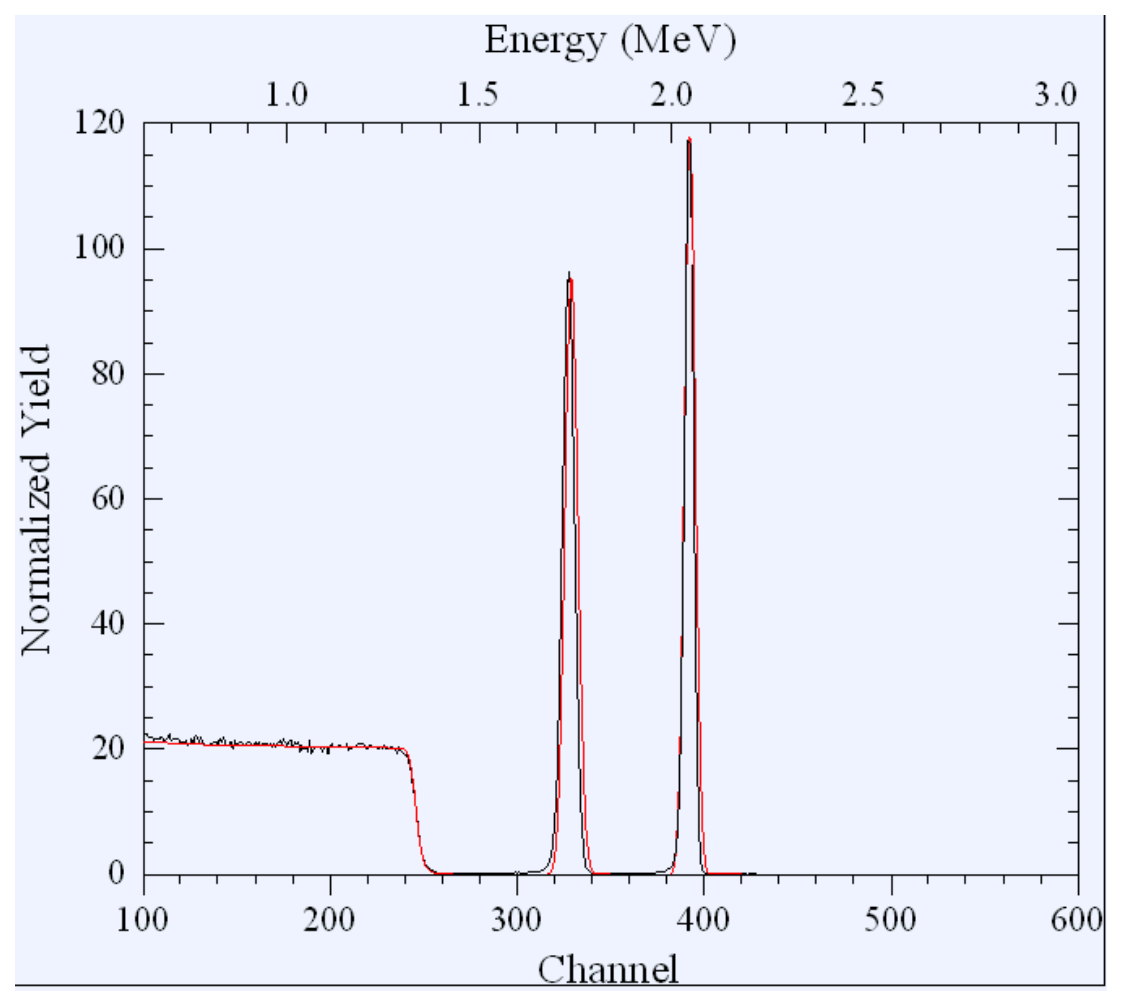

Figura 2.5 - Espectro obtido experimentalmente (preto) e seu ajuste teórico para a determinação das espessuras (vermelho). O pico maior determina a espessura do Ta, enquanto que o outro determina a presença de $\mathrm{Ni}, \mathrm{Fe}, \mathrm{Mn}$ e $\mathrm{Cu}$.

Através do programa RUMP para a análise dos espectros, desenvolvido pela GenPlot, foi possível obter a tabela 2.4, onde a mesma exibe a espessura de cada elemento ou liga e os valores esperados juntamente com sua nomeação(A, B, C...) para referências simplificadas no texto.

\begin{tabular}{|c|c|c|}
\hline Amostra & Espessuras nominais(nm) & $\begin{array}{c}\text { Espessuras medidas(nm) } \\
( \pm 0,4)\end{array}$ \\
\hline A & $\mathrm{Cu}(20) / \mathrm{NiFe}(10) / \mathrm{FeMn}(2) / \mathrm{Ta}(10)$ & $22,0 / 11,0 / 2,2 / 11,3$ \\
\hline $\mathrm{B}$ & $20 / 10 / 5 / 10$ & $22,0 / 11,6 / 5,5 / 11,2$ \\
\hline $\mathrm{C}$ & $20 / 10 / 7 / 10$ & $22,0 / 11,0 / 7,5 / 11,6$ \\
\hline $\mathrm{D}$ & $20 / 10 / 10 / 10$ & $22,0 / 11,0 / 11,0 / 11,2$ \\
\hline $\mathrm{E}$ & $20 / 10 / 12 / 10$ & $21,8 / 10,7 / 12,2 / 11,5$ \\
\hline $\mathrm{F}$ & $20 / 10 / 15 / 10$ & $22,9 / 11,3 / 16,4 / 11,9$ \\
\hline $\mathrm{G}$ & $20 / 10 / 20 / 10$ & $18,0 / 9,0 / 18,0 / 8,2$ \\
\hline H & $20 / 10 / 25 / 10$ & $21,7 / 10,8 / 25,7 / 11,6$ \\
\hline I & $20 / 10 / 30 / 10$ & $22,5 / 11,3 / 31,8 / 11,8$ \\
\hline J & $20 / 20 / 10 / 10$ & $20,0 / 20,0 / 10,0 / 11,0$ \\
\hline
\end{tabular}

Tabela 2.4 - Espessuras estimadas (à esquerda) e espessuras observadas (à direita) para as amostras $\mathrm{Si}[100] / \mathrm{Cu} / \mathrm{NiFe} / \mathrm{FeMn} / \mathrm{Ta}$. 
As outras duas amostras produzidas reproduziram as amostras $B$ e $I$, e, através de uma calibração prévia com amostras-testes de $\mathrm{NiFe} / \mathrm{Ta}, \mathrm{FeMn} / \mathrm{Ta}$ e $\mathrm{Cu} / \mathrm{Ta}$, foi possível estimar as espessuras (tab. 2.5).

\begin{tabular}{|c|c|}
\hline Amostra & Espessuras estimadas (nm) \\
\hline B2 & $20 / 10 / 5 / 10$ \\
\hline I2 & $20 / 10 / 30 / 10$ \\
\hline
\end{tabular}

Tabela 2.5 - Amostras produzidas para medições em baixas temperaturas.

Apesar da aparente dificuldade na distinção dos elementos $\mathrm{Ni}, \mathrm{Fe}, \mathrm{Mn}$ e $\mathrm{Cu}$ devido ao peso atômico muito parecidos, pode-se observar assimetrias no pico devido às diferentes proporções de cada material com picos de energia próximos, mas não iguais. Através do ajuste das espessuras para cada camada, é possível reproduzir essas assimetrias, sendo assim possível a determinação das espessuras. Um método auxiliar utilizado para as calibrações foi a de produzir três amostras apenas com uma composição distinta, onde uma delas composta por $\mathrm{Cu}$ e $\mathrm{Ta}$, a outra por NiFe e Ta e a última por FeMn e Ta. Observando suas espessuras e relacionando-as linearmente com o tempo de deposição, pôde-se confirmar as taxas de crescimento esperadas da tabela 2.1, sendo assim possível aferir as espessuras. 


\section{Capítulo 3}

\section{Aplicação do modelo de Preisach em filmes com Exchange Bias}

\section{1 - Descrição das simulações computacionais}

Geralmente, a formulação do modelo de Preisach atribui funções analíticas para a distribuição $\rho\left(\mathrm{h}_{\mathrm{c}}, \mathrm{h}_{\mathrm{b}}\right)$ com o intuito de reproduzir o comportamento magnético observado, por exemplo, nas FORCs (esses padrões serão vistos na análise experimental). Basicamente, a formulação propõe uma distribuição gaussiana em $h_{b} e$ uma distribuição lognormal em $h_{c}$.

Usualmente [45], as funções de interação, do campo de inversão e da componente reversível são dadas, respectivamente, por

$$
g\left(h_{b}\right)=\frac{e^{-\frac{h_{b}^{2}}{2 \sigma^{2}}}}{\sqrt{2 \pi} \sigma}, f\left(h_{c}\right)=\frac{B e^{-\frac{\ln ^{2}\left(\frac{h_{c}}{H_{s w}}\right)}{2 \omega^{2}}}}{\sqrt{2 \pi} \omega h_{c}}, r\left(h_{c}, h_{b}\right)=\frac{A}{\pi \omega_{2}\left(1+\frac{h_{b}^{2}}{\omega_{2}^{2}}\right)} \delta\left(h_{c}\right)
$$

$\sigma, \mathrm{H}_{\mathrm{sw}}, \omega, \mathrm{A}(0 \leq \mathrm{A} \leq 2 / \pi), \mathrm{B}(\mathrm{B}=1-\mathrm{A} \pi / 2 ; 0 \leq \mathrm{B} \leq 1)$ e $\omega_{2}$ são os parâmetros ajustáveis que definem as características de uma amostra. Aqui, os efeitos de assimetrias e de anisotropia de troca estão embutidos no campo efetivo, dados pela equação 3.9 com os limites de integração dependentes das variações executadas em H aplicado. A e B são encarregados de normalizar as integrais de forma a se obter os valores 1 ou -1 nas regiões de saturação. Caso A for zero, teremos $\mathrm{B}=1$.

Desta forma, torna-se possível a simulação de FORCs e, conseqüentemente, dos diagramas de FORCs. Para isto, deve-se usar as distribuições das equações em 3.1 acima sendo elas integradas computacionalmente pela equação 1.58 .

Aplicando a equação 3.1 no modelo com Exchange Bias, teremos duas situações de integração, onde uma descreve a inversão de magnetização, e a outra o retorno à saturação. Supondo que se tome o ponto inicial na saturação positiva, e usando os princípios do Modelo Móvel de Preisach e o campo efetivo dado por $\mathrm{H}_{\text {eff }}=\mathrm{H}_{\mathrm{a}}+\mathrm{H}_{\mathrm{MF}}$, onde $\mathrm{H}_{\mathrm{MF}}$ é o campo médio, e ainda impondo a condição $-1 \leq \mathrm{m} \leq+1$, teremos a magnetização dada por

$$
m\left(H_{a}\right)=1-\left\{\left[2 \int_{0}^{\infty} f\left(h_{c}\right) d h_{c} \int_{-\infty}^{-\left[h_{c}+H_{e f f}\right]} g\left(h_{b}\right) d h_{b}\right]+A\left(\frac{\pi}{2}+\arctan \left(-\frac{H_{e f f}}{\omega_{2}}\right)\right)\right\}
$$

A magnetização da curva se dará até um ponto determinado $\mathrm{H}=\mathrm{H}_{\mathrm{r}}$. Vê-se que, para cálculos computacionais, deve-se tomar o cuidado ao se determinar o passo de $\mathrm{H}$, pois $\mathrm{H}_{\mathrm{MF}}$ é dependente de $\mathrm{m}(\mathrm{H})$. Devido a este fato, um programa de computador poderá calcular $\mathrm{m}(\mathrm{H})$ considerando o valor de magnetização do ponto anterior já calculado. Assim, variações muito grandes de magnetização entre dois pontos podem fazer com que a magnetização calculada seja diferente da efetuada com passos pequenos, pois esses dois pontos precisam, necessariamente, ter valores parecidos para que a integral seja aceitável.

A integral de retorno tem o mesmo princípio, salvo a condição dos limites de integração (modelo móvel de Preisach)[40]. 


$$
\begin{aligned}
m\left(H_{r}, H_{a}\right) & =1-\left\{\left[2 \int_{0}^{\infty} f\left(h_{c}\right) d h_{c} \int_{-\infty}^{\operatorname{Min}\left\{-\left[h_{c}+H_{a}+H_{M F}\right],-\left[-h_{c}+H_{r}+H_{M F}\right]\right\}} g\left(h_{b}\right) d h_{b}\right]+A\left(\frac{\pi}{2}\right.\right. \\
& \left.\left.+\arctan \left(\frac{-H_{r}-H_{M F}}{\omega_{2}}\right)\right)\right\}
\end{aligned}
$$

Desta forma, pode-se simular diagramas de FORCs experimentais através da elaboração de um programa capaz de recriar estas equações com passos pequenos. Através da mudança de parâmetros, pode-se ajustar o diagrama simulado a fim de se assemelhar com o experimental.

Considerando apenas a contribuição reversível no processo de magnetização em uma simulação, espera-se, teoricamente, que este termo não influencie o diagrama de FORCs, onde as derivadas da equação 1.65 eliminariam o termo reversível da equação 3.3. O que se observa, tanto em diagramas simulados quanto em experimentais, é a presença desta componente na região de $h_{\mathrm{c}} \approx 0$ (fig. 3.1), evidenciando que as partículas magnéticas causadoras destes efeitos possuem campos de interação, mas seu campo de inversão é praticamente nulo. A componente irreversível pode ser atribuída às contribuições de outras regiões do diagrama (fig. 3.2). Esta exemplificação foi feita com os parâmetros $\mathrm{H}_{\mathrm{EB}}=-50 \mathrm{Oe}, \mathrm{H}_{\mathrm{SW}}=40 \mathrm{Oe}, \omega=0.8 \mathrm{Oe}, \sigma=6$ Oe e $\mathrm{B}=1$ para a componente irreversível e $\mathrm{H}_{\mathrm{EB}}=-50 \mathrm{Oe}, \omega_{2}=9$ Oe e $\mathrm{A}=2 / \pi$ para a componente reversível.
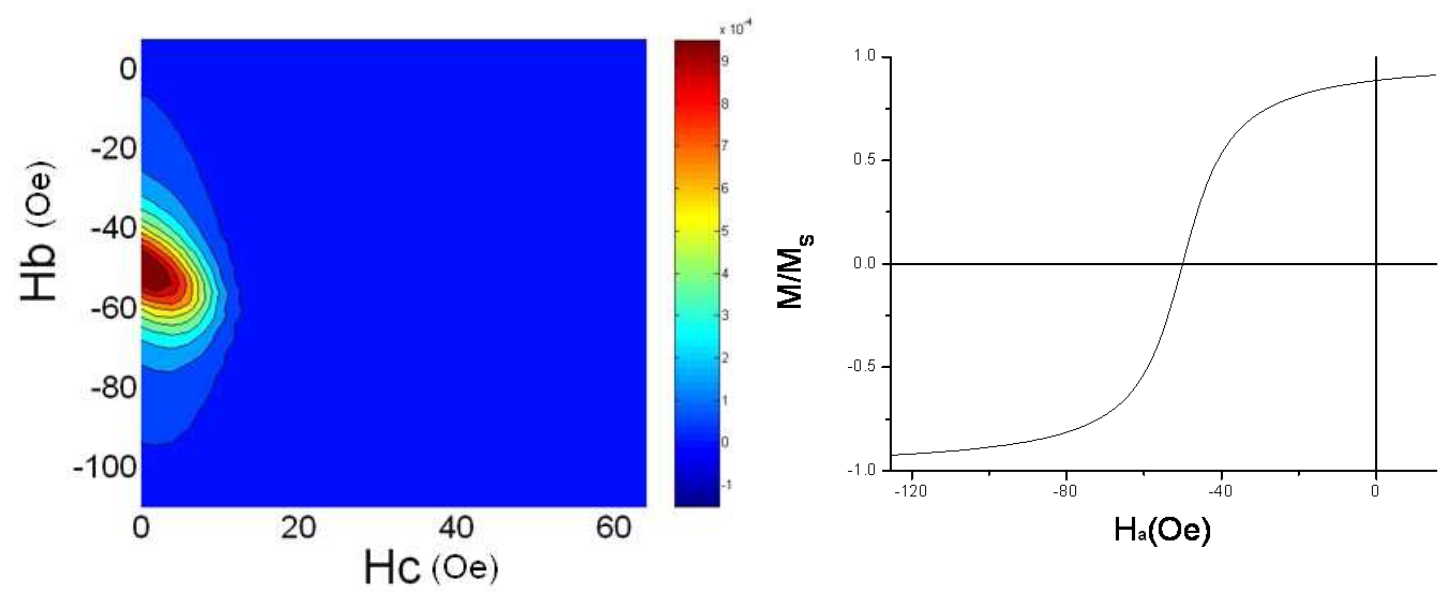

Figura 3.1 - Simulação de um diagrama de FORCs composto exclusivamente pela componente reversível juntamente com sua curva de histerese.
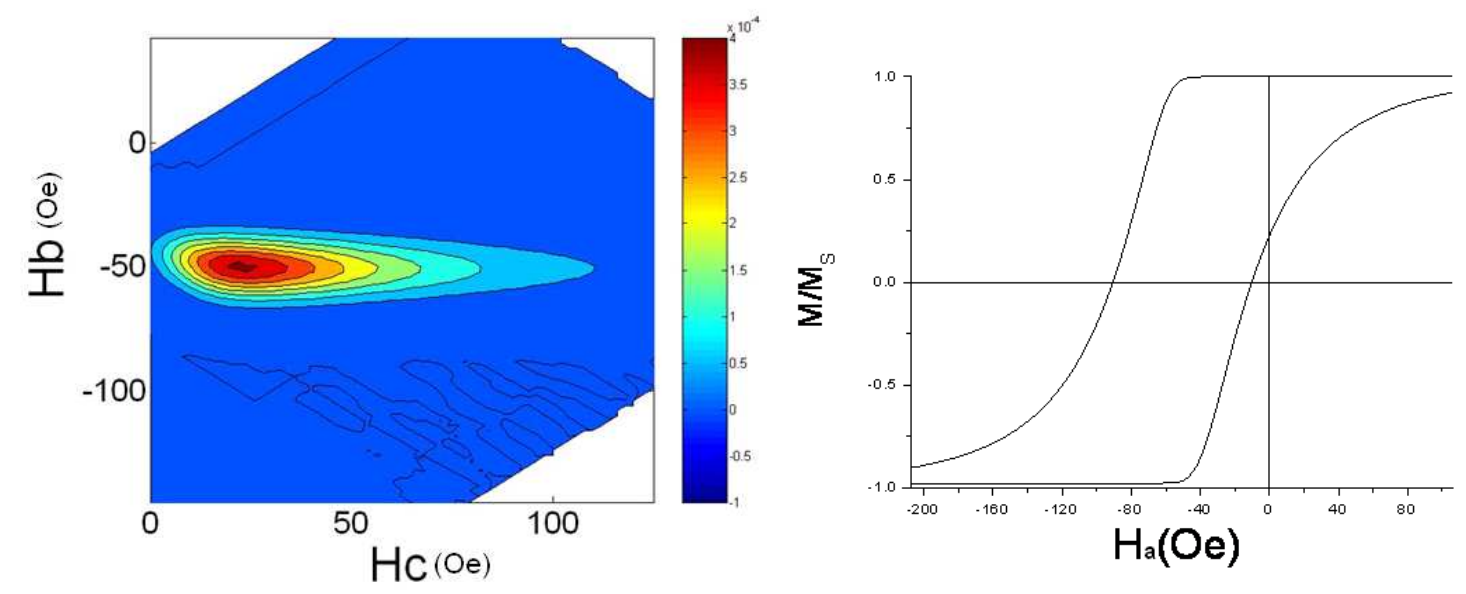

Figura 3.2 - Simulação de um diagrama de FORCs composto exclusivamente pela componente irreversível juntamente com sua curva de histerese. 
Assim, para que uma simulação seja feita, deve-se levar em conta as duas contribuições para que se possa reproduzir os diagramas obtidos experimentalmente, sendo assim possível obter os parâmetros da equação 3.1 .

O termo linear da contribuição do campo efetivo (eq. 3.9) também é perceptível nos diagramas de FORCs. Basicamente, a distribuição da componente irreversível sofre uma inclinação, característica do efeito de campo médio, juntamente com uma contribuição negativa abaixo da distribuição. Este comportamento, experimentalmente observado[40], pode ser simulado com o uso do modelo móvel de Preisach. Estes efeitos serão estudados de forma mais detalhada mais adiante.

\section{2 - Estudo de assimetrias no Modelo de Preisach com Exchange Bias}

De acordo com a Teoria de Campo Médio de P. Weiss [48] e de Bethe Peierls [49], o campo magnético efetivo possui um termo linear em $m$. Esta aproximação supõe um material puramente ferromagnético e não considera efeitos de borda nem falhas, aprisionamentos de paredes de domínios e interações de menor ordem. Mesmo para estas condições, a teoria ainda é imprecisa, sendo ela uma primeira aproximação para um possível aprofundamento teórico onde quer que seja aplicada. Levando em conta esses fatores, podemos introduzir, através da mesma análise feita por P. Weiss, uma função de campo efetivo não-linear e, através de uma justificativa matemática para isto, torna-se possível atribuir novos termos do campo efetivo no Modelo de Preisach com Exchange Bias.

Os efeitos de assimetria observadas em curvas de magnetização e no efeito trainning [47] também podem ser observados em FORCs e, conseqüentemente, em diagramas de FORCs. Observa-se na figura 4.6 esse efeito associado à um ciclo de histerese onde os mesmos podem ser observados. Vê-se, qualitativamente, que a saturação positiva se dá de forma suave e que a negativa converge abruptamente. Este fenômeno pode ser reproduzido através de simulações do Modelo de Preisach com Exchange Bias. Para isto, o modelo deve ser adaptado para a introdução de novos termos nas componentes de interação AF/FM (eq. 1.43). E, para realmente garantir que esses efeitos secundários não são devido á aprisionamentos de paredes de domínios ou até mesmo a regiões não saturadas completamente, três amostras foram submetidas a campos de até $20 \mathrm{kOe}$, onde as mesmas continuaram apresentando o comportamento assimétrico, evidenciando assim que essas observações não são conseqüentes da não saturação do material. Vale lembrar que a 200 Oe o material já apresenta uma saturação aparente e que a maioria das medidas de curvas de magnetização foi feita com H máximo de 400 Oe.

Como já foi abordado, a solução teórica do problema ainda está em aberto, e aproximações fenomenológicas tornam-se essenciais para a descrição quantitativa dos processos envolvidos. Assim, sob um ponto de vista do Modelo de Preisach com Exchange Bias, podemos atribuir novos termos na equação 1.43 , impondo as condições de contorno, que são $\zeta\left(+M_{S}\right)=$ $1 e \zeta\left(-M_{S}\right)=-1$. Considerando que a função $\zeta(M)$ não seja linear (fig. 3.3), mas que possa ser expressa por uma série de potências ímpares para que as c.c. sejam satisfeitas, pode-se chegar a um resultado aproximado do exato caso os primeiros termos forem considerados, supondo que a série seja convergente, teremos

$$
\zeta(M)=\frac{\sum_{i=1}^{\infty} a_{i}\left(\frac{M}{M_{S}}\right)^{i}}{\sum_{i=1}^{\infty} a_{i}}, i=\text { impar }
$$




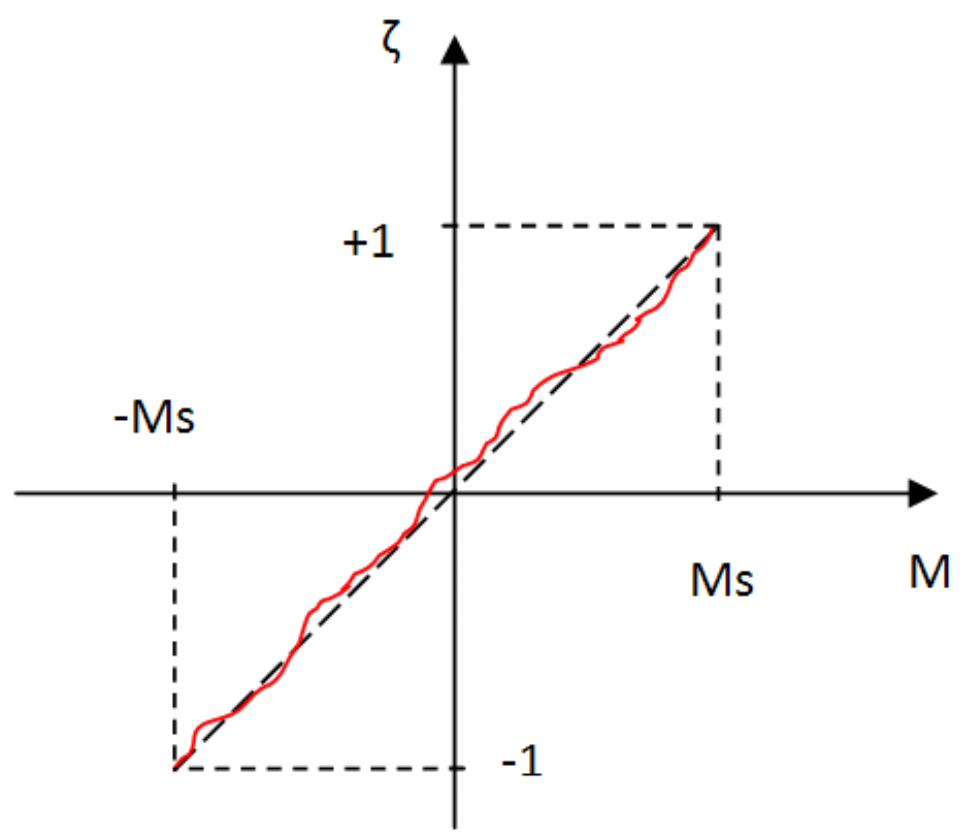

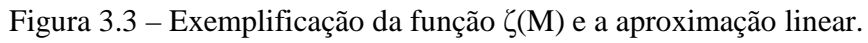

Considerando que o primeiro termo $\frac{M}{M_{S}}$ seja predominante na descrição do fenômeno, obteremos uma solução aproximada supondo

$$
\zeta(M)=\frac{\frac{M}{M_{S}}+\alpha \frac{M^{3}}{M_{S}^{3}}}{1+\alpha}
$$

Desta forma, obteremos o campo médio $\mathrm{H}_{\mathrm{MF}}$. Da equação 1.40, teremos a forma

$$
H_{M F}=\left(-N_{e f f}+\frac{8}{r} \frac{\gamma_{F M}}{\mu_{0} M_{S}^{2}}\right) M-\frac{\gamma_{A F-F M}}{t \mu_{0} M_{S}(1+\alpha)}-\frac{3 \alpha \gamma_{A F-F M} M^{2}}{t \mu_{0}(1+\alpha) M_{S}^{3}}
$$

com

$$
H_{E B}=\frac{\gamma_{A F-F M}}{t \mu_{0} M_{S}(1+\alpha)}
$$

Assim, é possível obter uma grandeza numérica $\alpha$ para as assimetrias e, através dos ajustes das curvas de magnetização, esta grandeza pode ser conhecida. Para uma maior simplificação para a manipulação das equações, pode-se também usar a forma

$$
H_{M F}=k_{1} M+k_{2} \frac{M^{2}}{M_{S}}-H_{E B}
$$

onde $\mathrm{k}_{1}$ e $\mathrm{k}_{2}$ são adimensionais, sendo expressos por

$$
\begin{aligned}
k_{1} & =\left(-N_{e f f}+\frac{8}{r} \frac{\gamma_{F M}}{\mu_{0} M_{S}^{2}}\right) \\
k_{2} & =-\frac{3 \alpha \gamma_{A F-F M}}{t \mu_{0}(1+\alpha) M_{S}^{2}}=-\frac{3 \alpha H_{E B}}{M_{S}}
\end{aligned}
$$


A hipótese assimétrica ainda é reforçada pelo fato de esse termo ser capaz de reproduzir os efeitos observados experimentalmente através de simulações computacionais (fig. 3.4).

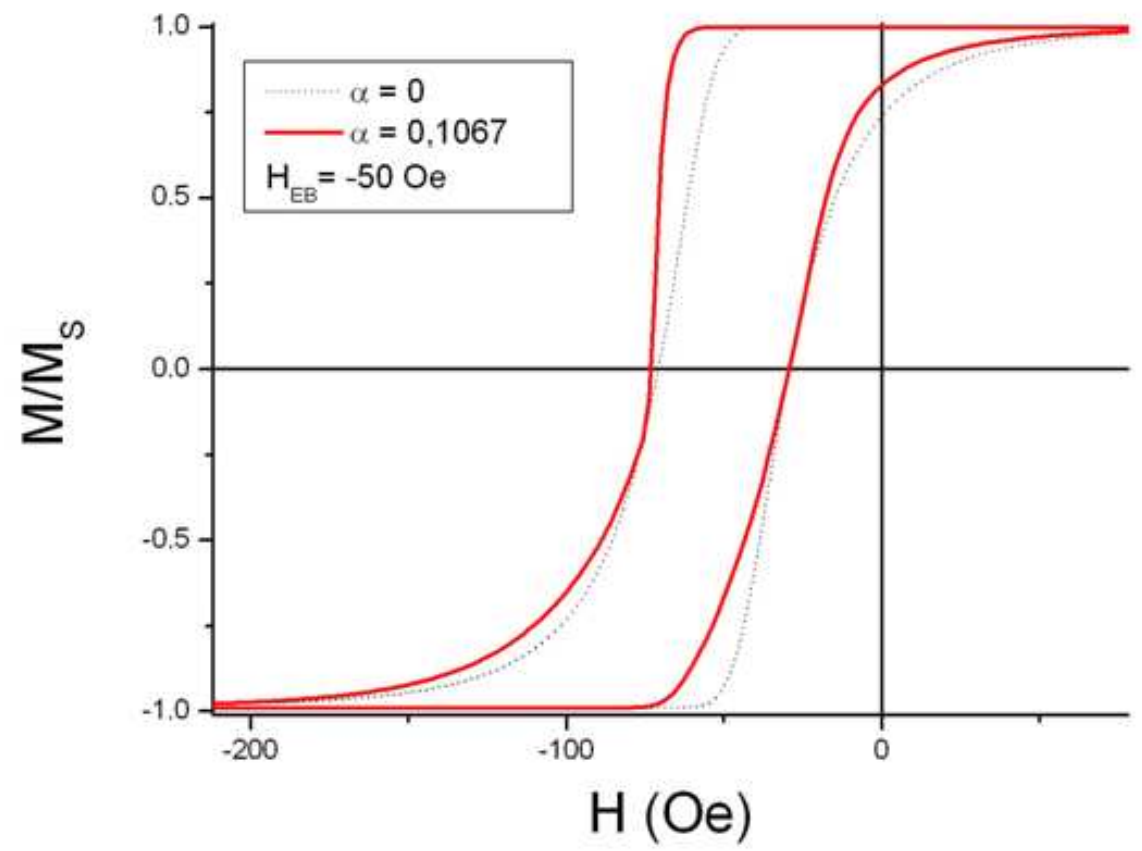

Figura 3.4 - Simulações utilizando o Modelo de Preisach com Exchange Bias para um valor fixo de $\mathrm{H}_{\mathrm{EB}}$ à -50 Oe, $\mathrm{k}=0, \alpha=0$ e $\alpha=0.1067$.

$\mathrm{O}$ primeiro termo de $\mathrm{k}_{1}$, que é o resultado da contribuição desmagnetizante, pode assumir um valor limite $\mathrm{N}_{\mathrm{eff}}=1$. O segundo termo pode assumir somente valores positivos que pode ser relativamente grande caso $r$ for pequeno e ser pequeno caso $r$ for grande. Os limites assumidos por $\mathrm{k}_{1}$ então se dão da forma [-1;œ[. Para o caso de $\mathrm{k}_{2}$, pode-se notar uma descontinuidade em $\alpha=-1$. No entanto, não há imposições quanto à limites inferiores ou superiores e, a princípio, $\mathrm{k}_{2}$ pode assumir qualquer valor através da definição de $\alpha$.

Com base nisto, simulações com a variação dos parâmetros $k_{1}$ e $k_{2}$ foram feitas para se entender mais precisamente o comportamento das distribuições de FORCs. Combinações foram feitas com $\mathrm{k}_{1}$ e $\mathrm{k}_{2}$ para $\mathrm{A}=0 ; \omega=0,8 ; \mathrm{H}_{\mathrm{sw}}=40 ; \sigma=6$ e $\mathrm{H}_{\mathrm{BB}}=-50$. Os gráficos estão dispostos a seguir, com as FORCs em seguida. Analisando a componente reversível de forma separada, também foram obtidos os diagramas das mesmas tomando $B=0 ; \omega_{2}=9$ e com a mesma variação dos k's. 


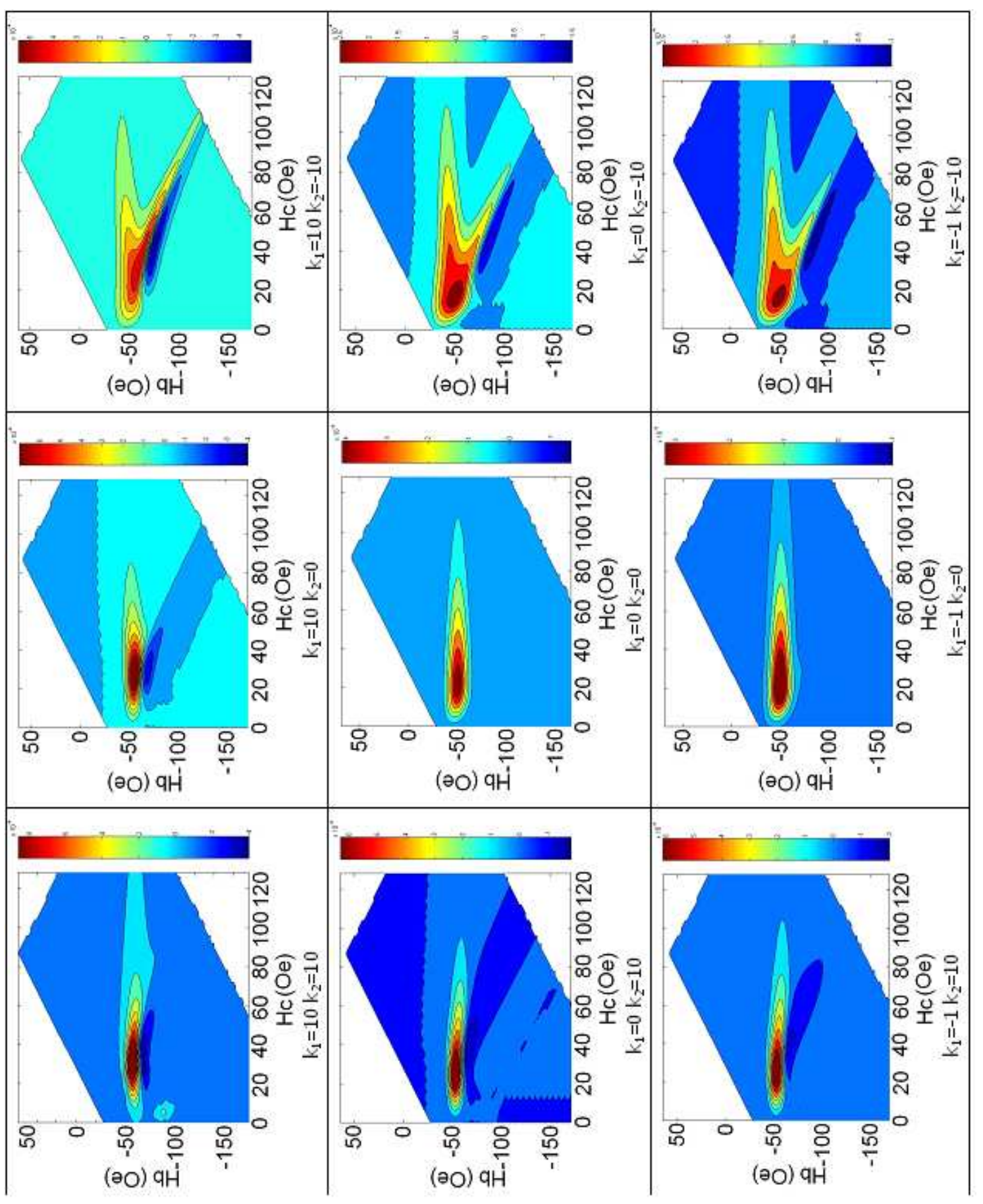

Figura 3.5 - Simulações da componente irreversível do modelo móvel de Preisach com Exchange Bias. 


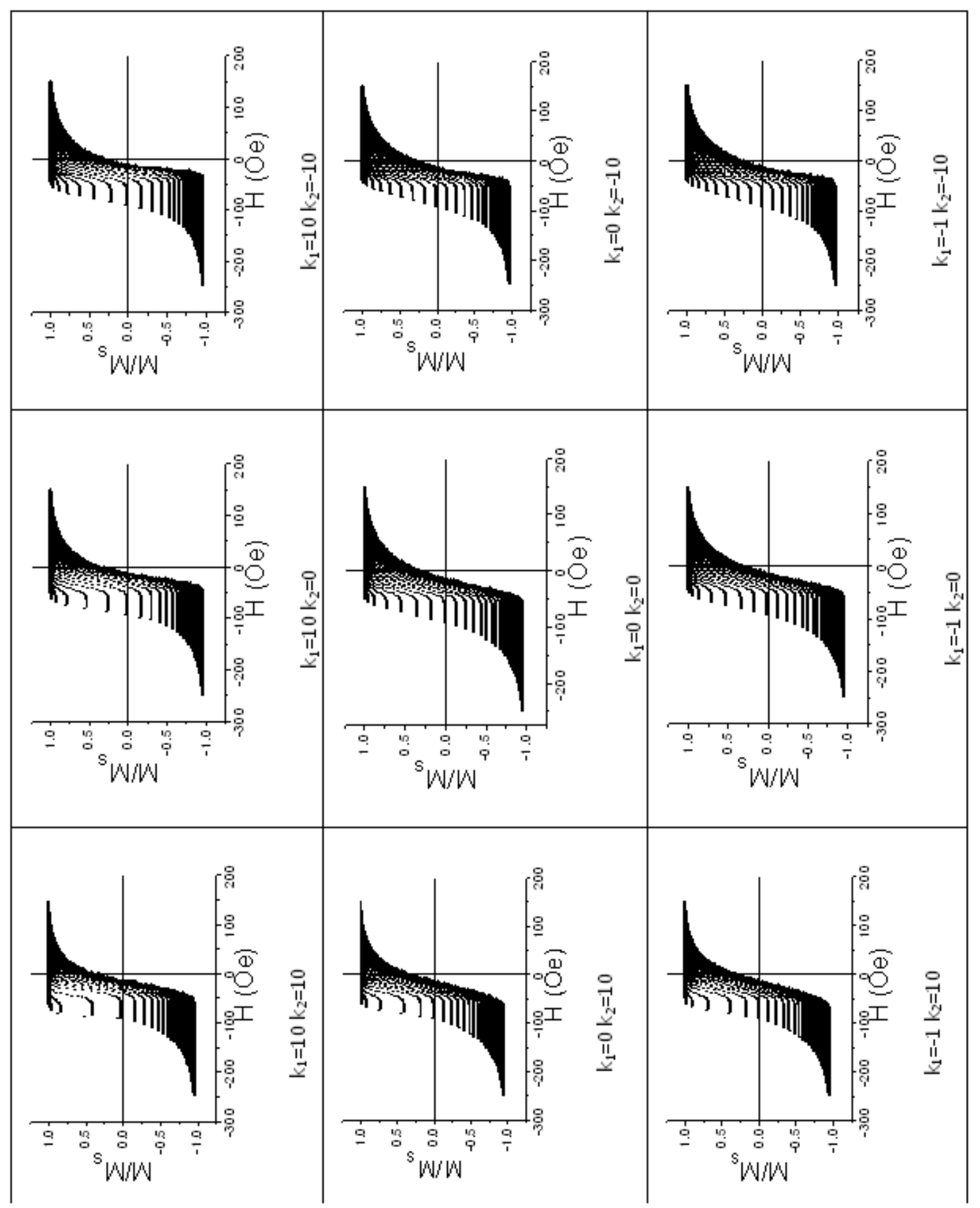

Figura 3.6 - Simulações feitas através do modelo móvel de Preisach com Exchange Bias com os efeitos de assimetria introduzidos no campo efetivo. As FORCs correspondem aos diagramas da figura 3.5. 


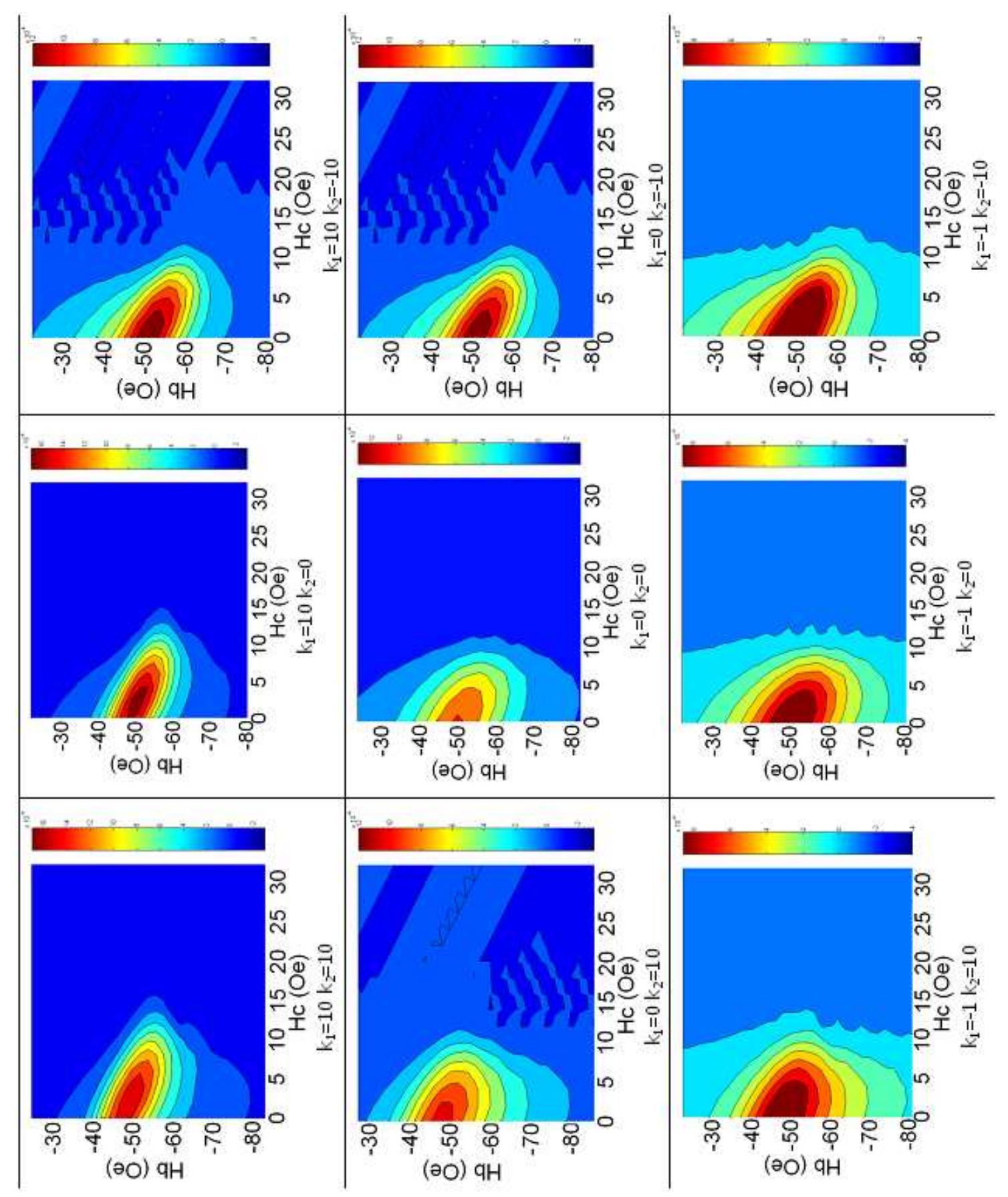

Figura 3.7 - Simulações da componente reversível do modelo móvel de Preisach com Exchange Bias. 


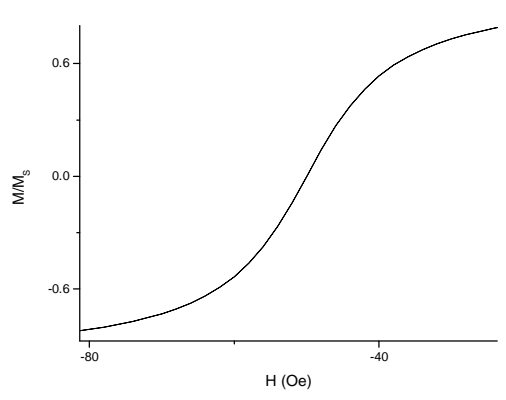

$\mathrm{k}_{1}=0 \mathrm{k}_{2}=0$

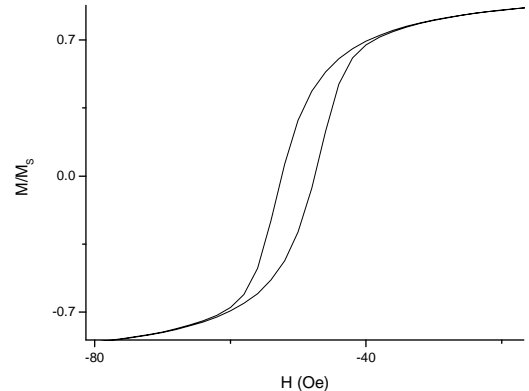

$\mathrm{k}_{1}=10 \mathrm{k}_{2}=0$

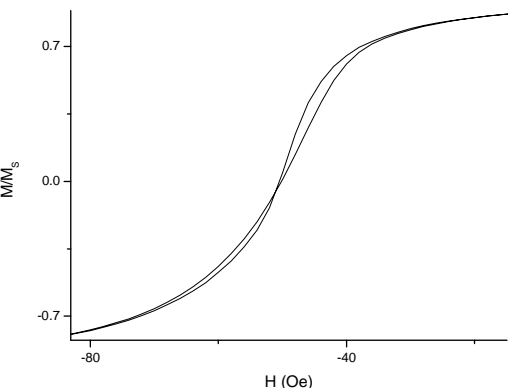

$\mathrm{k}_{1}=0 \mathrm{k}_{2}=10$

Figura 3.8 - Simulações feitas através do modelo móvel de Preisach com Exchange Bias com os efeitos de assimetria introduzidos no campo efetivo apenas com a componente reversível atuando no processo de magnetização. A seguir, três curvas de histerese relativas aos diagramas com os k's acima.

Essas simulações mostram uma quantidade muito grande de informações relevantes que serão usadas na modelagem de diagramas experimentais.

Uma observação que pode ser útil na modelagem experimental vêm do fato de valores positivos de $\mathrm{k}_{2}$ produzirem regiões negativas com o mínimo à frente (no eixo $\mathrm{h}_{\mathrm{c}}$ ) do pico da distribuição, enquanto que esse efeito atribuído à $\mathrm{k}_{1}$ se dá com o mínimo alinhado (no eixo $\mathrm{h}_{\mathrm{c}}$ ) com o pico da distribuição. Na verdade, esse fato pode ser determinante na escolha desses parâmetros caso os diagramas experimentais possuírem ruído o suficiente para impossibilitar uma distinção de inclinações (como foi discutido no parágrafo anterior).

Devido ao fato de os parâmetros das distribuições gaussiana e lognormal serem facilmente ajustáveis, um método de ajuste dos parâmetros através da obtenção das curvas $\rho$ vs $\mathrm{h}_{\mathrm{c}}$ e $\rho \mathrm{vs} \mathrm{h}_{\mathrm{b}}$ no ponto máximo da distribuição (também conhecido como cross-sections) pode ser sobreposta à mesma curva de distribuição sob os dados experimentais, sendo assim ajustadas através de sucessivas simulações, podendo serem feitas de forma manual. Esta técnica foi utilizada e será melhor descrita na análise dos diagramas experimentais.

As FORCs mostradas evidenciam variações de comportamento com a variação dos parâmetros. Para $k_{1}>0$, tem-se a formação de curvas mais acentuadas e, para $k_{1}<0$, mais inclinadas em relação ao eixo $\mathrm{H}$. A variação em $\mathrm{k}_{2}$ mostra uma suavização das curvas para $\mathrm{H}<\mathrm{H}_{\mathrm{EB}}$ (ou seja, o campo de saturação negativo passa a ter um valor mais distante de $\mathrm{H}_{\mathrm{EB}}$ ) e quando $\mathrm{k}_{2}>0$ tem-se uma suavização das curvas a partir de $\mathrm{H}>\mathrm{H}_{\mathrm{EB}}$.

O estudo detalhado da componente reversível também foi feito com o propósito de mostrar que a modelagem dos parâmetros $\mathrm{A}$ e $\omega_{2}$ não são tão simples quanto o ajuste dos outros. Pode-se observar que a largura da distribuição para os parâmetros fixos depende fortemente de $\mathrm{k}_{1}$ e a forma da distribuição possui uma dependência, em menor ordem, de $\mathrm{k}_{2}$.

Três curvas de histerese distintas foram mostradas para evidenciar as possíveis diferenças que podem ser encontradas com a variação dos parâmetros aqui ajustados. Para $\mathrm{k}_{1} \mathrm{e}$ $\mathrm{k}_{2}$ sendo zero tem-se uma curva típica de um material puramente dominado pela componente reversível. Com o aumento do $\mathrm{k}_{1}$, observa-se também um aumento na coercividade, atribuído aqui ao efeito de campo médio. Para $\mathrm{k}_{2}$, vê-se claramente o efeito já descrito aqui, que é a suavização da curva para $\mathrm{H}<\mathrm{H}_{\mathrm{EB}}$. Também pode-se observar o cruzamento da curva em $\mathrm{H}=\mathrm{H}_{\mathrm{EB}}$ neste gráfico. Esta observação é muito útil como exemplo para mostrar que o passo feito entre 
um ponto e outro pode gerar ruídos de pequena ordem(que inclusive pode ser observado em alguns diagramas). Estas simulações foram feitas com um passo de $2 \mathrm{Oe} \mathrm{em} \mathrm{H}$. 


\section{Capítulo 4}

\section{Medidas magnéticas e a aplicação do modelo de Preisach com Exchange Bias nos filmes de $\mathrm{Cu} / \mathrm{Py} / \mathrm{FeMn} / \mathrm{Ta}$}

Curvas de histerese com diferentes ângulos entre a direção de anisotropia unidirecional e o campo aplicado foram obtidas com o campo aplicado paralelo ao plano da amostra, dando assim informações sobre a anisotropia uniaxial e valores experimentais dos campos de Exchange Bias $\left(\mathrm{H}_{\mathrm{EB}}\right)$ e das coercividades $\left(\mathrm{H}_{\mathrm{C}}\right)$. Curvas de inversão de primeira ordem (FORCs) foram obtidas para as estruturas com buffers de cobre devido aos maiores valores de $\mathrm{H}_{\mathrm{EB}}$, apesar de a estrutura com Ta ser, teoricamente, mais estável [50].

Um programa baseado no modelo móvel de Preisach com Exchange Bias foi desenvolvido e utilizado, sendo capaz de reproduzir resultados experimentais através da adaptação dos parâmetros disponíveis e, atribuindo termos de assimetria nas curvas, foi possível simular os diagramas obtidos experimentalmente. Assim, uma relação dos valores assimétricos foram relacionados com as características das amostras. Duas amostras distintas foram estudadas à baixas temperaturas, evidenciando o comportamento magnético do sistema sob estas condições.

\section{1 - Dependência Angular e Valores Máximos de $H_{\mathrm{EB}}$ e $\mathrm{H}_{\mathrm{C}}$ à temperatura ambiente}

Todas as amostras tiveram os seus eixos de anisotropia unidirecional determinados, sendo assim possível obter os valores experimentais de $\mathrm{H}_{\mathrm{EB}}$ e $\mathrm{H}_{\mathrm{c}}$ através de curvas de histerese à temperatura ambiente (300K), no magnetômetro de amostra vibrante (VSM). Para ser possível fazer as medidas desses sistemas, que possuem uma magnetização de saturação pequena se comparada com amostras macroscópicas e a baixos campos $(\approx 200 \mathrm{Oe})$, foi utilizada um fonte capaz de gerar um campo máximo $\mathrm{H}$ de pouco mais de $1 \mathrm{kOe}$ e uma bobina pick-up sensível à pequenas magnetizações no centro do VSM, com a amostra inserida na mesma (fig. 4.1). Uma fonte com capacidade de gerar campos de até $20 \mathrm{kOe}$ também foi usada para a verificação da saturação de algumas amostras.

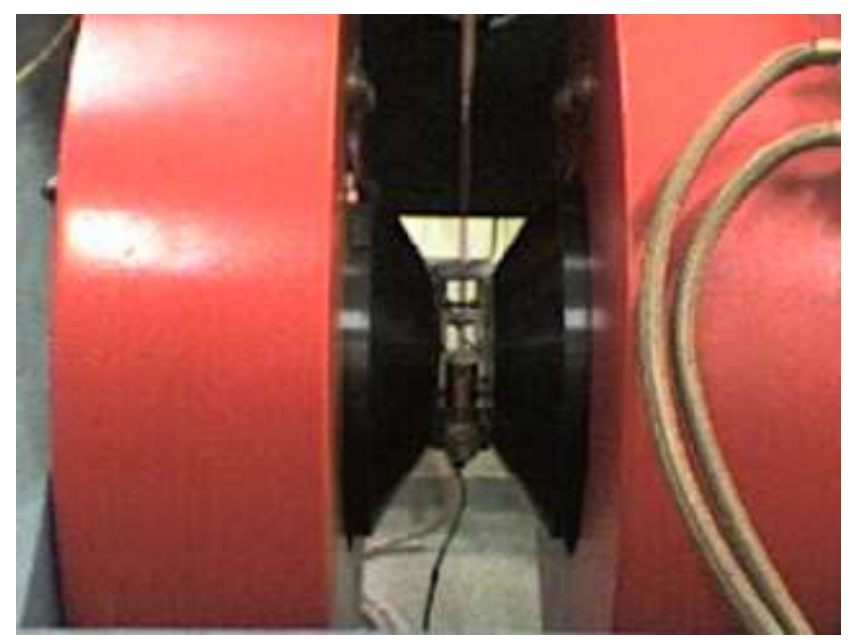

Figura 4.1 - Montagem experimental para medidas magnéticas.

O equipamento VSM possui a propriedade de rotacionar a amostra em torno do seu suporte. Com isto, foi possível fazer medidas de histerese para diferentes ângulos entre o campo 
aplicado e um eixo no plano da amostra passando pelo seu centro. Assim, pôde-se observar os valores de $\mathrm{H}_{\mathrm{EB}}$ e as coercividades para cada ângulo (figs. 4.2, 4.3 e 4.4).

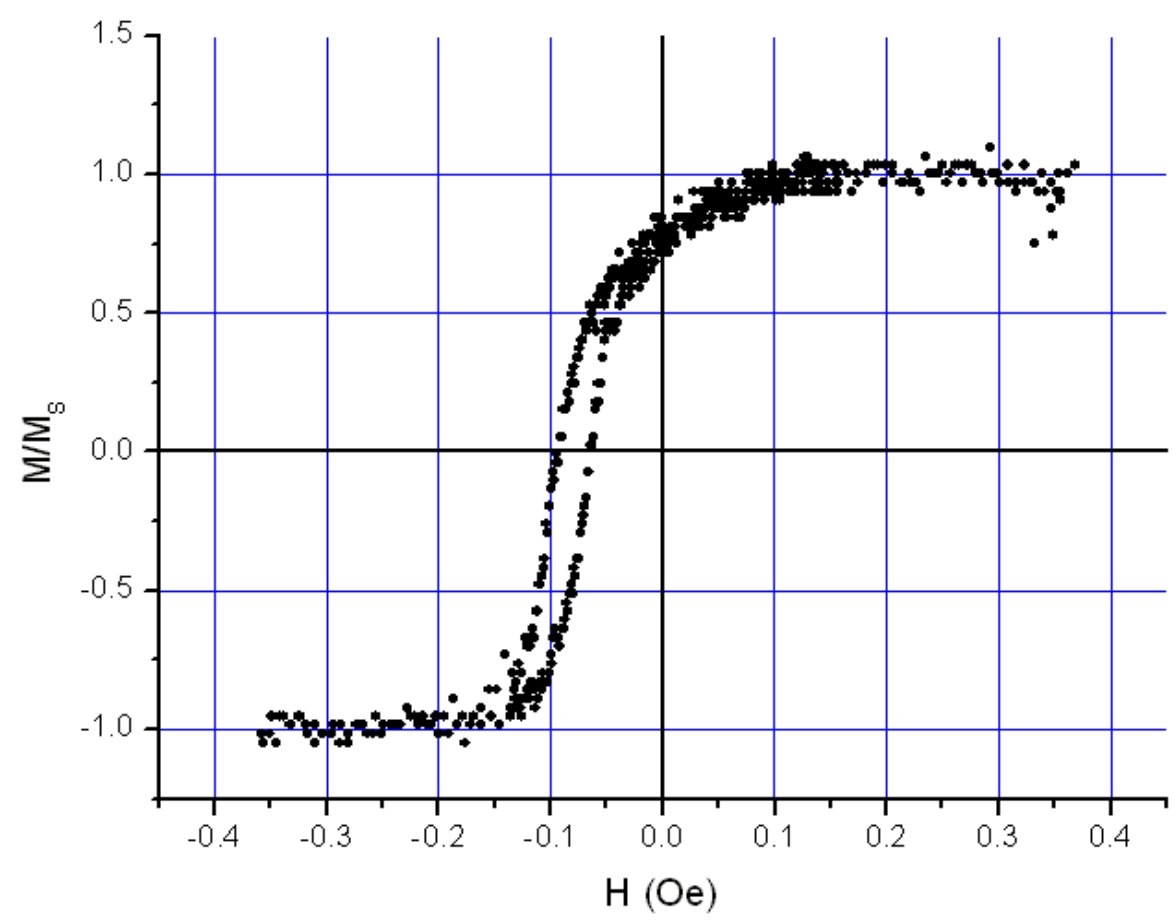

Figura 4.2 - ciclo de histerese medido sob o eixo de anisotropia da amostra $G$. 


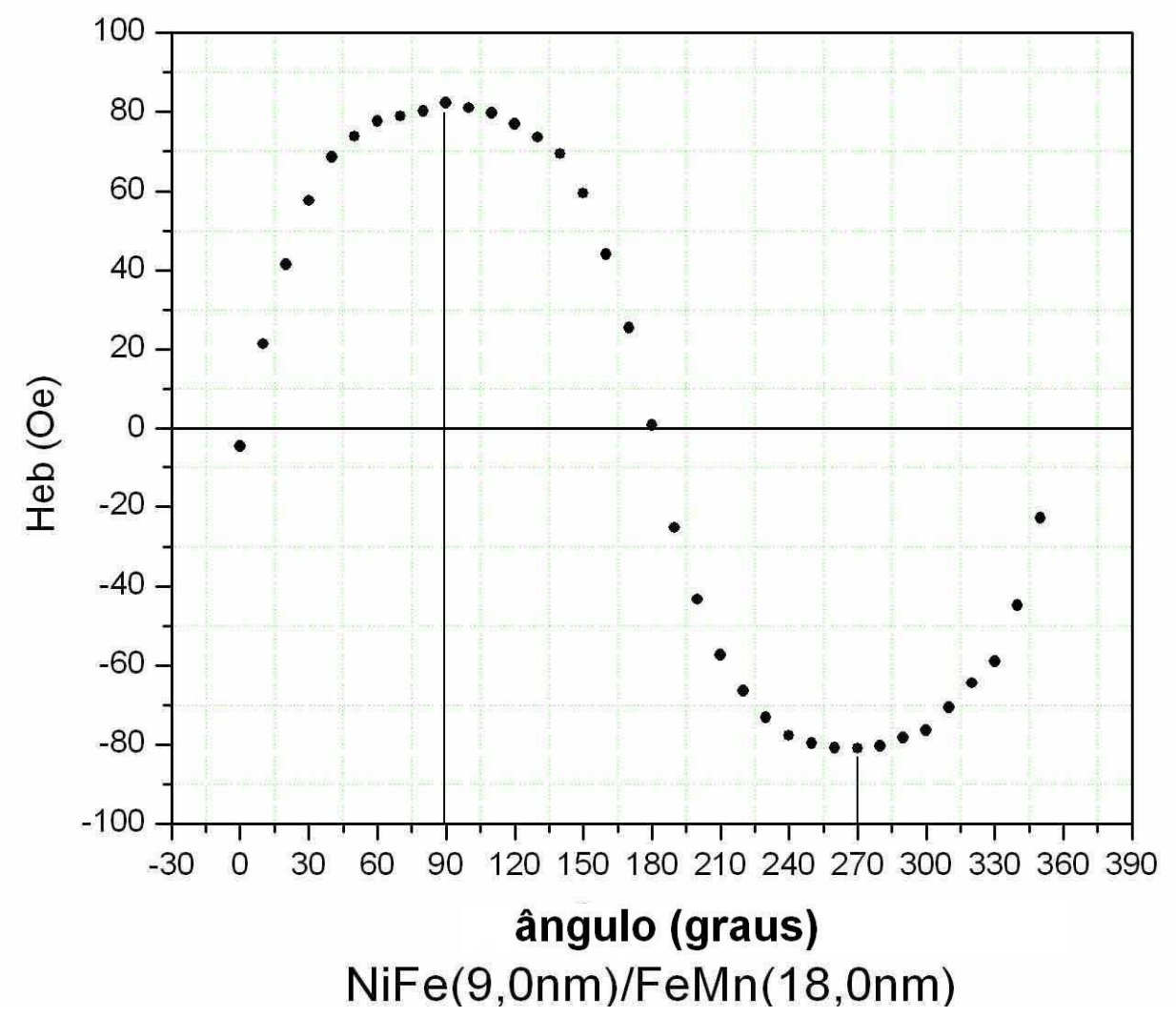

Figura 4.3 - Dependência angular de $\mathrm{H}_{\mathrm{EB}}$ com um eixo arbitrário paralelo ao plano do filme $G$. Estas medições evidenciam o eixo de anisotropia unidirecional da amostra.

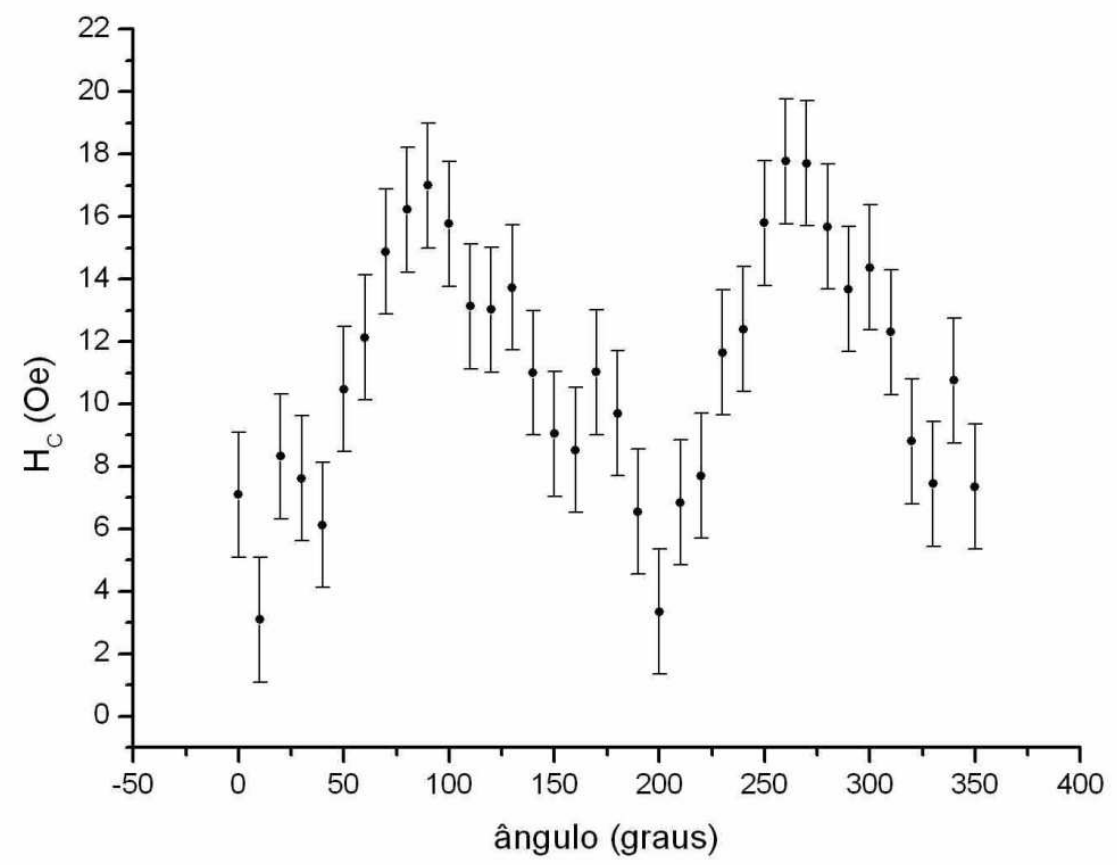

Figura 4.4 - Dependência angular de $\mathrm{H}_{\mathrm{C}}$ com um eixo arbitrário do filme. Estas medições evidenciam a direção de máximo $\mathrm{H}_{\mathrm{EB}}$. 
A figura 4.3 evidencia um comportamento senoidal para o campo de anisotropia de troca, estando em acordo com outros trabalhos [51].

Após a determinação feita em cada amostra, pôde-se verificar uma relação de dependência do valor máximo de $\mathrm{H}_{\mathrm{EB}}$ com as espessuras das camadas. Com isto, foi possível observar um comportamento de $\mathrm{H}_{\mathrm{EB}}$ proporcional à $\mathrm{t}_{\mathrm{FM}}{ }^{-1}$ e uma espessura de saturação de $\mathrm{H}_{\mathrm{EB}}$ de $18 \pm 2 \mathrm{~nm}$ para a camada de FeMn com o NiFe à $10 \pm 1 \mathrm{~nm}$, estando de acordo com a literatura[13](figs. 4.5-4.8). Também foi possível relacionar as coercividades com as espessuras. A relação de $\mathrm{t}_{\mathrm{FM}}{ }^{-1}$ com o efeito de $\mathrm{H}_{\mathrm{EB}}$ era prevista para a camada de NiFe sendo depositada primeiro[37,52].

Além destas observações, foi possível verificar, como é esperado, que o ângulo de maior coercividade, que indica o eixo de anisotropia das amostras, é coincidente com o maior valor de Exchange Bias (figs. 4.3 e 4.4), sendo isto válido para todas as amostras.

As amostras com Buffers de $\mathrm{Cu}$ e de Ta apresentaram comportamentos similares. $\mathrm{O}$ comportamento de $\mathrm{H}_{\mathrm{EB}}$ com a variação da espessura da camada de FeMn são qualitativamente iguais, sendo que $\mathrm{H}_{\mathrm{EB}}$ chega a um máximo por volta de $20 \mathrm{~nm}$. O que as diferem são os valores absolutos de $\mathrm{H}_{\mathrm{EB}}$.

Observa-se que $\mathrm{H}_{\mathrm{EB}}$ é cerca de 10 Oe maior para a saturação das amostras com buffer de $\mathrm{Cu}$ variando-se o FeMn e é cerca de 2 vezes maior com a variação do NiFe. Isto evidencia que o buffer de $\mathrm{Cu}$ permite um crescimento da camada de NiFe que favoreça uma maior formação da fase $\gamma$ do FeMn na junção AF/FM, tornando assim essas amostras mais interessantes para o estudo de anisotropia de troca. Isto se deve à maior similaridade da estrutura de $\mathrm{Cu}$ (constante de rede FCC de 0,361nm) com a liga NiFe (pode formar uma FCC com constante de rede próxima de 0,352nm). Para o caso do Ta (BCC com constante de rede de 0,331nm), tem-se constantes de rede diferentes e formações cristalinas diferentes (ou seja, planos cristalinos diferenciados), sendo assim não tão eficiente quanto o $\mathrm{Cu}$ para induzir uma formação cristalina no Py. 


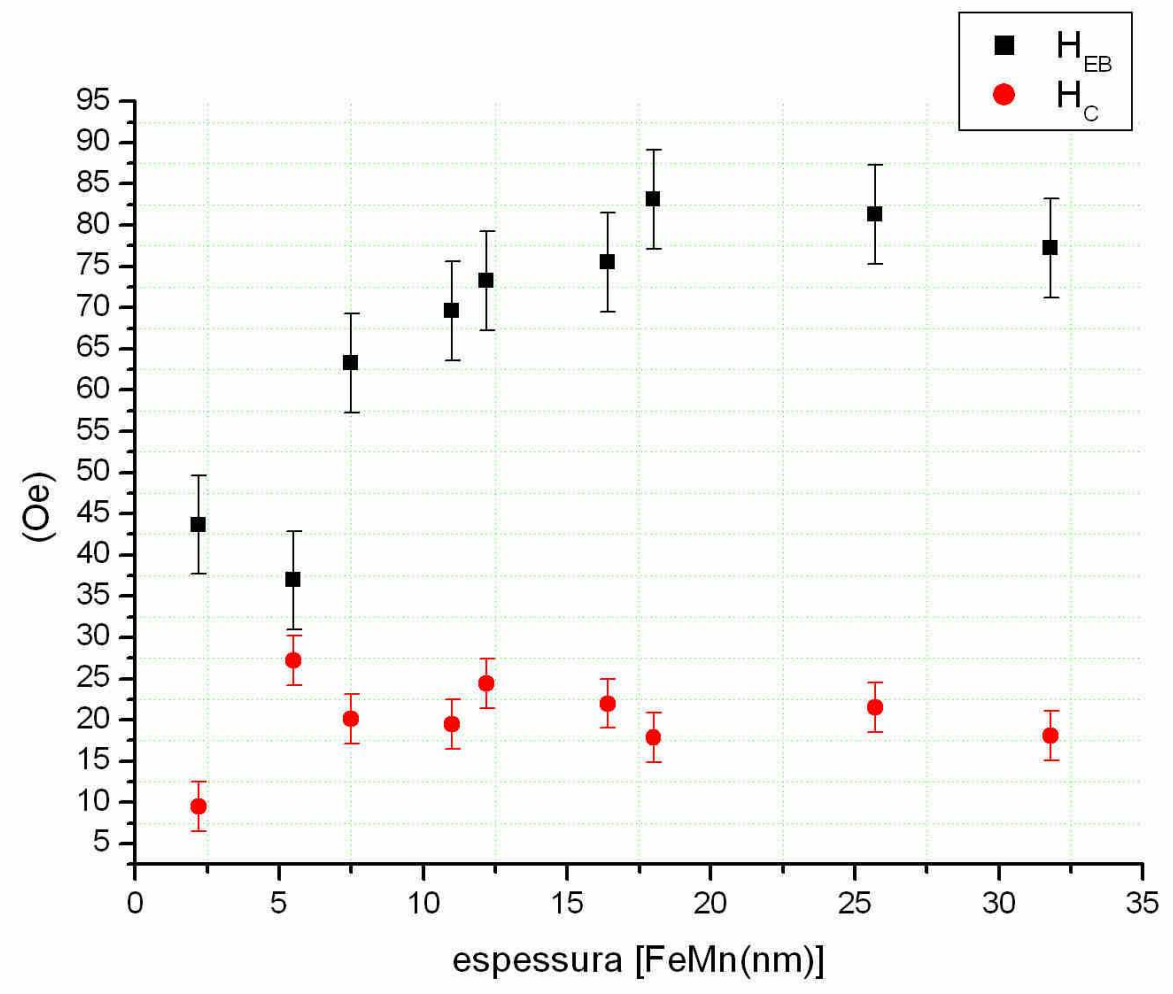

Figura $4.5-\mathrm{H}_{\mathrm{EB}}$ e $\mathrm{H}_{\mathrm{C}}$ para $\mathrm{Cu}(20 \mathrm{~nm}) / \mathrm{NiFe}(10 \mathrm{~nm}) / \mathrm{FeMn}(\mathrm{t}) / \mathrm{Ta}(10 \mathrm{~nm})$

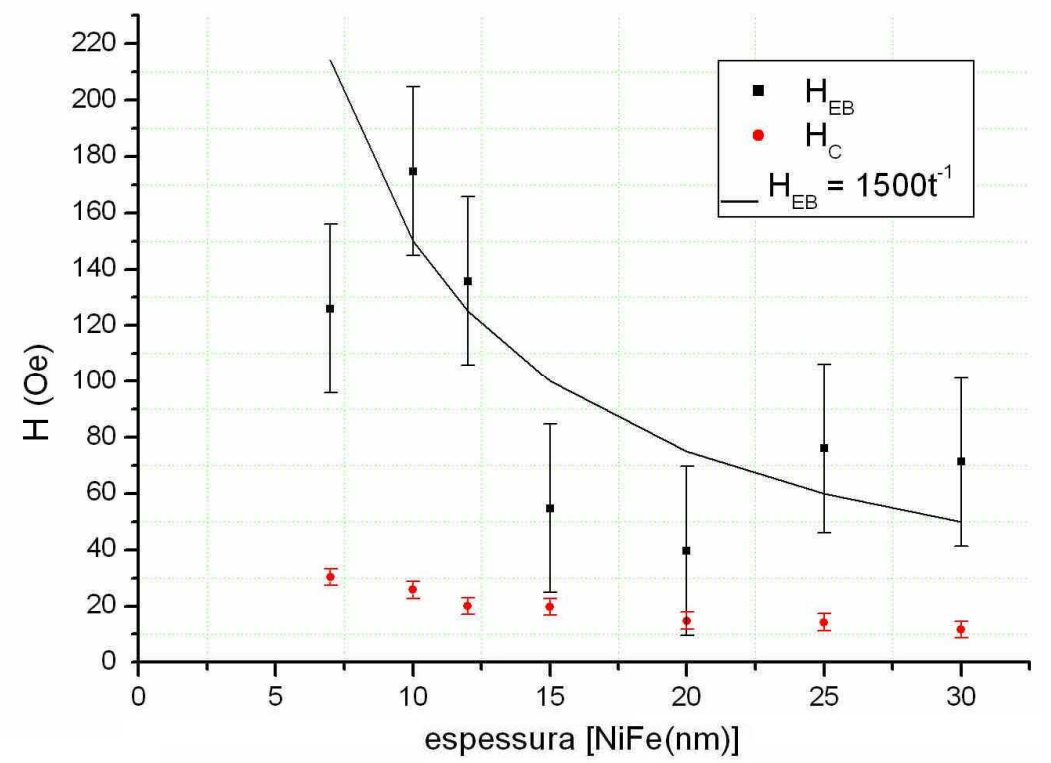

Figura 4.6 - $\mathrm{H}_{\mathrm{EB}}$ e $\mathrm{H}_{\mathrm{C}}$ para $\mathrm{Cu}(20 \mathrm{~nm}) / \mathrm{NiFe}(\mathrm{t}) / \mathrm{FeMn}(10 \mathrm{~nm}) / \mathrm{Ta}(10 \mathrm{~nm})$ Juntamente com o ajuste $\mathrm{H}_{\mathrm{EB}}=1500 \mathrm{t}^{-1}$ 


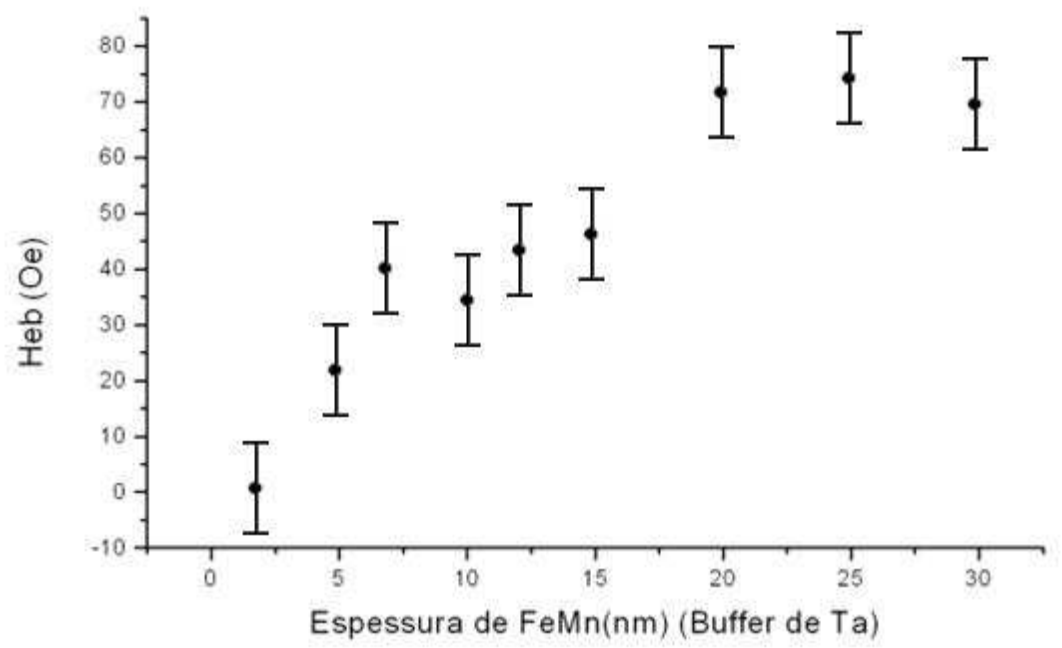

Figura $4.7-\mathrm{H}_{\mathrm{EB}}$ para $\mathrm{Ta}(30 \mathrm{~nm}) / \mathrm{NiFe}(10 \mathrm{~nm}) / \mathrm{FeMn}(\mathrm{t}) / \mathrm{Ta}(10 \mathrm{~nm})$

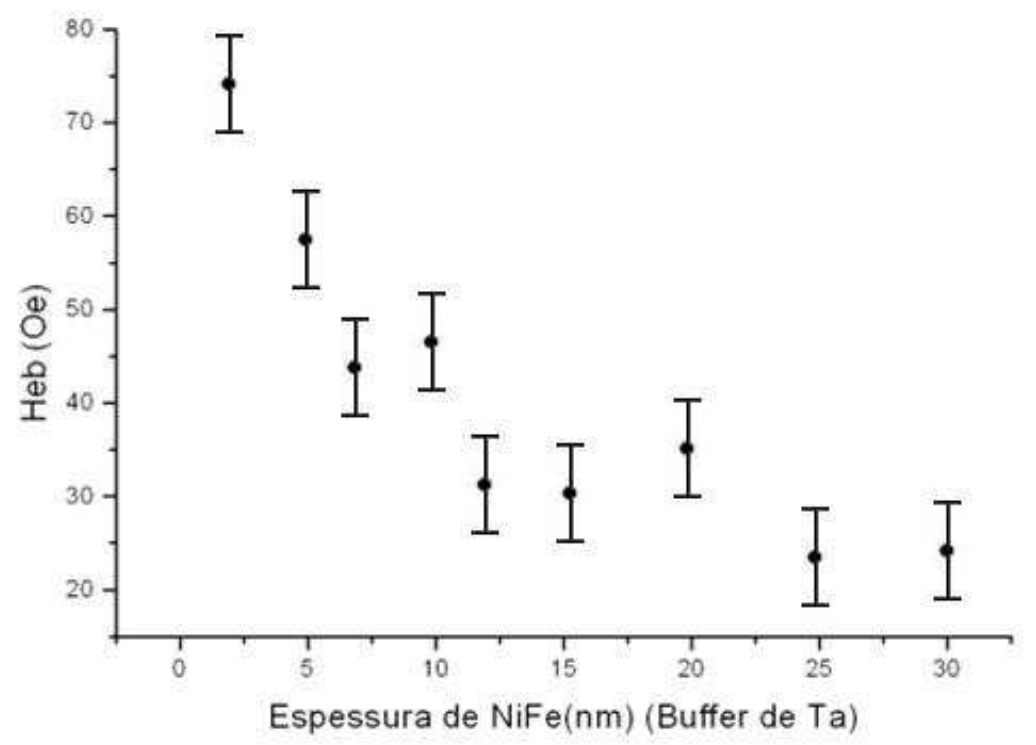

Figura $4.8-\mathrm{H}_{\mathrm{EB}}$ para $\mathrm{Ta}(30 \mathrm{~nm}) / \mathrm{NiFe}(\mathrm{t}) / \mathrm{FeMn}(10 \mathrm{~nm}) / \mathrm{Ta}(10 \mathrm{~nm})$

4.2 - Curvas de inversão de primeira ordem (FORCs) e simulações à temperatura ambiente

As FORCs foram obtidas à temperatura ambiente (300K) e com os eixos de anisotropia unidirecional alinhados com o campo magnético da bobina. Os diagramas foram feitos tanto para valores de $\mathrm{H}_{\mathrm{EB}}$ positivos quanto negativos para o sistema $\mathrm{Cu} / \mathrm{NiFe} / \mathrm{FeMn}(\mathrm{t}) / \mathrm{Ta}$ 
$(2 \mathrm{~nm} \leq \mathrm{t} \leq 32 \mathrm{~nm})$. Através dos diagramas foi possível extrair curvas comportamentais dos campos de interação $\left(h_{b}\right)$ e de inversão $\left(h_{c}\right)$ das amostras, fornecendo valores empíricos para as simulações computacionais de magnetização através do modelo móvel de Preisach com Exchange Bias. Com estes resultados, pôde-se relacionar alguns parâmetros com as espessuras do FeMn e com os campos de Exchange Bias.

O método de obtenção do diagrama com os parâmetros ajustados da amostra B será detalhado. $\mathrm{O}$ método de obtenção das simulações dos outros diagramas não será explicitado, pois a descrição a seguir evidencia todo o procedimento feito.

Tomando o diagrama experimental, a primeira coisa a ser feita é tomar as curvas em $\mathrm{h}_{\mathrm{b}}$ e $h_{c}$ no ponto máximo da distribuição para que uma estimativa inicial seja feita dos parâmetros a serem modelados nas simulações. A curva obtida $\rho v \mathrm{v}_{\mathrm{c}}$ poderá fornecer uma estimativa da distribuição lognormal, onde um ajuste prévio dos parâmetros $\omega$ e $\mathrm{H}_{\mathrm{Sw}}$ poderá ser feito. A curva $\rho$ vs $h_{b}$ dará uma estimativa inicial do $\sigma$ da distribuição gaussiana. Como a modelagem está baseada no modelo móvel de Preisach, esses valores poderão ter uma pequena divergência do que realmente será obtido, sendo necessária a tomada de algumas simulações para que os parâmetros sejam ajustados (manualmente) até que as curvas simuladas sejam capazes de reproduzir as curvas experimentais. Até mesmo o valor de $\mathrm{H}_{\mathrm{EB}}$ pode ser alterado para que seja possível ajustar o diagrama. Para exemplificar este fato, suponha uma simulação tomada apenas pela componente irreversível com $\mathrm{H}_{\mathrm{EB}}=-50, \mathrm{k}_{1}=5, \mathrm{k}_{2}=3, \mathrm{H}_{\mathrm{SW}}=40$ e $\omega=0,8$. Os gráficos abaixo mostram as FORCs simuladas e o diagrama FORC.
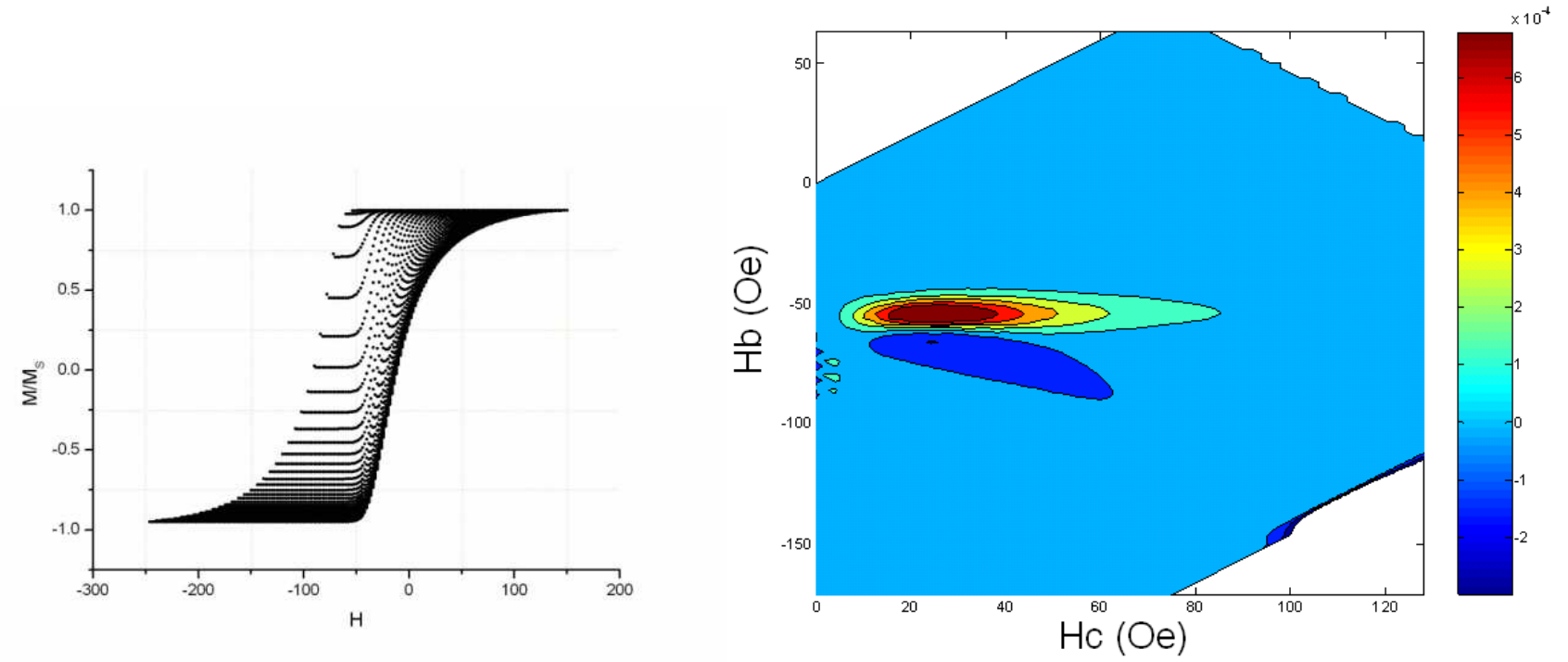

Figura 4.9 - FORCs simuladas e, conseqüentemente, o diagrama obtido como exemplificação do processo de ajuste de parâmetros. 

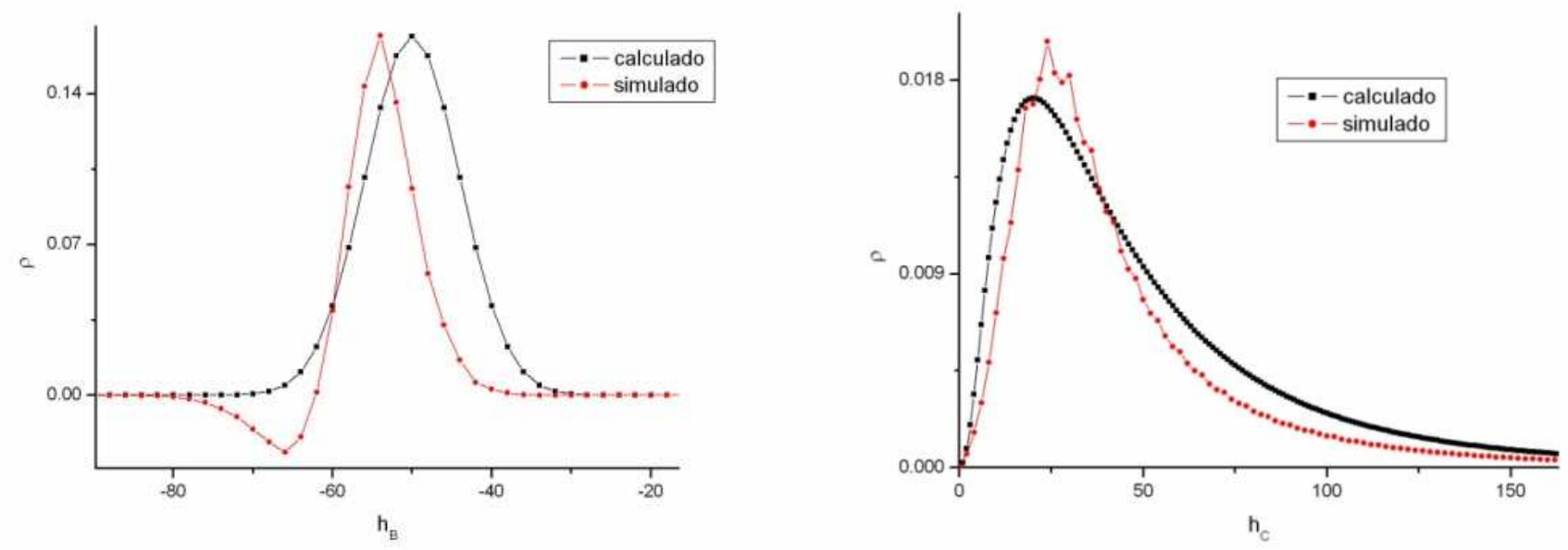

Figura 4.10 - Comparação entre os valores calculados e as distribuições obtidas através da simulação computacional.

Estes gráficos mostram que, uma vez tendo obtido alguns parâmetros como $\mathrm{H}_{\mathrm{EB}}, \sigma$, $\omega \mathrm{e}$ $\mathrm{H}_{\mathrm{SW}}$ do diagrama experimental, deve-se modificá-los nas simulações de forma a fazer a curva simulada convergir para a experimental. Assim, deve-se tomar os parâmetros obtidos experimentalmente como um ponto de partida para ser possível obter os simulados.

O ajuste inicial da componente reversível pode ser feita de forma manual, estimando-se os valores de $\mathrm{A}$ e $\omega_{2}$ e, após sucessivas simulações de ajustes, obter uma forma que seja equivalente à observada experimentalmente. Deve-se lembrar que a variação do campo efetivo poderá distorcer a largura e a intensidade do pico desta distribuição. Assim, após ajustados os valores de $\mathrm{k}_{1}$ e $\mathrm{k}_{2}$, deve-se (quase sempre) reajustar esses parâmetros.

Para o caso da amostra B, o diagrama obtido (fig. 4.11) forneceu as curvas em $h_{b}$ e em $\mathrm{h}_{\mathrm{c}}$ no pico da distribuição. Devido ao fato de o diagrama ser obtido com $\mathrm{SF}=3$ por causa do ruído, podemos assumir que os parâmetros $\omega, \omega_{2}$ e $\sigma$ sejam (arbitrariamente) um pouco menores que o aferido experimentalmente (fig. 4.12). Os parâmetros iniciais baseados nas curvas experimentais foram de $\mathrm{H}_{\mathrm{EB}}=-43 \mathrm{Oe}, \sigma=6 \mathrm{Oe}, \omega=0,35 \mathrm{Oe}$ e $\mathrm{H}_{\mathrm{SW}}=32 \mathrm{Oe}$. 


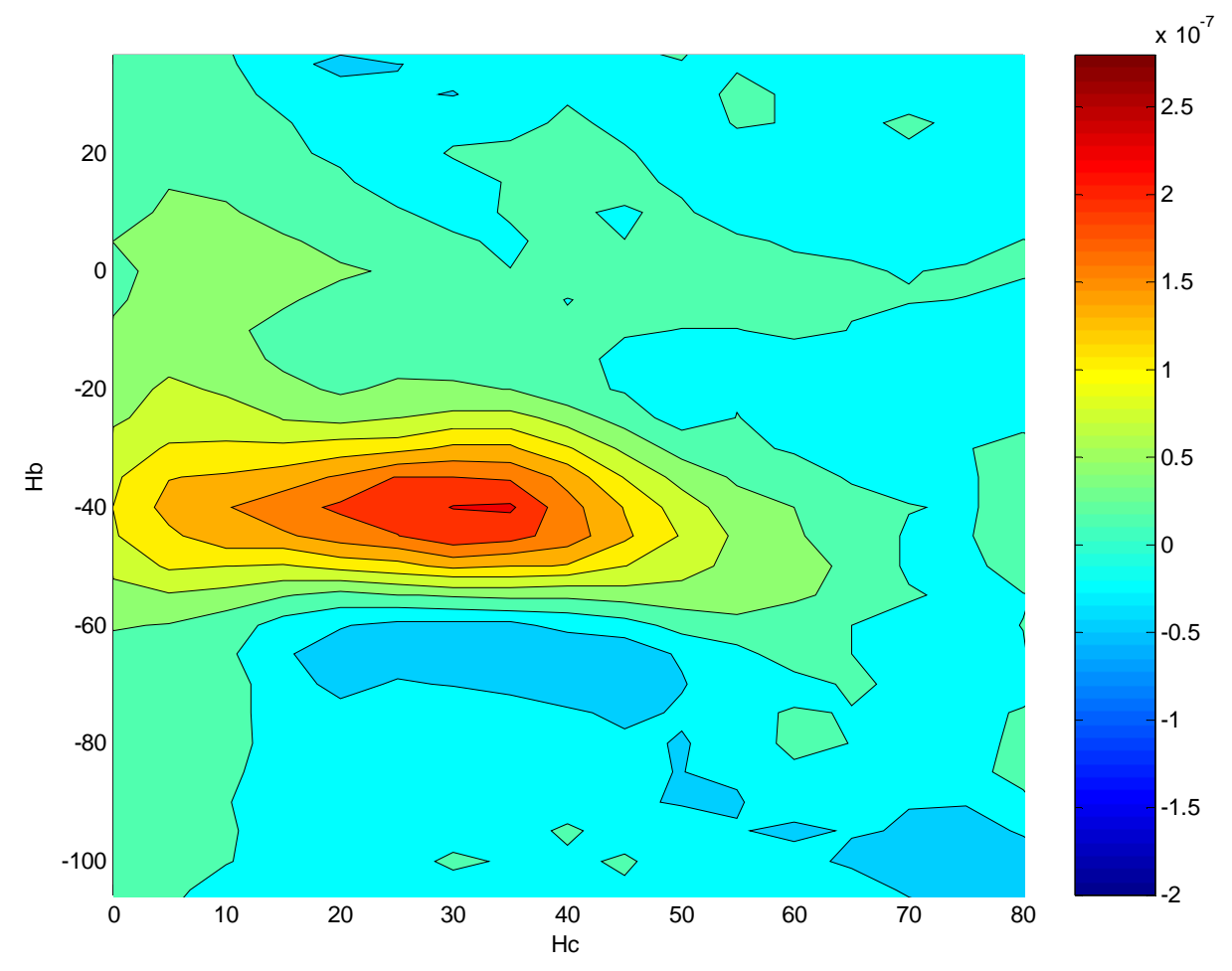

Figura 4.11 - Diagrama de FORCs experimental da amostra B. Hb e Hc estão em Oe.
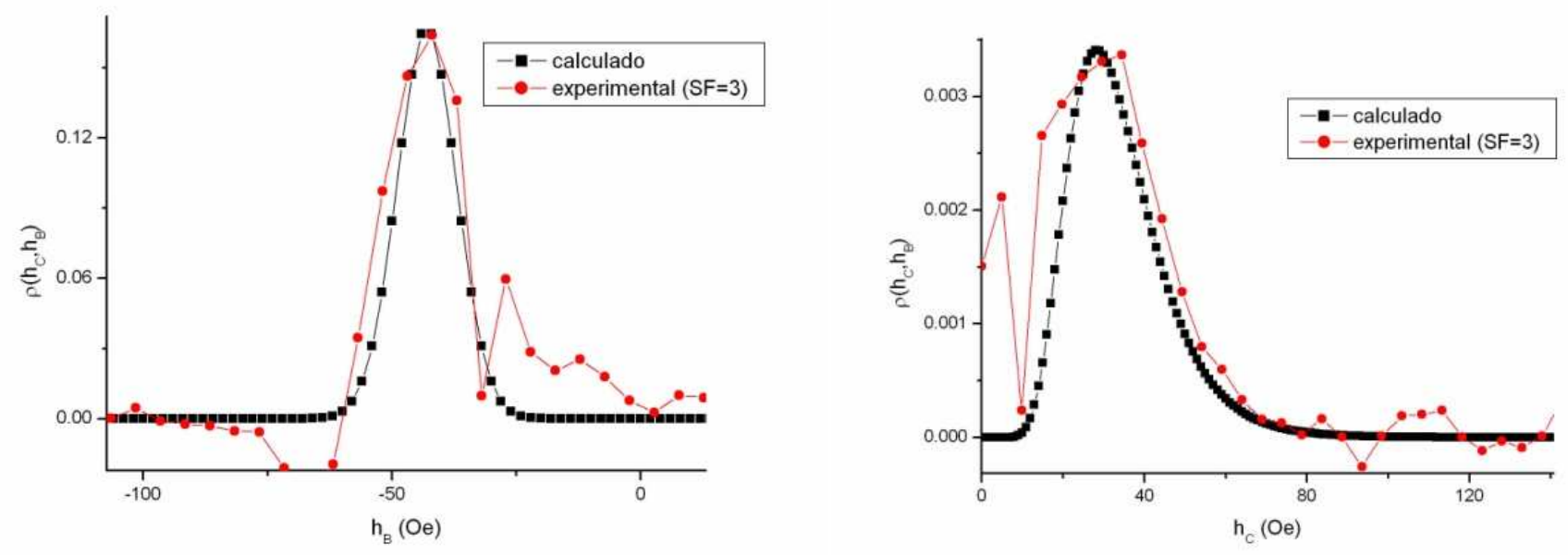

Figura 4.12 - Curvas no pico máximo do diagrama experimental junto a um ajuste de parâmetros de uma curva teórica.

Após um ajuste inicial dos parâmetros da componente reversível, $\mathrm{k}_{1}$ e $\mathrm{k}_{2}$ foram variados com $\mathrm{o}$ intuito de reproduzir a forma levemente curvada da distribuição e com o ponto de mínimo alinhado $\left(e m h_{c}\right.$ ) com o pico da distribuição. Este fato sugere que o termo $\mathrm{k}_{1}$ seja dominante neste filme. Após a atribuição adequada desses parâmetros, não foi necessária a alteração dos parâmetros da componente reversível. Caso fosse, novos valores deveriam ser atribuídos às constantes e simulações deveriam ser feitas até se obter um resultado satisfatório (fig. 4.13). 
Os valores ajustados com sucessivas simulações foram de $\mathrm{H}_{\mathrm{EB}}=-40, \sigma=6, \omega=0,5$, $\omega_{2}=0,27, \mathrm{~A}=0,187$ e $\mathrm{H}_{\mathrm{SW}}=22$. Tomando um passo de variação do campo magnético de $1 \mathrm{Oe}$, pode-se obter o diagrama a seguir, sem os ajustes de campo efetivo.

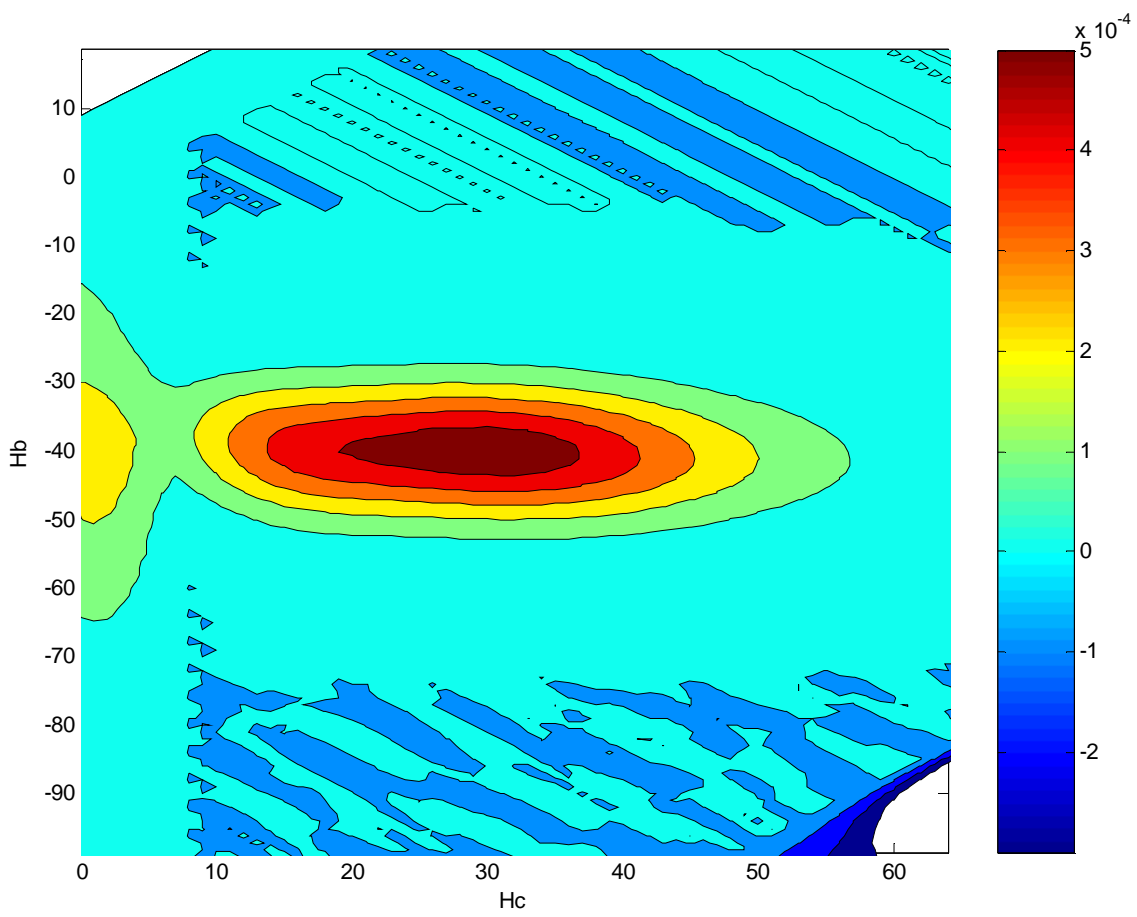

Figura 4.13 - Diagrama ajustado sem a introdução do campo efetivo.

Assim, fazendo os ajustes do campo efetivo, poderemos obter um diagrama satisfatório com o experimental (fig. 4.14) (há uma diferença de escala no eixo H das FORCs a seguir). 

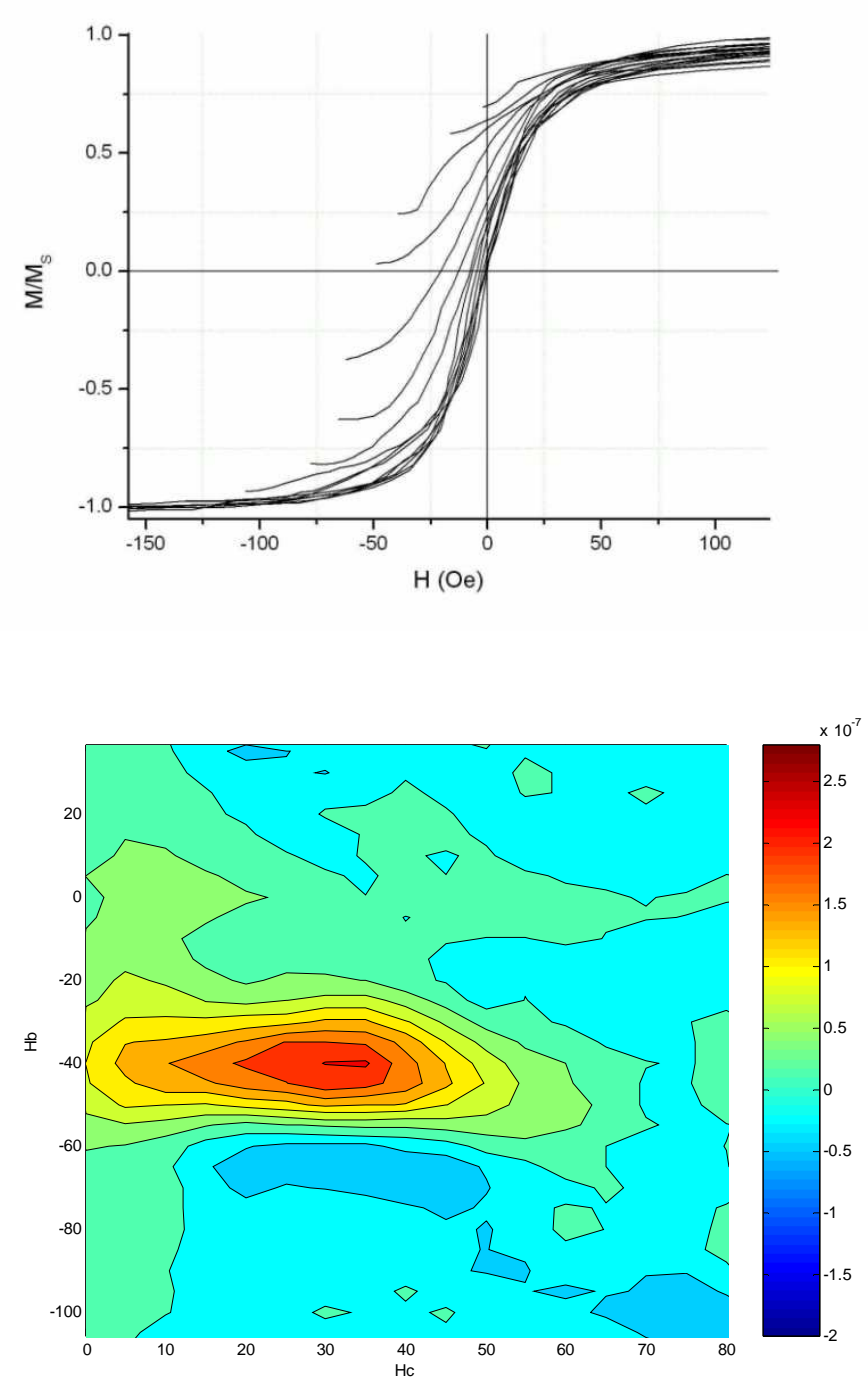
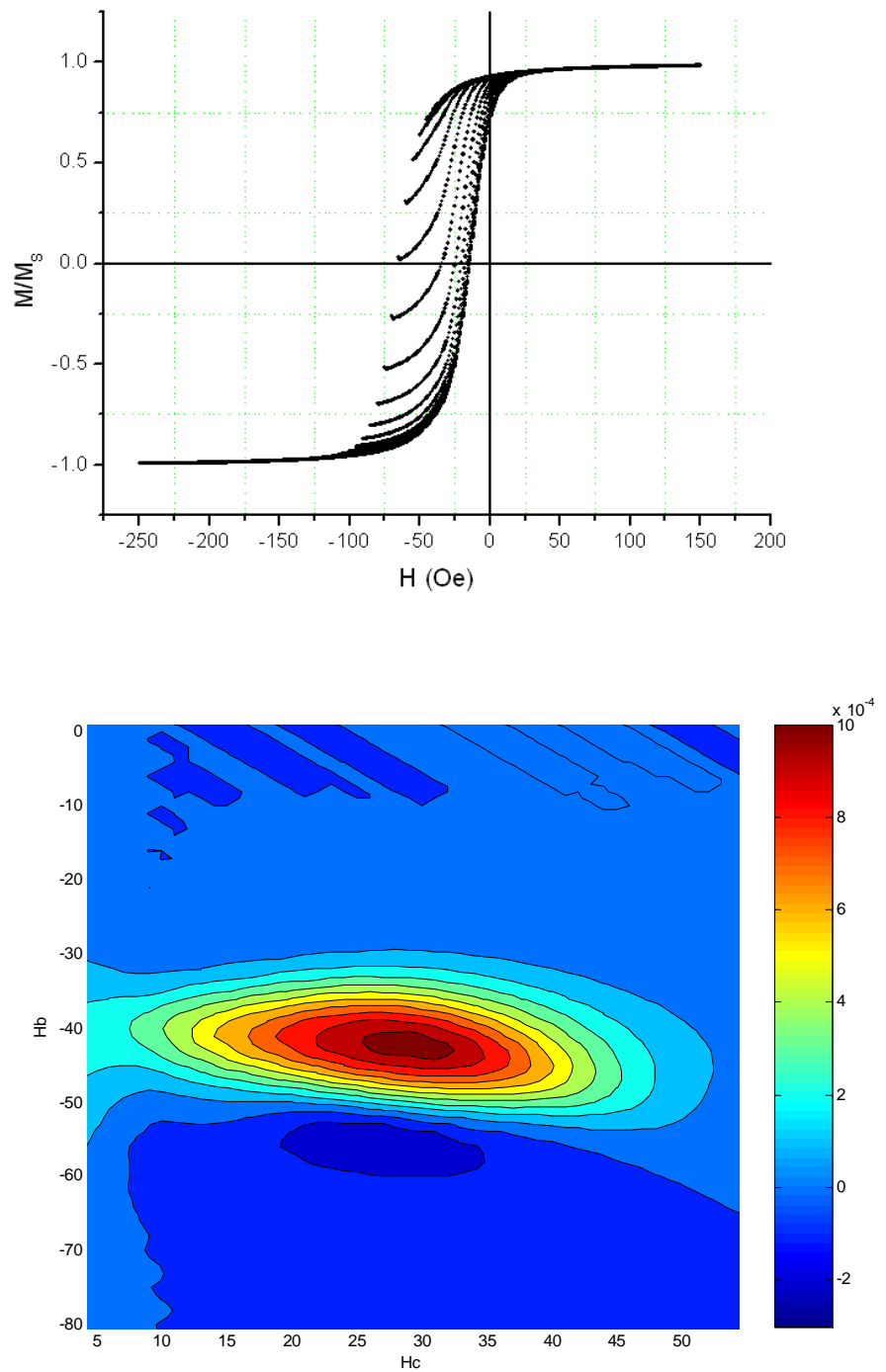

Figura 4.14 - Simulações do diagrama e das FORCs à direita. Medidas experimentais à esquerda. Hb e Hc estão em Oe.

A seguir, todos os diagramas simulados e os obtidos experimentalmente são mostrados, assim como as curvas de $h_{b}$ e $h_{c}$ nos picos. As imagens estão agrupadas para que uma análise seja feita. 

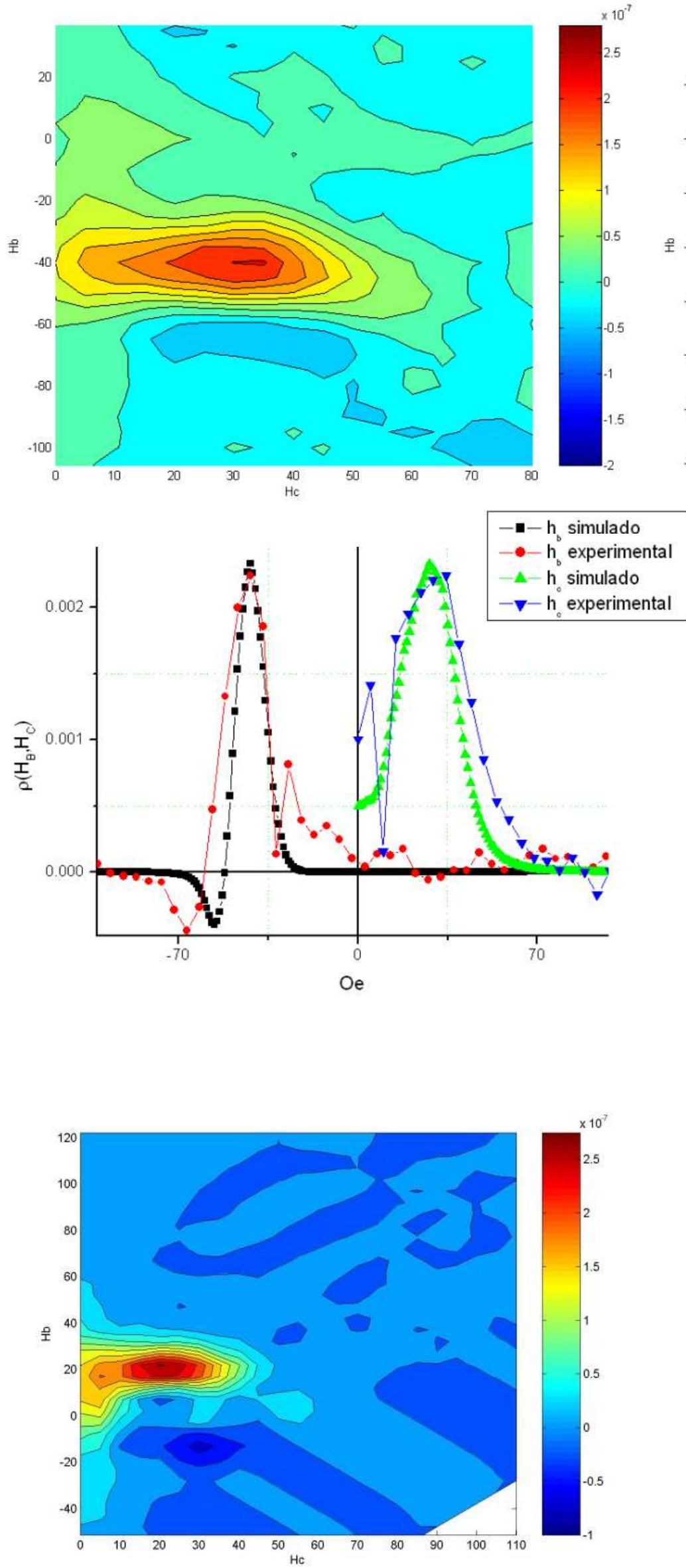
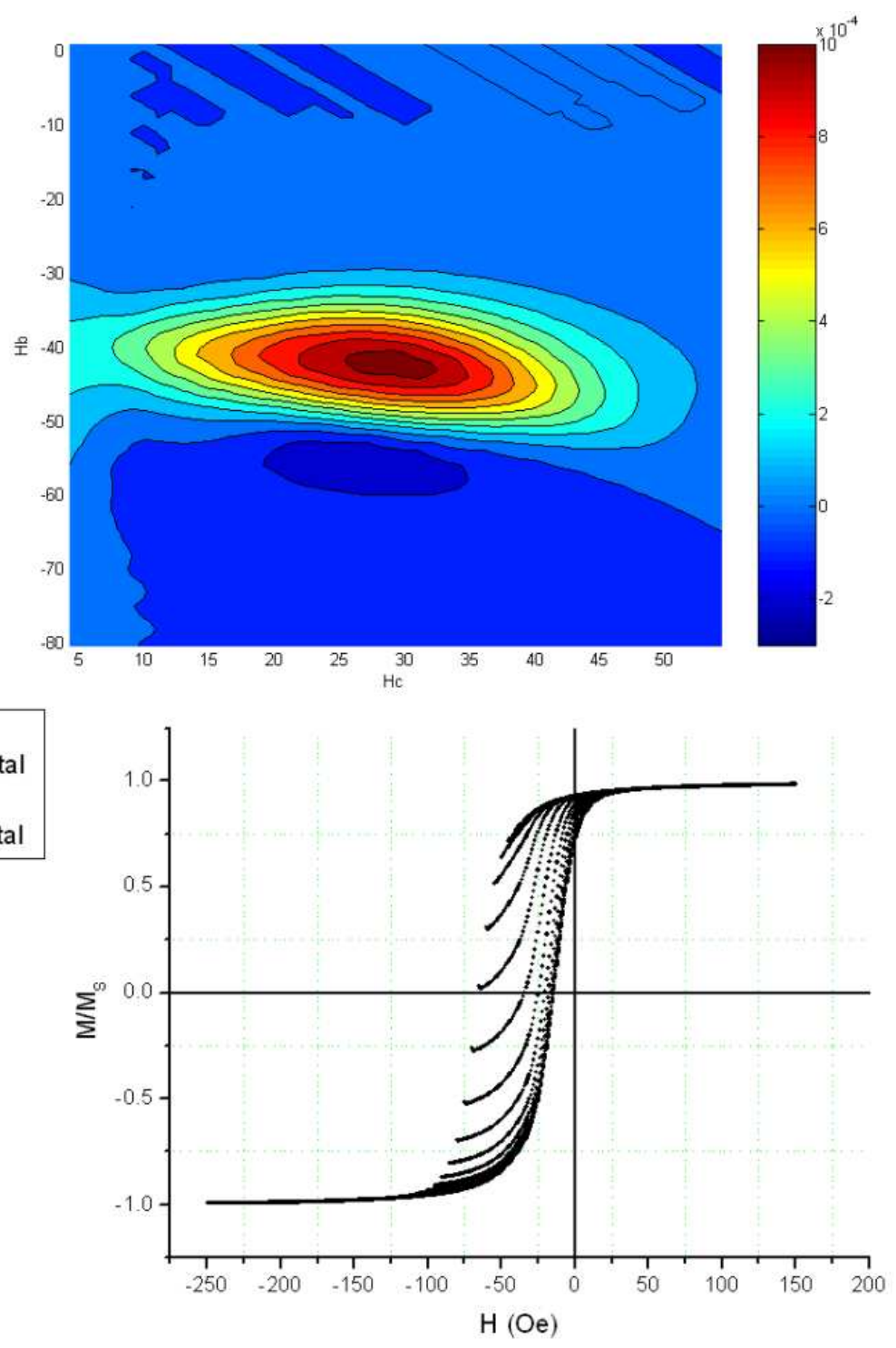

Figura 4.15 - Amostra B. Diagrama de FORCs experimental (à esquerda) e sua simulação (à direita). Abaixo, curvas sob o pico de $h_{b}$ e $h_{c}$ dos diagramas, juntamente com as FORCs simuladas. Ao lado, o diagrama de FORCs experimental para $\mathrm{H}$ orientado antiparalelamente ao eixo de anisotropia unidirecional da amostra. 

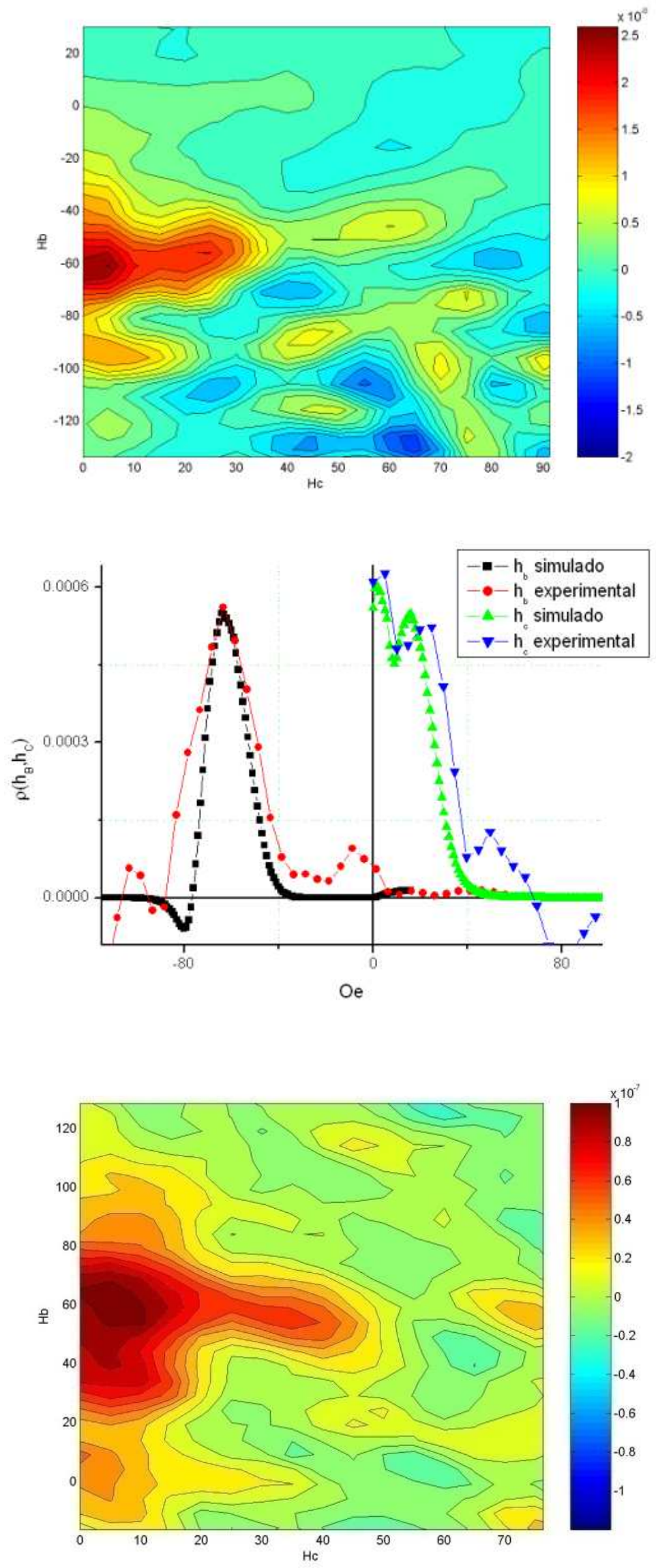
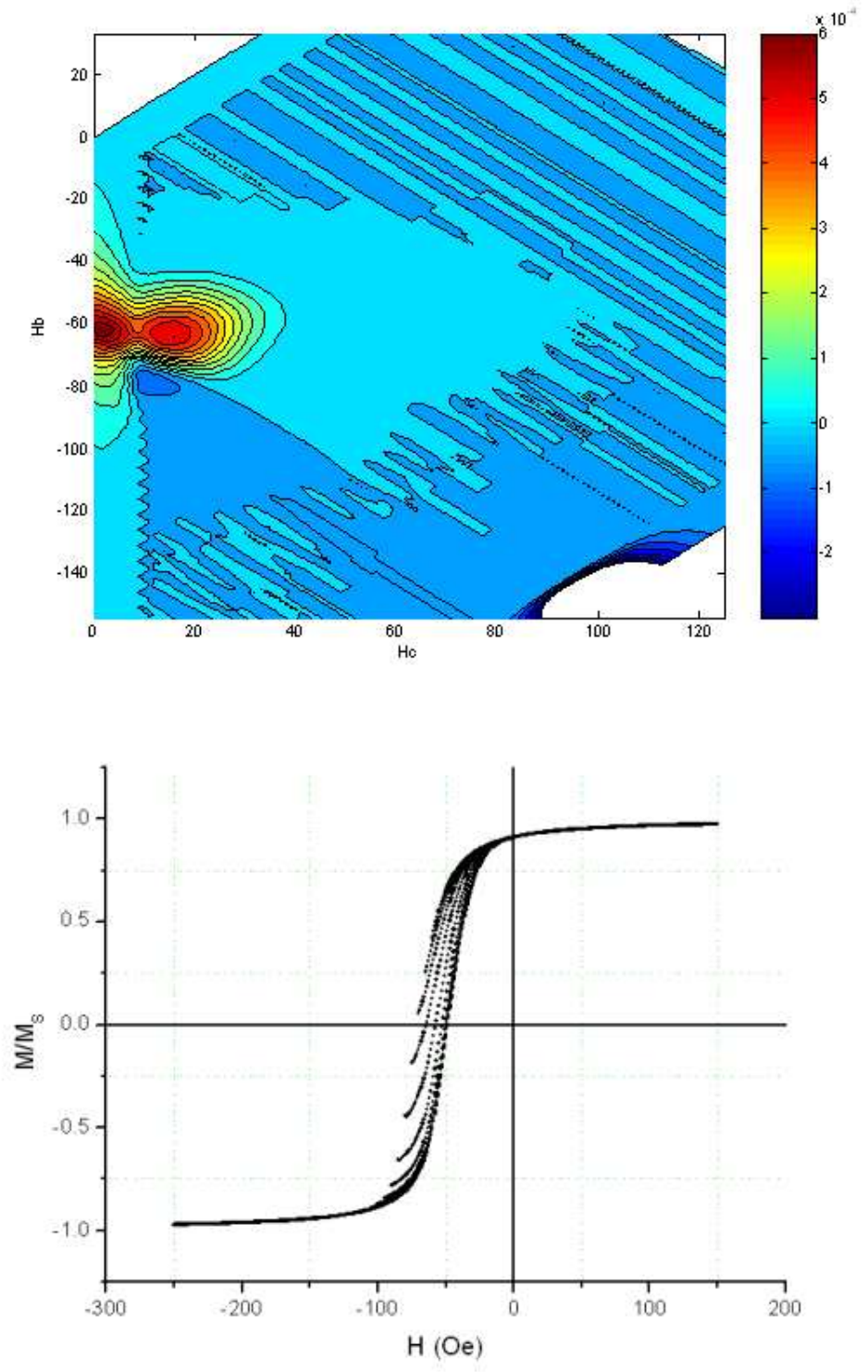

Figura 4.16 - Amostra C. Diagrama de FORCs experimental (à esquerda) e sua simulação (à direita). Abaixo, curvas sob o pico de $h_{b}$ e $h_{c}$ dos diagramas, juntamente com as FORCs simuladas. Ao lado, o diagrama de FORCs experimental para $\mathrm{H}$ orientado antiparalelamente ao eixo de anisotropia unidirecional da amostra. 

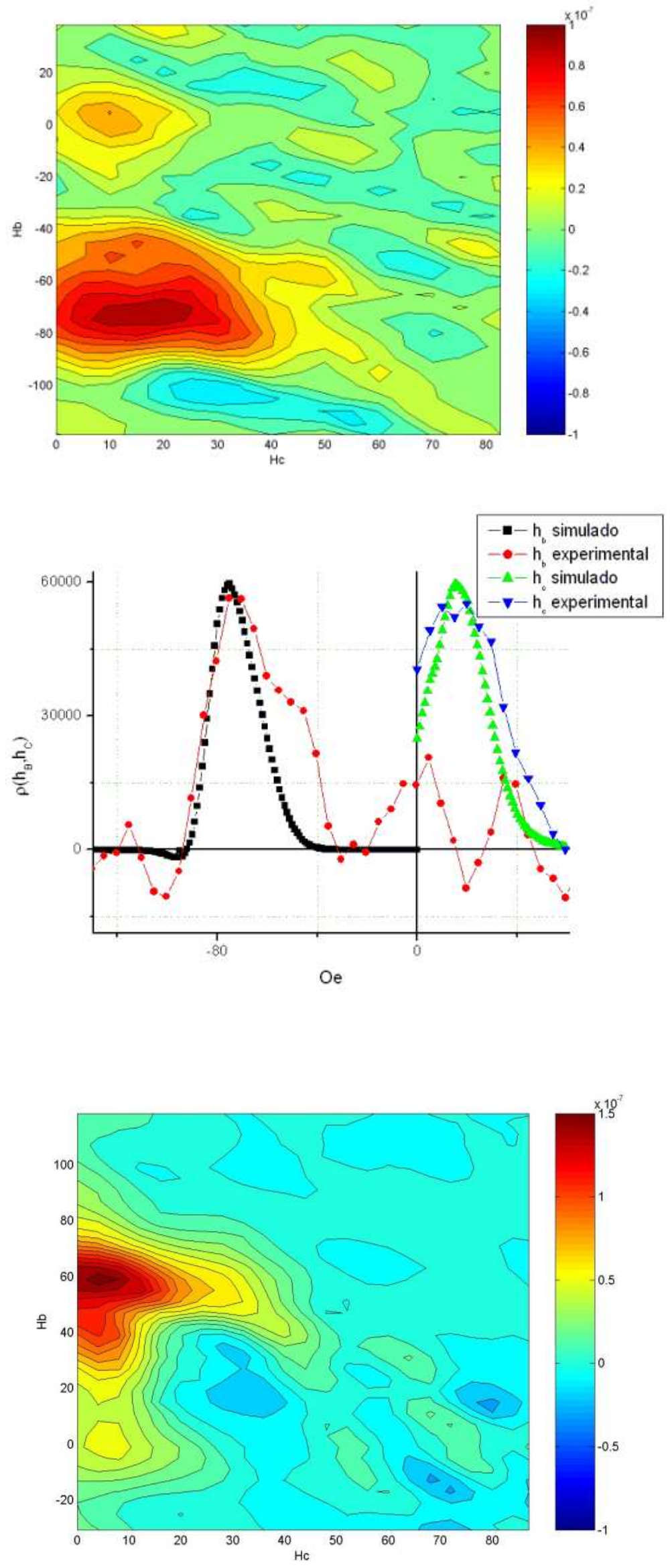
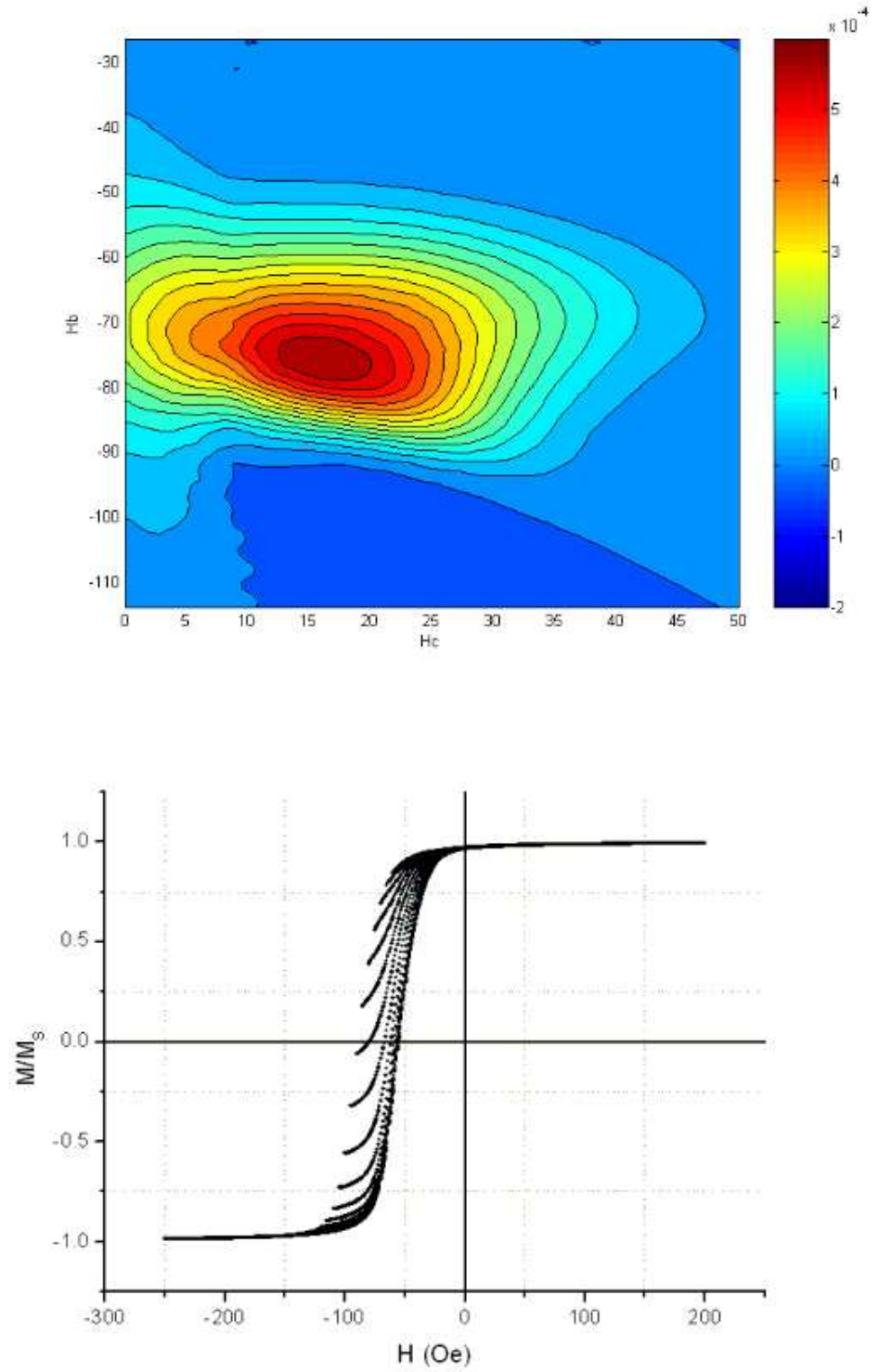

Figura 4.17 - Amostra D. Diagrama de FORCs experimental (à esquerda) e sua simulação (à direita). Abaixo, curvas sob o pico de $h_{b}$ e $h_{c}$ dos diagramas, juntamente com as FORCs simuladas. Ao lado, o diagrama de FORCs experimental para $\mathrm{H}$ orientado antiparalelamente ao eixo de anisotropia unidirecional da amostra. 

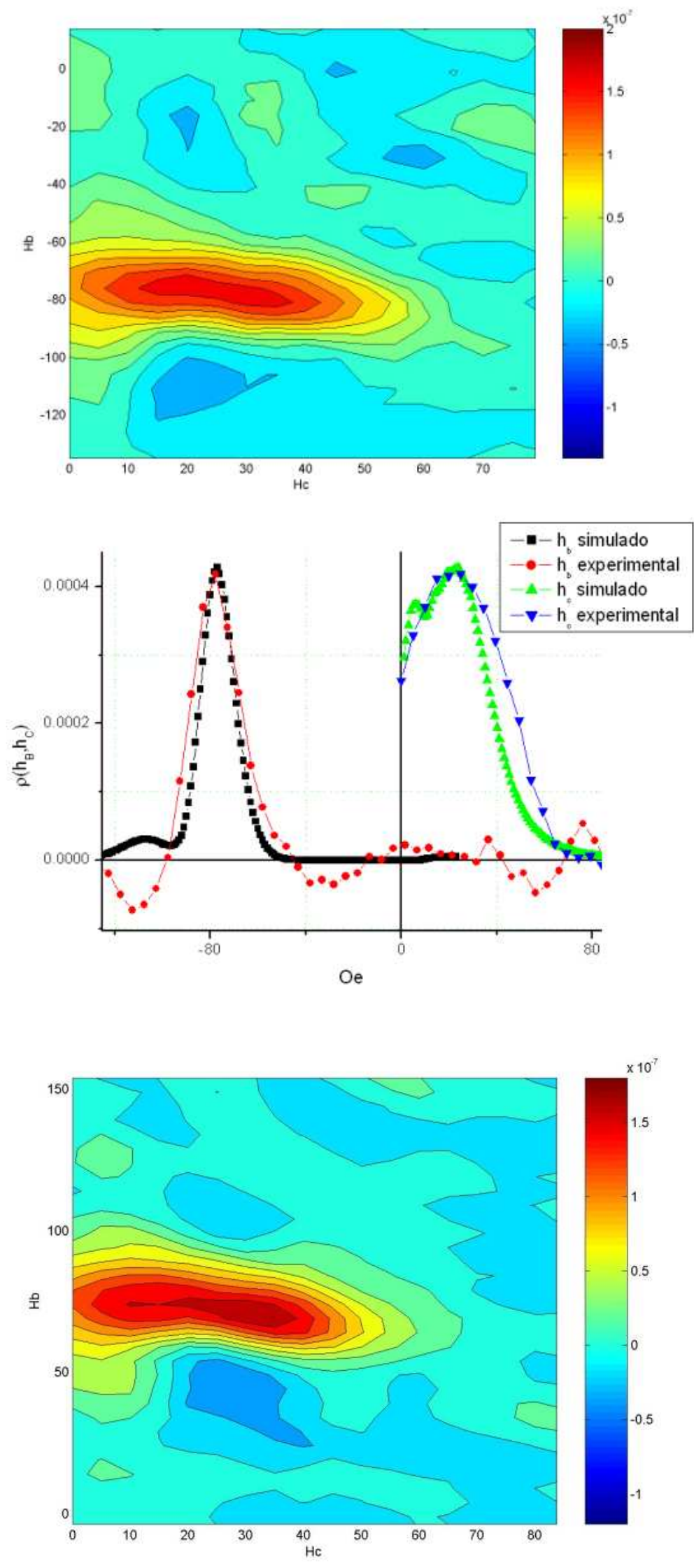
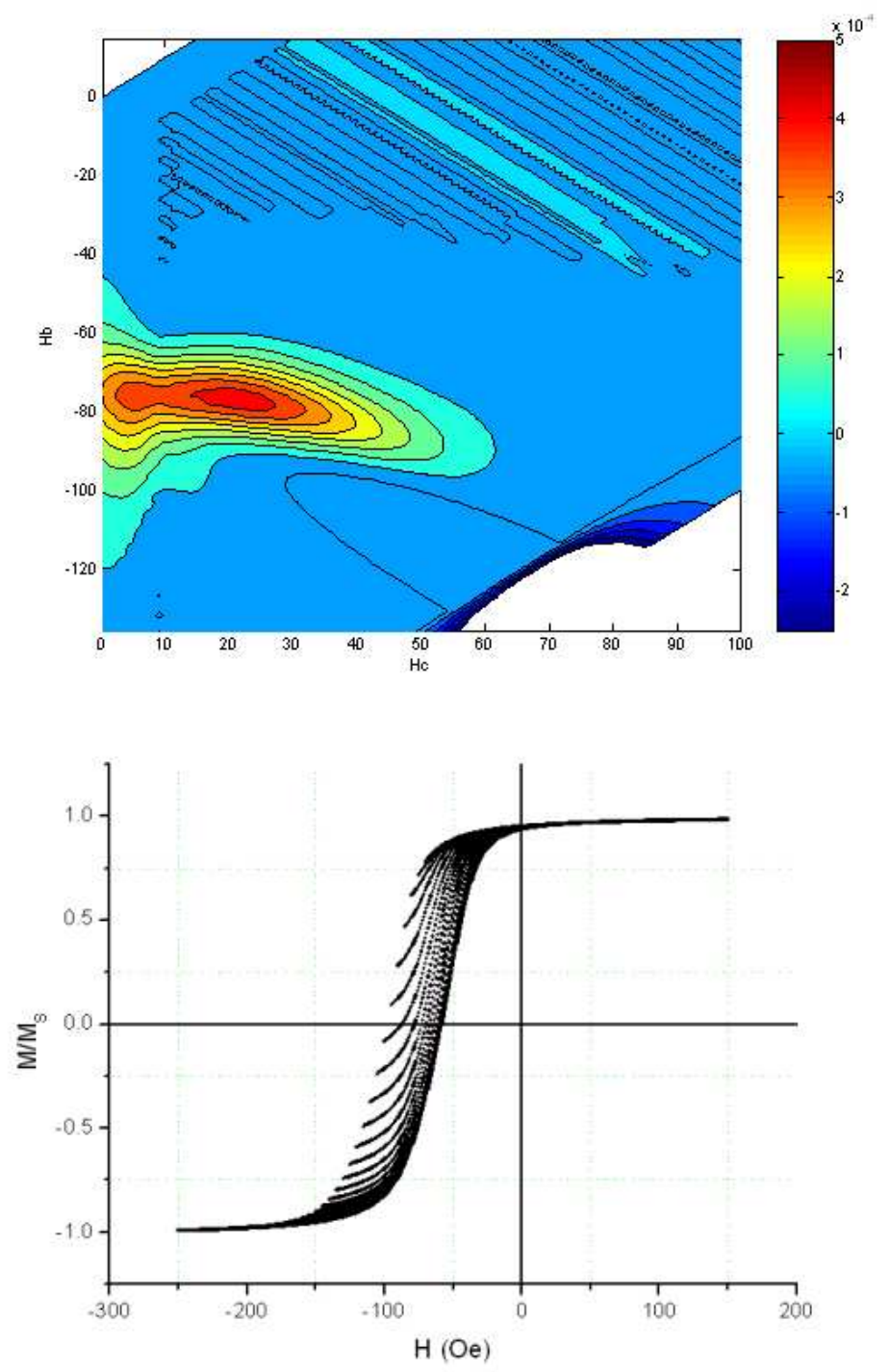

Figura 4.18 - Amostra E. Diagrama de FORCs experimental (à esquerda) e sua simulação (à direita). Abaixo, curvas sob o pico de $h_{b}$ e $h_{c}$ dos diagramas, juntamente com as FORCs simuladas. Ao lado, o diagrama de FORCs experimental para $\mathrm{H}$ orientado antiparalelamente ao eixo de anisotropia unidirecional da amostra. 

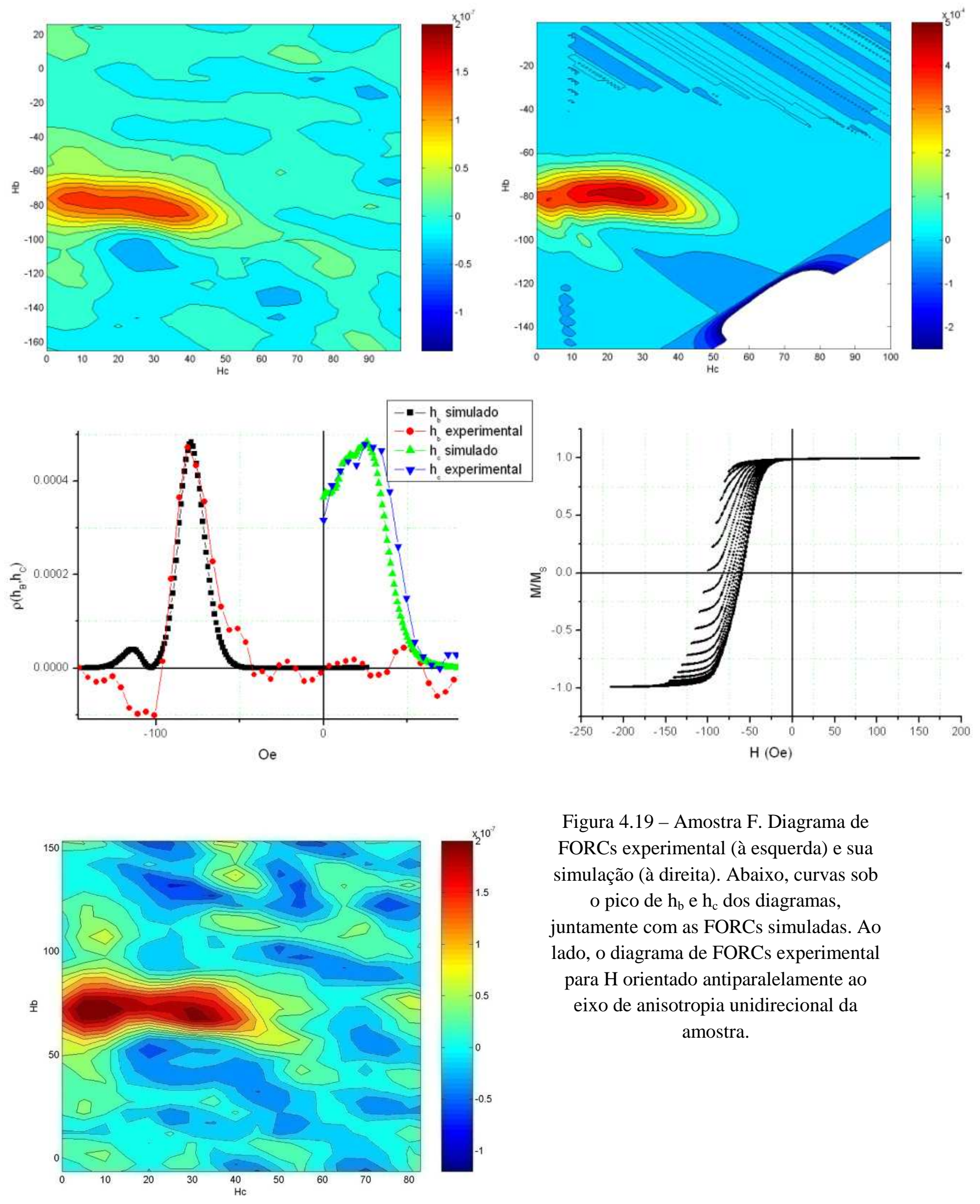

Figura 4.19 - Amostra F. Diagrama de FORCs experimental (à esquerda) e sua simulação (à direita). Abaixo, curvas sob o pico de $h_{b}$ e $h_{c}$ dos diagramas, juntamente com as FORCs simuladas. Ao lado, o diagrama de FORCs experimental para $\mathrm{H}$ orientado antiparalelamente ao eixo de anisotropia unidirecional da amostra. 

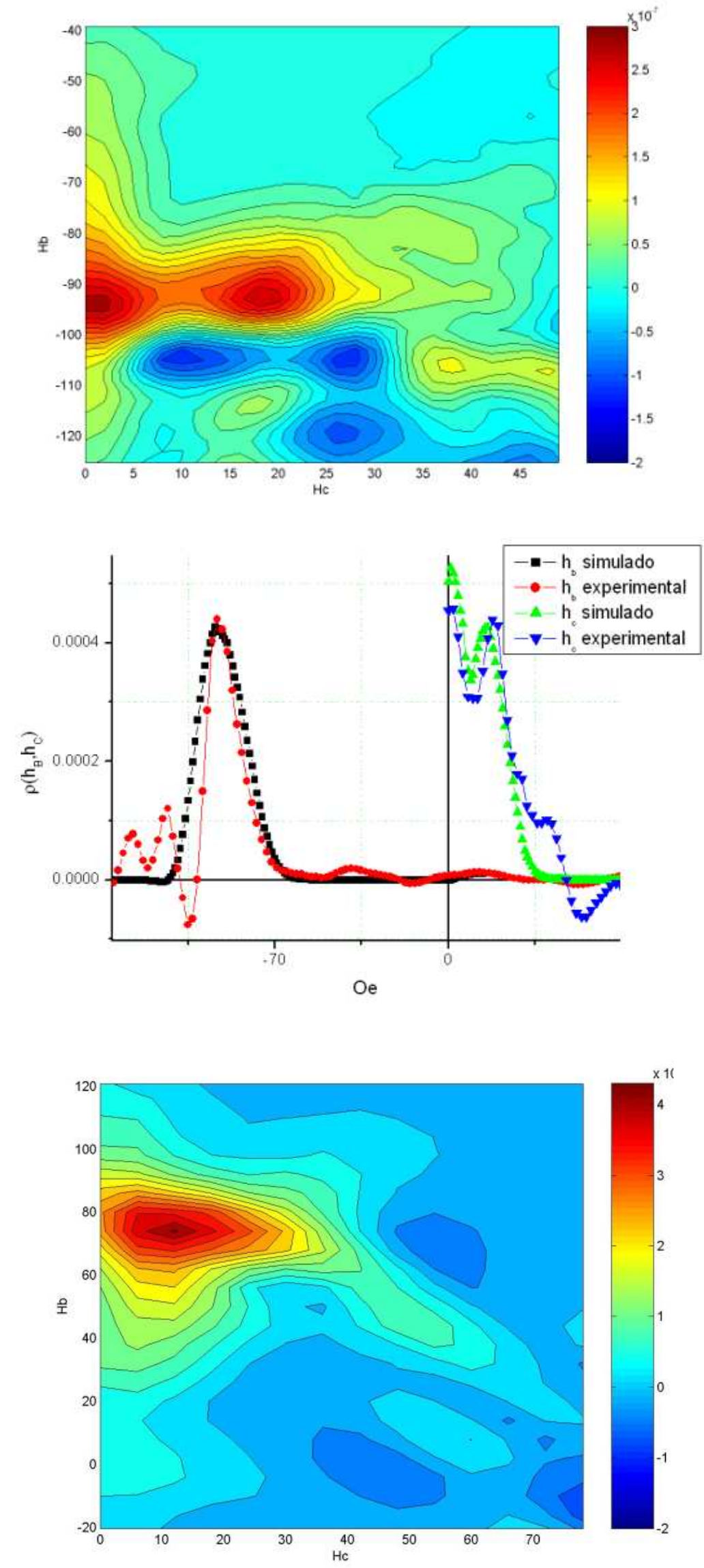
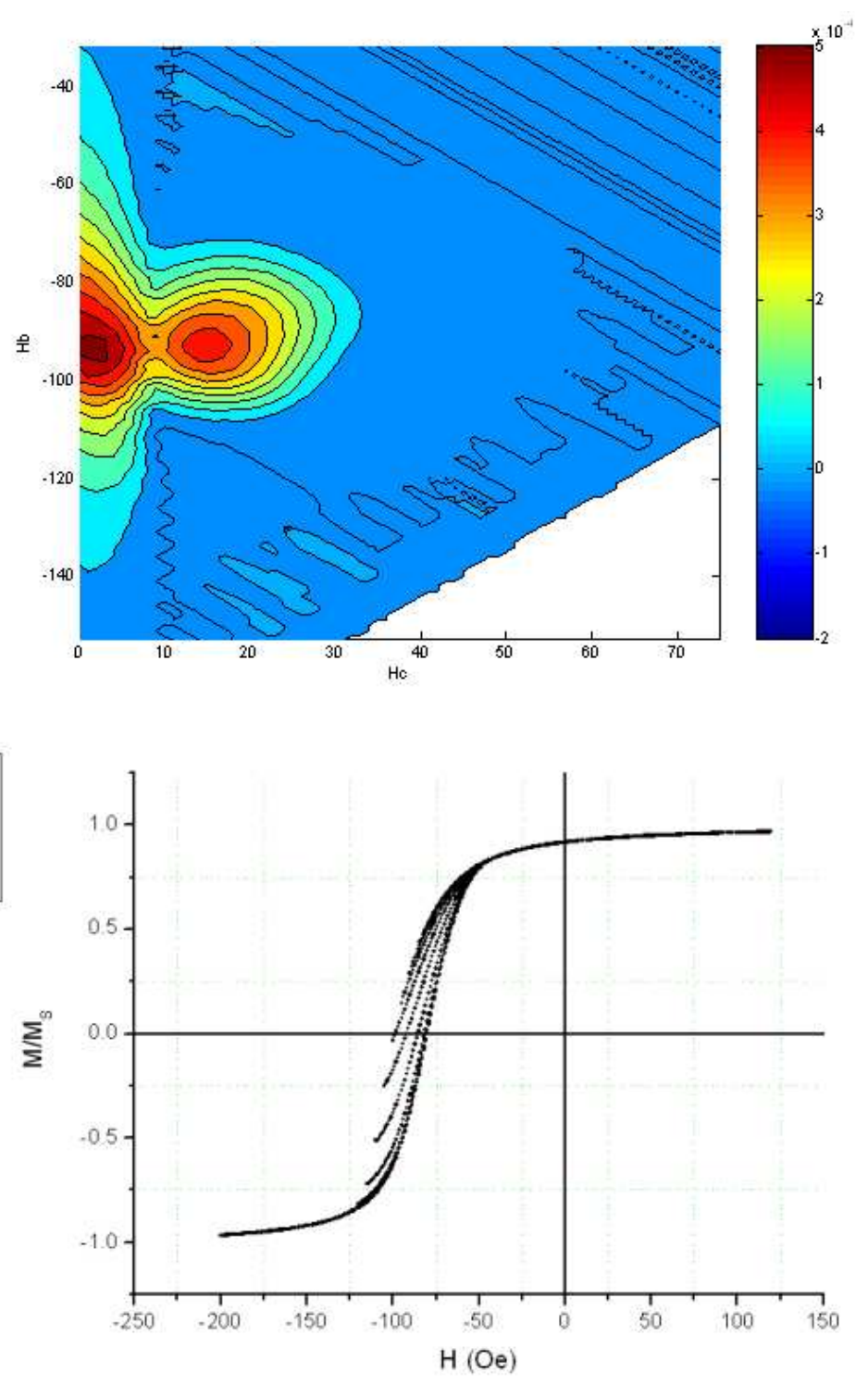

Figura 4.20 - Amostra G. Diagrama de FORCs experimental (à esquerda) e sua simulação (à direita). Abaixo, curvas sob o pico de $h_{b}$ e $h_{c}$ dos diagramas, juntamente com as FORCs simuladas. Ao lado, o diagrama de FORCs experimental para $\mathrm{H}$ orientado antiparalelamente ao eixo de anisotropia unidirecional da amostra. 

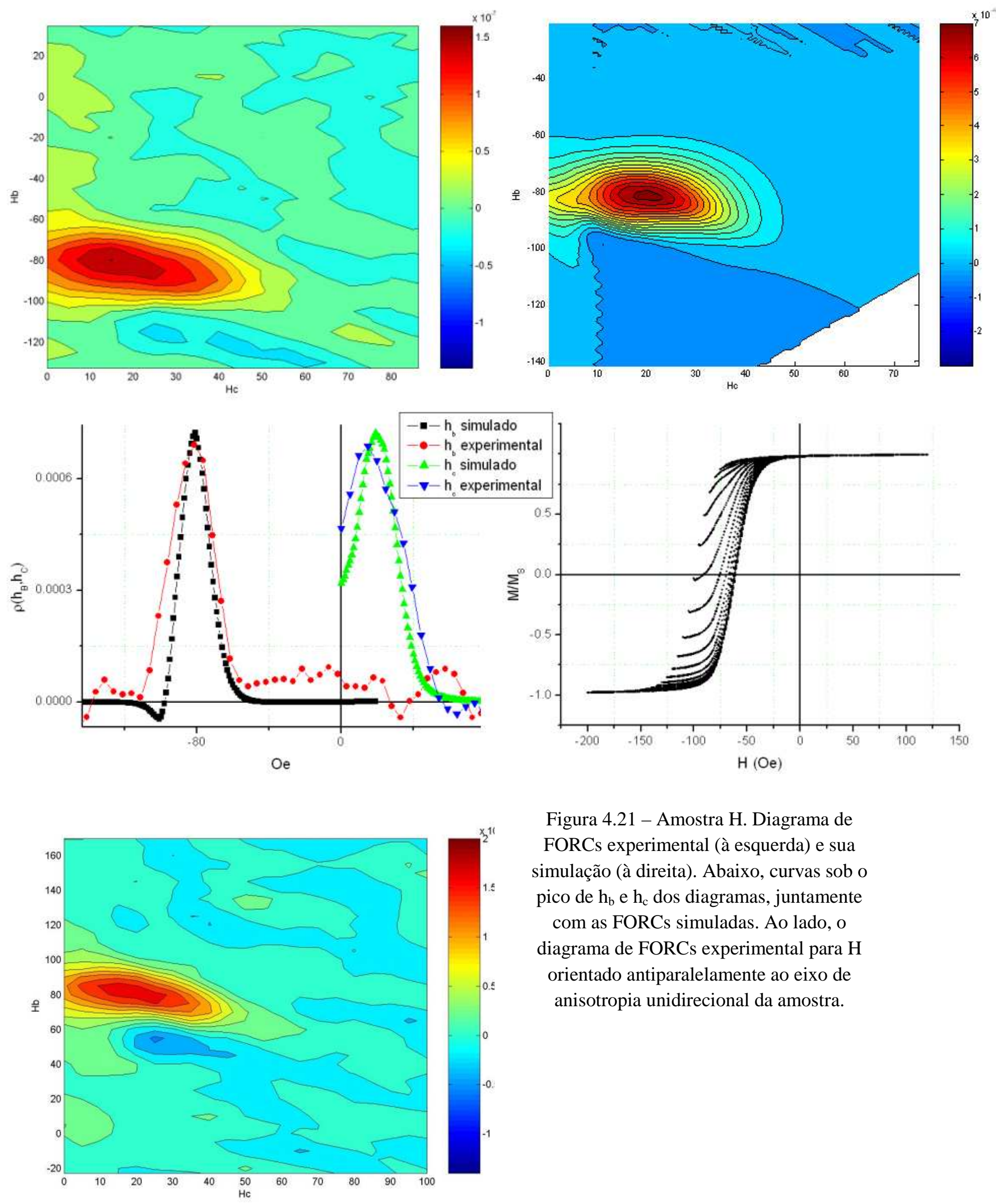

Figura 4.21 - Amostra H. Diagrama de FORCs experimental (à esquerda) e sua simulação (à direita). Abaixo, curvas sob o pico de $h_{b}$ e $h_{c}$ dos diagramas, juntamente com as FORCs simuladas. Ao lado, o diagrama de FORCs experimental para $\mathrm{H}$ orientado antiparalelamente ao eixo de anisotropia unidirecional da amostra. 

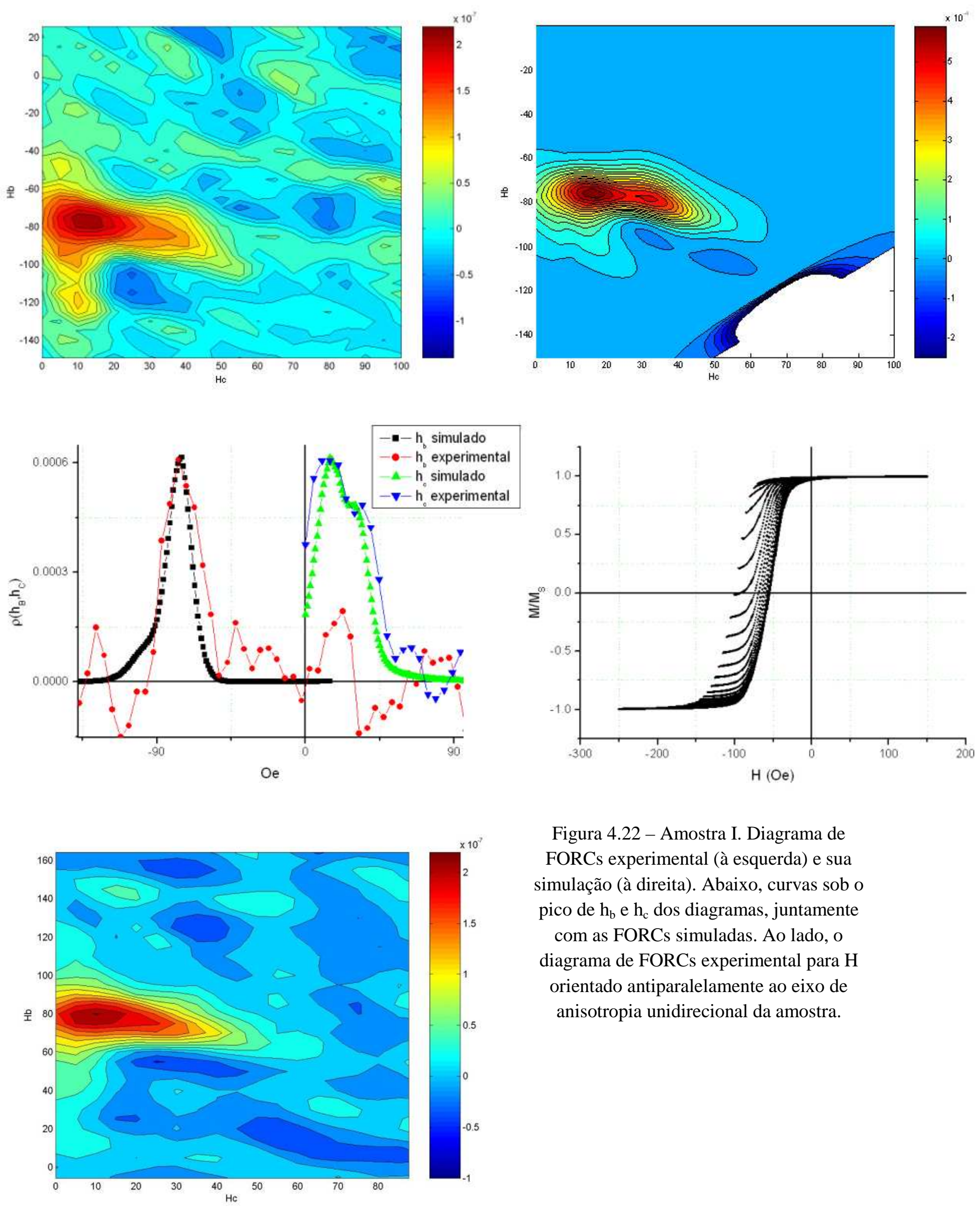

Figura 4.22 - Amostra I. Diagrama de FORCs experimental (à esquerda) e sua simulação (à direita). Abaixo, curvas sob o pico de $h_{b}$ e $h_{c}$ dos diagramas, juntamente com as FORCs simuladas. Ao lado, o diagrama de FORCs experimental para $\mathrm{H}$ orientado antiparalelamente ao eixo de anisotropia unidirecional da amostra. 
As curvas simuladas de $h_{b}$ e $h_{c}$ nos picos dos diagramas evidenciam larguras maiores que nos resultados experimentais. Isto foi propositalmente feito, pois os diagramas experimentais foram construídos com um Smooth Factor (SF)[53] $\geq 3$, que é uma ferramenta matemática usada para a diminuição do ruído, uma vez que ele faz ajustes matemáticos de amortização nos pontos baseados num quadrado com vizinhos (interpolação). Uma característica negativa do SF é a suavização das curvas, fazendo com que elas fiquem mais largas, e quanto maior for seu valor, mais suaves e largas elas ficarão. Para compensar essa falha, pode-se criar diagramas das simulações com larguras um pouco menores que as obtidas experimentalmente com $\mathrm{SF} \geq 2$. $\mathrm{O}$ valor exato da correção não foi matematizado, mas um ajuste visual foi feito, com o critério de produzir linhas teóricas tangenciando as experimentais. Um outro método possível seria utilizar o mesmo SF que foi empregado à uma medida em uma amostra para a simulação da mesma e, através de ajustes de parâmetros, coincidir as curvas teóricas e experimentais em $\mathrm{h}_{\mathrm{b}}$ e $\mathrm{h}_{\mathrm{c}}$.

Observa-se tanto nos diagramas experimentais quanto nos simulados regiões negativas, que podem ser atribuídas aos efeitos de viscosidade magnética, e, além disto, observa-se também uma quebra de simetria para pequenos valores de $h_{c}$, evidente na figura 4.22 , por exemplo. Atribui-se a distorção dos campos de interação e de inversão, e inclusive uma contribuição na viscosidade magnética, à influência de $\alpha$. Assim, para $\alpha=0$, espera-se um diagrama com uma quebra de simetria apenas provocada pela viscosidade magnética. Desta forma, é possível determinar $\alpha$ também utilizando apenas os diagramas FORCs. Conclui-se então que as assimetrias observadas em curvas de magnetização são refletidas nos diagramas obtidos pela simulação do modelo de Preisach.

Através das simulações, foi possível também observar semelhanças entre as FORCs teóricas e experimentais (fig. 4.23), evidenciando que o modelo móvel de Preisach com Exchange Bias descreve corretamente o comportamento magnético das amostras estudadas.
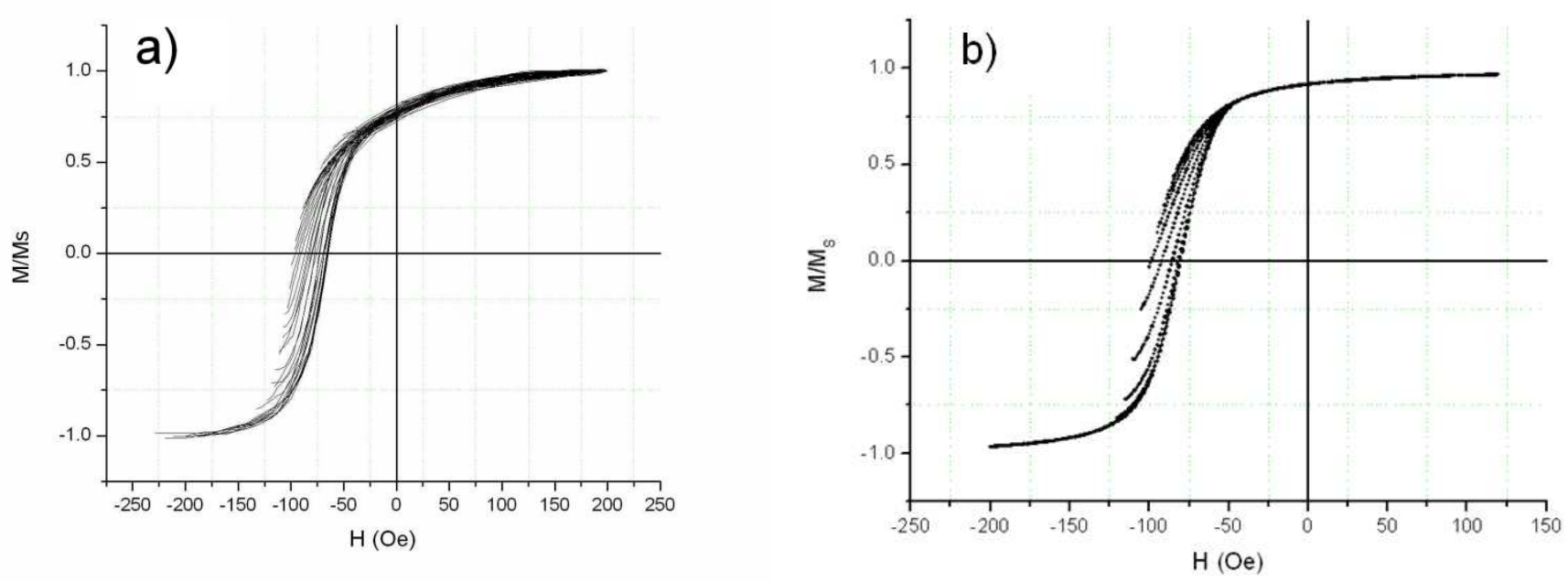

Figura 4.23 - a) FORCs obtidas experimentalmente através do VSM para a amostra G e b) FORCs obtidas através do modelo móvel de Preisach com Exchange Bias para a amostra G.

De forma qualitativa, observa-se uma equivalência entre os diagramas FORCs obtidos com os eixos de anisotropia paralelos ( $\mathrm{H}_{\mathrm{EB}}$ 's negativos) e antiparalelos ( $\mathrm{H}_{\mathrm{EB}}$ 's positivos) ao campo H aplicado, sendo assim possível supor que os campos de inversão e de interação sejam parecidos às duas possibilidades de alinhamento e que estejam correlacionados de alguma forma 
com a variação da espessura da camada de FeMn. Relacionando as larguras das distribuições simuladas $\left(\sigma_{\mathrm{s}}^{\prime}\right)$ com os valores de $\mathrm{H}_{\mathrm{EB}}$, pode-se comparar mais profundamente o comportamento dos campos de interação (fig. 4.24). De maneira geral, espera-se a obtenção de parâmetros equivalentes tanto para as medições com $\mathrm{H}_{\mathrm{EB}}$ positivo quanto para as negativas. Este foi um critério utilizado para que as simulações fossem feitas para o alinhamento do eixo de anisotropia paralelamente ao campo aplicado, sendo desnecessário reproduzir os resultados de forma antiparalela.

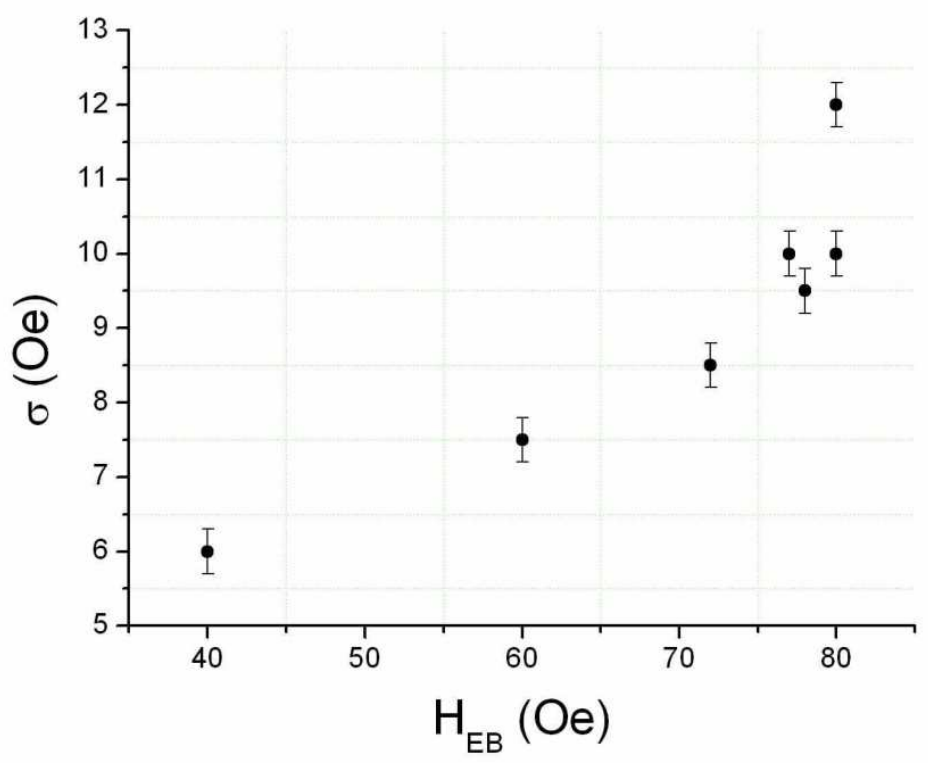

Figura 4.24 - Larguras obtidas pelas simulações dos picos em $\mathrm{h}_{\mathrm{b}}$ em função de $\mathrm{H}_{\mathrm{EB}}$ dos diagramas. A medida da amostra $\mathrm{G}$ foi excluída.

Observa-se na figura 4.24 que, para altos valores de $\mathrm{H}_{\mathrm{EB}}\left(\mathrm{t}_{\mathrm{FeMn}} \geq 20 \mathrm{~nm}\right)$, as larguras convergem para um valor próximo à 10 Oe. Devido ao fato de a amostra $\mathrm{G}$ possuir valores inferiores nas espessuras de todas as camadas (tab. 2.3), observou-se um comportamento diferenciado para todos os parâmetros analisados, refletindo em medidas fora de qualquer tendência nos gráficos, sem a inclusão no comportamento dinâmico das variáveis analisadas. A análise da amostra $G$ foi excluída dos gráficos. Para baixos valores de $\mathrm{H}_{\mathrm{EB}}\left(\mathrm{t}_{\mathrm{FeMn}} \leq 5 \mathrm{~nm}\right)$, vê-se que a largura converge para zero. Isto se deve ao fato de o NiFe ser menos influenciado pela camada antiferromagnética quando a mesma é pouco espessa, tendendo a assumir um comportamento próprio do Permalloy, ou seja, com um baixo valor dos campos de interação, resultando em uma anisotropia pequena. A convergência para altas espessuras revela que, na junção $\mathrm{AF} / \mathrm{FM}$, as estruturas mais afastadas já não influenciam tanto o valor de $\mathrm{H}_{\mathrm{EB}} \mathrm{e}$ os campos de interação das partículas magnéticas.

As simulações das curvas de magnetização permitiram a determinação do parâmetro $\alpha$ através da equação 3.7. Os efeitos assimétricos das curvas foram reproduzidos, resultando nas figuras 4.25 e 4.26 . 


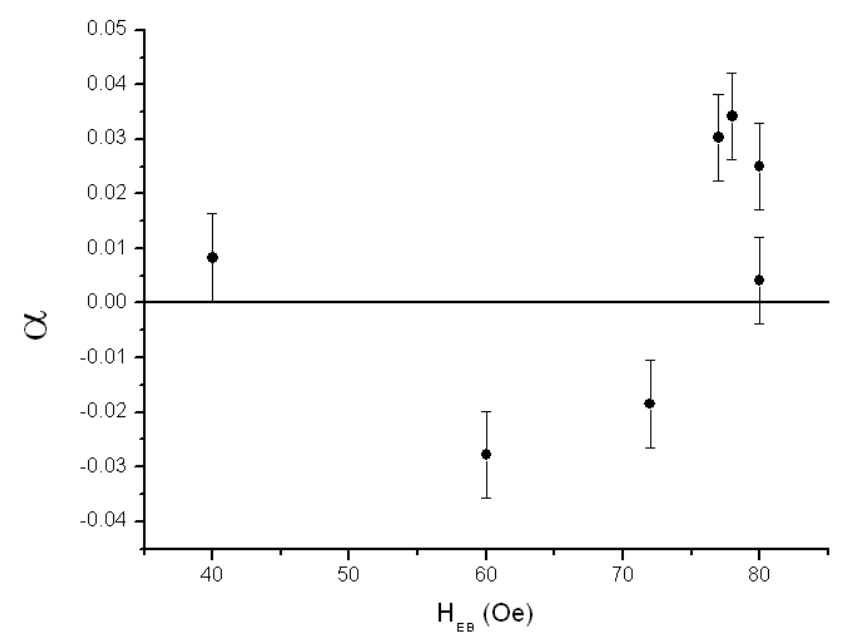

Figura 4.25 - analise do parâmetro $\alpha$ em função de $\mathrm{H}_{\mathrm{EB}}$.

Observa-se também uma convergência de $\alpha$ para um valor em torno de 0,035, evidenciando que, para $\mathrm{H}_{\mathrm{EB}} \approx 80$ Oe $\left(\mathrm{t}_{\mathrm{FeMn}} \geq 20 \mathrm{~nm}\right)$, as configurações de spins mais afastadas da interface $\mathrm{AF} / \mathrm{FM}$ não são mais determinantes nas interações com o material ferromagnético, estando em acordo com o comportamento de saturação das larguras à meia altura. Observa-se também que para baixos valores de $\mathrm{H}_{\mathrm{EB}}$, ou seja, pequenas espessuras do FeMn, $\alpha$ tende a zero, apresentando valores negativos para espessuras no intervalo $7 \mathrm{~nm} \leq \mathrm{t}_{\mathrm{FeMn}} \leq 10 \mathrm{~nm}$. Uma outra descrição é mostrada na figura 4.26. Nela, observa-se diretamente a dependência de $\alpha$ com a espessura do $\mathrm{FeMn}$, com o $\mathrm{NiFe}$ à $10 \mathrm{~nm}$. Assim, espera-se um valor próximo de zero ou negativo para baixas espessuras e valores positivos para altas espessuras.

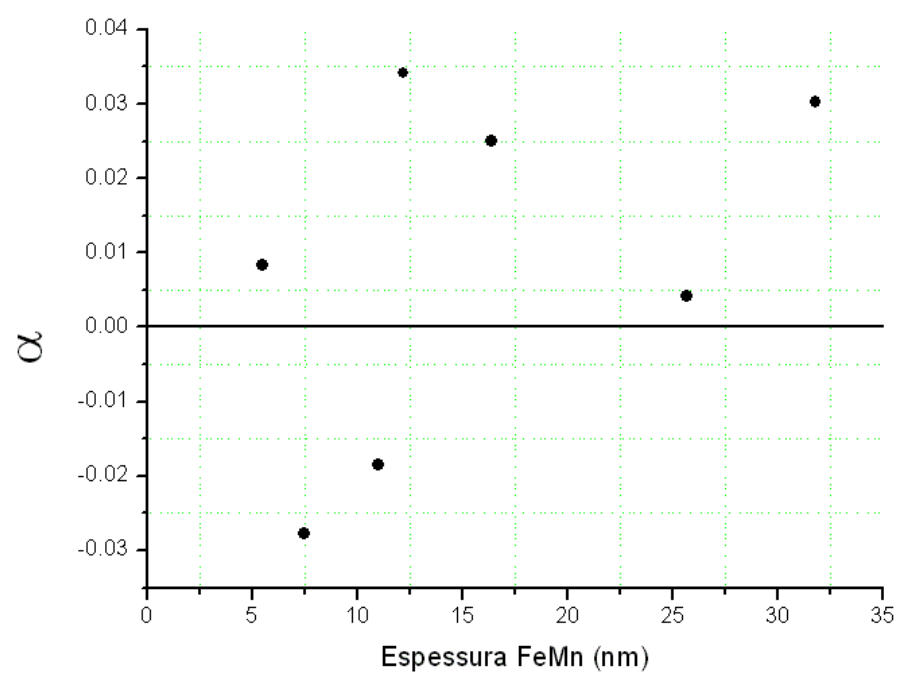

Figura 4.26 - Valores obtidos para o coeficiente $\alpha$ em função da espessura

Uma outra análise dos parâmetros da simulação é a de relacionar o parâmetro $\mathrm{k}_{1}$ (adimensional) da equação 3.9, responsável pelo termo linear da contribuição de $\mathrm{M}$ para o 
campo efetivo, com $\mathrm{H}_{\mathrm{EB}}$ (fig. 4.27). Pode-se observar um valor considerável de $\mathrm{k}_{1}$ para pequenos valores de $\mathrm{H}_{\mathrm{EB}}$ e uma tendência de convergência para zero quando $\mathrm{H}_{\mathrm{EB}}$ atinge a saturação, revelando que, para a saturação do $\mathrm{H}_{\mathrm{EB}}$, a componente desmagnetizante compete com a magnetizante e, para baixos valores de $\mathrm{H}_{\mathrm{EB}}<$ teremos a componente magnetizante dominante. Há um ponto fora da tendência, que também pode ser observado em todos os outros gráficos, que se refere à amostra $\mathrm{H}$. Para ser possível compreender a dinâmica da relação, deve-se reproduzir todo o estudo para diferentes condições de espessuras das camadas, tornando esta relação válida apenas para as estruturas $\mathrm{Cu}(20 \mathrm{~nm}) / \mathrm{NiFe}(10 \mathrm{~nm}) / \mathrm{FeMn}(\mathrm{t}) / \mathrm{Ta}(10 \mathrm{~nm})$, com $\mathrm{t} \geq 5 \mathrm{~nm}$.

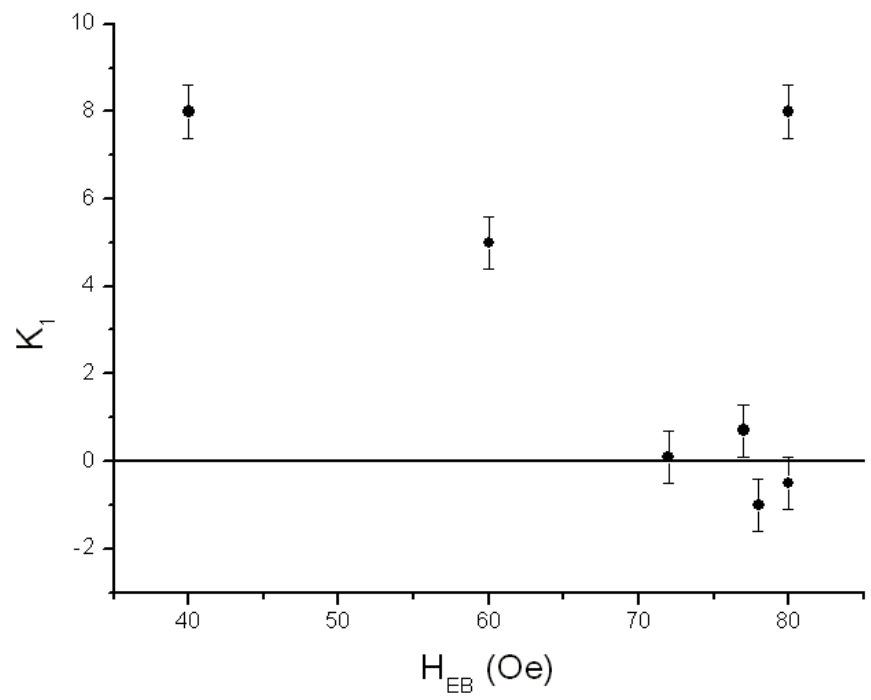

Figura $4.27-\mathrm{k}_{1}$ vs $\mathrm{H}_{\mathrm{EB}}$ obtidos através das simulações dos diagramas de FORCs.

Quanto à observação dos efeitos da componente reversível nos diagramas e nas curvas de magnetização, os parâmetros $\mathrm{A}$ e $\omega_{2}$ (eq. 3.1) foram ajustados nas simulações com base nos diagramas obtidos experimentalmente, revelando assim sua dependência com $\mathrm{H}_{\mathrm{EB}}$.
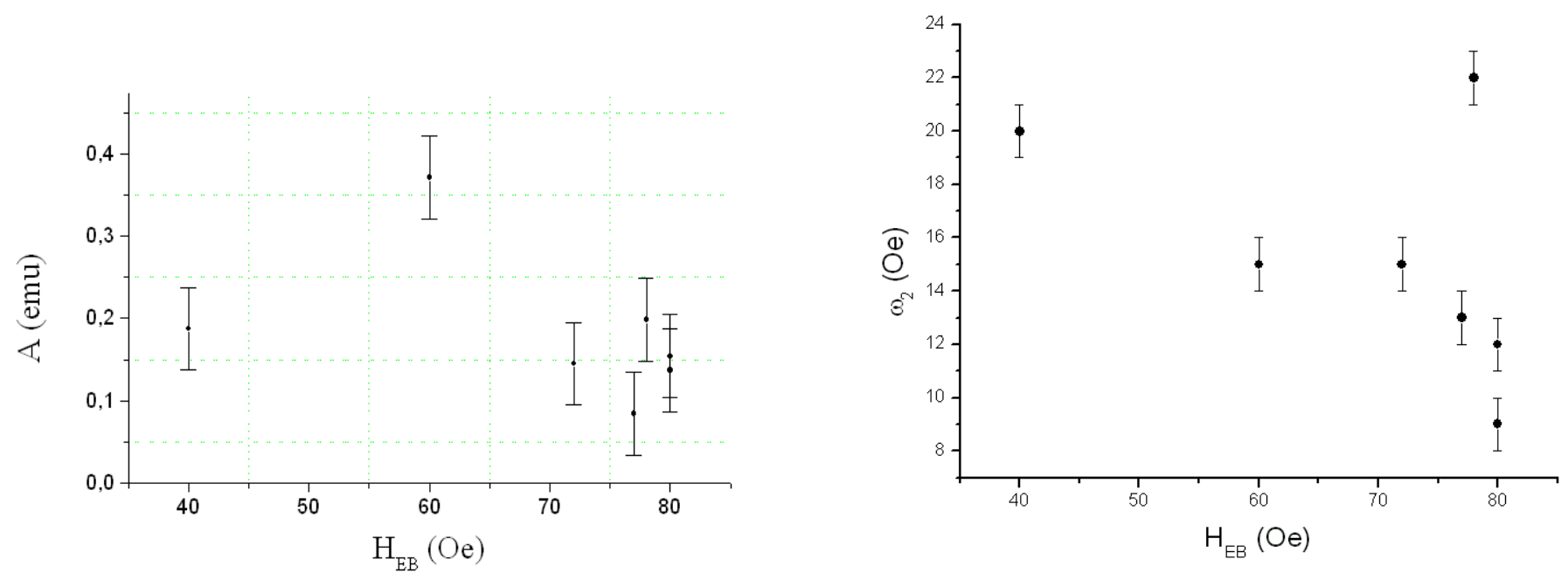

Figura 4.28 - Parâmetros A e $\omega_{2}$ da componente reversível de magnetização em função de $\mathrm{H}_{\mathrm{EB}}$. 
Os parâmetros revelam uma convergência dos mesmos com o aumento de $\mathrm{H}_{\mathrm{EB}}$, evidenciando novamente as propriedades originais do Permalloy, pois o mesmo possui coercividade praticamente nula $(\approx 1 \mathrm{Oe})$ na ausência de FeMn, tendo assim seu processo de magnetização dominado pela componente reversível. Assim, atribui-se a diminuição da componente reversível ao acréscimo da espessura da camada $\mathrm{AF}$ e, conseqüentemente, ao campo de Exchange Bias. Observa-se uma convergência de A próxima de $0.15 \mathrm{emu}$ e de $\omega_{2}$ próxima à 12 Oe. Novamente, o ajuste dos parâmetros da amostra G divergiu, evidenciando que se trata de uma amostra diferenciada do padrão.

\section{3 - Medidas em baixas temperaturas e efeitos do tratamento térmico}

$\mathrm{O}$ fato de as amostras B2 e I2 terem sido produzidas provém da não compatibilidade do orifício de introdução de amostras na bobina supercondutora (diâmetro de $\approx 8 \mathrm{~mm}$ ) com o tamanho das amostras B e I (dimensões laterais $\geq 10 \mathrm{~mm}$ ). De forma mais clara, a justificativa de novas amostras terem sido produzidas vêm do fato de que as antigas não entrariam na bobina supercondutora, sendo necessárias amostras menores.

$\mathrm{O}$ fator determinante de essas amostras terem sido selecionadas para o estudo à baixas temperaturas e submetidas ao tratamento térmico (TT) vêm do fato de possuírem parâmetros totalmente distintos entre elas, como grandes diferenças na componente reversível de magnetização, nas assimetrias e uma distinção evidente na distribuição em $\mathrm{h}_{\mathrm{b}}$.

Vale lembrar que as amostras supostamente idênticas não possuem os mesmos parâmetros como a coercividade e o campo de $\mathrm{H}_{\mathrm{EB}}$, pois esses valores sofrem pequenos desvios de um valor médio, fazendo com que as amostras B e B2, I e I2 sejam equiparadas comportamentalmente e não numericamente, através de comparações de diagramas e pela evolução térmica dos parâmetros analisados.

Assim, submetendo a amostra I2 a ciclos de histerese à diferentes temperaturas, foi possível observar mudanças na magnetização de saturação $M_{S}$, em $H_{E B}$ e em $H_{c}$ (fig. 4.29).

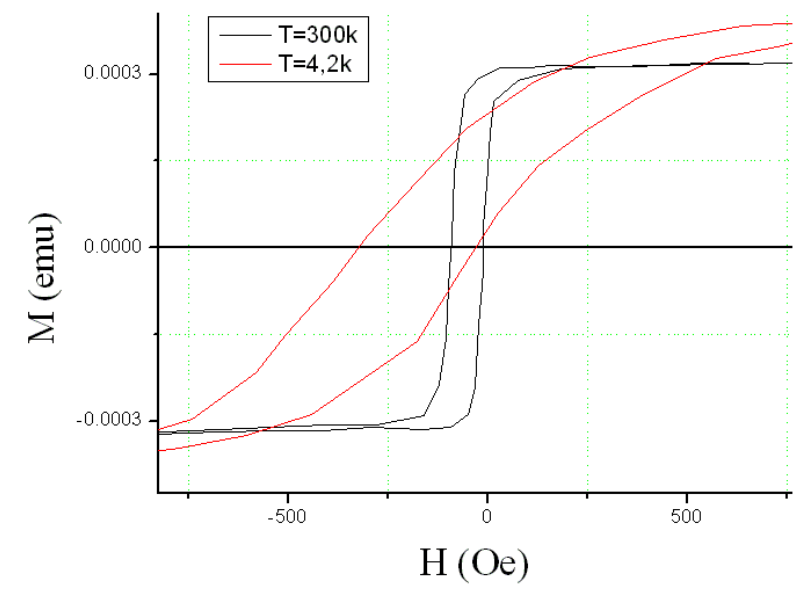

Figura 4.29 - Ciclos de histerese da amostra I2 à T=300k e T=4,2k a) Antes do tratamento térmico e b) Após o

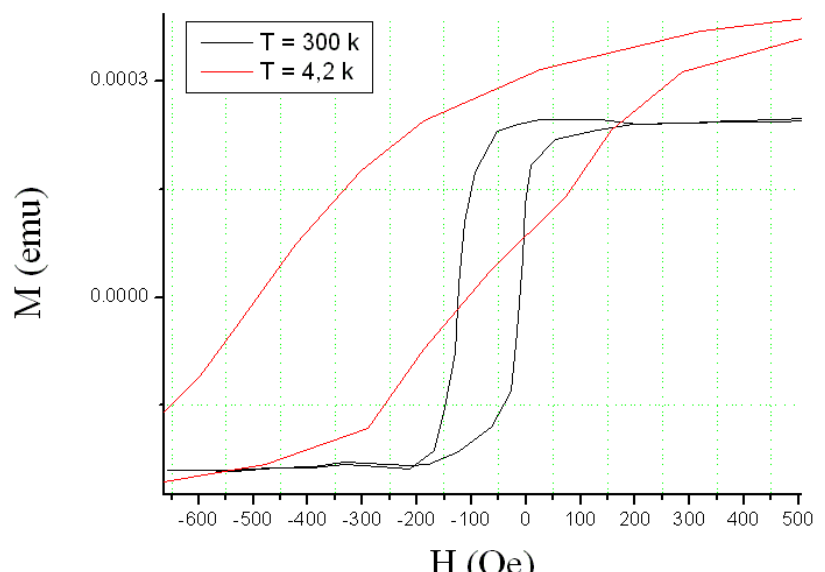

$\mathrm{H}(\mathrm{Oe})$ tratamento térmico.

b)

a) 
$\mathrm{H}_{\mathrm{C}}$ e o campo de $\mathrm{H}_{\mathrm{EB}}$ também puderam ser determinados, resultando na figura 4.30.
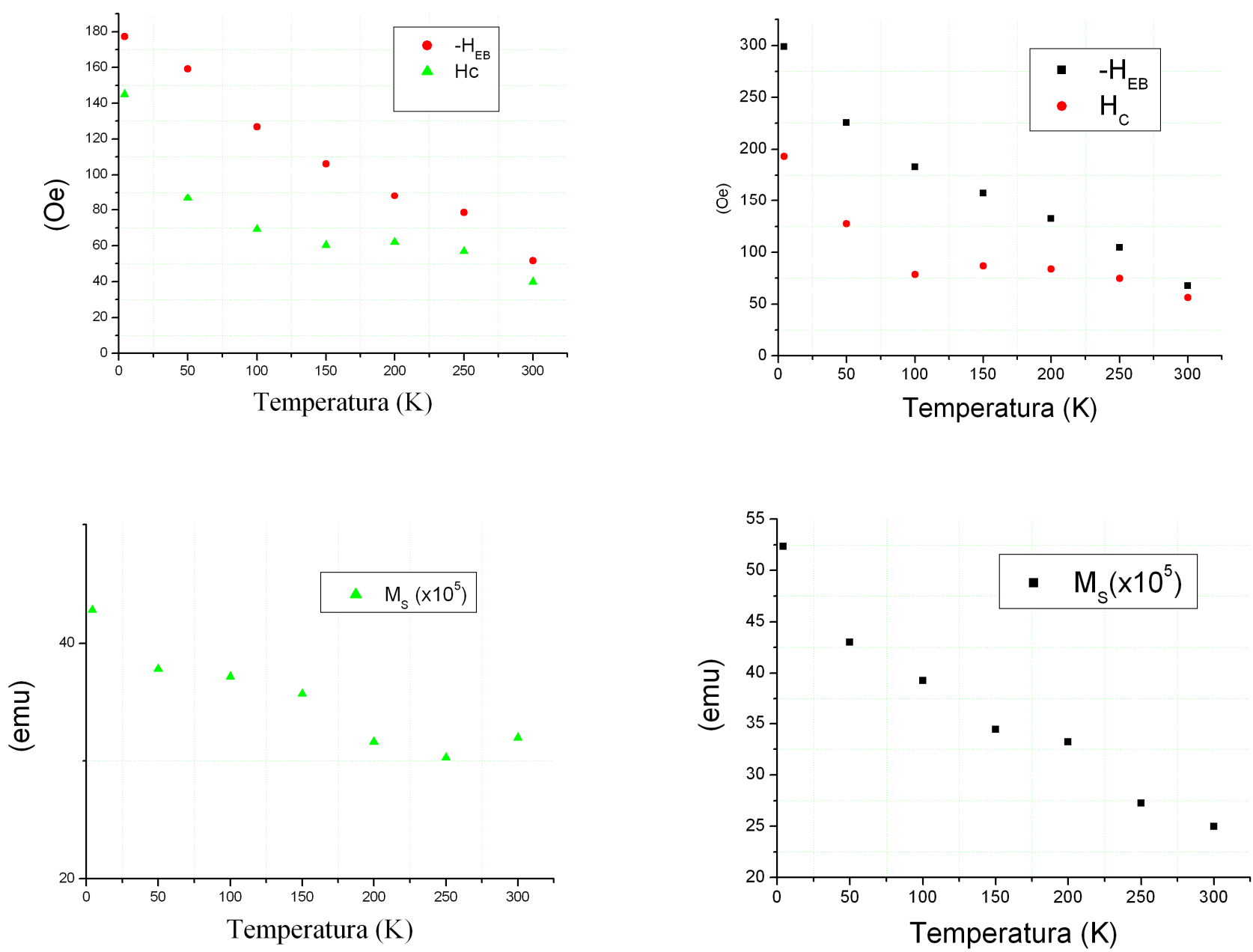

Figura 4.30 - - $\mathrm{H}_{\mathrm{EB}}, \mathrm{H}_{\mathrm{C}}$ e $\mathrm{M}_{\mathrm{S}}$ em função da temperatura para a amostra I2 antes do tratamento térmico (lado esquerdo) e após o tratamento térmico (lado direito).

Neste gráfico, observa-se que a magnetização decai quase que linearmente com o aumento da temperatura, evidenciando que, através da formulação $M(T) \sim\left(T_{C}-T\right)^{\beta}[48]$, a temperatura $T_{c}$ é muito maior que $300 \mathrm{~K}$, pois a região linear da mesma se dá para $\mathrm{T}<<\mathrm{T}_{\mathrm{C}}$. $\mathrm{H}_{\mathrm{EB}} \mathrm{e}$ $\mathrm{H}_{\mathrm{C}}$ também possuem um comportamento quase linear entre $4,2 \mathrm{~K}$ e $300 \mathrm{~K}$, como era esperado $[24,54]$. A princípio, espera-se um valor de $\mathrm{H}_{\mathrm{EB}}$ mais alto em amostras termicamente tratadas. Uma análise aceitável deste efeito pode ser feito através do estudo do parâmetro energético $\gamma_{\mathrm{AF}-\mathrm{FM}}$ do modelo de Preisach com Exchange Bias.

Pelo modelo de Preisach com Exchange Bias, atribui-se o aumento em $\mathrm{H}_{\mathrm{EB}}$ devido ao aumento da energia livre por unidade de área na interface AF/FM. Desta forma, pode-se determinar $\gamma_{\mathrm{AF}-\mathrm{FM}}$ em função da temperatura através da equação 3.8, pois, apesar de $\mathrm{T}$ não estar explícito na mesma, tem-se os valores empíricos de $\mathrm{H}_{\mathrm{EB}}$ e $\mathrm{M}_{\mathrm{S}}$ em função da temperatura. 
Tomando $\gamma_{0}$ como sendo seu valor para $\mathrm{T}=4,2 \mathrm{~K}$, teremos $\gamma(\mathrm{T})$ configurado para a amostra $\mathrm{I} 2$ na figura 4.31 .

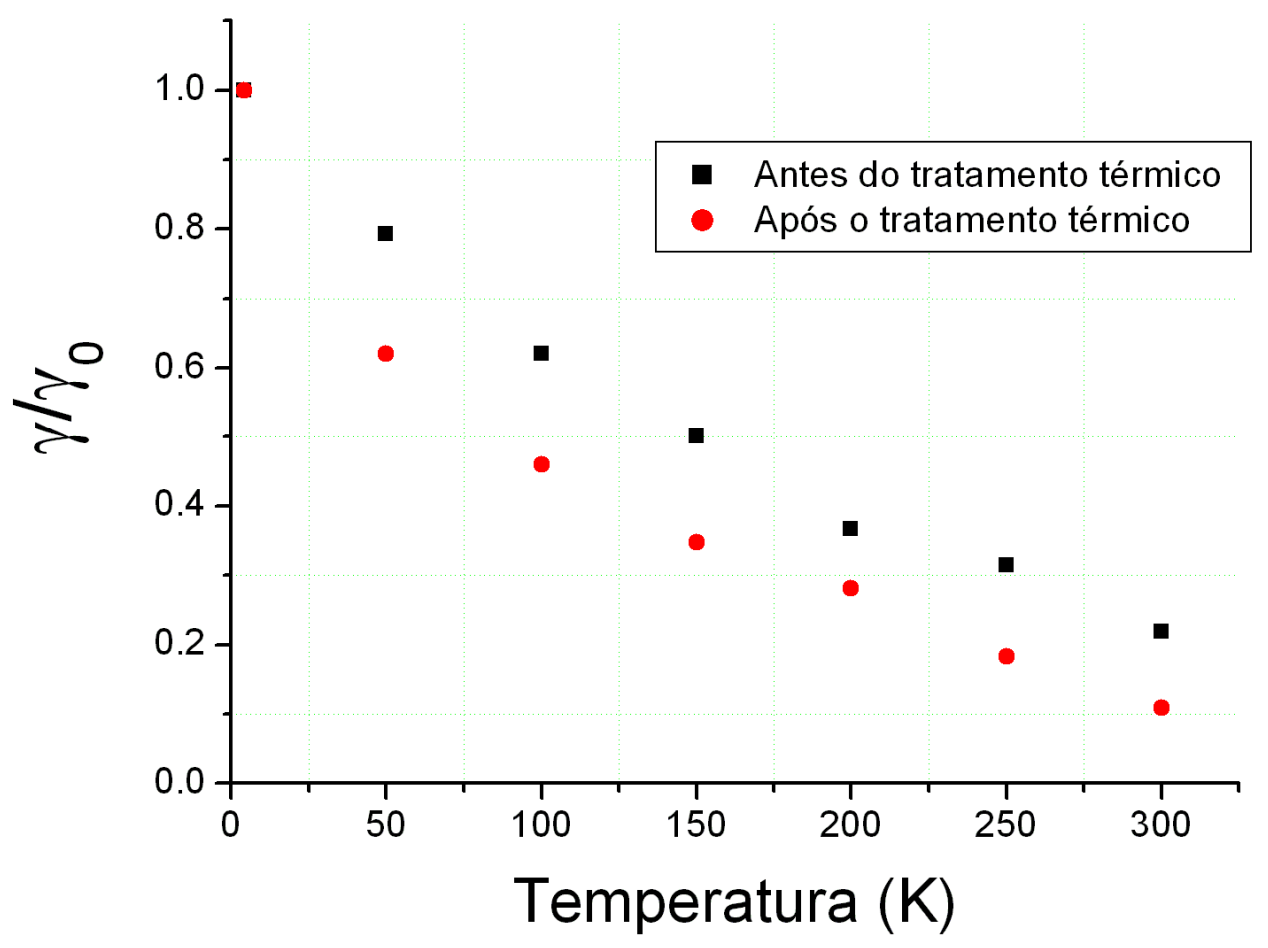

Figura $4.31-\frac{\gamma}{\gamma_{0}}$ em função da temperatura para a amostra I2 antes e após o tratamento térmico.

Através da figura em 4.31, observa-se, em ambos os casos, um acréscimo considerável na energia livre de acoplamento AF-FM em baixas temperaturas. Espera-se também que o valor $\gamma_{0}$, não determinado nesta análise, seja maior para a amostra termicamente tratada, mas com a relação $\gamma / \gamma_{0}$ sendo maior no caso contrário, como mostra a figura. Levando em conta este fato, Vê-se que a energia livre após o TT torna-se muito mais sensível à temperatura.

As curvas de inversão de primeira ordem também foram obtidas após o tratamento térmico, evidenciando nos diagramas de FORCs que o ordenamento dos spins do FeMn realmente aconteceu, influenciando de forma considerável o comportamento das partículas magnéticas do NiFe (fig. 4.32). 

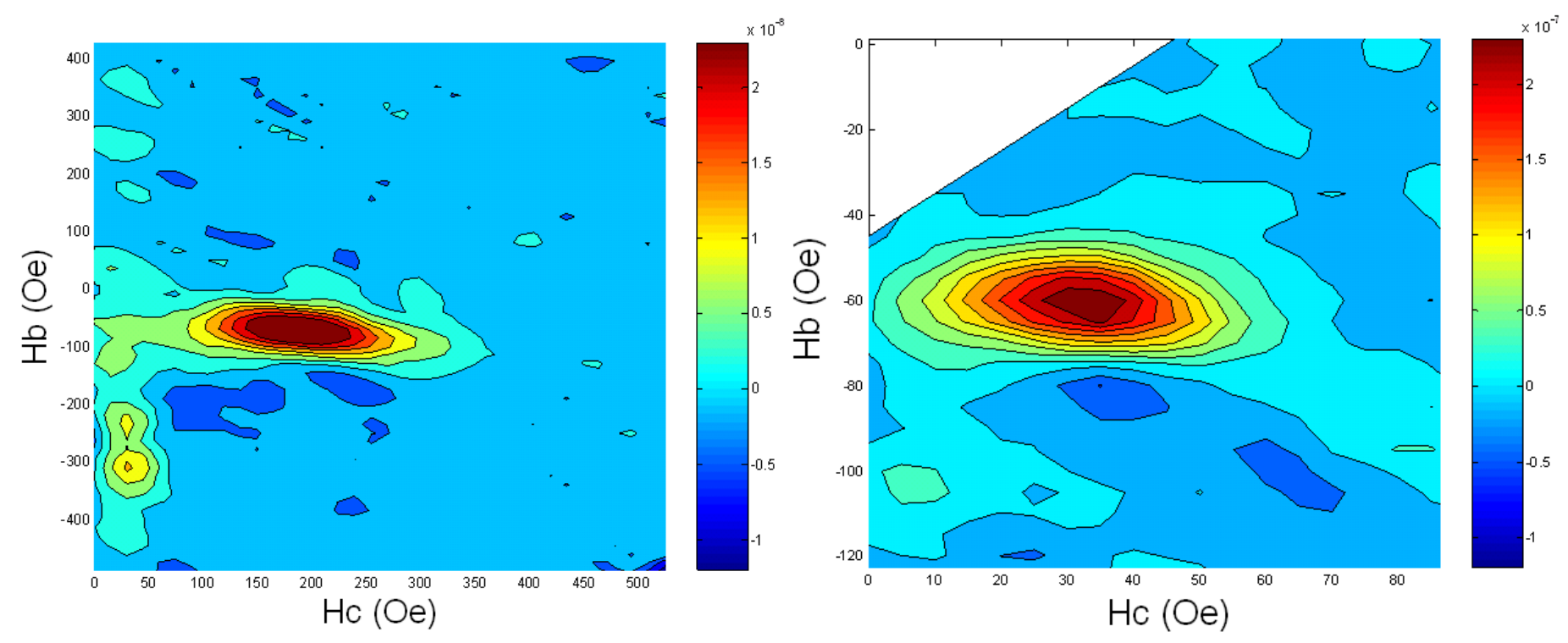

Figura 4.32 - Diagramas de FORCs à T=300K para a amostra B2 (lado esquerdo) e para a amostra I2 (lado direito).

Pode-se observar em ambos os diagramas que a componente reversível tornou-se completamente desprezível, tendo as assimetrias nas formas também alteradas, mantendo a viscosidade magnética como característica inerente. Observa-se que a ordem de grandeza numérica considerada na distribuição no eixo $\mathrm{h}_{\mathrm{C}}$ foi alterada se comparada às figuras $4.15 \mathrm{e}$ 4.22, evidenciando um aumento no valor do campo de inversão das partículas, justificando assim o aumento da coercividade também (fig. 4.33).

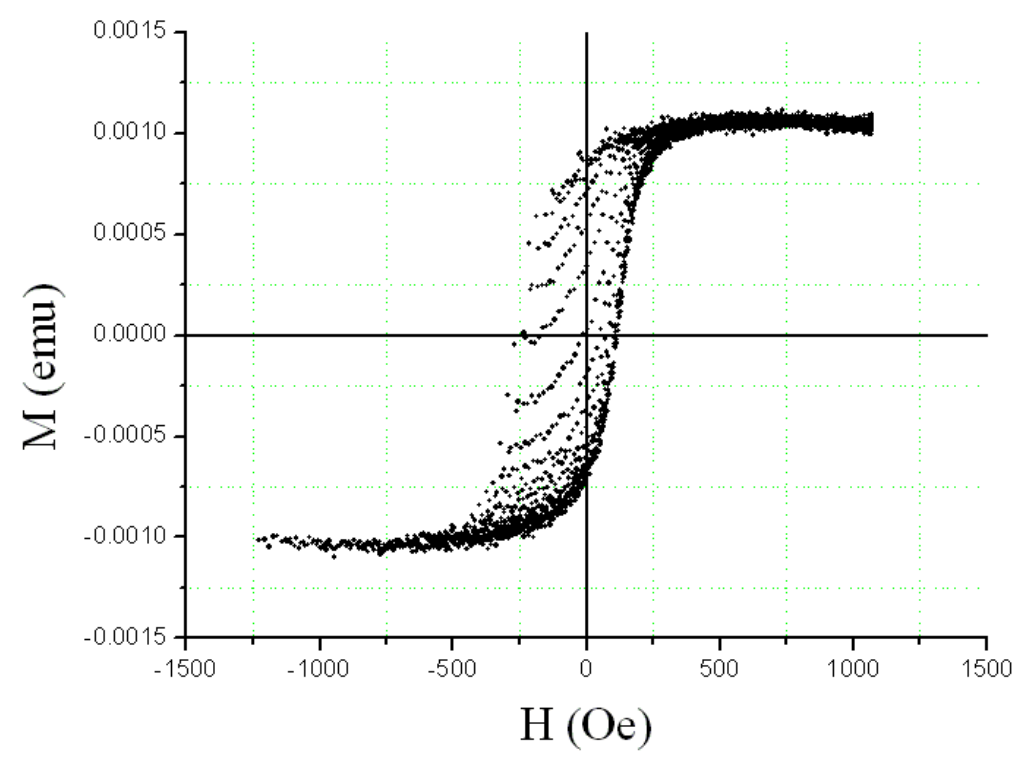

Figura 4.33 - FORCs obtidas para a amostra B2 à T=300k.

As simulações das FORCs (fig. 4.34) forneceram valores empíricos dos parâmetros ajustáveis (eq. 3.1), dando assim condições de comparar este comportamento com o das 
amostras B e I. Considerando que as amostras B2 e I2 foram submetidas ao TT, pode-se ver uma mudança na ordem de grandeza dos parâmetros ajustáveis (tab. 4.1).
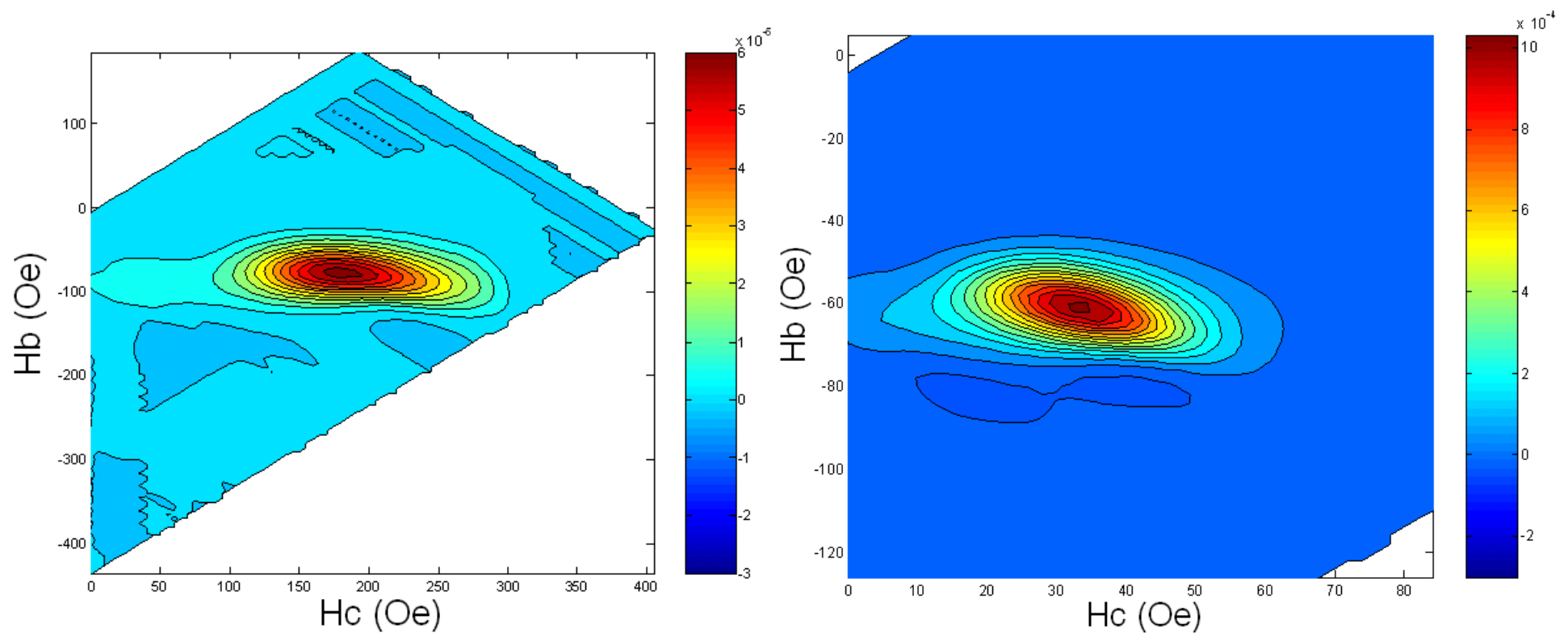

Figura 4.34 - Diagramas de FORCs obtidos através das simulações dos resultados experimentais de B2 (esquerda) e I2 (direita).

\begin{tabular}{|c|c|c|c|c|c|}
\hline amostra & $\mathrm{k}_{1}$ & $\alpha$ & $\sigma(\mathrm{Oe})$ & $\mathrm{B}(\mathrm{emu})$ & $\omega_{2}(\mathrm{Oe})$ \\
\hline $\mathrm{B}$ & 8 & 0.0083 & 6 & 0,71 & 13.5 \\
\hline B2 & 5 & 0.0439 & 5 & 0,99 & 7 \\
\hline $\mathrm{I}$ & 0.7 & 0.0303 & 10 & 0,87 & 6.5 \\
\hline I2 & 5 & 0.0056 & 5 & 0,96 & 7 \\
\hline
\end{tabular}

Tabela 4.1 - Parâmetros ajustados da equação 2.1 para as simulações das amostras B em comparação com B2 e I em comparação com I2. B2 e I2 foram submetidas ao TT.

De acordo com a tabela, observa-se uma estabilização dos parâmetros após o tratamento térmico, como em $k, \sigma$ e em $\omega_{2}$. A constante $B$ mostrou que, com o TT, as amostras passaram a ter uma componente irreversível dominante, sendo esta maximizada após o tratamento.

Uma análise interessante no estudo dos efeitos do tratamento térmico consiste em comparar medidas de $\mathrm{H}_{\mathrm{EB}}$ e $\mathrm{H}_{\mathrm{C}}$ feitas com o eixo de anisotropia unidirecional formando um ângulo $\theta$ com o campo aplicado. A amostra $\mathrm{F}$ foi selecionada por possuir as características típicas bem determinadas do sistema estudado, sendo assim possível determinar $\mathrm{o}$ comportamento de $\mathrm{H}_{\mathrm{C}}$ e $\mathrm{H}_{\mathrm{EB}}$ (fig. 4.35). 


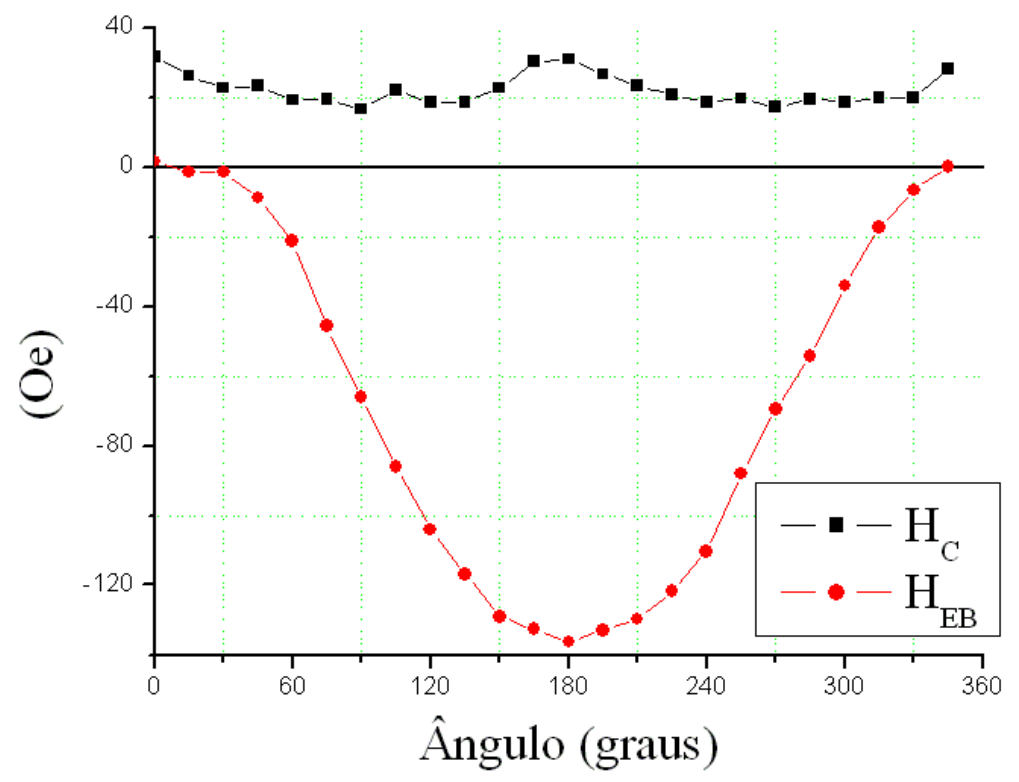

Figura 4.35 - Dependência de $\mathrm{H}_{\mathrm{C}}$ e $\mathrm{H}_{\mathrm{EB}}$ com o ângulo formado entre o eixo de anisotropia da amostra e o campo magnético $\mathrm{H}$ para a amostra $\mathrm{F}$.

A coercividade máxima observada é de 31,7 Oe, maior que os 22 Oe observados antes do TT. O valor de $\mathrm{H}_{\mathrm{EB}}$ também aumentou. $\mathrm{O}$ valor máximo observado é de 136,2 Oe frente aos 75,5 Oe observados anteriormente.

O mais relevante nessas comparações não é o aumento da coercividade ou do campo de Exchange Bias, mas sim sua forma. Comparativamente com a figura 4.3, que apresenta uma forma senoidal de dependência de $\mathrm{H}_{\mathrm{EB}}$ com o ângulo entre o eixo de anisotropia e o campo magnético aplicado, a figura 4.35 não apresenta valores positivos de $\mathrm{H}_{\mathrm{EB}}$, tendo um comportamento da forma -senoidal ${ }^{2}$. Esta mudança de $\mathrm{H}_{\mathrm{EB}}$ reflete uma mudança estrutural no alinhamento antiferromagnético. Destas medidas supõe-se que [51], antes do tratamento térmico, os domínios de FeMn tinham orientações de spins de forma não paralela ao plano da amostra, refletindo na observação de campos de $\mathrm{H}_{\mathrm{EB}}$ positivos e negativos. Com o TT, estes estados passaram a ter um alinhamento paralelo ao plano da amostra, tendo como conseqüências a observação de campos de $\mathrm{H}_{\mathrm{EB}}$ somente negativos. 


\section{Capítulo 5}

\section{Medidas magnéticas em válvulas de spin}

O motivo pelo qual foram feitas amostras com espaçadores de 1, 2, 3, 4 e 6 nm vêm do fato de as amostras com 1, 2 e $3 \mathrm{~nm}$ possuírem a camada livre interagente com a presa, revelando um termo de anisotropia não desprezível [30] e de as amostras com 4 e $6 \mathrm{~nm}$ não evidenciarem esta propriedade tão intensamente. Sabe-se que, para estas estruturas de válvulas de Spin, espessuras de 3 a $4 \mathrm{~nm}$ do espaçador de cobre regem a transição da ordem de interação entre as camadas [55].

\section{1 - Obtenção dos diagramas de FORCs}

De acordo com o trabalho desenvolvido em bicamadas, as válvulas de Spin foram submetidas ao TT e diagramas de FORCs foram obtidos com o intuito de revelar as características magnéticas das amostras. De forma complementar, a amostra com o espaçador de $4 \mathrm{~nm}$ de cobre foi estudada mais profundamente. Devido ao grande interesse no entendimento da dinâmica de magnetização e em seus efeitos como a MRA (magnetoresistência anisotrópica) [56], por exemplo, diagramas de FORCs foram obtidos para diferentes ângulos entre o campo aplicado (no plano da amostra) e o eixo de anisotropia antes e depois do tratamento térmico, assim como suas curvas de histerese, desde $300 \mathrm{~K}$ à $4,2 \mathrm{~K}$, com o campo aplicado paralelamente ao eixo de anisotropia do material. Simulações não foram feitas pois o modelamento descrito na introdução não pode ser aplicado em válvulas de spin sem que hajam modificações nas equações.

Como foi mecionado, o fato de esta amostra ter sido escolhida dentre todas vêm do fato de ela possuir uma espessura do espaçador adequada para que haja uma interação de baixa ordem, mas não desprezível, entre as camadas de $\mathrm{NiFe}$.

Após o TT nas amostras, FORCs e curvas de histerese foram obtidas à temperatura ambiente no VSM com o eixo de anisotropia paralelo ao campo magnético aplicado H (figs. 5.1 $-5.5)$. 

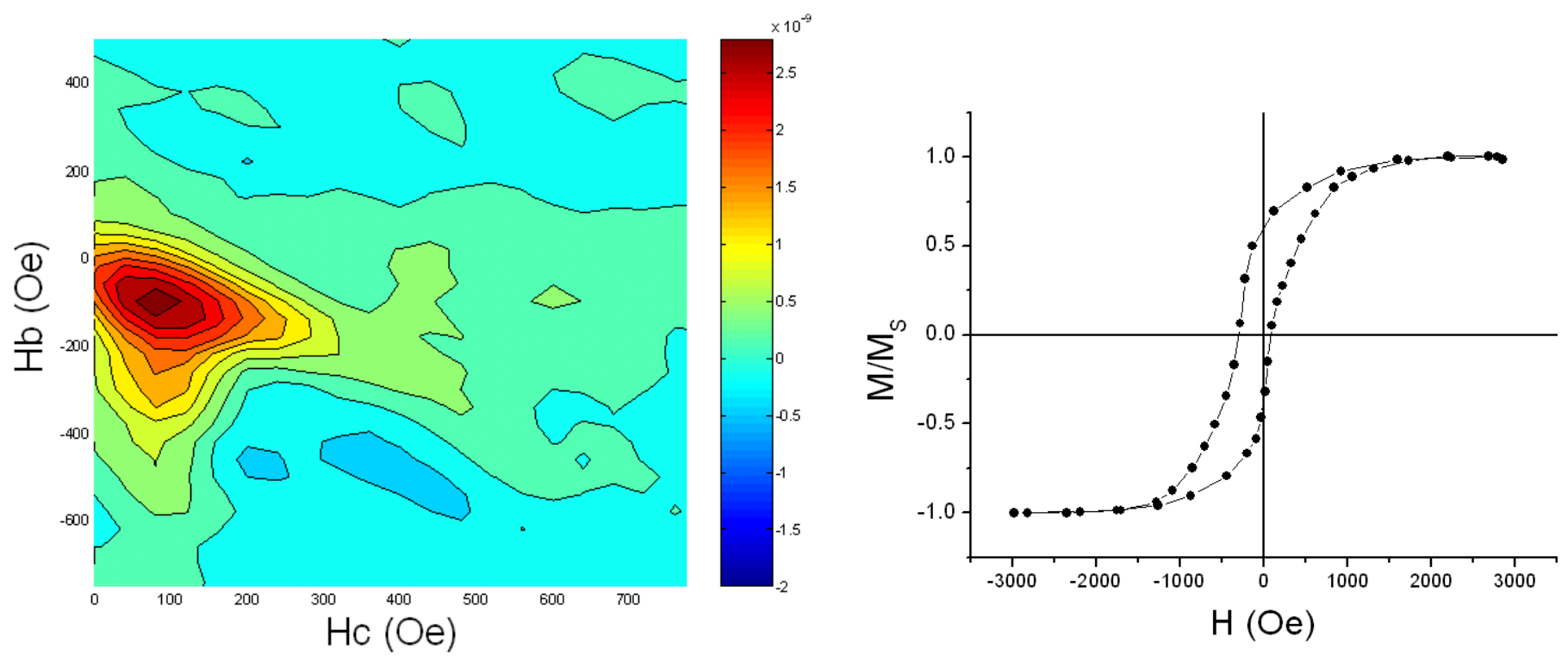

Figura 5.1 - Diagrama de FORCs da amostra vs1 com tratamento térmico com sua curva de histerese à 300K.
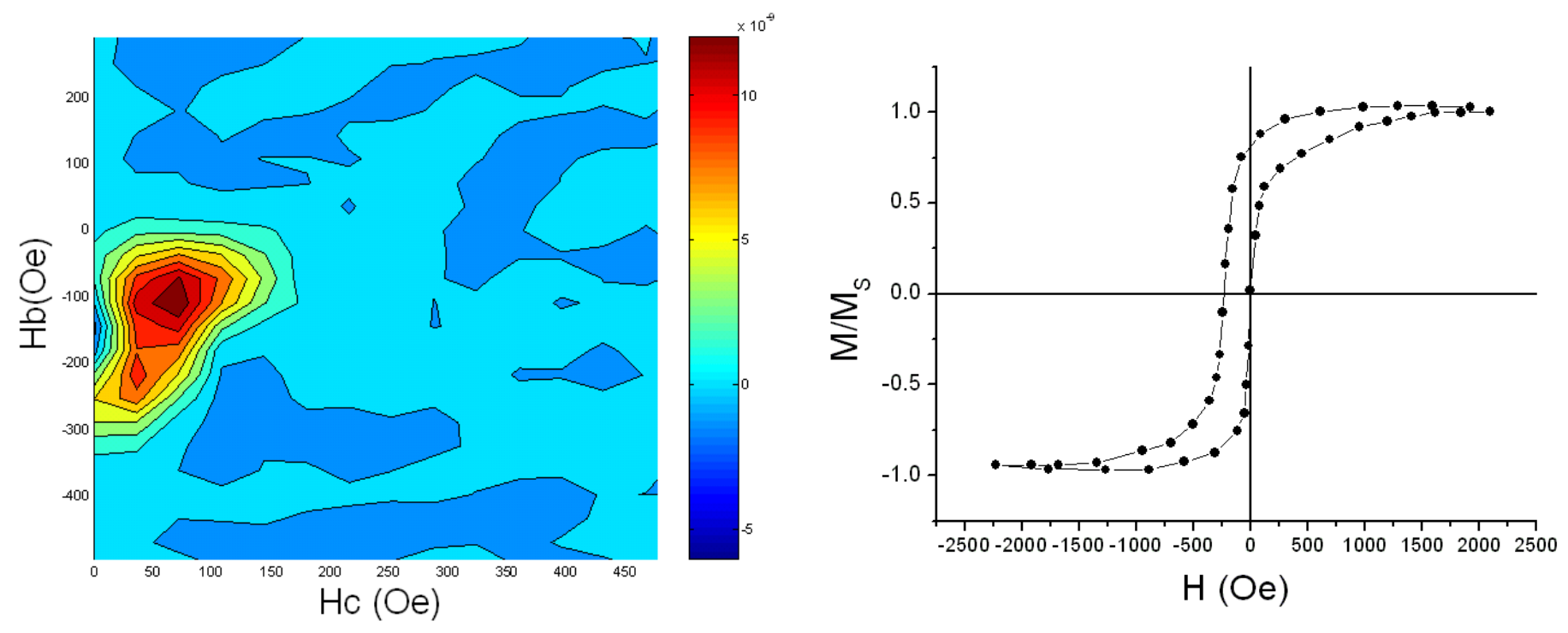

Figura 5.2 - Diagrama de FORCs da amostra vs2 com tratamento térmico com sua curva de histerese à 300K. 

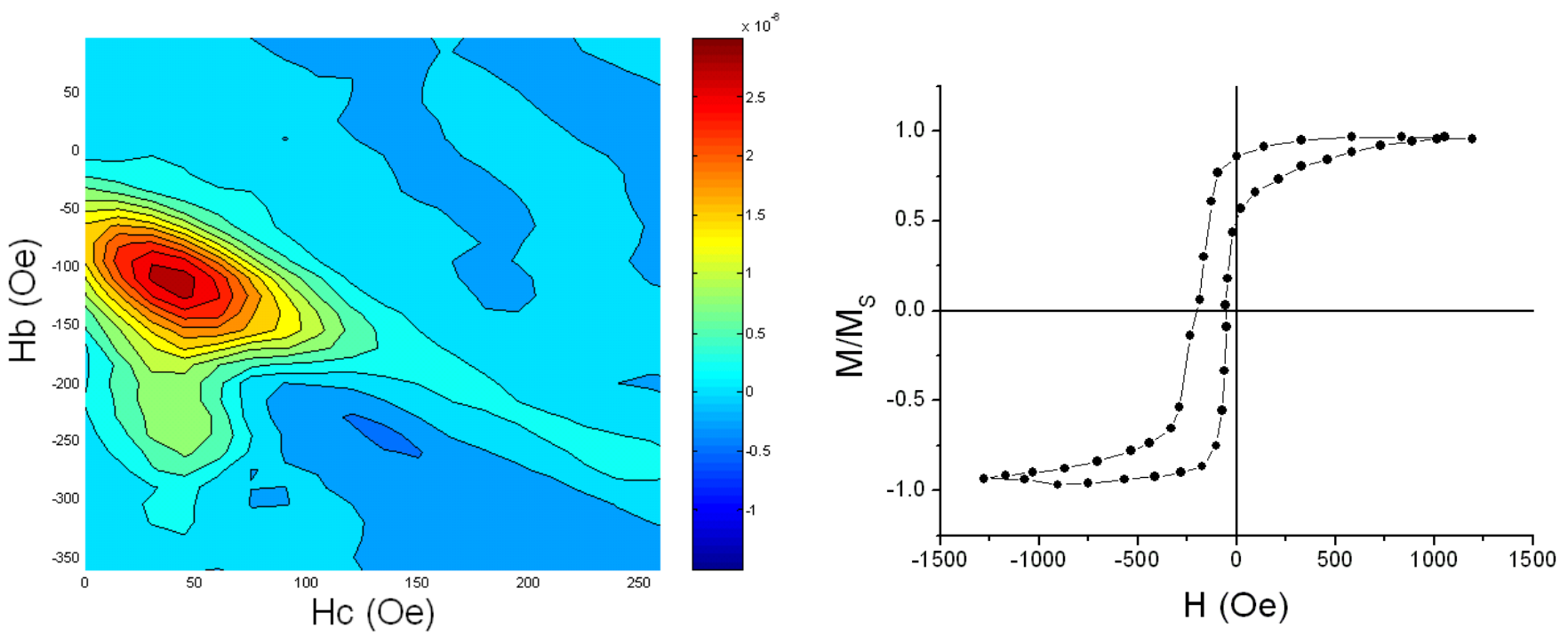

Figura 5.3 - Diagrama de FORCs da amostra vs3 com tratamento térmico com sua curva de histerese à 300K.
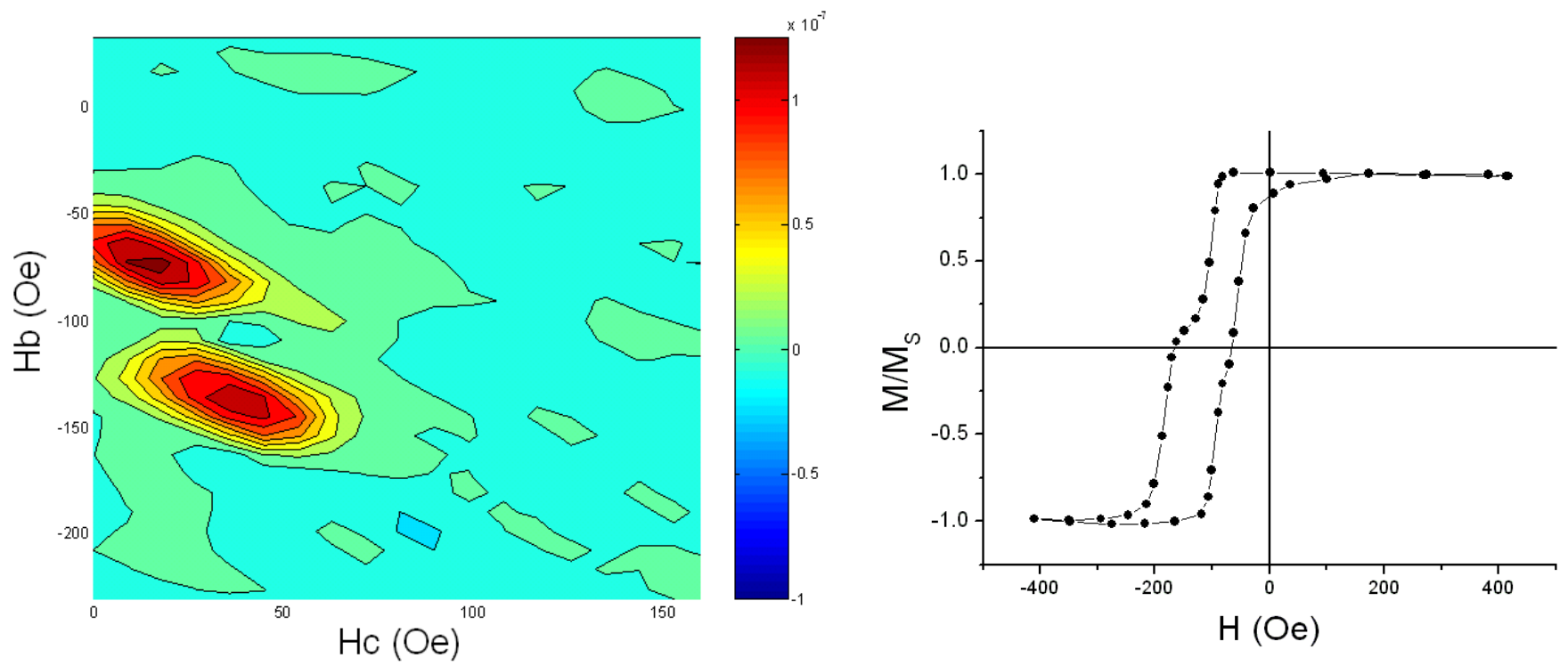

Figura 5.4 - Diagrama de FORCs da amostra vs4 com tratamento térmico com sua curva de histerese à 300K. 

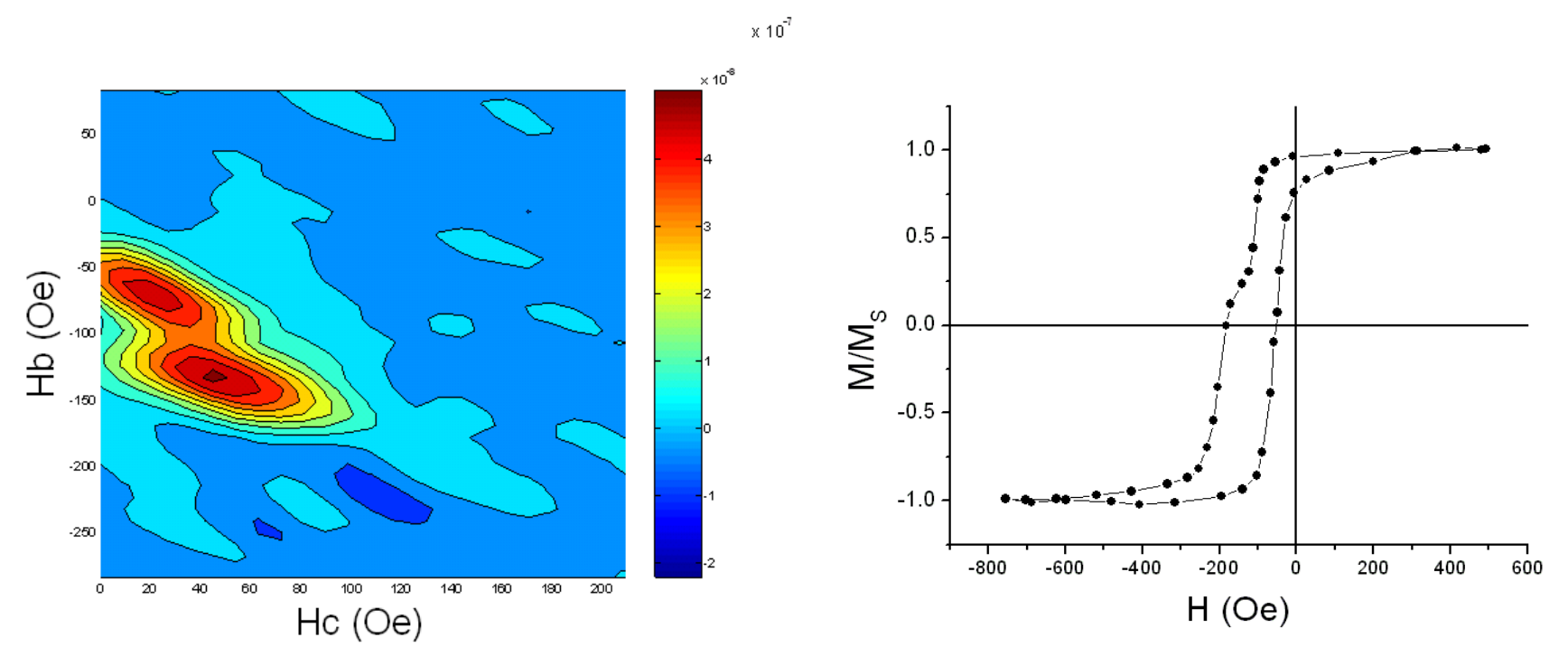

Figura 5.5 - Diagrama de FORCs da amostra vs6 com tratamento térmico com sua curva de histerese à 300K.

Estes diagramas evidenciam o processo de evolução das características magnéticas, além de mostrar que existe um campo médio do tipo kM intenso atuando nas amostras devido às inclinações acentuadas das distribuições [40,57]. Vê-se que, para uma camada de $1 \mathrm{~nm}$ de $\mathrm{Cu}$ (fig. 5.1), a camada livre interage fortemente com a presa. As amostras subseqüentes evidenciam uma diminuição desta interação, fazendo com que a camada presa tenha seu pico no diagrama cada vez mais deslocado devido ao campo de Exchange Bias, tornando a camada livre mais independente para mudar sua magnetização. Fica evidente que a separação dos picos deve ocorrer em uma espessura do espaçador de cobre entre 3 e $4 \mathrm{~nm}$ (figs. 5.3 e 5.4).

Num estudo mais profundo, a amostra vs4 $(\mathrm{Cu}(20 \mathrm{~nm}) / \mathrm{NiFe}(10) / \mathrm{Cu}(4) / \mathrm{NiFe}(10) / \mathrm{FeMn}(30) / \mathrm{Ta}(10))$ foi submetida às FORCs antes e após o TT, com o eixo de anisotropia fazendo ângulos de $0^{0}, 15^{\circ}, 30^{\circ}, 45^{\circ}, 60^{\circ}, 75^{\circ}$ e $90^{\circ}$ com o campo $\mathrm{H}$ aplicado para ambas as situações (figs. 5.6 - 5.12).
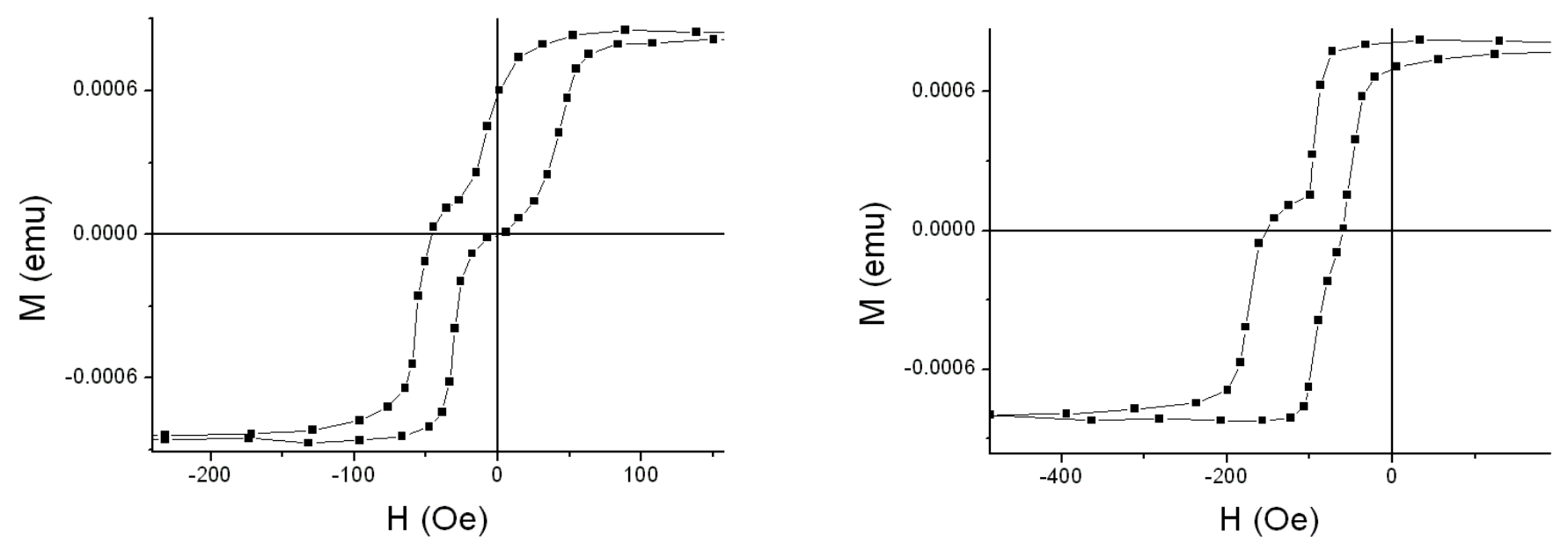

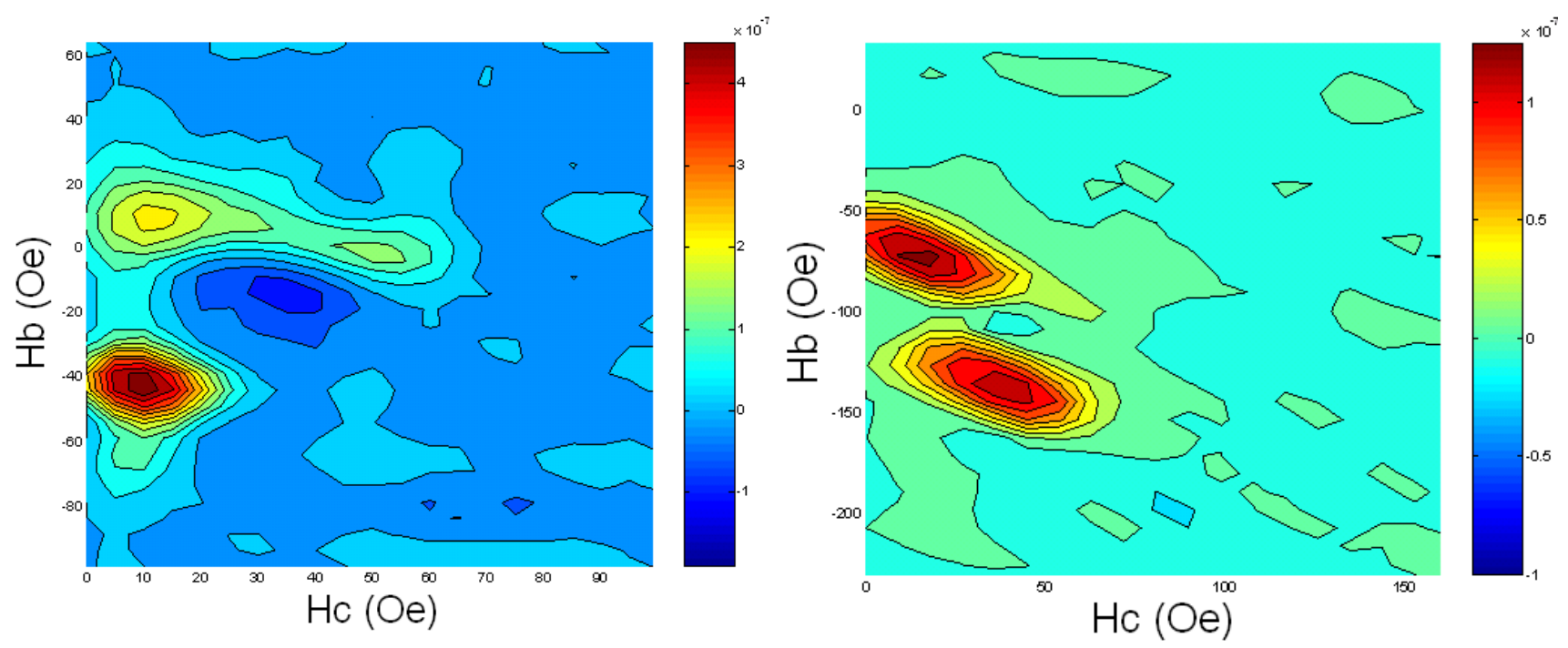

Figura 5.6 - Diagrama de FORCs com sua curva de histerese da amostra vs4 com um ângulo de $0^{0}$ entre o eixo de anisotropia e o campo aplicado para a amostra vs4 sem tratamento térmico (esquerda) e com tratamento térmico (direita).
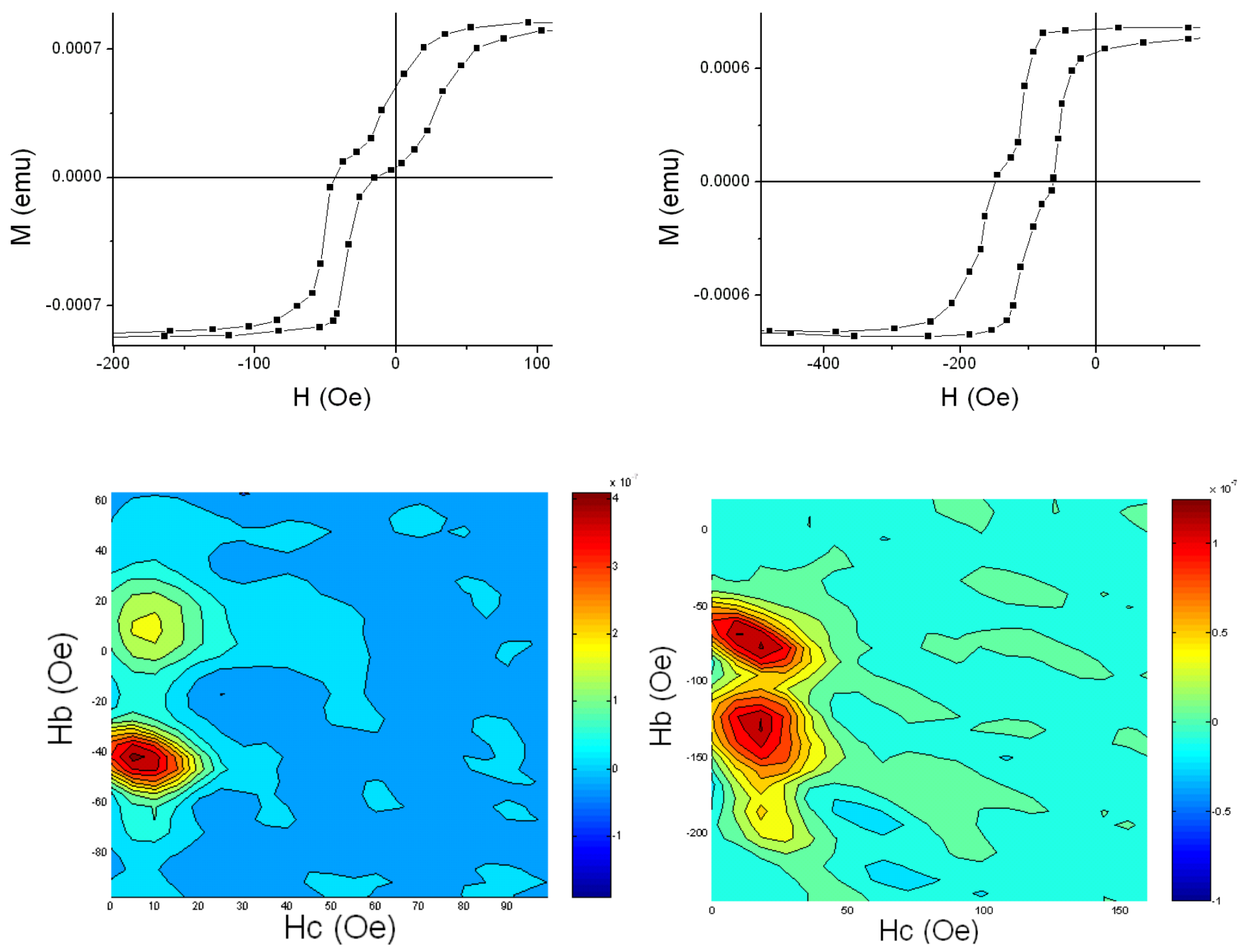

Figura 5.7 - Diagrama de FORCs com sua curva de histerese da amostra vs4 com um ângulo de $15^{0}$ entre o eixo de anisotropia e o campo aplicado para a amostra vs4 sem tratamento térmico (esquerda) e com tratamento térmico (direita). 

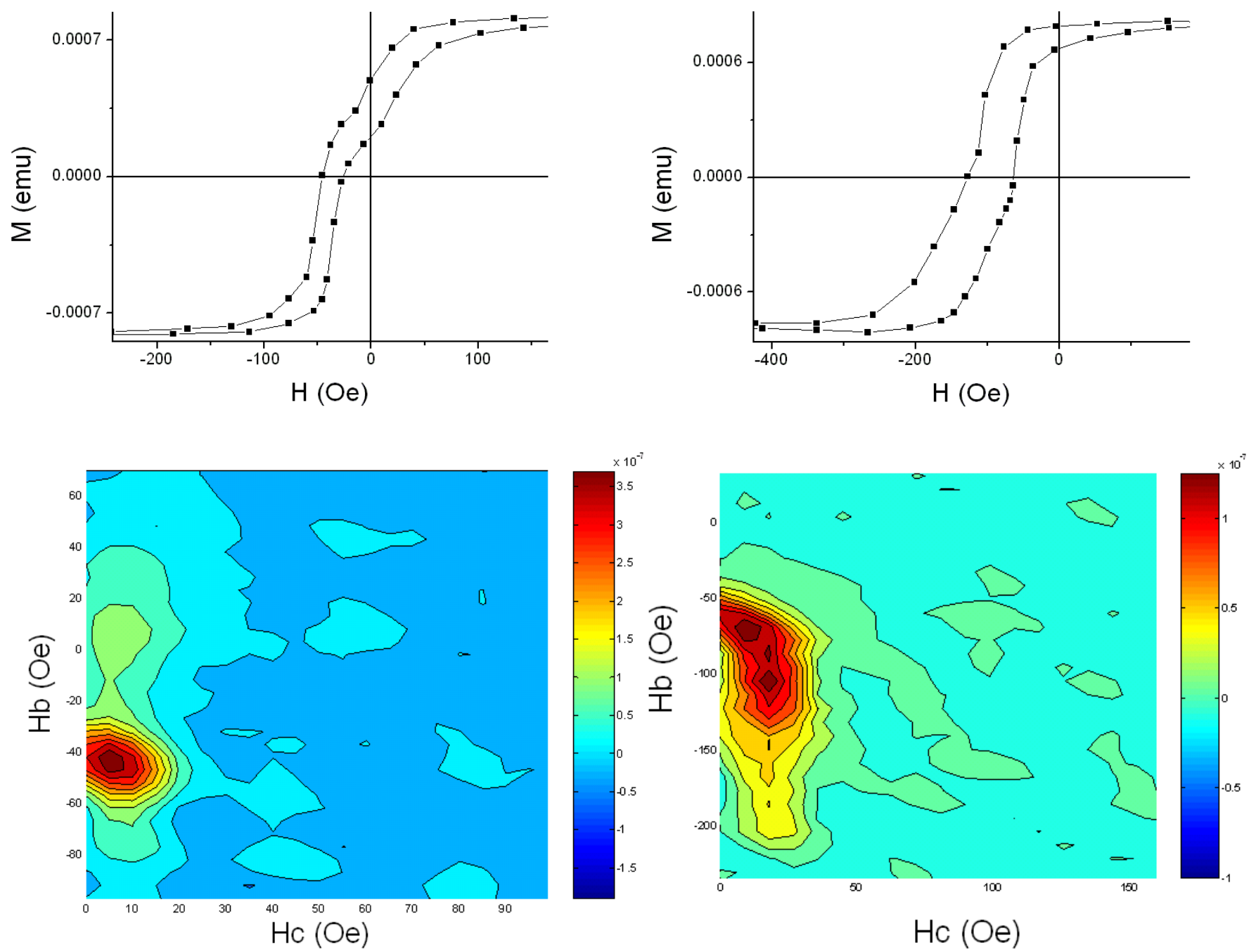

Figura 5.8 - Diagrama de FORCs com sua curva de histerese da amostra vs4 com um ângulo de $30^{0}$ entre o eixo de anisotropia e o campo aplicado para a amostra vs4 sem tratamento térmico (esquerda) e com tratamento térmico (direita). Os eixos $\mathrm{Hb}$ e Hc possuem dimensão de Oe.
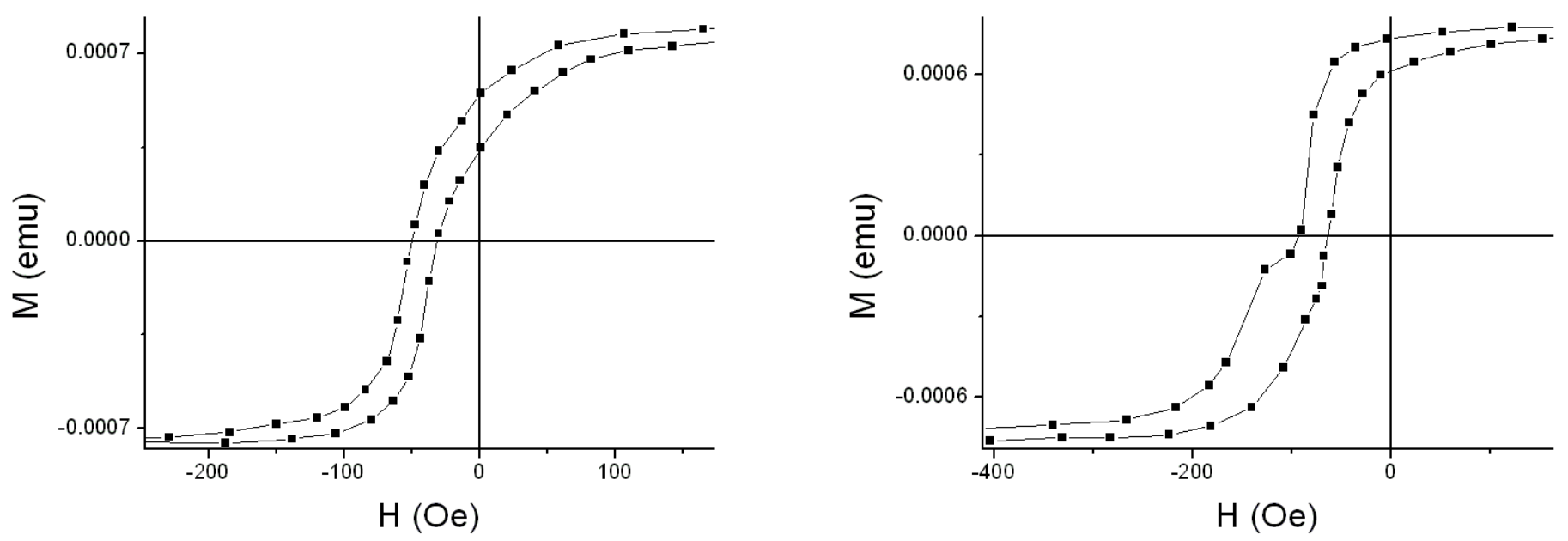

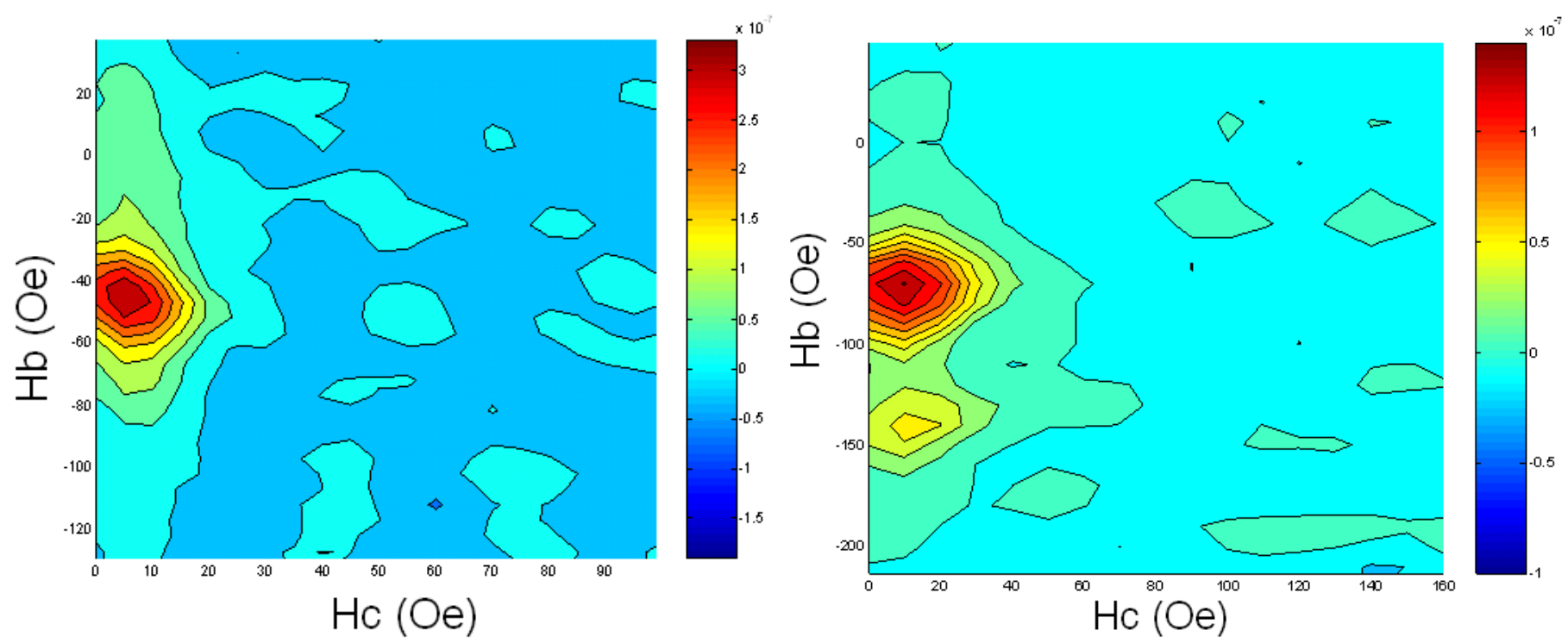

Figura 5.9 - Diagrama de FORCs com sua curva de histerese da amostra vs4 com um ângulo de $45^{\circ}$ entre o eixo de anisotropia e o campo aplicado para a amostra vs4 sem tratamento térmico (esquerda) e com tratamento térmico (direita).
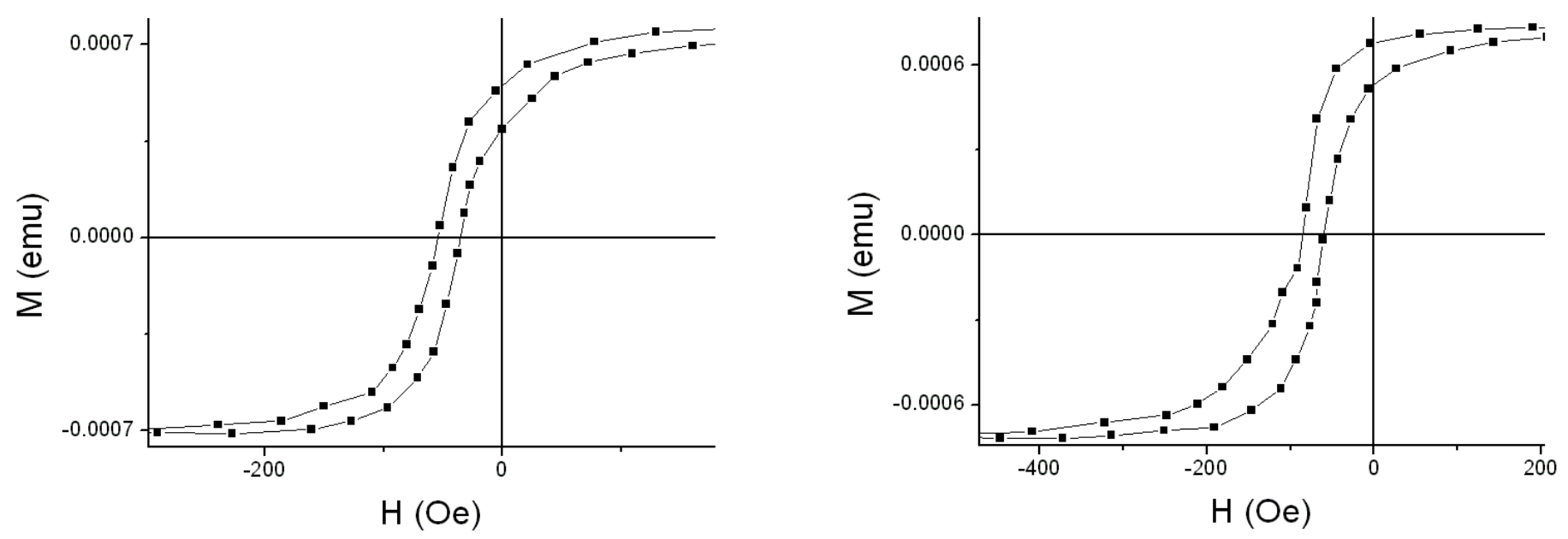

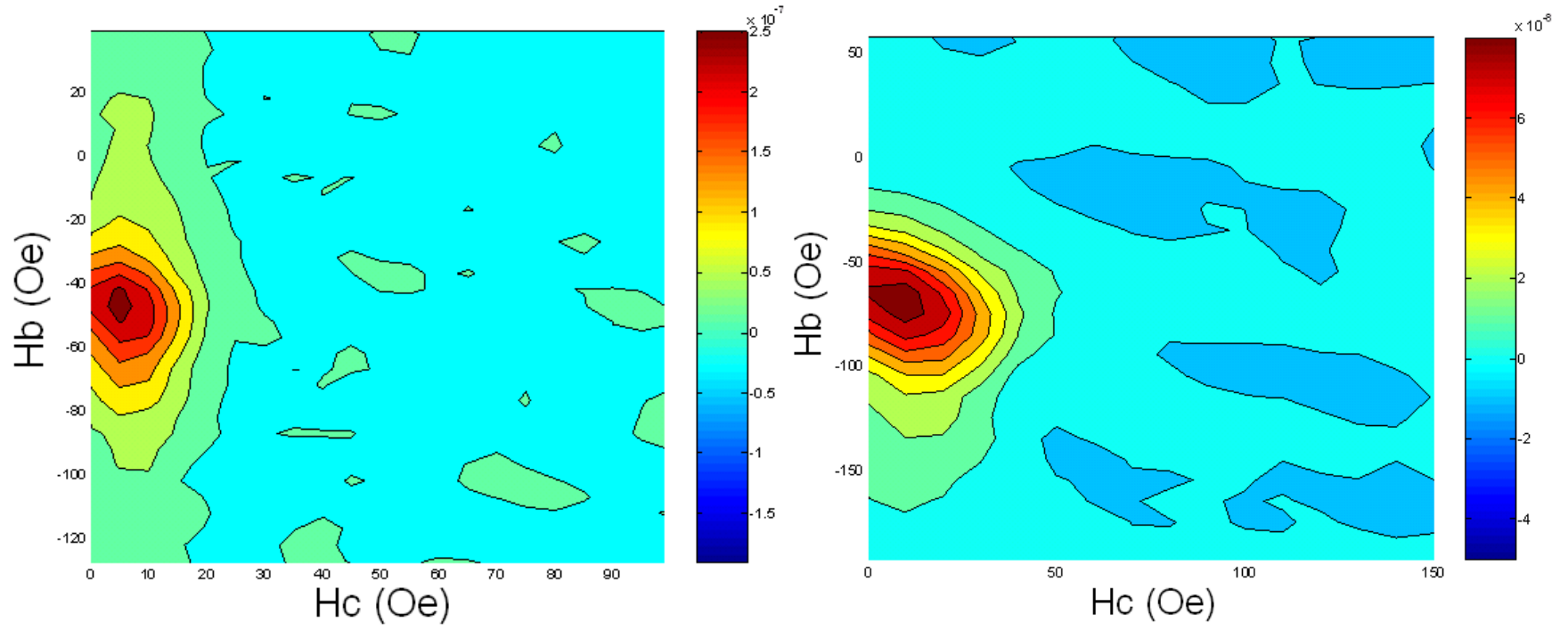

Figura 5.10 - Diagrama de FORCs com sua curva de histerese da amostra vs4 com um ângulo de $60^{\circ}$ entre o eixo de anisotropia e o campo aplicado para a amostra a vs4 sem tratamento térmico (esquerda) e com tratamento térmico (direita).
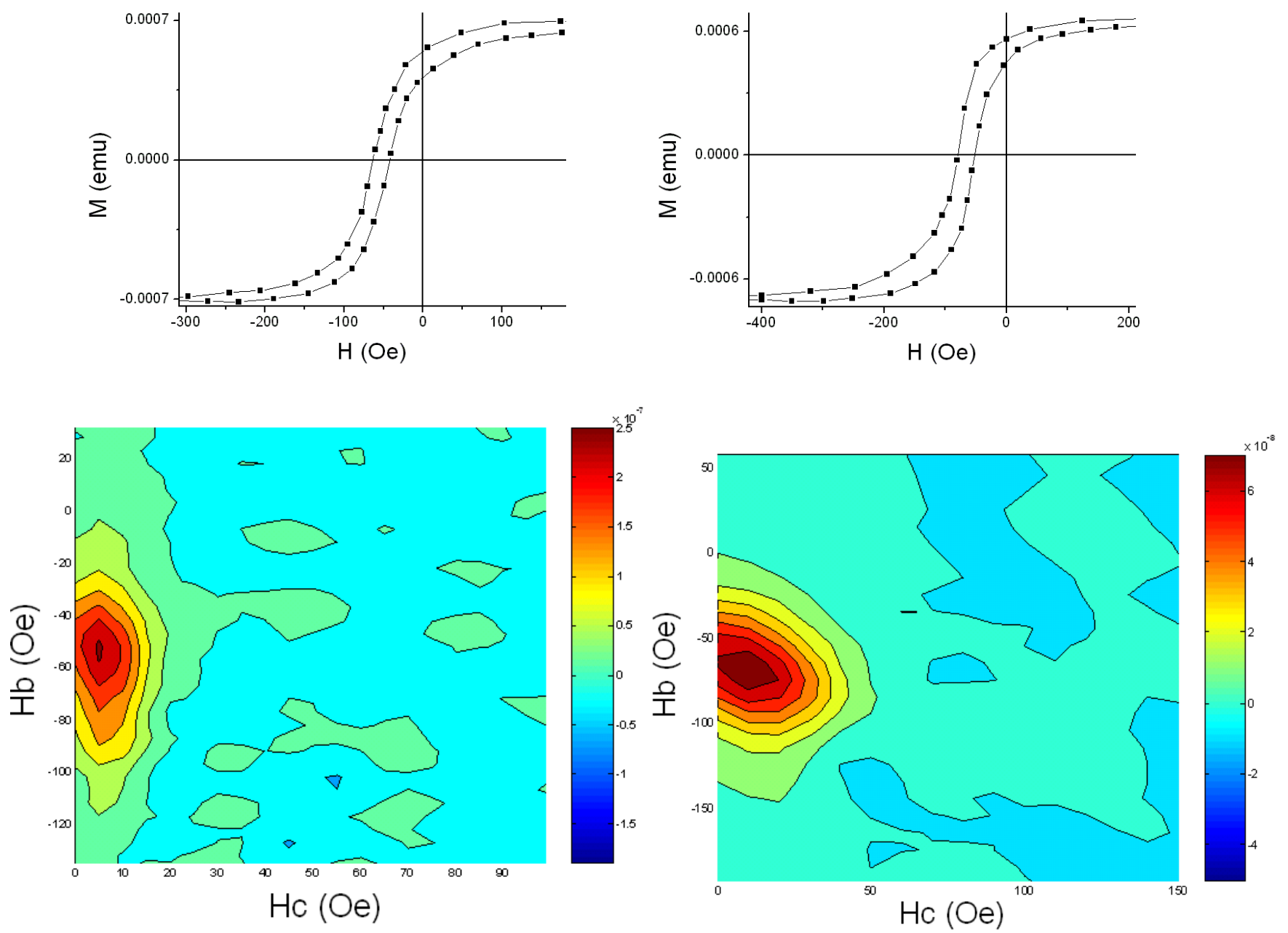

Figura 5.11 - Diagrama de FORCs com sua curva de histerese da amostra vs4 com um ângulo de $75^{\circ}$ entre o eixo de anisotropia e o campo aplicado para a amostra vs4 sem tratamento térmico (esquerda) e com tratamento térmico (direita). 

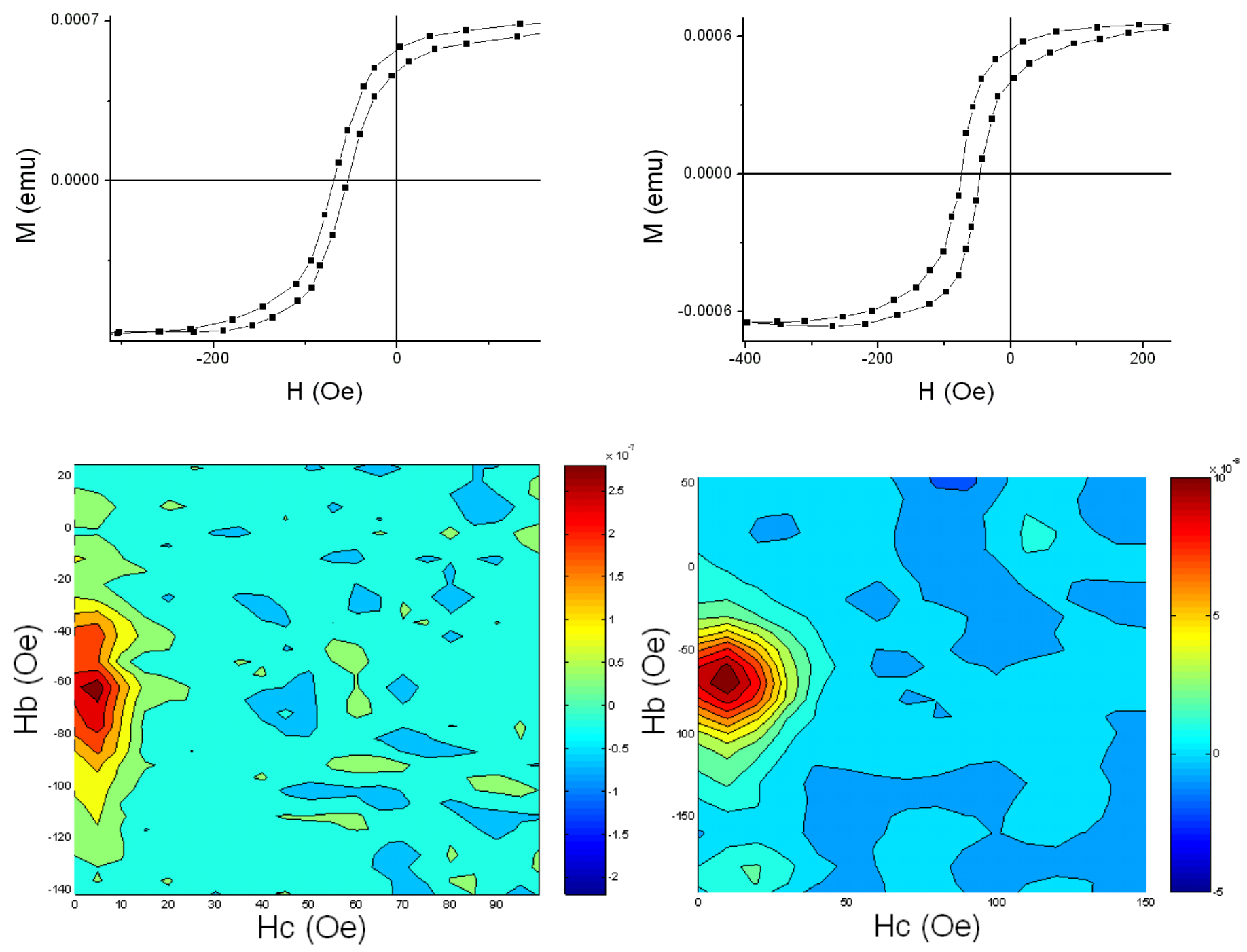

Figura 5.12 - Diagrama de FORCs com sua curva de histerese da amostra vs4 com um ângulo de $90^{\circ}$ entre o eixo de anisotropia e o campo aplicado para a amostra vs4 sem tratamento térmico (esquerda) e com tratamento térmico (direita).

Fica evidente que o tratamento térmico influenciou a forma das distribuições. Nota-se qualitativamente, principalmente na figura 5.6 onde a distinção da distribuição das duas camadas é mais evidente, que a reorientação magnética tornou o efeito de campo médio mais eficiente, sendo também intensamente observado nas outras amostras (figs. 5.1 - 5.5) através das inclinações das distribuições [40]. Uma interpretação plausível para esta mudança baseia-se na modificação de estruturas de domínios nas camadas ferromagnéticas devido à maior intensidade da densidade de energia nos contatos entre partículas AF/FM (eq. 1.41), já que $\gamma_{A F-F M} \propto H_{E B}$ e $\mathrm{H}_{\mathrm{EB}}$ aumentou com o tratamento térmico, tendo como consequiências o aumento da energia por unidade de superfície nos contatos entre partículas e o aumento da energia magnetostática, associadas ao campo médio na equação 1.45 do modelo de Preisach com Exchange Bias. 
Percebe-se também que, quanto maior for o ângulo entre o eixo de anisotropia do material e o campo aplicado, maior será a contribuição da componente reversível ao diagrama.

Uma outra representação dos diagramas das figuras 5.6a e 5.6b pode ser feita com o uso de um sistema cartesiano de coordenadas $(\mathrm{H}, \mathrm{M})$, sendo possível observar as regiões das distribuições diretamente no espaço das FORCs (fig. 5.13).

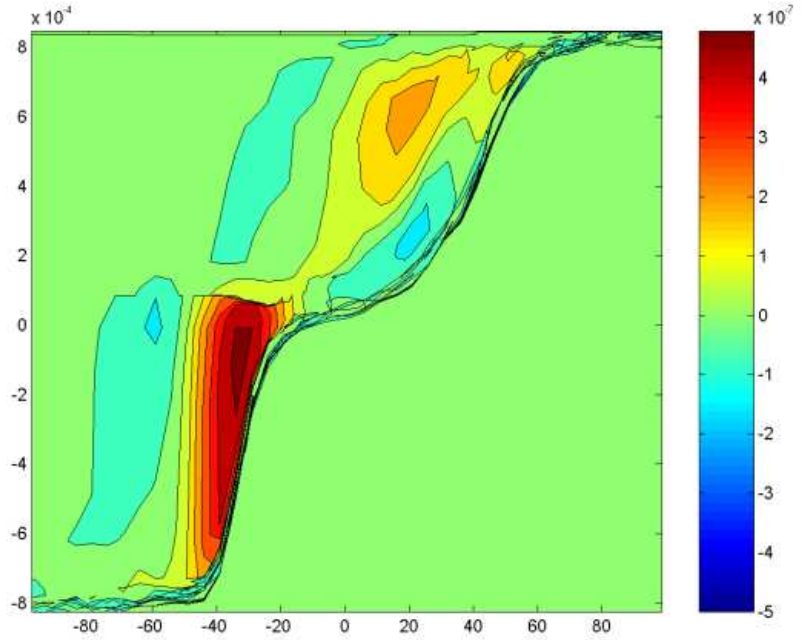

a)

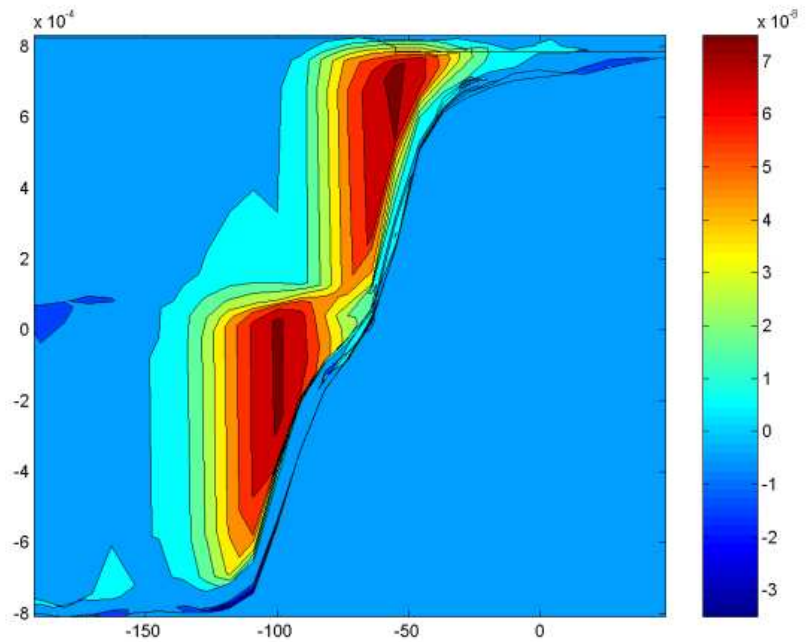

b)

Figura 5.13 - Representação dos diagramas de FORCs da amostra vs4 (fig. 5.4) em termos das coordenadas (H,M) a) antes do TT e b) após o TT.

Esta forma de representação, apesar de não ser relevante se comparada às distribuições nos eixos $\left(\mathrm{h}_{\mathrm{b}}, \mathrm{h}_{\mathrm{c}}\right)$, permite observar a distinção entre as contribuições de ambas as camadas ferromagnéticas, dando assim um maior embasamento na interpretação dos diagramas. Uma sobreposição direta das curvas de primeira ordem obtidas não pode ser feita, pois mesmo esta representação (fig. 5.13) possui pequenas divergências relativas à amortização (fator Smooth Factor).

\section{2 - Estudo em baixas temperaturas}

A amostra vs4 foi submetida a curvas de histerese em baixas temperaturas através de uma bobina supercondutora antes e após o TT. Como anteriormente, espera-se um acréscimo no campo de anisotropia de troca, juntamente com o aumento da coercividade, que deve ser distinto para cada camada. Assim, curvas de magnetização foram obtidas desde temperaturas de 300K até 4,2K (fig. 5.14) e suas características foram experimentalmente determinadas (fig. 5.15). 

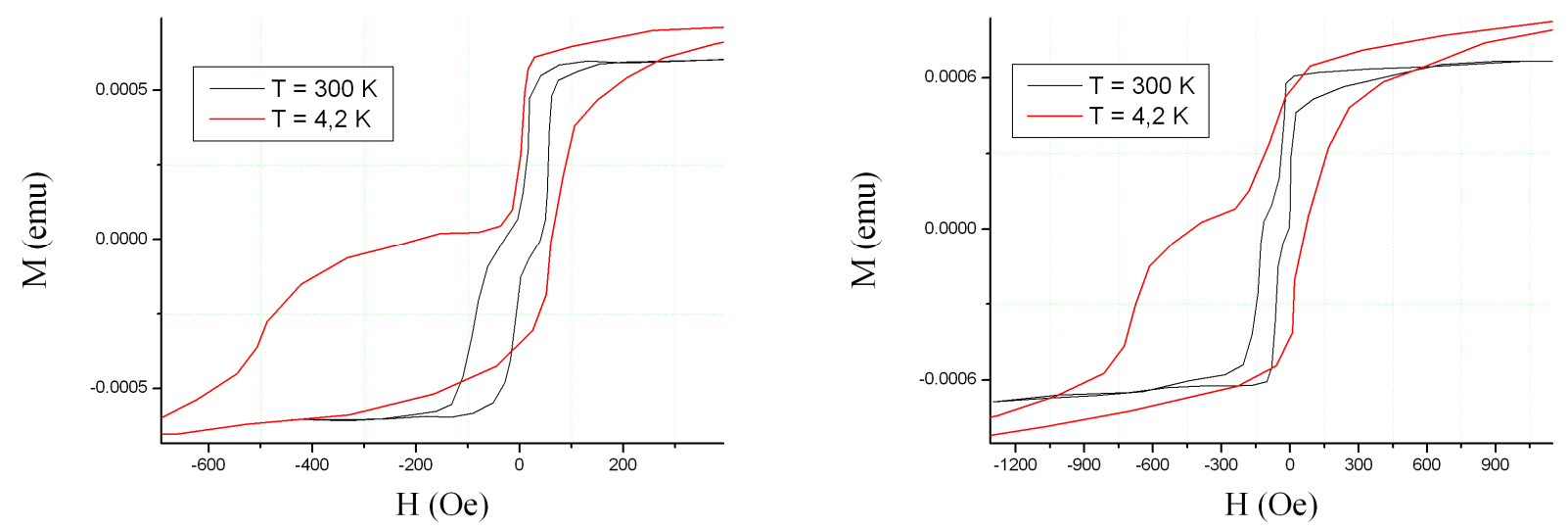

Figura 5.14 - Ajuste dos ciclos de histerese da amostra vs4 à $\mathrm{T}=300 \mathrm{~K}$ e $\mathrm{T}=4,2 \mathrm{~K}$ antes do tratamento térmico (esquerda) e após o tratamento térmico (direita).
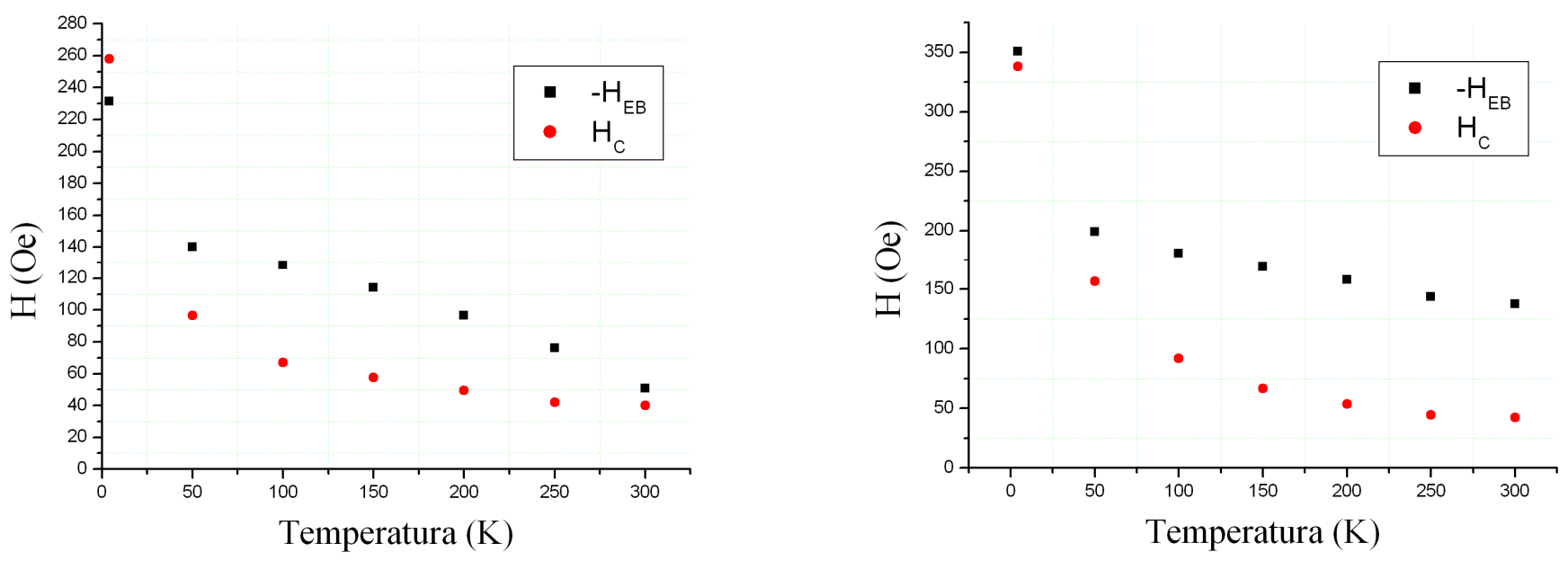

Figura 5.15 - - $\mathrm{H}_{\mathrm{EB}}$ e $\mathrm{H}_{\mathrm{C}}$ em função da temperatura para a amostra vs4 antes do tratamento térmico (esquerda) e após o tratamento térmico (direita).

Observa-se na figura 5.14 que o TT causou um aumento dos campos de Exchange Bias e coercivos, confirmado pelas figuras 5.15. Os gráficos mostram que, antes do tratamento térmico, os valores estimados de $\mathrm{H}_{\mathrm{EB}}$ e de $\mathrm{H}_{\mathrm{C}}$ são da mesma ordem, com $\mathrm{H}_{\mathrm{EB}}$ se destacando após o tratamento e $\mathrm{H}_{\mathrm{C}}$ permanecendo com uma coercividade próxima à das medidas iniciais. 


\section{Capítulo 6}

\section{Conclusões}

\section{Caracterização inicial e efeitos do tratamento térmico nas bicamadas de $\mathrm{NiFe} / \mathrm{FeMn}$}

As bicamadas de $\mathrm{NiFe} / \mathrm{FeMn}$ produzidas via Sputtering apresentaram um comportamento de $\mathrm{H}_{\mathrm{EB}}$ e $\mathrm{H}_{\mathrm{C}}$ compatíveis com o esperado. As amostras com buffers de Ta apresentaram menores valores de coercividade e de campo de Exchange Bias em comparação às amostras com buffers de $\mathrm{Cu}$. Estas tiveram o campo de $\mathrm{H}_{\mathrm{EB}}$ determinado em função do ângulo entre o eixo de anisotropia do material e o campo magnético, revelando um comportamento senoidal, com valores positivos e negativos de Exchange Bias. Com o tratamento térmico, a dependência angular de $\mathrm{H}_{\mathrm{EB}}$ torna-se do tipo -senoidal ${ }^{2}$. Este comportamento revela que as estruturas de Spins antiferromagnéticas possuem orientações não paralelas ao plano da amostra sem o tratamento térmico. Com o tratamento com o campo paralelo ao plano da amostra $\mathrm{f}$, a mesma apresentou um aumento tanto na coercividade quanto em $\mathrm{H}_{\mathrm{EB}}$, além de reorientar $\mathrm{o}$ alinhamento antiferromagnético, aumentando assim a energia livre magnética proveniente do acoplamento AF-FM, matematizada pelo termo $\gamma_{A F-F M}$. A componente reversível tornou-se irrelevante no processo de magnetização após o tratamento térmico, observado nos diagramas das amostras $B 2$ e $I 2$, sendo resultado do melhor acoplamento entre as camadas.

Foi observada uma dependência do tipo $\mathrm{H}_{\mathrm{EB}} \alpha 1 / \mathrm{t}_{\mathrm{FM}}$ para a variação da espessura da camada ferromagnética para ambos os buffers utilizados, assim como uma queda na coercividade observada. Para as estruturas $\mathrm{Cu}(20 \mathrm{~nm}) / \mathrm{NiFe}(\mathrm{t}) / \mathrm{FeMn}(10) \quad(\mathrm{t}<10 \mathrm{~nm})$, foi constatado que $\mathrm{H}_{\mathrm{EB}}$ possui valores da ordem de 150 Oe, superiores aos obtidos com o buffer de Ta $(\approx 75$ Oe). Para a variação da espessura da camada de FeMn, foi constatado que o campo de Exchange Bias é crescente com o aumento da espessura, tendo seu valor saturado em $\approx 20 \mathrm{~nm}$ para as amostras com ambos os buffers. Para o caso do $\mathrm{Cu}$, o valor máximo de tendência obtido foi de $\approx 85$ Oe, tendo o valor máximo obtido de $\approx 75$ Oe para as amostras com buffers de Ta e espessuras de $10 \mathrm{~nm}$ de $\mathrm{NiFe}$.

As medidas em baixas temperaturas permitiram o estudo do comportamento da densidade superficial de energia $\gamma_{A F-F M}$ no acoplamento AF-FM. $\gamma_{A F-F M}$ decresce praticamente de forma linear com o aumento da temperatura no intervalo [50k ;300k], tendo uma relação $\gamma / \gamma_{0}$ inferior a $20 \%$ à temperatura ambiente. O mesmo comportamento linear foi observado para o decréscimo na coercividade e no campo de Exchange Bias. De um modo geral, o tratamento térmico mudou a escala dos parâmetros estudados, mas as mesmas características são observadas para todas as variáveis.

\section{Diagramas de FORCs das bicamadas de NiFe/FeMn}

Os diagramas de FORCs feitos em amostras com buffers de $\mathrm{Cu}(20 \mathrm{~nm})$ e com espessuras de NiFe de $10 \mathrm{~nm}$ revelaram a dependência das distribuições com o campo de Exchange Bias desses sistemas. A contribuição reversível diminuiu com o aumento da espessura do FeMn, evidenciando que, quanto menor for o campo de $\mathrm{H}_{\mathrm{EB}}$, mais evidente ficará o comportamento do Py. Assim, atribui-se o aumento da contribuição irreversível ao efeito de Anisotropia de 
Exchange. $\mathrm{O}$ termo assimétrico $\alpha$ evidencia um comportamento tendendo para um valor fixo positivo quando se satura $\mathrm{o} \mathrm{H}_{\mathrm{EB}}$, da ordem de 0.035 , para espessuras maiores que $20 \mathrm{~nm}$. Podese observar que o parâmetro $\alpha$ é vinculado com o fenômeno de Exchange Bias, sendo assim compatível com o esperado(i. e. a assimetria aparece quando há $\mathrm{H}_{\mathrm{EB}}$ ). $\mathrm{O}$ parâmetro $\mathrm{k}_{1}$ do campo médio foi relacionado com $\mathrm{H}_{\mathrm{EB}}$, evidenciando uma dependência entre o campo médio e o efeito de anisotropia de troca, tendo uma relação linear para valores entre zero e 50 Oe de $\mathrm{H}_{\mathrm{EB}} \mathrm{e}$ convergindo para zero quando $\mathrm{H}_{\mathrm{EB}}$ torna-se próximo à $80 \mathrm{Oe}$, evidenciando que, para estes valores de $\mathrm{H}_{\mathrm{EB}}$, o material ferromagnético terá a componente desmagnetizante da mesma ordem da componente magnetizante.

As simulações mostraram-se válidas na reprodução dos resultados obtidos experimentalmente. Conclui-se que, para estas estruturas, o Modelo de Preisach com Exchange Bias é eficiente na descrição dos processos de magnetização envolvidos.

\section{Estudo das válvulas de spin}

O estudo das válvulas de spin apresentou uma separação das distribuições que dependente da espessura do espaçador $\mathrm{Cu}$ e do tratamento térmico nos diagramas de FORCs. Os diagramas das amostras com espaçadores de 1, 2 e 3nm mostraram que a camada livre está fortemente acoplada com a presa. O efeito de campo médio está presente em todas as amostras termicamente tratadas. As amostras com espaçadores de 4 e $6 \mathrm{~nm}$ apresentaram uma maior separação das distribuições no diagrama. Fica evidenciado também que, com o aumento da espessura do espaçador, a camada presa passa a ser representada cada vez mais fortemente pela componente irreversível de magnetização.

\section{Estudo da válvula de spin com o espaçador de $4 \mathrm{~nm}$}

A amostra vs4 foi submetida à medições de FORCs antes e após o tratamento térmico com o eixo de anisotropia ferromagnética formando ângulos entre $0^{0}$ e $90^{\circ}$ com o campo aplicado. Observa-se que, para baixos ângulos, o campo médio se tornou mais intenso, assim como um aumento considerável nas escalas dos campos de inversão $\left(h_{c}\right)$ e de interações $\left(h_{b}\right)$, além do maior deslocamento da distribuição da camada presa, mostrando assim um aumento no campo $\mathrm{H}_{\mathrm{EB}}$. Pode-se perceber que, para ângulos maiores que $45^{\circ}$, as distribuições convergem para a mesma região, tendo a componente reversível como dominante.

As medidas em baixas temperaturas na amostra vs4 mostraram que, apesar de não ser coerente usar os modelos teóricos e fenomenológicos propostos para bicamadas, espera-se um aumento na energia de interação entre a camada presa e a antiferromagnética com a diminuição da temperatura, sendo esta intensa para temperaturas menores que 50k se comparada à temperatura ambiente. 


\section{Referências bibliográficas}

[1] S. Cardoso, R. Ferreira, F. Silva, P. P. Freitas, L. V. Melo, R. C. Sousa, O. Redon, M. MacKenzie and J. N. Chapman. J. Appl. Phys. 99, 08N901 (2006)

[2] G. H. O. Daalderop, P. J. Kelly, and M. F. H. Schuurmans. Phys. Rev. B 41, 11919 (1990)

[3] A. Lessard, T. H. Moos, and W. Hübner. Phys. Review B 56, 2594 (1997)

[4] C. Kittel. Phys. Review 70, 965 (1946)

[5] A. H. Morris. The Physical Principles of Magnetism. Cap. 8

[6] R. L. R. Suárez. Tese de Doutorado UFPE - Departamento de Física

[7] L. Néel. J. Phys. Radium 15, 225 (1954)

[8] P. Grünberg, R. Schreiber, and Y. Pang. Phys. Review Letters 57, 2442 (1986)

[9] J. Barnaś and P. Grünberg. J. Mag. Magn. Mat. 121, 1-2 (1993)

[10] J. Slonczewski. Phys. Review Letters 67, 3172 (1991)

[11] J. Slonczewski. J. Mag. Magn. Mat. 150, 13 (1995)

[12] R. C. O’Handley. Modern Mag. Mat. - Editora Wiley

[13] J. Nogués and I. K. Schuller. J. Magnetism and Magnetic Materials 192 (1999) 203-232

[14] D. Mauri, E. Kay, D. School and J. K. Howard. J. Appl. Phys. 62(7) (1987) 2929

[15] H. Zijlstra. IEEE Trans. Mag. 15, 1246 (1979)

[16] M. D. Stiles and R. D. McMichael. Phys. Review B 59, 3722 (1999)

[17] R. D. McMichael et. al. Phys. Review B 58, 8605 (1997)

[18] W. H. Meiklejohn, C. P. Bean. Phys. Review 105, 3 (1957)

[19] M. Bahiana and B. Koiller. Phys. Review E 59, 3884 (1999)

[20] S. X. Wang and J. Hong. IEEE Trans. Mag. 37 (4) (2001)

[21] L. Néel. Ann. Phys. Paris 2 (1967) 61

[22] A. P. Malozemoff. Phys. Review B 35, 7 (1987)

[23] A. P. Malozemoff. J. Apl. Phys. 63, 8 (1988)

[24] D. R. Cornejo, E. Hernández, A. Azevedo and S. M. Rezende. J. Appl. Phys. 97, 10 (2005)

[25] J.R.L. de Almeida and S.M.Rezende. Phys. Review B 65 (2002)

[26] C. M. Soukoulis, K. Levin and G. S. Grest. Phys. Review Letters 48, 1756 (1982)

[27] T. P. Pareek. Phys. Review B 75 (2007) 
[28] B. Dieny, V. S. Speriosu, S. S. P. Parking, B. A. Gurney, D. R. Wilhoit and D. Mauri. Phys. Review B 43, 1 (1991)

[29] A. Fert and I. A. Campbell. J. Phys. F 6, 5, 849 (1976)

[30] P. Weinberger. Phys. Review B 75, 6 (2007)

[31] I. N. Krivorotov, D. V. Berkov, N. L. Gorn, N. C. Emley, J. C. Sankey, D. C. Ralph, and R. A. Buhrman. Phys. Review B 76, 024418 (2007)

[32] C. S. Liu. Zeitschrift für angewandte Mathematik und Physik 55, 4 (2004)

[33] R. A. McCurrie. Ferromagnetic Materials. London (1994)

[34] H. Umebayashi and Y. Ishikawa. J. Phys. Soc. Japan 21(7) (1966) 1281

[35] Z. Lu, W. Lai and C. Chai. Thin Solid Films 375, 224 (2000)

[36] A. M. Chouck, IEEE Trans. Mag. 33 (5), 3676 (1997)

[37] C. Tsang, N. Heiman, and K. Lee. J. Appl. Phys. 52(3) (1981) 2471

[38] R. Jungblut, R. Coehoorn, M. Johnson, J. Stegge, and A. Reinders. J. Appl. Phys. 75, 6659 (1994)

[39] I. D. Mayergoyz. Mathematical Models of Hysteresis, Springer-Verlag (1991)

[40] C. R. Pike, A. P. Roberts and K. L. Verosub. J. Appl. Phys. 85, 9 (1999)

[41] A. Stancu, C. Pike, L. Stoleriu, P. Postolache and D. Cimpoesu. J. Appl. Phys. 93, 6620 (2003)

[42] A. B. Barrera. Tese de Doutorado cod. 1378240. IFUSP (2005)

[43] A. Hernando, M. Vazquez, T. Kulik and C. Prados. Phys. Review B 51, 3581 (1995)

[44] S. W. Kim, J. K. Kim, J. H. Kim, B. H. Kim, J. Y. Lee, D. G. Hwang and J. R. Rhee. J. Appl. Phys. 93, 6602 (2003)

[45] D. R. Cornejo, M. Bue, V. Basso, G. Bertotti and F. Missell. J. Appl. Phys. 81, 5588 (1997)

[46] A. Stancu and P. Andrei. Physica B 372, $72-75$ (2006)

[47] S. Brems, K. Temst and C. V. Haesendonck. Phys. Review Letters 99, 6 (2007)

[48] N. W. Ashcroft e N. D. Mermin. Solid State Physics. Brooks Cole (1976)

[49] A. C. S.-Barana1, M. Yoshida1 and V. Líbero. Revista. Bras. Ensino de Fís. 26, 4 (2004)

[50] O. Allegranza and M. M. Chen. J. Appl. Phys. 73, 6218 (1993)

[51] T. R. Gao, D. Z. Yang, S. M. Zhou, R. Chantrell, P. Asselin, J. Du, and X. S. Wu. Phys. Review Letters 99, 057201 (2007)

[52] Y. K. Kim, K. Ha and L. L. Rea. IEEE Trans. Magn. 31(6), 3823 (1995) 
[53] D. Heslop and A. R. Muxworthy. J. Magnetism and Magnetic Materials 288 (2005) 155

[54] V. Baltz, J. Sort, B. Rodmacq, B. Dieny and S. Landis. Phys. Review B 72, 10 (2005)

[55] S. Jo and M. A. Seigler. J. Magnetism and Magnetic Materials 316 (2007) 93-97

[56] M. Xu and Z. Mai. Phys. Review B 60, 13 (1999)

[57] Z. Szabó. Physica B 372 (2006) 61-67

[58] S. R. Mishra, I. Dubenko, M. Khan, T. Young, H. Ganegoda, N. Ali and N. H. Marasinghe. IEEE Trans Mag. 42, 2808 (2006)

[59] G. Bertotti. Hysteresis in Magnetism - Academic Press

[60] D. Heslop and A. R. Muxworthy. J. Magn. Magn. Mater. 288, 155-167 (2005) 